MARCELO MONTEIRO MISSATO

\title{
ANÁLISE DAS RECOMENDAÇÕES PARA USO DE DISPOSITIVOS DE PROTEÇÃO LATERAL E A SEGURANÇA VIÁRIA EM RODOVIAS
}

Dissertação apresentada à Escola Politécnica da Universidade de São Paulo para obtenção do título de Mestre em Engenharia. 
MARCELO MONTEIRO MISSATO

\section{ANÁLISE DAS RECOMENDAÇÕES PARA USO DE DISPOSITIVOS DE PROTEÇÃO LATERAL E A SEGURANÇA VIÁRIA EM RODOVIAS}

Dissertação apresentada à Escola

Politécnica da Universidade de São Paulo para obtenção do título de Mestre em Engenharia.

Área de Concentração:

Engenharia de Transportes

Orientador:

Prof. Dr. Hugo Pietrantonio 
Este exemplar foi revisado e alterado em relação à versão original, sob responsabilidade única do autor e com a anuência de seu orientador.

São Paulo, 29 de novembro de 2011.

Assinatura do autor

Assinatura do orientador

FICHA CATALOGRÁFICA

Missato, Marcelo Monteiro

Análise das recomendações para uso de dispositivos de proteção lateral e a segurança viária em rodovias I M.M. Missato. -ed.rev. -- São Paulo, 2011.

$214 \mathrm{p}$.

Dissertação (Mestrado) - Escola Politécnica da Universidade de São Paulo. Departamento de Engenharia de Transportes.

1. Segurança rodoviária 2. Acidentes de trânsito I. Universi dade de São Paulo. Escola Politécnica. Departamento de Engenharia de Transportes II. t. 


\section{DEDICATÓRIA}

Dedico este trabalho à minha esposa Luciane e à minha filha Larissa. 


\section{AGRADECIMENTOS}

Ao Prof. Dr. Hugo Pietrantonio pela orientação e pelos valiosos ensinamentos transmitidos ao longo deste trabalho.

Pela paciência e auxílio, agradeço à Luciane Lopes Missato, que ao longo desta jornada passou de namorada à esposa, e agora mãe de minha filha Larissa.

Ao Eng. Lauro Hiramoto, aos professores Dr. Felipe Issa Kabbash Jr. e Dr. Carlos Yukio Suzuki pela compreensão e ajuda.

Ao Eng. Leandro Cardoso Trentin pela ajuda na obtenção de dados e pelas sugestões.

Ao Departamento de Estradas de Rodagem do Estado de São Paulo pelas informações prestadas necessárias à aplicação do estudo prático, em especial ao Eng. Daniel Shimabukuro.

À Agência Reguladora de Serviços Públicos Delegados de Transportes do Estado de São Paulo pelo fornecimento das informações sobre acidentes de trânsito utilizados no estudo prático, em especial à Arq. Elaine Cristina de Barros Matsuda e ao Eng. Marcos Venicius Brito.

Aos meus pais, Manoel e Celeste, pelo carinho, compreensão e incentivo.

À Deus, por me ajudar a superar cada obstáculo que encontro em meu caminho. 


\section{RESUMO}

Esta dissertação trata do uso de dispositivos de proteção lateral. Tão importante quando o projeto da rodovia é o projeto do seu entorno, que está diretamente relacionada à segurança dos veículos desgovernados que saem da pista, seja qual for o motivo. O entorno viário deve ser tal que as conseqüências da saída de pista sejam minimizadas, provendo um entorno livre de obstáculos (sejam árvores, postes, terrenos não atravessáveis, etc.) que possam causar danos severos aos seus motoristas, ou utilizando dispositivo de proteção lateral, na impossibilidade de eliminar os obstáculos agressivos, como estratégias complementares da redução dos danos decorrentes das saídas de pista. Na revisão bibliográfica realizada, os conceitos básicos relacionados com proteção lateral, critérios de seleção do tipo de dispositivos e de posicionamento, além da análise das recomendações para os tratamentos de segurança dos dispositivos de drenagem, foram analisados com o objetivo de identificar os estudos que deram origem aos critérios recomendados tradicionalmente (procurando destacar os pontos importantes que esclarecem a aplicação de tais critérios). Além das recomendações tradicionais, também foram analisados os modelos compreensivos, que tratam de forma mais explícita as saídas de pista e a presença dos dispositivos de proteção lateral, considerando o produto de probabilidades condicionais que envolvem as probabilidades de ocorrência de saídas de pista, a probabilidade da saída de pista estar na envoltória do obstáculo, a probabilidade da distância lateral de saída de pista ser suficiente para haver um impacto, a probabilidade de ocorrência de danos ao motorista e seus ocupantes e o custo associados a estes danos. O trabalho de campo desenvolvido analisou a prática do uso de dispositivos de proteção lateral em uma rodovia paulista examinando a observância às recomendações para o uso de dispositivo de proteção lateral e analisando a relação entre as recomendações para o uso de proteção lateral e a ocorrência de acidentes. Os resultados obtidos demonstram que existe carência de aplicação em locais onde os dispositivos são recomendados pelos critérios tradicionais e por critérios ampliados. Estes critérios tradicionais e ampliados foram também comparados baseados nos conceitos de sensibilidade e especificidade, porém, pouco se pode concluir com a utilização dos dados de acidentes obtidos. 


\section{ABSTRACT}

This research provides a review of the recommended criteria for the use of lateral safety devices. As important as the roadway design is the roadside design, that is directly related to the safety of vehicles that encroach on the roadside, regardless of the reason. The roadside must mitigate the consequences of run-off-the-road accidents, providing a contiguous area free of obstacles (trees, poles, unrecoverable grounds, etc.) which can cause severe injury to the vehicle occupants, or deploying lateral protective devices, when it is impossible to remove the hazards, both as complementary strategies for reducing damages from run-off-the road accidents. In the literature review, the basic concepts related to roadside protection, the warrants for selecting the type and placement of devices, besides the analysis of recommendation for the safety treatment of drainage devices, were analyzed to identify the studies which gave rise to the traditionally recommended criteria (trying to emphasize the important points that explain the application of such criteria). In addition to traditional recommendations, the comprehensive models were also analyzed, which deals more explicitly with the encroachments and the presence of lateral safety devices as the product of conditional probabilities that involve the encroachment probability, the probability of the encroachment occurring in a hazard envelope, the probability that the vehicle will encroach laterally far enough to reach the hazard, the probability of injury to the driver and passengers, and the cost associated with this injury. Then, the field work analyzed the practice on the use of lateral protective devices in a highway of the State of São Paulo, examining the observance to recommended criteria for using lateral protective devices and analyzing the relationship between the recommendations for the use of lateral protective devices and accident history. The results have shown that there is a deficit in the deployment on sites where the devices were recommended by traditional criteria and improved criteria. This traditional and improved criteria was also compared based on sensitivity and specificity concept, but no valuable conclusions was obtained with the use of accident data available. 


\section{LISTA DE ILUSTRAÇÕES}

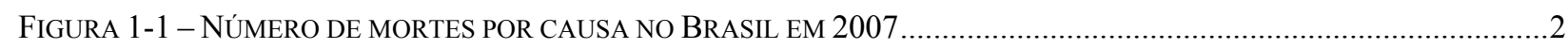

FIGURA 1-2 - NÚMERO DE MORTES POR FAIXA ETÁRIA DAS VÍTIMAS DE ACIDENTES DE TRÂNSITO EM 2007 ..................2

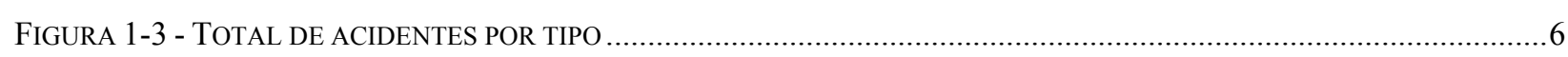

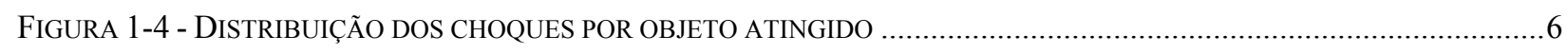

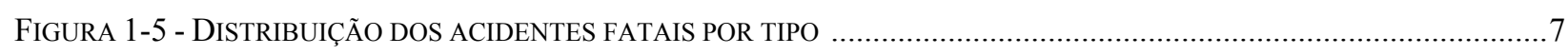

FIGURA 1-6 - DISTRIBUIÇÃO DOS ACIDENTES FATAIS POR TIPO DE CHOQUE ..............................................................

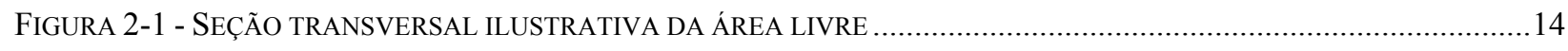

FIGURA 2-2 - SEÇÃO TRANSVERSAL ILUSTRATIVA DA ÁREA LIVRE APRESENTADA PELO TAC (1999) ..........................15

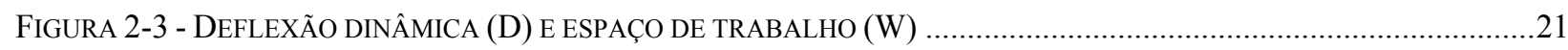

FIGURA 2-4- ÁBACO PARA VALORES SUGERIDOS DE LARGURA DA ÁREA LIVRE ..........................................................22

FIGURA 2-5 - ÁBACO APRESENTADO PELO RURAL ROAD DESIGN PARA DETERMINAÇÃO DA ÁREA LIVRE ....................25

FIGURA 2-6 - FATOR DE CORREÇÃO DA LARGURA DA ÁREA LIVRE EM CURVAS.........................................................25

FIGURA 2-7-NECESSIDADE DE PROTEÇÃO LATERAL DE TALUDES DE ATERRO EM FUNÇÃO DA ALTURA E INCLINAÇÃO DO TALUDE .28

FIGURA 2-8 - NECESSIDADE DE PROTEÇÃO LATERAL DE TALUDES DE ATERRO EM FUNÇÃO DA ALTURA E INCLINAÇÃO DO TALUDE.

FIGURA 2-9 - TRÊS TIPOS DE EQUAÇÕES ESTUDADAS NA ANÁLISE DE REGRESSÃO PARA OS PESOS DE SEVERIDADE 1-625 . 32

FIGURA 2-10 - NECESSIDADE DE PROTEÇÃO EM ATERROS (TAC 1999) …...................................................................34

FIGURA 2-11 - NECESSIDADE DE PROTEÇÃO LATERAL (ADAPTADO: AUSTROADS, 2003) .......................................34

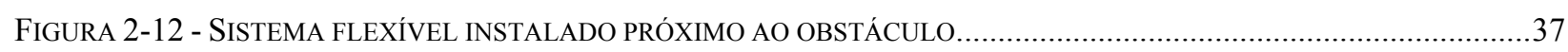

FigURA 2-13 - TRAJETÓRIA dO PÁRA-CHOQUE DO VEÍCULO DURANTE A SAÍDA DE PISTA (RDG, 2006) ......................44

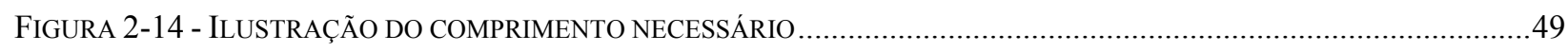

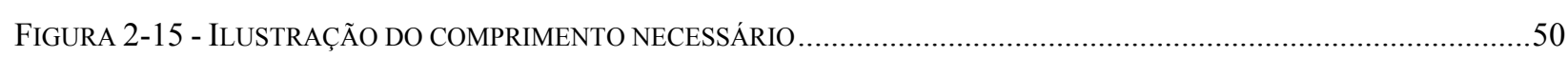

FIGURA 2-16 - COMPRIMENTO DA BARREIRA EM TRÁFEGO UNIDIRECIONAL …..................................................52

FIGURA 2-17 - COMPRIMENTO DA BARREIRA EM TRÁFEGO BIDIRECIONAL .................................................................52

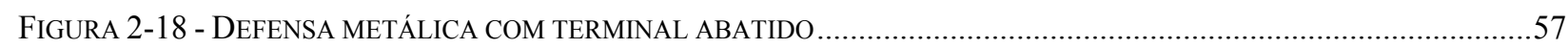

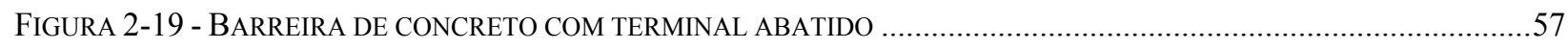

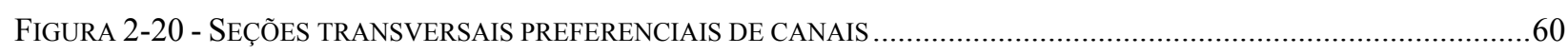

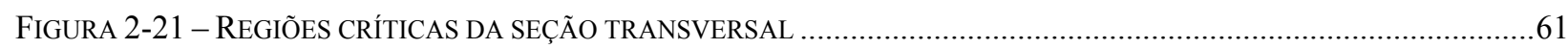

Figura 2-22 - SEÇÃo TRANSVERSAL DE CANAL EM V, ARREDONDADO COM ATÉ 2,4M E TRAPEZOIDAL ATÉ 1,2M (ARREDONDADO OU NÃO).

Figura 2-23 - SEÇÃo TRANSVERSAL DE CANAL ARREDONDADO COM 1,8M A 3,6M E TRAPEZOIDAL COM 1,2M A 2,4M64 Figura 2-24 - SEÇÃo TRANSVERSAL DE CANAL ARREDONDADO COM MAIS DE 3,6M, TRAPEZOIDAL COM MAIS DE 2,4M, E ARREDONDADO E TRAPEZOIDAL COM MAIS DE 1,2M.....

FIGURA 2-25 - USO DE BARRAS COMO TRATAMENTO DE SEGURANÇA PARA EXTREMIDADES DE BUEIROS TRANSVERSAIS

FigURA 2-26 - USO DE BARRAS COMO TRATAMENTO DE SEGURANÇA PARA EXTREMIDADES DE BUEIROS PARALELOS 69 
FIGURA 2-27 - DESLOCAMENTO LATERAL DO BUEIRO PARA UMA REGIÃO MENOS PROVÁVEL DE SER ATINGIDO..... .69

FIGURA 3-1 - FREQUÊNCIA DE SAÍDA DE PISTA EM FUNÇÃO DO VOLUME DE TRÁFEGO ADOTADO PELO RSAP .............84

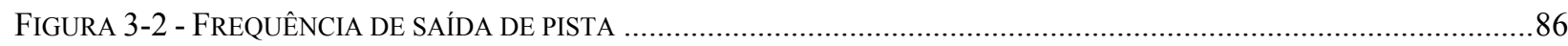

FIGURA 3-3 - FATORES DE AJUSTE PARA CURVAS HORIZONTAIS E RAMPAS VERTICAIS .............................................88

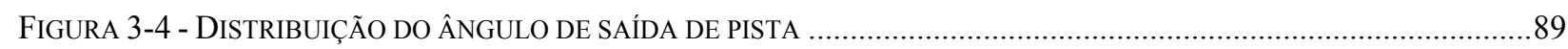

FIGURA 3-5 - DiSTRIBUIÇÃO DA EXTENSÃO LONGITUDINAL DE SAÍDA DE PISTA …..................................................89

FIGURA 3-6 - DiSTRIBUIÇÃO DA EXTENSÃO LATERAL DE SAÍDA DE PISTA ................................................................90

FIGURA 3-7 - DISTRIBUIÇÃO DA EXTENSÃO LATERAL E SEÇÃO TRANVERSAL DO CANTEIRO CENTRAL...........................91

FIGURA 3-8 - DiSTRIBUIÇÃO HIPOTÉTICA DA VELOCIDADE ADOTADA PELO ROADSIDE ..........................................92

FIGURA 3-9 - DISTRIBUIÇÃO DO ÂNGULO DE SAÍDA DE PISTA ADOTADA PELO ROADSIDE .......................................92

FIGURA 3-10 - DISTRIBUIÇÃO REMODELADA DO ÂNGULO DE SAÍDA DE PISTA ADOTADA PELO ROADSIDE ................93

FIGURA 3-11 - ÂNGULO MÁXIMO DE SAÍDA NO MODELO DE MASSA PONTUAL ……..................................................93

FIGURA 3-12 - CURVA DE DISTRIBUIÇÃO DA EXTENSÃO LATERAL …......................................................................95

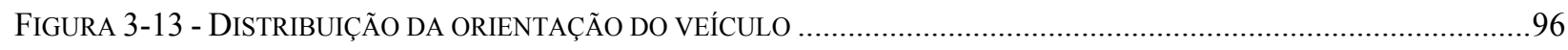

FIGURA 3-14 - ORIENTAÇ̃̃O DO VEÍCULO EM RELAÇÃO AO ÂNGULO DE SAÍDA DE PISTA .............................................97

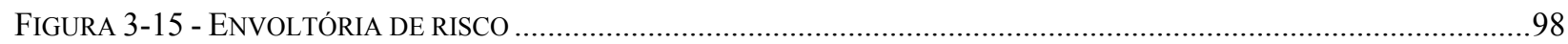

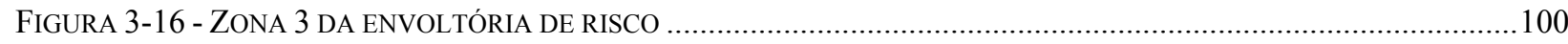

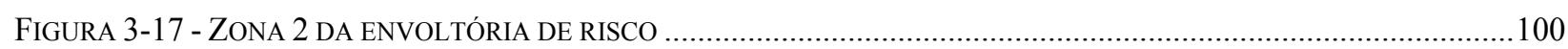

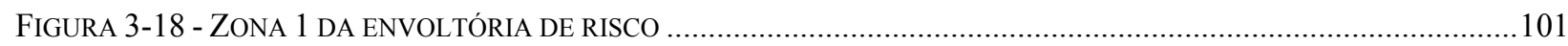

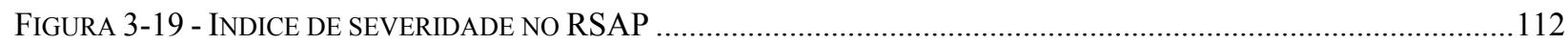

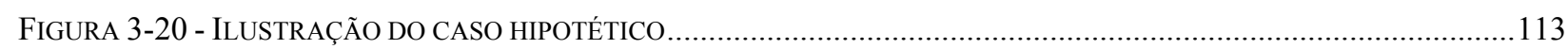

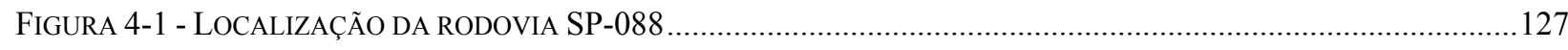

FigURA 4-2 - CARACTERÍSTICAS DO ENTORNO, KM 34, SENTIDO MOGI DAS CRUZES.................................................128

FigurA 4-3 - CARACTERÍSTICAS DO ENTORNO, KM 35+200, SENTIDO MOGI DAS CRUZES.......................................129

FigurA 4-4 - CARACTERÍSTICAS DO ENTORNO, KM 36+500, SENTIDO MOGI DAS CRUZES........................................129

FigURA 4-5 - CARACTERÍSTICAS DO ENTORNO, KM 37+400, SENTIDO MOGI DAS CRUZES.........................................130

FigURA 4-6 - PARÂMETROS TOMADOS PARA O CADASTRAMENTO DOS OBSTÁCULOS................................................132

FIGURA 4-7 - POSTES SOBRE CORTES ALTOS NÃO FORAM CONSIDERADOS COMO OBSTÁCULOS POTENCIAIS ................133

FIGURA 4-8 - À ESQUERDA, PLACA DE SINALIZAÇÃO, E À DIREITA, ARBUSTOS.........................................................133

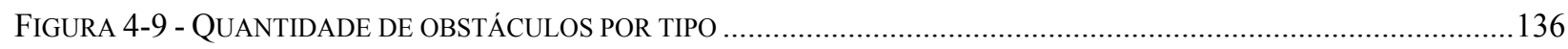

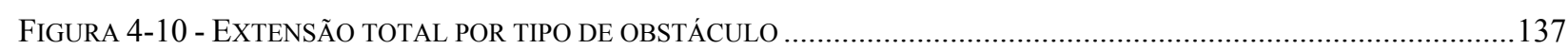

FigURA 4-11 - AFASTAMENTO LATERAL MÉDIO DO OBSTÁCULO À BORDA DA PISTA ...............................................137

FIGURA 4-12 - NÚMERO DE ACIDENTES COM SAÍDAS DE PISTA X SEGMENTO (LADO DIREITO, HIPÓTESE 1) ..................143

FIGURA 4-13 - NÚMERO DE ACIDENTES COM SAÍDAS DE PISTA X SEGMENTO (LADO ESQUERDO, HIPÓTESE 1)..............143

FigURA 4-14 - NÚMERO DE ACIDENTES COM SAÍDAS DE PISTA X SEGMENTO (LADO DIREITO, HIPÓTESE 2) .................144

FIGURA 4-15 - NÚMERO DE ACIDENTES COM SAÍDAS DE PISTA X SEGMENTO (LADO ESQUERDO, HIPÓTESE 2).............144

Figura 4-16 - PoRCENTAGEM dos OBSTÁCULOS OU SEGMENTOS DE OBSTÁCULOS QUE OBSERVAM OS CRITÉRIOS ...149

Figura 4-17 - PoRCENTAGEM dos OBSTÁCULOS OU SEGMENTOS DE OBSTÁCULOS QUE REQUEREM PROTEÇÃo E QUE

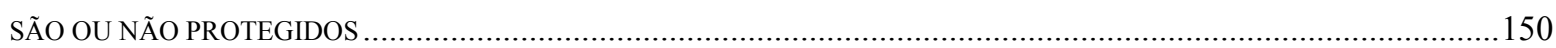

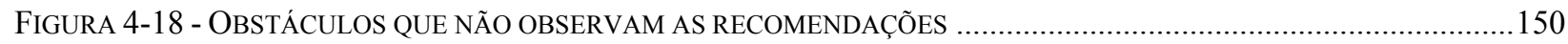


FiguRA 4-19 - ALTERNATIVAS AO USO DE PROTEÇÃO LATERAL PARA OS OBSTÁCULOS QUE NÃO FORAM PROTEGIDOS

FigURA 4-20 - DiSTRIBUIÇÃO DAS SITUAÇÕES DOS SEGMENTOS COM RELAÇÃO À NECESSIDADE DE PROTEÇÃO E A OCORRÊNCIA DE ACIDENTES (CRITÉRIO DO RDG E HIPÓTESE 1)

FigURA 4-21 - DisTRIBUIÇÃO DAS SITUAÇÕES DOS SEGMENTOS COM RELAÇÃO A NECESSIDADE DE PROTEÇÃO E A OCORRÊNCIA DE ACIDENTES (CRITÉRIO DO RDG E HIPÓTESE 2)

FIGURA 4-22 - OBSTÁCULOS COM INOBSERVÂNCIA OS CRITÉRIOS, PRESENTES EM SEGMENTOS COM E SEM ACIDENTES COM SAÍDA DE PISTA: (CRITÉRIO DO RDG, HIPÓTESE 1 E HIPÓTESE 2).

FigURA 4-23 - DiSTRIBUIÇÃO DAS SITUAÇÕES DOS SEGMENTOS COM RELAÇÃO A NECESSIDADE DE PROTEÇÃO E A OCORRÊNCIA DE ACIDENTES (CRITÉRIO AMPLO E HIPÓTESE 1)

FiguRA 4-24 - DisTRIBUiÇÃO DAS SITUAÇÕES DOS SEGMENTOS COM RELAÇÃO A NECESSIDADE DE PROTEÇÃO E A OCORRÊNCIA DE ACIDENTES (CRITÉRIO AMPLO E HIPÓTESE 2)

FIGURA 4-25- OBSTÁCULOS COM INOBSERVÂNCIA OS CRITÉRIOS PRESENTES EM SEGMENTOS COM E SEM ACIDENTES COM SAÍDA DE PISTA: (CRITÉRIO AMPLIADO, HIPÓTESE 1 E HIPÓTESE 2).

FIGURA 4-26 - OBSTÁCULOS QUE REQUEREM PROTEÇÃO, ESTÃO PROTEGIDOS E A OCORRÊNCIA DE ACIDENTES COM SAÍDA DE PISTA (HIPÓTESES 1 E 2) 


\section{LISTA DE TABELAS}

TABELA 2-1 - TIPOS DE OBSTÁCULOS QUE NORMALMENTE REQUEREM PROTEÇÃO …………………………………....16

TABELA 2-2 - VALORES SUGERIDOS PARA LARGURA DA ÁREA LIVRE .........................................................................23

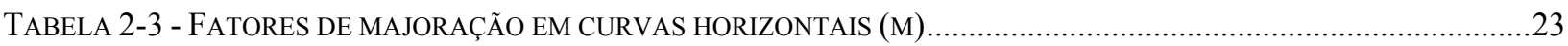

TABELA 2-4 - NÚMERO DE ACIDENTES DO TIPO CHOQUE COM DEFENSA METÁLICA ………...............................................31

TABELA 2-5 - NÚMERO DE ACIDENTES COM ATRAVESSAMENTO DE ATERRO …………….........................................31

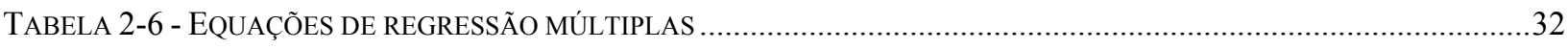

TABELA 2-7-VALORES DO AFASTAMENTO DA LINHA DE INTIMIDAÇÃO (SHY LINE, RDG, 2006) .....................................41

TABELA 2-8 - VALOR DE DEFLEX̃̃O APRESENTADO PELO RDG (2006) ....................................................................46

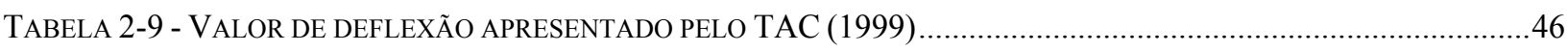

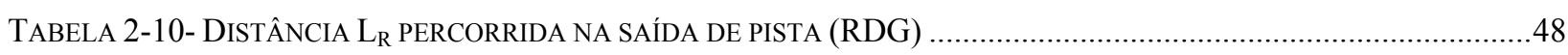

TABELA 2-11 - DISTÂNCIA E PERCORRIDA NA SAÍDA DE PISTA (TAC, 1999) ............................................................48

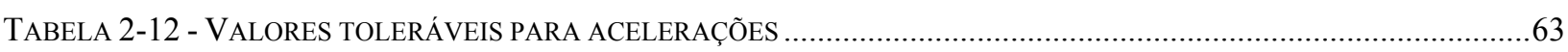

TABELA 2-13 - PROPRIEDAde dos VEÍCULOS 700C, 820C E 2000P (FONTE: NCHRP REPORT 350) ……………..........72

TABELA 2-14 - PROPRIEDADE dOS VEÍCULOS 8000S, 36000V E 36000T ………...............................................73

TABELA 2-15 - MATRIZ DE TESTES PARA DISPOSITIVOS DE PROTEÇÃO LONGITUDINAIS (NCHRP REPORT 350)............74

TABELA 2-16 - REQUISITOS PARA A ADEQUAÇ̃̃O ESTRUTURAL (NCHRP REPOR 350) ................................................74

TABELA 2-17 - REQUISITOS DO RISCO PARA OS OCUPANTES (NCHRP REPORT 350) ..............................................76

TABELA 2-18 - REQUISITOS PARA A TRAJETÓRIA DO VEÍCULO APÓS O IMPACTO (NCHRP REPORT 350) ........................77

TABELA 3-1 - FREQUÊNCIA E TAXA DE SAÍDA DE PISTA (HUTCHINSON E KENNEDY, 1967)...................................86

TABELA 3-2 - PARÂMETROS ESTATÍSTICOS ASSOCIADOS ÀS CARACTERÍSTICAS DAS SAÍDAS DE PISTA...........................89

TABELA 3-3 - RELAÇÃO ENTRE O SI E A PROBABILIDADE DE DANOS NO RSAP .....................................................111

TABELA 3-4 - EQUIVALÊNCIA DOS TIPOS DE DANOS E RESPECTIVOS CUSTOS ...........................................................117

TABELA 3-5 - RELAÇÃO ENTRE SI, PROBABILIDADE DE DANOS E CUSTO SOCIAL …………………………...................117

TABELA 3-6 - CUSTOS SOCIAIS CORRESPONDENTES AOS SIS, COM VALORES COMPREENSIVOS DO FHWA ..................124

TABELA 3-7 - VALORES DE BENEFÍCIOS E CUSTOS DE ACORDO COM OS CUSTOS COMPREENSIVOS DO FHWA .............124

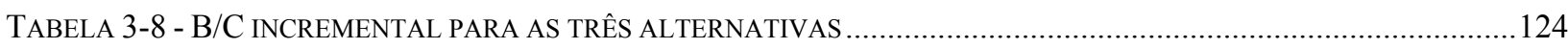

TABELA 4-1 - DistribuiÇão DOS ACIDENTES DA PLANILHA DO DER/SP EM SEGMENTOS DE 100M (SENTIDO

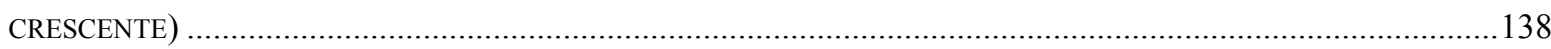

TABELA 4-2 - DistribuiçÃo doS ACIDENTES DA PLANILHA DO DER/SP EM SEGMENTOS DE 100M (SENTIDO DECRESCENTE)

TABELA 4-3 - PROPORÇ̃̃o DE ACIDENTE COM SAídA DE PISTA CALCULADOS A PARTIR DOS DADOS DOS RELATÓRIOS DE ACIDENTES RELEVANTES DE CINCO CONCESSIONÁRIAS DE RODOVIAS DE PISTA SIMPLES DA ARTESP. .142

TABELA 4-4 - SitUAÇ̃̃o DOS SEGMENTOS QUANTO AOS CRITÉRIOS E PRESENÇA DE ACIDENTES COM SAÍDAS DE PISTA (LADO DIREITO) 146

TABELA 4-5 - SituAÇÃO DOS SEGMENTOS QUANTO AOS CRITÉRIOS E PRESENÇA DE ACIDENTES COM SAÍDAS DE PISTA (LADO ESQUERDO). 
TABELA 4-6 - QUANTIDADE DE OBSTÁCULOS OU SEGMENTOS DE OBSTÁCULOS QUE OBSERVAM OU NÃO OS CRITÉRIOS DO RDG (2006) PARA O USO DE PROTEÇÃO LATERAL E CRITÉRIO AMPLIADO...................................................150

TABELA 4-7 - NÚMERO DE OBSTÁCULOS QUE REQUEREM PROTEÇÃO E NÃO ESTÃO PROTEGIDOS ...............................151

TABELA 4-8 - NÚMERO DE OBSTÁCULOS COM TRATAMENTO ALTERNATIVO À PROTEÇÃO LATERAL.............................152

TABELA 4-9 - TESTE QUI-QUADRADO PARA ACIDENTES X TALUDE DE CORTE ............................................................158

TABELA 4-10 - TESTE QUI-QUADRADO PARA ACIDENTES X CURVAS HORIZONTAIS .....................................................158

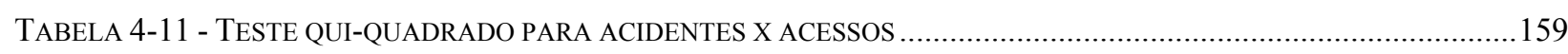

TABELA 4-12- SITUAÇÕES POSSÍVEIS PARA A CLASSIFICAÇÃO DOS SEGMENTOS ......................................................161

TABELA 4-13 - NÚMERO DE SEGMENTOS ENQUADRADOS EM CADA UMA DAS QUATRO SITUAÇÕES POSSÍVEIS (CRITÉRIO RDG, HIPÓTESE 1).... 163

TABELA 4-14 - NÚMERO DE SEGMENTOS ENQUADRADOS EM CADA UMA DAS QUATRO SITUAÇÕES POSSÍVEIS (CRITÉRIO

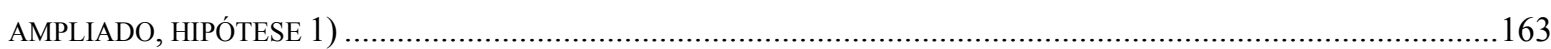

TABELA 4-15 - NÚMERO DE SEGMENTOS ENQUADRADOS EM CADA UMA DAS QUATRO SITUAÇÕES POSSÍVEIS (CRITÉRIO RDG, HIPÓTESE 2). 163

TABELA 4-16 - NÚMERO DE SEGMENTOS ENQUADRADOS EM CADA UMA DAS QUATRO SITUAÇÕES POSSÍVEIS (CRITÉRIO AMPLIADO, HIPÓTESE 2) . .164

TABELA 4-17 - TESTE T DE STUDENT PARA O PAR "CRITÉRIO X HIPÓTESE" 166 


\section{LISTA DE ABREVIATURAS}

AASHTO American Association of State Highway and Transportation Officials

ABNT Associação Brasileira de Normas Técnicas

ARTESP Agência Reguladora de Serviços Públicos Delegados de Transportes do Estado de São Paulo

DER/SP Departamento de Estradas de Rodagens do Estado de São Paulo

DMRB Design Manual for Roads and Bridges

DNER Departamento Nacional de Estradas de Rodagem

DNIT Departamento Nacional de Infra-Estrutura de Transportes

HVOSM Highway Vehicle Objective Simulation Model

IPEA Instituto de Pesquisa Econômica Aplicada

NCHRP National Cooperative Highway Research Program

RDG Roadside Design Guide

RSAP Roadside Safety Analysis Program

TAC Transportation Association of Canadá

VDM Volume Diário Médio 


\section{SUMÁRIO}

RESUMO

ABSTRACT

LISTA DE ILUSTRAÇÕES

LISTA DE TABELAS

1. INTRODUÇÃO

1.1. ASPECTOS GERAIS 1

1.2. OBJETIVOS DO TRABALHO 3

1.3. JUSTIFICATIVA 5

1.4. ESTRUTURA DO TRABALHO 8

2. ANÁLISE DOS CRITÉRIOS ATUAIS PARA A SEGURANÇA DO ENTORNO VIÁRIO 9

2.1. CONCEITOS UTILIZADOS 10

2.1.1. Entorno tolerante 10

2.1.2. Talude traspassável 11

2.1.3. Talude de aterro recuperável, não recuperável e crítico 12

2.1.4. Área livre (clear zone) 13

2.1.5. Obstáculo traspassável 15

2.1.6. Dispositivo colapsivel 16

2.1.7. Dispositivos de proteção (ou de contenção) 17

2.1.8. Linha de intimidação (ou de preocupação) 20

2.1.9. Nivel de proteção (capacidade de contenção, nivel de teste ou contenção) 20

2.1.10. Espaço de trabalho (ou distância de trabalho, ou ainda, deflexão dinâmica) 20

2.2. EXTENSÃO RECOMENDADA PARA A ÁREA LIVRE 21

2.3. CRITÉRIOS GERAIS PARA O USO DE PROTEÇÃO LATERAL 26

2.3.1. Uso de proteção lateral devido à presença de aterros 27

2.3.2. Uso de proteção lateral devido à presença de obstáculos laterais 35

2.4. CRITÉRIOS DE SELEÇÃO DO TIPO DE PROTEÇÃO LATERAL CONTÍNUA 36

2.5. CRITÉRIOS PARA O POSICIONAMENTO E ARRANJO DA PROTEÇÃO CONTÍNUA 40

2.5.1. Afastamento lateral com relação à pista 40

2.5.2. Influência da superficie do terreno $\quad 42$

2.5.3. Segmento defletido de transição da proteção lateral 45

2.5.4. Comprimento necessário de proteção lateral 47

2.6. TERMINAIS 53

2.7. TRATAMENTO PARA OBSTÁCULOS E DISPOSITIVOS DE DRENAGEM 58

2.7.1. Dispositivos de drenagem 58

2.7.2. Obstáculos rígidos (árvores, pilares, postes e suportes de sinalização) 70

2.8. CONSIDERAÇÕES SOBRE OS TESTES DE IMPACTO E CRITÉRIOS DE DESEMPENHO 71 
3.1. ESTRUTURA DOS MODELOS COMPREENSIVOS 79

3.2. CARACTERÍSTICAS DAS SAÍDAS DE PISTA 83

3.2.1. Frequência básica de saídas de pista 84

3.2.2. Fatores de ajuste da frequência básica de saídas de pista 88

3.2.3. Características das saídas de pista $\quad 88$

3.3. PREVISÃO DA PROBABILIDADE DE CHOQUE 97

3.4. PREVISÃO DA SEVERIDADE E CUSTO DO ACIDENTE 106

3.5. EXEMPLO DE APLICAÇÃO NUMÉRICA DE MODELO COMPREENSIVO PARA UM CASO HIPOTÉTICO E COMPARAÇÃO COM OS CRITÉRIOS CONVENCIONAIS 113

3.5.1. Aplicação dos critérios convencionais $\quad 114$

3.5.2. Aplicação dos modelos compreensivos $\quad 115$

3.6. VIABILIDADE DA APLICAÇÃO DE MODELOS COMPREENSIVOS 125

4. ESTUDO DE CASO: RODOVIA PEDRO EROLES (SP-088) 126

4.1. SELEÇÃO DA RODOVIA PARA O ESTUDO DE CAMPO 127

4.2. COLETA DE DADOS DA RODOVIA SP-088 131

4.2.1. Levantamento dos obstáculos $\quad 131$

4.2.2. Obtenção e tratamento dos dados de acidentes 137

4.2.3. Localização dos acidentes com saída de pista 142

4.3. ANÁLISE DA OBSERVÂNCIA ÀS RECOMENDAÇÕES PARA O USO DE DISPOSITIVOS DE $\begin{array}{ll}\text { PROTEÇÃO LATERAL } & 148\end{array}$

4.4. ANÁLISE DA RELAÇÃO ENTRE OS CRITÉRIOS RECOMENDADOS E A OCORRÊNCIA DE ACIDENTES COM SAÍDAS DE PISTA 152

4.4.1. Relação entre o critério recomendado e a ocorrência de acidentes com saídas de pista 153

4.4.2. Associação entre a ocorrência de acidentes e as características da via 157

4.4.3. Análise do critério do RDG (2006) e do critério ampliado 160

$\begin{array}{rr}\text { 5. CONCLUSÃO } & 168\end{array}$

REFERÊNCIAS
175

$\begin{array}{lr}\text { ANEXO A } & 181\end{array}$

$\begin{array}{lr}\text { ANEXO B } & 190\end{array}$

$\begin{array}{lr}\text { ANEXO C } & 198\end{array}$ 


\section{INTRODUÇÃO}

\subsection{ASPECTOS GERAIS}

As Figuras 1-1 e 1-2 demonstram que os acidentes de trânsito são uma causa relevante de mortes no Brasil, com incidência peculiar nas faixas etárias produtivas, segundo os dados do Ministério da Saúde (BRASIL, 2010a,b).

Os acidentes de trânsito comovem não só pelo grande número de vítimas envolvidas como também pela faixa etária que atinge, visto que boa parte das pessoas envolvidas nos acidentes de trânsito são pessoas entre 15 e 59 anos de idade (ver figura 1-2).

Nesta faixa etária o indivíduo está em plena capacidade produtiva, com uma longa vida pela frente, no auge da profissão, produzindo riquezas, pagando impostos e previdência social, e em muitos casos possui filhos dependentes deles. Ao perder a vida num acidente de trânsito, este indivíduo leva consigo todo o investimento que recebeu do país na forma de educação, saúde e lazer, além de deixar de produzir e pagar impostos, e o mais importante, deixa seus amigos, cônjuge e filhos, de forma traumática e repentinamente. 


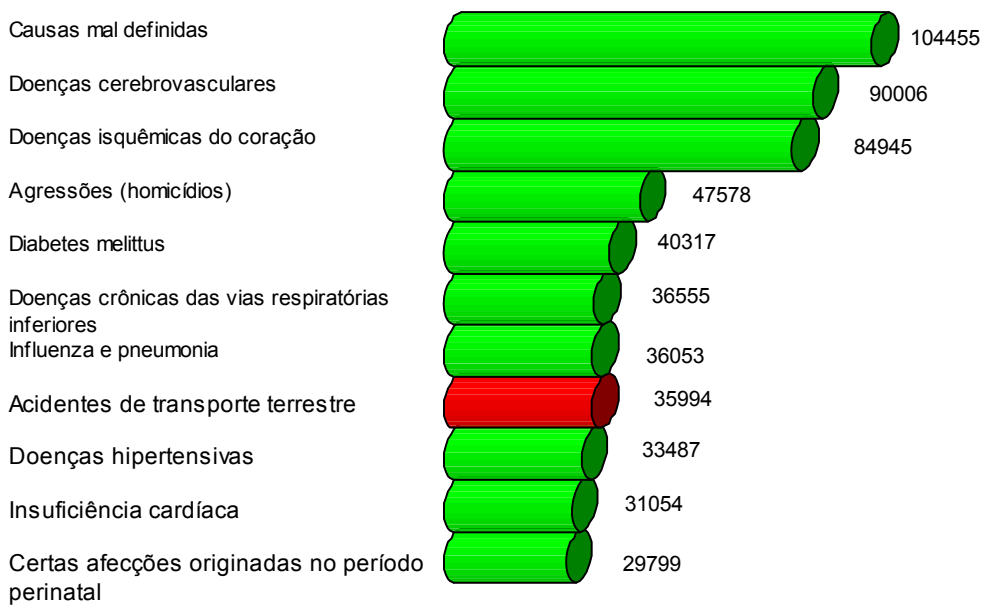

Figura 1-1 - Número de mortes por causa no Brasil em 2007 (BRASIL, 2010a)

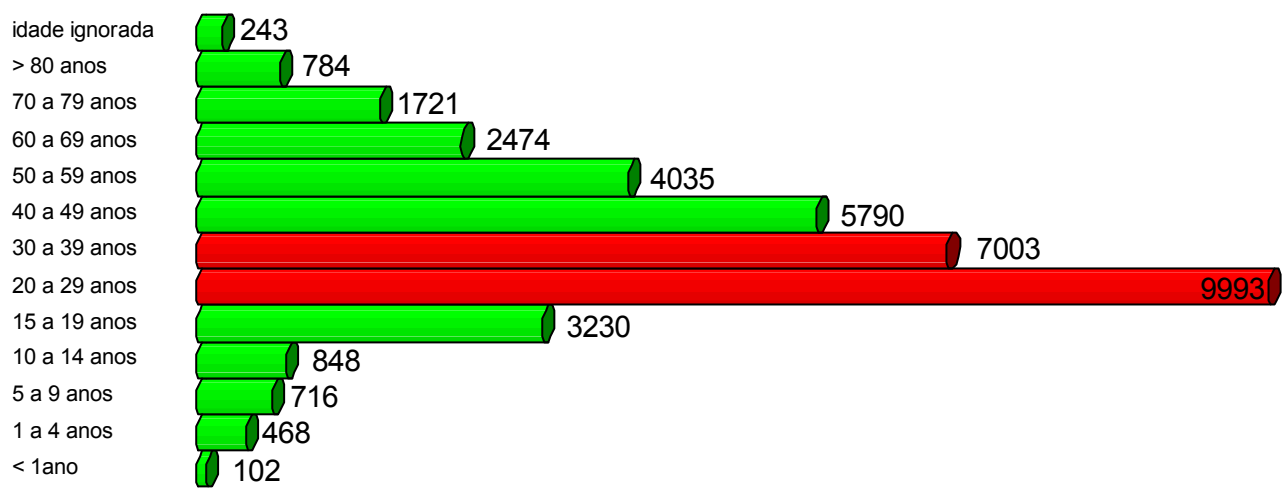

Figura 1-2 - Número de mortes por faixa etária das vítimas de acidentes de trânsito em 2007 (BRASIL, 2010b)

Outro ponto importantíssimo são os acidentes sem vítimas fatais e que produzem vítimas que irão conviver com deficiências físicas e/ou psíquicas para o resto de suas vidas, tornando-se dependentes de parentes e serviços de apoio médico, trazendo perda da qualidade de vida para si e para seus familiares, que perderão dias de trabalho, estudo e lazer, para acompanhá-los em tratamentos ou necessidades especiais.

Segundo o relatório executivo "Impactos sociais e econômicos dos acidentes de trânsito nas rodovias brasileiras", de 2006, do Instituto de Pesquisas Econômicas Aplicadas (IPEA, 2006), com base em dados de 2004, o custo de um acidente de trânsito sem vítima é de R\$16.840,00, com vítima não fatal é de $\mathrm{R} \$ 86.032,00$ e com vítimas fatais é de $\mathrm{R} \$ 418.341,00$. Nestes custos estão envolvidos os custos associados à pessoa, aos veículos, custos institucionais e os custos 
associados à via e ao meio ambiente. Os custos associados à pessoa seriam aqueles referentes aos custos do atendimento pré-hospitalar, atendimento hospitalar, custo pós-hospitalar, custo da perda de produção, custo de remoção e translado, e gasto previdenciário. Os custos associados aos veículos seriam os custos dos danos materiais aos veículos, custo da perda da carga, custo de remoção e diárias de pátio de armazenamento, e os custos de reposição incorridos pela substituição do veículo. Os custos institucionais constituem-se dos custos de processos judiciais e de atendimento policial. Os custos associados à via e ao meio ambiente do local do acidente são aqueles relativos aos custos dos danos à propriedade pública e à propriedade privada. Não estão computados nestes valores o sofrimento de se perder um ente querido ou de se perder a qualidade de vida, no caso de vítimas que se tornaram deficientes físicos e/ou mentais, e os danos ambientais decorrentes de derramamento de produtos químicos tóxicos, "custos" estes dificilmente mensuráveis de forma precisa.

Provavelmente, mesmo neste enfoque restrito, os efeitos são maiores. Umas das grandes dificuldades para se analisar a magnitude do problema da segurança viária é com relação ao número preciso de vítimas fatais, uma vez que a vítima do acidente de trânsito pode vir a falecer depois de meses, ou até anos, após o acidente devido a algum tipo de seqüela. No Brasil, de acordo com a NBR 10697:1989 da ABNT, considera-se vítima fatal de acidente de trânsito aquelas que venham a falecer até 30 dias após o acidente. Assim, para o cômputo exato do número de vítimas fatais seria necessário o acompanhamento da vítima de acidente de trânsito ao longo de sua vida, com a identificação da possível causa do falecimento, quando vir a ocorrer, e sua relação com o acidente, tornando extremamente complexa a obtenção dos dados precisos de vítimas fatais. Em outros países, considera-se necessário avaliar um horizonte ainda maior.

\subsection{OBJETIVOS DO TRABALHO}

O projeto de uma rodovia não deve contemplar somente o espaço por onde trafegam os veículos e os demais elementos necessários para garantir seu adequado funcionamento, como os dispositivos de drenagem, as obras de artes especiais, o pavimento, a sinalização e etc. Tão importante quanto o espaço por onde os veículos trafegam, caracterizado pela via em si, é o espaço do entorno da via, nas laterais dela, onde estão presentes elementos que complementam a via ou que são parte delas (elementos feitos pelo homem), ou ainda, elementos naturais que estão ali presentes antes da concepção da rodovia. Assim, ao se falar em rodovia, deve-se lembrar do 
sentido mais amplo, na qual rodovia é a via por onde trafegam os veículos e seu entorno, somados aos demais elementos fundamentais para garantir sua funcionalidade.

Segundo o Roadside Design Guide (AASHTO, 2006, daqui por diante referido como RDG, 2006), o projeto de segurança do entorno da via como parte total do projeto da rodovia, é um conceito recente, que foi incorporado a partir da década de 70 (nos Estados Unidos). Ainda de acordo com o RDG (2006), o projeto do entorno é aquele que envolve a área compreendida entre a borda externa do acostamento e o limite da faixa de domínio.

O correto projeto do entorno da via é extremamente importante, tendo em vista que muitos dos acidentes de trânsito estão relacionados com motoristas que perdem o controle de seu veículo e saem da pista, desdobrando-se em tombamento, capotamento, queda em precipício, atropelamento de pedestres ou colisão com ciclistas, e choque com obstáculos presentes no entorno. Estes obstáculos podem ser naturais, como árvores, rochas, terrenos não traspassáveis, cursos d'água, etc., ou feitos pelo homem, resultantes do projeto viário ou não, como os taludes de corte e aterro, dispositivos de drenagem, pilares de pontes/viadutos, postes de iluminação/energia/telefonia/sinalização, muros de contenção, etc.

A perda do controle do veículo pode ser causada por diversos fatores (RDG, 2006):

1. Falta de atenção ou cansaço do motorista,

2. Efeito de álcool ou drogas,

3. Excesso de velocidade,

4. Manobras evasivas,

5. Deficiência do projeto da rodovia (superelevação inadequada, inconsistência do traçado, falta de visibilidade, etc.),

6. Estado precário da via,

7. Condições climáticas,

8. Falha mecânica no veículo e

9. Combinação dos fatores anteriores.

Tendo em mente o acima exposto, o foco do presente trabalho é o entorno da via e os acidentes com saídas de pista e suas conseqüências, independente da causa. Assim, os objetivos da pesquisa são três, a saber, (a) revisar os critérios no Brasil e no exterior para promover a segurança no entorno das vias, (b) analisar a observância às recomendações para o uso de 
dispositivo de proteção lateral e (c) analisar a relação entre estas recomendações e a ocorrência de acidentes.

\subsection{JUSTIFICATIVA}

De toda a esfera que envolve os acidentes de trânsito, uma parte dela será o foco deste estudo: os acidentes decorrentes de saídas de pista. Na medida em que a infra-estrutura da pista melhora, os acidentes decorrentes de saídas de pista passam a se destacar com relação aos acidentes que ocorrem na pista. Isso porque além da redução dos acidentes ocorridos na pista proporcionada pela melhor infra-estrutura, um pavimento melhor, por exemplo, acaba induzindo velocidade praticada maior, criando oportunidades para as perdas de controle e maiores extensões nas saídas de pista ou maiores velocidades de impacto.

A Figura 1-3 abaixo mostra a distribuição do total de acidentes por tipo, obtida de estudo da ARTESP, e nota-se que o choque aparece em primeira colocação, com quase $32 \%$ do total de acidentes, entre os anos de 2007 e 2009. O tipo choque não necessariamente ocorre em sua totalidade fora da pista, visto que pode ocorrer um choque com veículo parado na pista. Por outro lado, tombamentos, atropelamentos, capotamentos e quedas podem ocorrer fora da pista. Se fossem agrupados todos os acidentes com saídas de pista, certamente representariam uma grande proporção do total.

A Figura 1-4 mostra a distribuição dos choques por objeto atingido. Note-se que, como mencionado anteriormente, uma parcela corresponde a choque com veículo parado na pista, objeto sobre a pista, cancela de pedágio, objeto não identificado e outros, poderiam ser excluídos dos acidentes com saídas de pista. Entretanto, mesmo ainda com o remanescente desta exclusão, os acidentes com saídas de pista representariam uma grande parcela do total.

Vale lembrar que os dados obtidos junto à ARTESP refletem a realidade de rodovias concedidas já consolidadas, isto é, os dados foram obtidos de rodovias que atendem a certos requisitos de segurança, daí o grande número de choques com defensas e barreiras. A distribuição de choques que se esperaria de uma rodovia de pista simples, não concedida, de menor padrão, poderia ser diferente, com concentração de choques em árvores, postes, taludes e dispositivos de drenagem. 
Quando se analisam as fatalidades, ilustradas na Figura 1-5, os atropelamentos tomam o primeiro lugar dos choques, obviamente pela vulnerabilidade dos pedestres. Novamente, ressalta-se que os atropelamentos podem ocorrer tanto dentro quanto fora da pista, bem como os tombamentos, capotamentos e quedas.

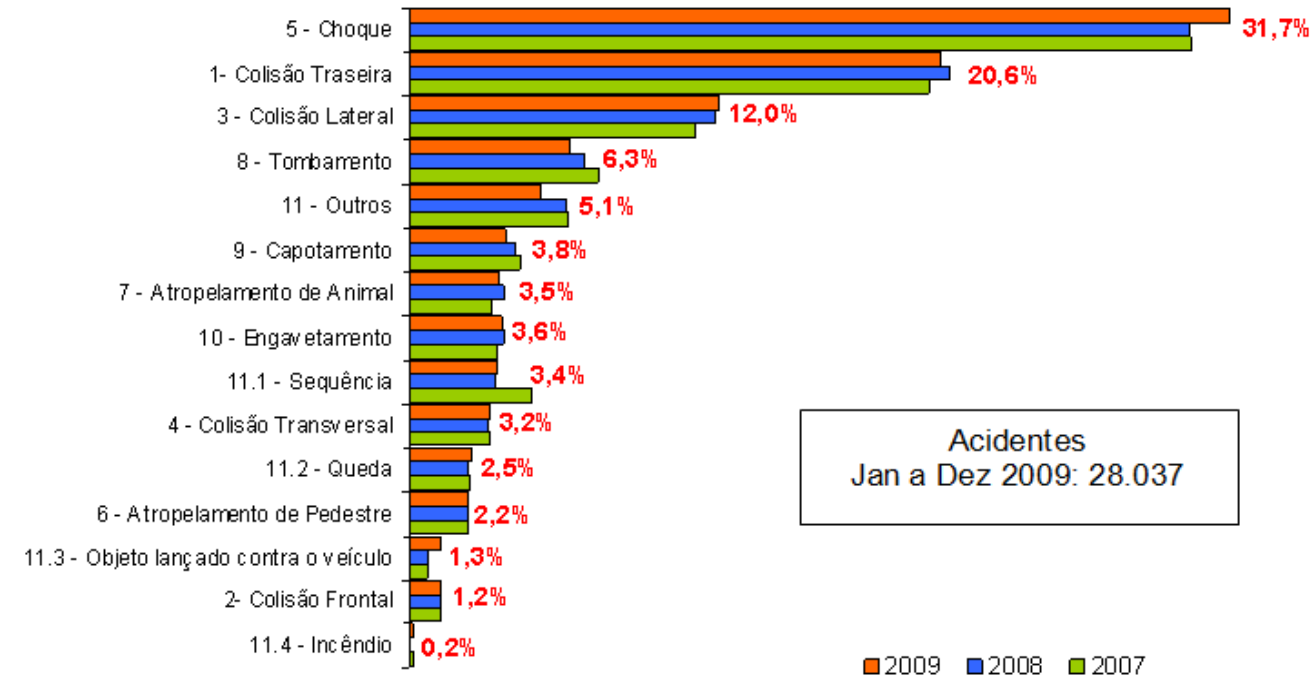

Figura 1-3 - Total de acidentes por tipo (ARTESP, 2010)

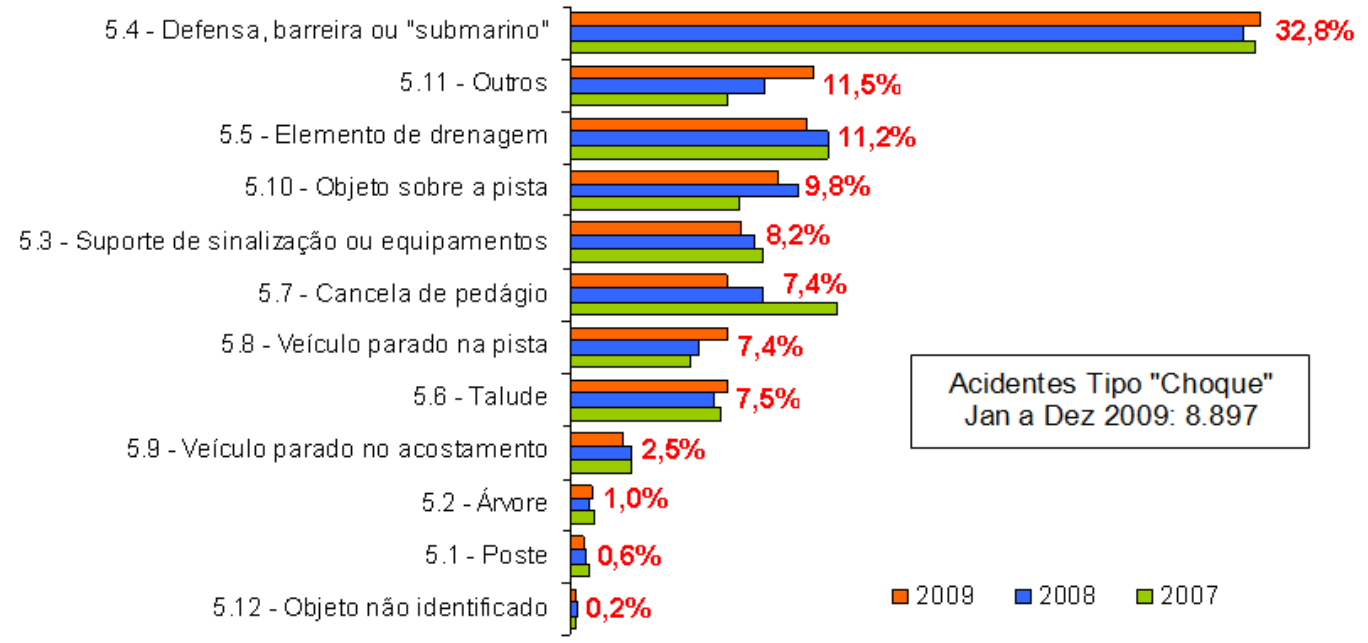

Figura 1-4 - Distribuição dos choques por objeto atingido (ARTESP, 2010) 


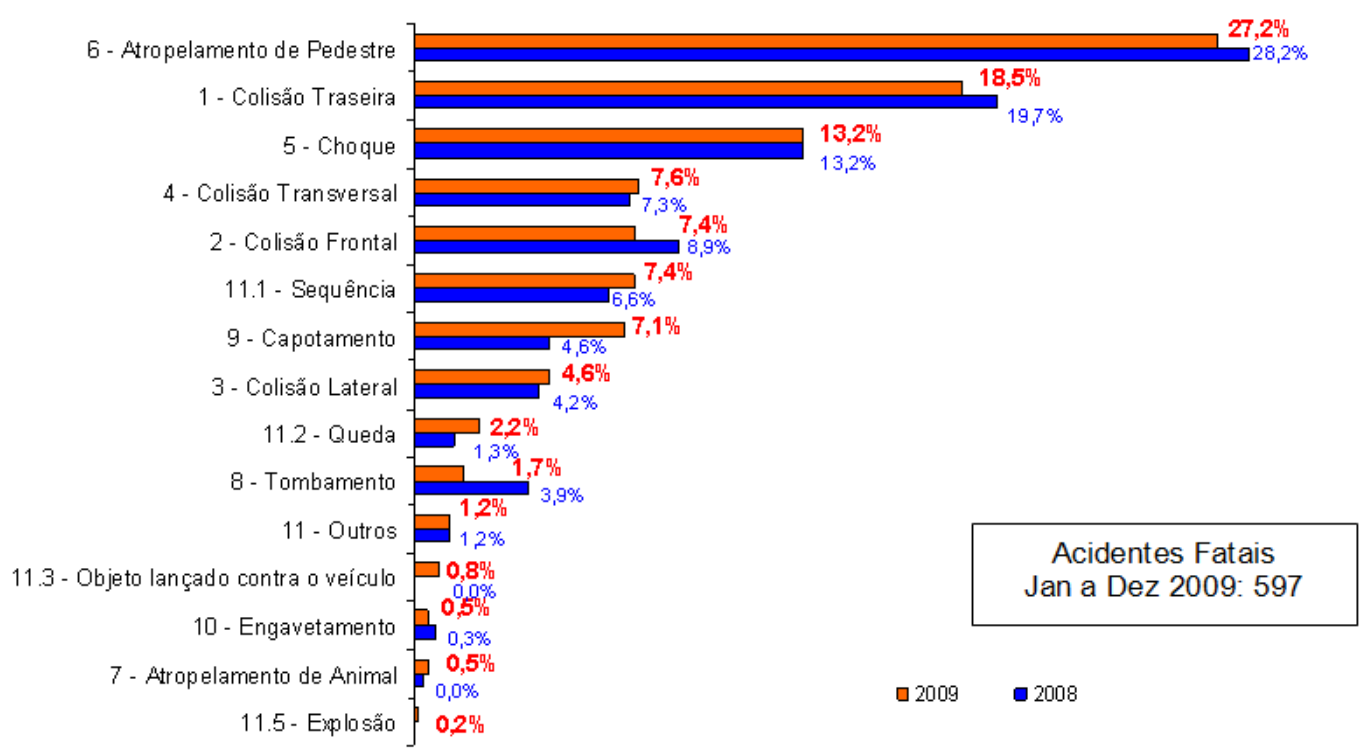

Figura 1-5 - Distribuição dos acidentes fatais por tipo (ARTESP, 2010)

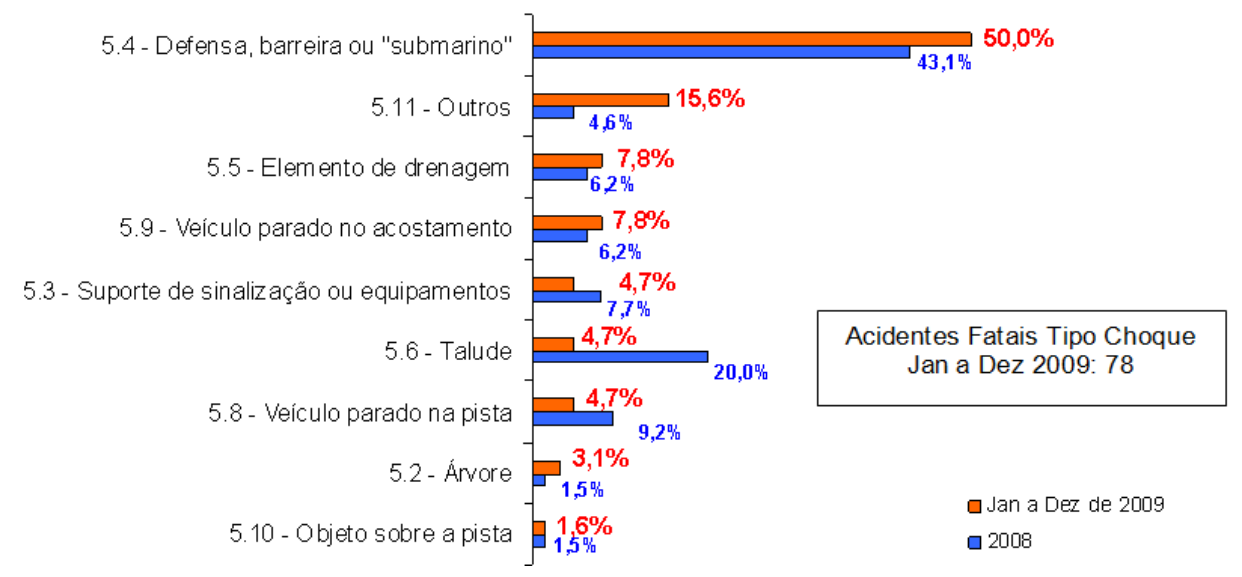

Figura 1-6 - Distribuição dos acidentes fatais por tipo de choque (ARTESP, 2010)

Como se pode ver na Figura 1-6, os acidentes fatais com defensa e barreira (incluindo os elementos de proteção das cabines de cobrança de pedágio, conhecidos por submarino) representam grande parte do total das fatalidades por choque. Nota-se uma grande parcela de fatalidades relacionadas com taludes no ano de 2008. A pequena quantidade de fatalidades de choque com árvores, a inexistência no caso de postes, a uniformidade com relação aos demais e a grande quantidade de choque com proteção lateral, reforçam a idéia de que, nestas rodovias, já existem algum tipo de tratamento de segurança do entorno viário.

Por fim, os dados apresentados mostram que grande parcela dos acidentes envolvem saídas de pistas e, por isso, torna-se extremamente importante o estudo da segurança do entorno da via e das recomendações existentes para o uso de dispositivos de proteção lateral. 


\subsection{ESTRUTURA DO TRABALHO}

O trabalho está estruturado em 5 capítulos.

No capítulo 2 será feita a revisão dos critérios atuais para o uso dos dispositivos de proteção lateral, buscando as diferenças entre as fontes pesquisadas.

No capítulo 3 serão apresentados os modelos compreensivos e a apresentação de dois programas de computador que utilizam estes modelos. Entende-se por modelos compreensivos, um método de análise que trata de forma explícita o risco de ocorrência de acidentes em saída de pista e o efeito da proteção lateral na frequência e/ou gravidade dos acidentes.

O capítulo 4 busca, por meio de um estudo de caso prático, analisar a observância aos critérios recomendados para o uso de dispositivo de proteção lateral e a relação entre estes critérios e a segurança viária, através dos acidentes ocorridos no trecho de rodovia do estudo prático.

E por fim, o capítulo 5 traz a conclusão do estudo. 


\section{ANÁLISE DOS CRITÉRIOS ATUAIS PARAA SEGURANÇA DO ENTORNO VIÁRIO}

O presente capítulo tem por objetivo apresentar a revisão bibliográfica acerca da segurança do entorno da via, definindo conceitos e comparando critérios atualmente aceitos contidos nos manuais/normas nacionais e internacionais.

Os seguintes manuais/normas foram revisados:

- Nacionais:

1. Manual de Projeto Geométrico de Rodovias Rurais, DNER, 1999; secundariamente também o manual de Defensas Rodoviárias, DNER, 1979;

2. Segurança no tráfego - Dispositivos de contenção viária, ABNT NBR 15486:2007; secundariamente também as normas construtivas Segurança no tráfego - Barreiras de concreto, ABNT NBR 14885:2004 e Defensas metálicas - Projeto e implantação, ABNT NBR 6971:1999 (que possuem alguns critérios de aplicação);

- Internacionais:

1. A Policy on Geometric Design of Highways and Streets, AASHTO, 2004;

2. Roadside Design Guide, AASHTO, 2006 (a revisão e complementação atual da terceira edição de 2002), secundariamente também a segunda edição de 1996 (a primeira edição é de 1989).

Como referências complementares, foram consultados os manuais correspondentes de outros países, particularmente o Canadá (Geometric Design Guide for Canadian Roads, TAC, 1999), o 
Reino Unido (Requirements for Road Restraint Systems, TD 19/06, DMRB, 2006) e a Austrália (Rural Road Design, RRD, Austroads, 2003).

Além disso, quando possível, buscou-se identificar e apresentar os estudos científicos que deram origem aos critérios presentes nos manuais, dentro do tópico relacionado.

Percebeu-se, durante a revisão dos manuais, que os trabalhos brasileiros e canadenses seguem a linha americana, e muitas vezes adotam o mesmo critério. Portanto, chamar-se-á atenção para as diferenças que um ou outro manual adota, mesmo que sutis. Por outro lado, vê-se claramente que os manuais britânico e australiano, seguem uma linha diferente da dos americanos. Percebeu-se também que a AASHTO, até o momento, é a única que dedicou uma publicação exclusiva de segurança do entorno viário, por meio do RDG (nas suas diversas edições). Assim, neste capítulo será feita a revisão dos critérios e, paralelamente, será destacada as diferenças entre os textos revisados. Em geral, será citado o RDG (2006), mas grande parte das suas recomendações corresponde aos critérios tradicionais apresentados nas edições anteriores (pelo menos em relação ao RDG, 1996, que também foi revisado).

Busca-se também neste capítulo, o entendimento da relação entre as variáveis e parâmetros utilizados nos critérios estudados e as conseqüências dos acidentes com saídas de pista, para que o planejamento e a metodologia do estudo de caso sejam feitas da maneira mais eficaz, precisa e fidedigna possível.

Na primeira parte do presente capítulo apresentar-se-ão alguns conceitos básicos relacionados, e na segunda parte, apresentar-se-ão os critérios e comparações supramencionados.

\subsection{CONCEITOS UTILIZADOS}

\subsubsection{Entorno tolerante}

Talvez uma das expressões mais presentes na literatura técnica internacional acerca da segurança viária do entorno das vias é forgiving roadside, que poderia ser traduzido por "entorno tolerante". A ABNT, através da NBR 15486:2007, menciona a expressão "a rodovia que perdoa", referindose ao mesmo conceito. 
Segundo o RDG (2006), o entorno tolerante é aquele que possibilita a redução das consequências da saída de pista de um veículo desgovernado, seja qual for o motivo. E para promovê-lo, seria necessário, em ordem de preferência:

a) A remoção de obstáculos que podem acarretar choque com conseqüências graves;

b) Tornar os obstáculos traspassáveis sem danos relevantes aos veículos;

c) Relocar o obstáculo para um local com menos chance de ser atingido;

d) Reduzir a gravidade do impacto com a utilização de materiais quebráveis/deformáveis;

e) Proteger o obstáculo com barreiras ou atenuadores de impacto;

f) Delinear o obstáculo para torná-lo mais previsível.

Os objetivos gerais dessas intervenções são os de tornar menos provável a ocorrência de um acidente quando houver uma saída de pista ou, no caso de não ser possível evitá-lo, tornar o acidente menos grave, especialmente nas consequências para os ocupantes do veículo. A expressão "proteger o obstáculo" na alínea "e", na verdade se refere a proteger os ocupantes do veículo desgovernado da ameaça imposta pelo obstáculo. A alínea "f” busca um objetivo anterior: tornar a saída de pista menos provável (estratégia de preservação na via). Outras ações, não mencionadas acima, poderiam ser incluídas como estratégia de preservação na via, como correções geométricas, controle de velocidade, combate à fadiga dos condutores e ao uso de álcool. Entretanto, como dito anteriormente, o foco deste trabalho é a segurança do entorno da via e os acidentes com saídas de pista, e por essa razão, as medidas de preservação do veículo na via serão deixadas de lado, apesar de serem igualmente importantes para a segurança viária.

O entorno tolerante também é mencionado no Geometric Design Guide for Canadian Roads (TAC, 1999), como sendo aquele que incorpora elementos projetados que reduzem as conseqüências da saída de pista de um veículo desgovernado.

\subsubsection{Talude traspassável}

A ABNT, através da NBR 15486:2007, define talude traspassável como sendo "aqueles onde a superfície é suave e regular, sem descontinuidades significantes, e sem objetos fixos protuberantes, permitindo que veículos trafeguem ou deslizem sobre eles sem enganchamento e sem paradas abruptas". 
Apesar de utilizar o termo traspassável, tanto o TAC (1999) quanto o RDG (2006), não definem claramente o conceito, mas deixam implícito o significado na descrição de outros conceitos relacionados, como talude recuperável, não recuperável e talude crítico.

GLENNON (2004) faz uma rápida discussão sobre o conceito, mencionando que taludes suaves e arredondamento generoso das quebras de inclinação são as características de um terreno traspassável.

\subsubsection{Talude de aterro recuperável, não recuperável e crítico}

Para um melhor entendimento do conceito de área livre que será apresentado adiante, conceituarse-ão neste item três condições de taludes descendentes, encontrados principalmente em aterros, que são resultantes da própria inserção da rodovia no terreno adjacente.

As definições apresentadas a seguir, foram extraídas da ABNT NBR 15486:2007. O RDG (2006) e o TAC (1999) definem estes tipos de talude igualmente. Muito provavelmente, a definição da ABNT baseia-se no RDG (2002), enquanto a do TAC (1999), na definição contida no RDG (1996). Não há distinção relevante, pois tanto a versão do RDG de 2006, quando a versão de 2002, repetem a definição apresentada na versão de 1996.

\section{$\underline{\text { Talude recuperável: }}$}

Pela definição da ABNT, através da NBR 15486:2007, talude recuperável são os “taludes com declividade $4 \mathrm{H}: 1 \mathrm{~V}$ ou mais planos nos quais, quando traspassáveis e livres de obstáculos fixo, os motoristas podem geralmente conduzir seus veículos a uma parada segura ou reduzir a velocidade o suficiente para retornar à pista em segurança”. O conceito teórico e operacional (isto é, o limite de declividade) é similar ao estabelecido no RDG (1996, 2002, 2006).

\section{Talude não recuperável:}

Pela definição da NBR 15486:2007, "talude com declividades entre 3H:1V e 4H:1V, e que são considerados traspassáveis se forem suaves e estiverem livres de obstáculos fixos, mas onde a maioria dos veículos não consegue parar ou retornar à pista com facilidade. Nesses casos 
é esperado que tais veículos atinjam o fundo do talude, onde é recomendado encontrar uma área livre" (que seria uma área de acomodação). O conceito teórico e operacional (isto é, o limite de declividade) é novamente similar ao estabelecido no RDG (1996, 2002, 2006).

\section{Talude crítico:}

Pela definição da NBR 15486:2007, "taludes com declividade maior que 3H:1V, onde a maioria dos veículos tende a capotar”. Da mesma forma, o conceito teórico e operacional (isto é, o limite de declividade) é similar ao estabelecido no RDG (1996, 2002, 2006).

Os valores limites dos taludes acima, isto é, os valores $4 \mathrm{H}: 1 \mathrm{~V}$ e $3 \mathrm{H}: 1 \mathrm{~V}$, muito provavelmente foram extraídos do RDG (2006). Estes valores também são apresentados em outras referências, como o TAC (1999). Segundo GLENNON (2004), os valores $1 \mathrm{~V}: 4 \mathrm{H}$ como limite para taludes recuperáveis e $1 \mathrm{~V}: 3 \mathrm{H}$ como limite para taludes críticos foram originados do estudo de WEAVER, MARQUIS, OLSON (1975), que também estudaram as características dos canais de drenagem traspassáveis. Este estudo será apresentado posteriormente no item "2.7. Tratamento para obstáculo e dispositivos de drenagem”.

\subsection{4. Área livre (clear zone)}

Outro conceito largamente empregado pelos diversos manuais é o conceito de área livre (clear zone), ou zona livre de obstáculos, como se refere a ABNT, que a define, através da NBR 15486:2007, como sendo a "área lateral à pista de rolamento que seja traspassável, sem obstruções e sem obstáculos fixos, podendo ser utilizada por veículos errantes para recobrar o controle ou chegar a uma parada segura”. Portanto, área livre ou zona livre é parte do conceito de entorno tolerante, isto é, a utilização de área livre contribui para um entorno tolerante. Estes dois conceitos não devem ser confundidos, lembrando que o entorno tolerante pode estar presente mesmo na ausência de área livre, podendo ser promovido com outras medidas, tais como o uso de postes colapsíveis ou uso de proteção lateral.

Segundo AASHTO (2004), o termo clear zone é atribuído à área desobstruída e relativamente suave, provida além da borda da faixa de rolamento, para a recuperação de veículos desgovernados. Esta área inclui o acostamento e as faixas auxiliares. 
O TAC (1999) apresenta um conceito mais amplo, onde o conceito da área livre está inserido: zona de recuperação (recovery zone). Enquanto a área livre é, de acordo com o TAC (1999), a área total isenta de obstáculos e disponível para veículos desgovernados, a zona de recuperação é a área total traspassável e desobstruída, disponível ao longo da rodovia, medida a partir da extremidade da faixa de rolamento, e pode conter taludes recuperáveis, não recuperáveis e área de acomodação (runout area). Portanto, a área livre está contida na zona de recuperação, e esta ainda contém a área de acomodação (ou área de escape, segundo a ABNT), que deve ser provida ao final do talude traspassável não recuperável, caso exista.

GLENNON (2004) cita a área livre como sendo aquela ao longo da rodovia, reservado para emergências e projetado para acomodar, de forma segura, veículos que inadvertidamente saíram da pista.

Os australianos, em coerência com o acima exposto, através do AUSTROADS (2003), definem a área livre como sendo aquela largura horizontal, medida da extremidade da faixa de rolamento, que deve ser mantida livre de obstáculos, para permitir a recuperação de veículos desgovernados. Mencionam ainda que a área livre é o equilíbrio entre a área de recuperação, o custo para provêla e a probabilidade do veículo desgovernado encontrar um obstáculo.

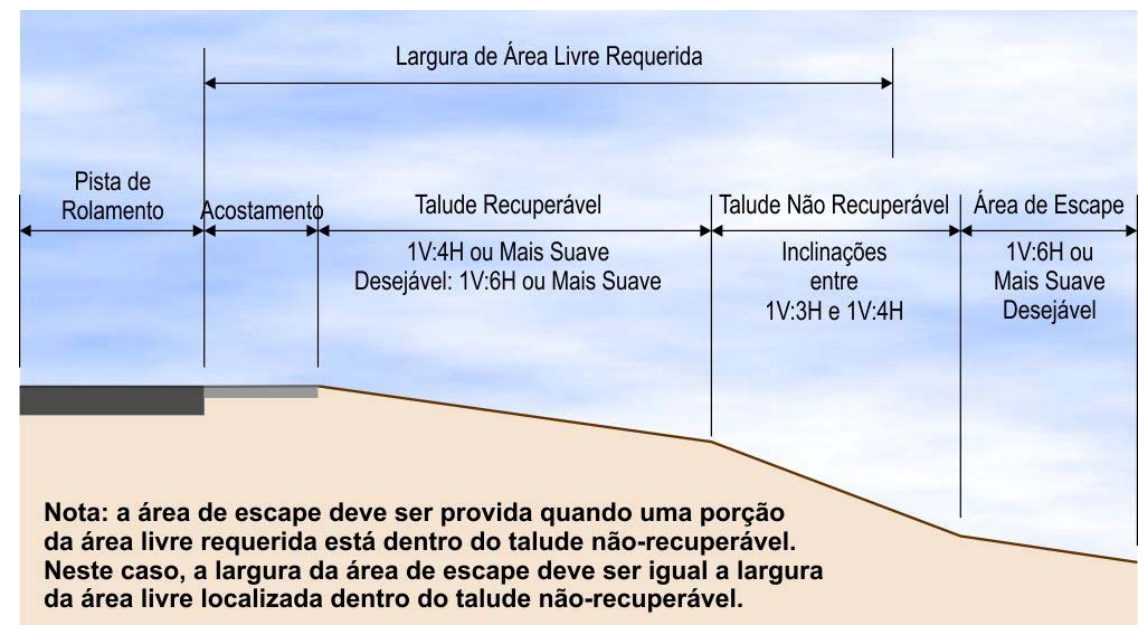

Figura 2-1 - Seção transversal ilustrativa da área livre (Adaptado de RDG, 2006) 


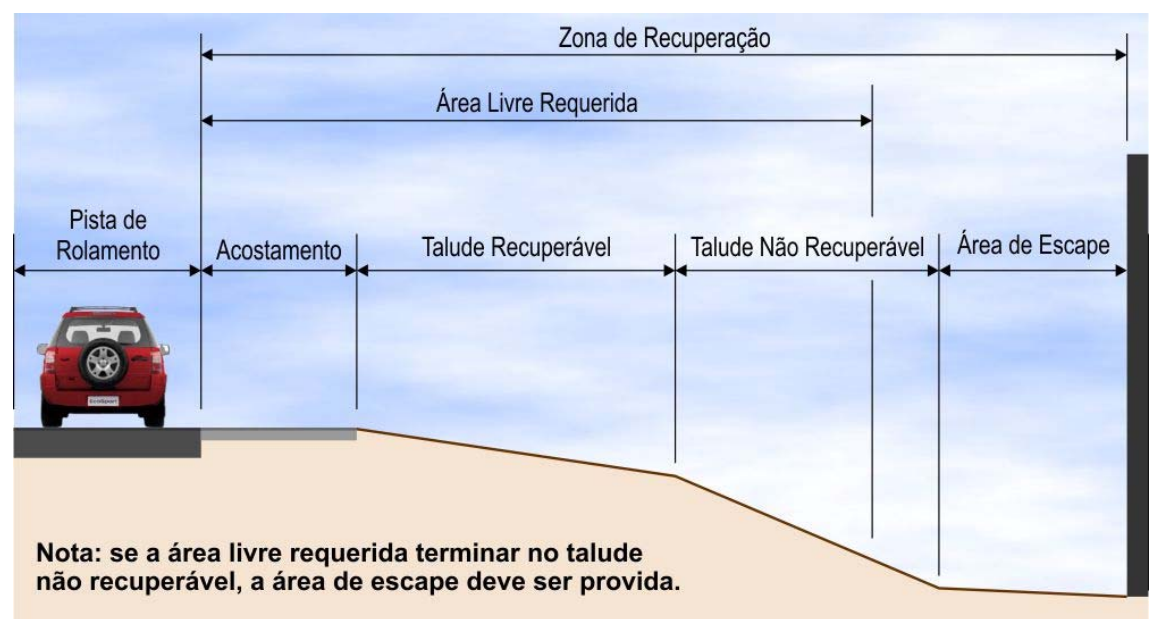

Figura 2-2 - Seção transversal ilustrativa da área livre apresentada pelo TAC (1999)

Observa-se que a maioria dos manuais cita situações de obstáculos, sejam objetos fixos, sejam terrenos não traspassáveis, dentro da área livre para chamar a atenção de que nesta situação algum tipo de tratamento deve ser feito. Ora, se existe obstáculo dentro da área livre, poder-se-ia questionar que esta área não é livre. Portanto, é necessário esclarecer as idéias de área livre requerida, para uma determinada situação de projeto, e área livre disponível. Se existir um obstáculo, por exemplo, uma torre de energia elétrica irremovível, dentro da área livre requerida, este obstáculo fará com que a área livre disponível seja menor que a requerida e, portanto, algum tratamento de segurança deverá ser feito. Se o tratamento mais adequado para esta situação for, por exemplo, a instalação de dispositivo de proteção lateral, o conjunto estará dentro da área livre requerida, todavia, o conceito de entorno tolerante estará garantido.

\subsubsection{Obstáculo traspassável}

Embora não seja formulado explicitamente, o conceito de obstáculo traspassável pode ser deduzido da discussão sobre as características dos obstáculos que exigem proteção (os demais não exigem e seriam, portanto, traspassáveis).

A NBR 15486:2007 não é sistemática na discussão deste aspecto, mas conceitua obstáculos fixos como "estruturas naturais (árvores com diâmetro maior que $10 \mathrm{~cm}$, rochas, etc.) ou construídas (postes de sinalização, pilares de pontes, elementos de drenagem, etc.), deixadas ao longo da pista ou introduzidas durante sua construção, que em caso de acidente produzem desacelerações acentuadas ou paradas abruptas."

O RDG (2006) discute de forma mais ampla este aspecto e relaciona tipos de obstáculos que normalmente requerem proteção. Esta relação está na Tabela 2-1 a seguir. Pode-se ver que os 
critérios tradicionalmente recomendados para projetar canais de drenagem correspondem a transformá-los em obstáculos traspassáveis. Em diversas outras situações, no entanto, não há recomendações claras e exige-se julgamento subjetivo do projetista.

Tabela 2-1 - Tipos de obstáculos que normalmente requerem proteção (RDG, 2006) Obstáculo Recomendações

Pilares, apoios e guarda-corpo de pontes

Matacão

Bueiros, tubos e muros de ala

Taludes de corte e aterro (superfície lisa)

Taludes de corte e aterro (superfície irregurar)

Canais (paralelas)

Canais (transversais)

Aterro

Muros de contenção

Suportes de sinalização / iluminação (ver nota 3)

Suportes de sinalização de tráfego (ver nota 4)

Árvores

Postes de eletricidade

Corpos d'água permanente
Proteção geralmente requerida

Decisão baseada na natureza do objeto fixo e na probabilidade do impacto

Decisão baseada no tamanho, forma e localização do obstáculo

Proteção geralmente não requerida

Decisão baseada na probabilidade do impacto

Ver figura 2-20

Proteção geralmente requerida caso a probabilidade de impactos frontais seja alta

Decisão baseada na altura do aterro e na declividade

Decisão baseada na suavidade relativa da parede e no máximo ângulo de impacto previsto

Proteção geralmente requerida para suportes não colapsíveis

Em rodovias rurais de alta velocidade, sinalizações de tráfego isoladas dentro da área livre requerida, podem exigir proteção

Decisão baseada em circunstâncias específicas do local

Proteção pode ser requerida baseada em avaliação caso a caso

Decisão baseada na localização e profundidade do corpo d'água e probabilidade da saída de pista

Notas:

1. A proteção de um terreno não traspassável ou de um obstáculo rodoviário é geralmente recomendada somente quando estes estão na área livre e não podem, de forma prática ou econômica, ser removidos, relocados ou feitos com materiais colapsáveis, e, é verificado que a barreira provê melhoria de segurança se comparado com a situação do obstáculo desprotegido.

2. Situações específicas, relacionadas com o posicionamento ou a omissão de barreira, irão usualmente ser decididas pela análise do histórico de acidentes, tanto no local como em locais similares.

3. Onde possível, todos os suportes de sinalização e iluminação deverão ser projetados para serem colapsíveis independentemente da sua distância com relação à rodovia caso haja uma probabilidade razoável destes serem atingidos por veículos desgovernados. $\mathrm{O}$ posicionamento e a localização para suportes colapsíveis devem também considerar a segurança de pedestres com relação a detritos resultantes do sistema após o impacto.

4. Na prática, relativamente poucos suportes de sinalização de tráfego, incluindo cancelas e sinalizações luminosas piscantes utilizadas em travessias de linhas férreas, são protegidas. Entretanto, atenuadores de impacto são algumas vezes empregados no lugar da instalação de barreira longitudinal, caso proteções sejam consideradas necessárias.

\subsubsection{Dispositivo colapsível}

A NBR 15486:2007 define dispositivo colapsível como "todo tipo de suporte de sinais ou luminárias projetado para romper quando impactado por um veículo." Cita também diversos mecanismos de rompimento: base deslizante, elemento de fratura, dobradiças, ou uma combinação destes, mencionando que devem romper de uma maneira previsível quando impactados. Naturalmente, a definição aplica-se a outros tipos de dispositivos. 


\subsubsection{Dispositivos de proteção (ou de contenção)}

Os dispositivos de proteção são definidos pela capacidade de absorver o impacto dos choques decorrentes dos acidentes de trânsito, conter os veículos desgovernados, capturá-los ou redirecioná-los à pista, de maneira a reduzir a gravidade de eventuais acidentes decorrentes de saídas de pista (perda de controle dos veículos). Podem ser usados também para proteger pedestres e ciclistas do tráfego veicular.

Neste sentido, os dispositivos de proteção diferenciam-se dos dispositivos de segregação ou separação de fluxos de tráfego que buscam impedir que veículos ou outros usuários da via transponham certos limites da pista, mas não tem capacidade adequada de absorção, contenção e mitigação dos danos no caso de virem a ser colididos. Portanto, barreiras (ou defensas) de proteção distinguem-se de barreiras de segregação, grades ou gradis.

\subsubsection{1. $\quad$ Dispositivo de Proteção Contínuo}

A NBR 15486:2007 define genericamente como barreiras de proteção, que correspondem aos dispositivos de proteção contínuos, que por sua vez são divididos em dispositivos de contenção lateral ou central. Podem ser rígidos, semi-rígidos ou semi-flexíveis e flexíveis em função da resistência oferecida ao choque e capacidade de absorver a energia do impacto (usualmente através da sua deformação).

O termo barreira pode referir-se genericamente a elementos rígidos ou flexíveis. No Brasil são utilizados com mais freqüência as barreiras de concreto como elementos rígidos e as defensas metálicas (guard rails) como elemento flexível. Os elementos de barreiras metálicas podem, entretanto, ser dimensionados para obter graus variados de rigidez ou capacidade de absorver a energia de impacto (variando o espaçamento ou rigidez dos postes de fixação ou a rigidez dos elementos longitudinais e seus fixadores). O grau de flexibilidade determina também a deformabilidade da barreira de proteção.

O DER-SP (Departamento de Estradas de Rodagem do Estado de São Paulo) por meio da IP-DEL00-003 (DER-SP, 2005), define defensa metálica como o "Dispositivo ou sistema de segurança flexível contínuo, maleável ou semi-maleável, constituído por perfis metálicos implantados ao longo das rodovias, com forma, resistência e dimensões capazes de absorver a energia cinética de 
veículos desgovernados pela deformação do dispositivo, de forma a reconduzi-los à pista sem brusca redução de velocidade ou perda de direção." Neste mesmo documento, o DER/SP define barreira de concreto como sendo o "Dispositivo ou sistema de segurança rígido e contínuo, implantado ao longo das rodovias, com forma e dimensões tais que, quando colidido por veículo desgovernado, reconduz esse veículo à pista com desacelerações suportáveis pelo corpo humano e com os menores danos possíveis aos veículos e ao próprio dispositivo, impedindo o acesso a locais que ofereçam risco de acidente.”

O RDG (2006) adota a distinção principal entre barreiras laterais (roadside barriers) e centrais (median barriers), ao invés da distinção entre barreiras rígidas e flexíveis. Enumera, no entanto, diversos sistemas classificados como flexíveis, semi-rígidos e rígidos.

\subsection{Dispositivo de Proteção Lateral Contínuo}

Dispositivos longitudinais usados para proteger os motoristas de obstáculos localizados ao longo de ambos os lados da rodovia. A NBR 15486:2007 define os dispositivos de contenção lateral como sendo "estruturas projetadas e construídas de modo a prevenir que um veículo saindo da pista atinja algum obstáculo fixo ou terreno não traspassável, que cumprem sua função contendo e redirecionando os veículos de um modo seguro". Segundo o RDG (2006), dispositivos longitudinais de proteção lateral são aqueles usados para proteger obstáculos laterais e terrenos não traspassáveis, e ocasionalmente são utilizados para proteger pedestres do fluxo veicular.

\subsection{Dispositivo de Proteção Central Contínuo}

Dispositivos longitudinais usados para separar fluxos opostos em rodovias de pistas duplas e normalmente instalados na área correspondentes aos canteiros centrais. São também utilizadas para separar fluxos da via principal e das vias marginais. A NBR 15486:2007 define os dispositivos de contenção central como "dispositivos utilizados basicamente para separar tráfego de sentidos opostos em auto-estradas com canteiro central. Podem também separar o tráfego de passagem do tráfego local ou separar faixas exclusivas das faixas de uso geral". De acordo com o RDG (2006), além das funções acima mencionadas, os dispositivos de proteção centrais são usados para prevenir que um veículo desgovernado atravesse o canteiro central. Este tipo de dispositivo não será tratado nesta dissertação. 


\subsubsection{Dispositivo de Proteção Pontual}

A NBR 15486:2007 define genericamente como dispositivos amortecedores de impacto, que correspondem aos dispositivos de proteção pontual e podem incluir os atenuadores de impacto, normalmente utilizados para proteger estruturas rígidas, os terminais de barreiras e outros dispositivos como os utilizados para proteger áreas expostas onde se concentram pedestres e/ou moradores (pontaletes, perfis, bollards, etc.). Estes dispositivos também não serão discutidos nesta dissertação, sendo apenas sumariamente descritos a seguir.

\subsection{Terminais de barreiras e defensas}

São elementos localizados nas extremidades das barreiras e defensas com a função de reduzir a gravidade do impacto, pois a própria extremidade da barreira constitui um obstáculo.

O TAC (1999) define como sendo o método pelo qual a extremidade da barreira exposta frontalmente ao tráfego é tratada para minimizar sua ameaça intrínseca aos veículos desgovernados.

\subsection{Atenuadores de impacto}

São elementos que absorvem a energia do impacto reduzindo sua gravidade. Podem ser classificadas em deformáveis ou inerciais, dependendo da forma como desaceleram os veículos desgovernados.

Um termo similar é adotado pela ABNT: dispositivo amortecedor de impacto. Através da NBR 15486:2007, a ABNT define dispositivo amortecedor de impacto como sendo os "dispositivos de proteção que impedem que veículos errantes atinjam um objeto fixo e cumprem seu objetivo desacelerando gradualmente o veículo até sua parada segura, no caso de impactos frontais, ou redirecionando o veículo para fora do perigo, nos casos de impactos laterais." Definições similares são encontradas no RDG (2006) e TAC (1999).

De acordo com DER-SP (2005), atenuadores de impacto são "dispositivos de proteção para veículos desgovernados, capazes de absorver o impacto mais lentamente do que em caso de colisão com objeto rígido, fazendo com que as consequências do acidentes sejam minimizadas.” 
O U.K.DfT (2006), define atenuadores de impacto como dispositivos que absorvem a energia com uma taxa controlada, prevenindo veículos desgovernados do impacto com objetos fixos e rígidos ou estruturas adjacentes à via, minimizando a potencial gravidade para os ocupantes do veículo.

\subsubsection{Linha de intimidação (ou de preocupação)}

A linha de intimidação (shy line, segundo o RDG, 2006), ou linha de preocupação segundo a ABNT (NBR 15486:2007), nada mais é que a distância além da qual um objeto não é interpretado pelo motorista como um obstáculo, que o induziria a reduzir a velocidade ou deslocar-se lateralmente para o lado oposto. Esta característica de percepção não afastaria, entretanto, a eventual necessidade de proteção do obstáculo (visto que neste caso está sendo considerada a condição de um veículo desgovernado).

\subsubsection{Nível de proteção (capacidade de contenção, nível de teste ou contenção)}

A capacidade ou nível de contenção relaciona-se ao desempenho da proteção lateral submetida ao impacto e ao nível de proteção fornecida. O termo nível de proteção pode ser eventualmente preferido por comunicar que não se adota o ponto de vista restrito da resistência estrutural ao impacto (a capacidade de contenção em sentido estrito), mas também outros requisitos funcionais como limites para as acelerações impostas aos ocupantes dos veículos e não penetração dos compartimentos de passageiros (para proteção dos ocupantes).

A normatização americana (NCHRP Report 350) relaciona este conceito com os níveis de teste (TL - test level) definidos como requisito para a certificação de dispositivos de proteção submetidos a testes de impacto (crash tests). A normatização européia (EN 1317) relaciona este conceito com os chamados níveis de contenção (containement level), definindo critérios alternativos para a certificação de dispositivos de proteção, submetidos a testes de impacto (crash tests).

\subsubsection{Espaço de trabalho (ou distância de trabalho, ou ainda, deflexão dinâmica)}

De acordo com a NBR 15486:2007, é a "distância entre a face frontal do sistema de contenção antes do impacto e a posição dinâmica máxima de qualquer parte do sistema”. 
Para o U.K.DfT (2006), o espaço de trabalho deve incorporar além da largura do sistema de contenção e a máxima deflexão dinâmica, a intrusão do veículo além do sistema de contenção. Esta intrusão geralmente ocorre quando a parte superior do veículo invade a projeção vertical do sistema de contenção. A Figura 2-3 ilustra esta situação.

A normatização européia relaciona este conceito com as chamadas classes de distância de trabalho (ou de deflexão), não estabelecidas na normatização americana atual.
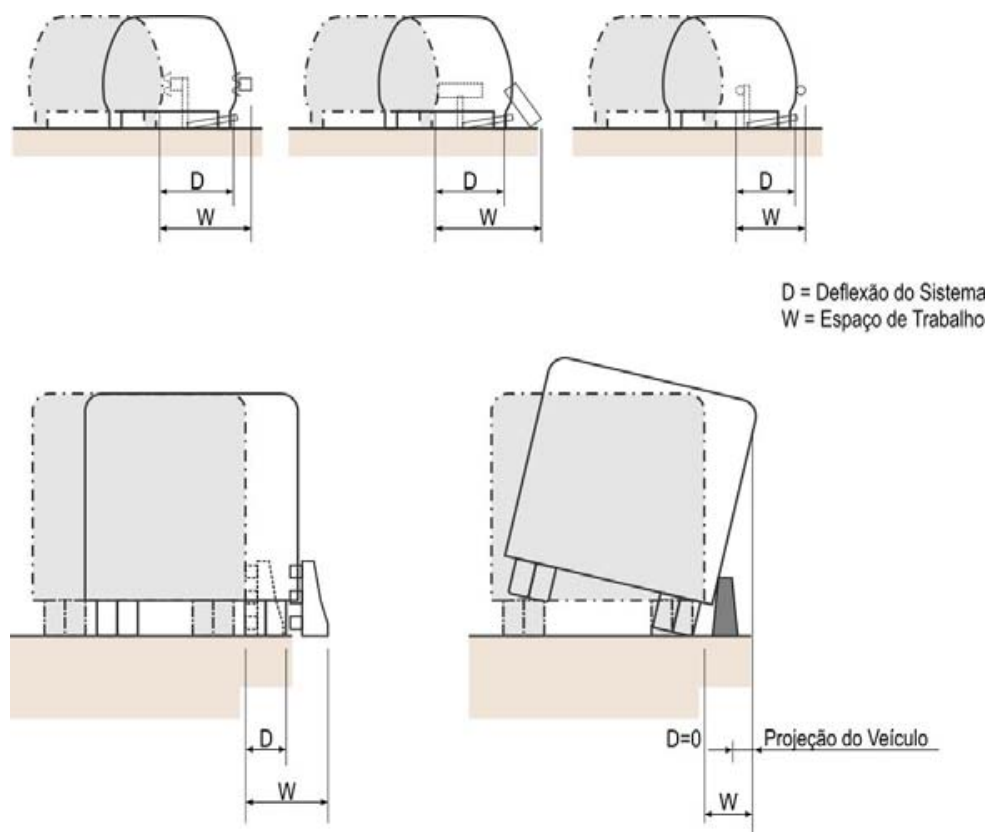

Figura 2-3 - Deflexão dinâmica (D) e espaço de trabalho (W) (U.K.DfT, 2006)

\subsection{EXTENSÃO RECOMENDADA PARA A ÁREA LIVRE}

Parece haver um consenso entre os manuais nacionais e internacionais de que a largura da área livre deve ser a mais prática possível, mas que é inviável prover uma largura que permita livrar todos os veículos desgovernados do perigo. Assim, na determinação da largura da área livre deve-se levar em conta fatores como a velocidade de projeto, o volume de tráfego, presença de taludes de corte e aterro e a inclinação das mesmas, a presença de curvas e a magnitude dos raios e histórico de acidentes do local.

A Figura 2-4 e a Tabela 2-2 ilustram valores sugeridos para largura da área livre recomendada em função do volume de tráfego, da velocidade de projeto e das condições do terreno, extraídos 
do RDG (2006). O RGD (2006) ressalta que estes valores são apenas uma referência aproximada, devendo o projetista ter em mente as particularidades de cada local e, portanto, estes valores não devem ser tomados como precisos e absolutos. As curvas da Figura 2-4 baseiam-se em dados empíricos limitados que foram extrapolados para fornecer informação de um conjunto maior de condições.

Na presença de curvas horizontais, o RDG (2006) apresenta fatores de majoração da largura da área livre para raios de curva menores que $900 \mathrm{~m}$ a serem aplicados no lado externo da curva. Estes fatores estão ilustrados na Tabela 2-3 e, segundo o RDG (2006), são normalmente considerados quando histórico de acidentes indicar a necessidade, ou uma condição específica do local mostrar a potencialidade de acidentes.

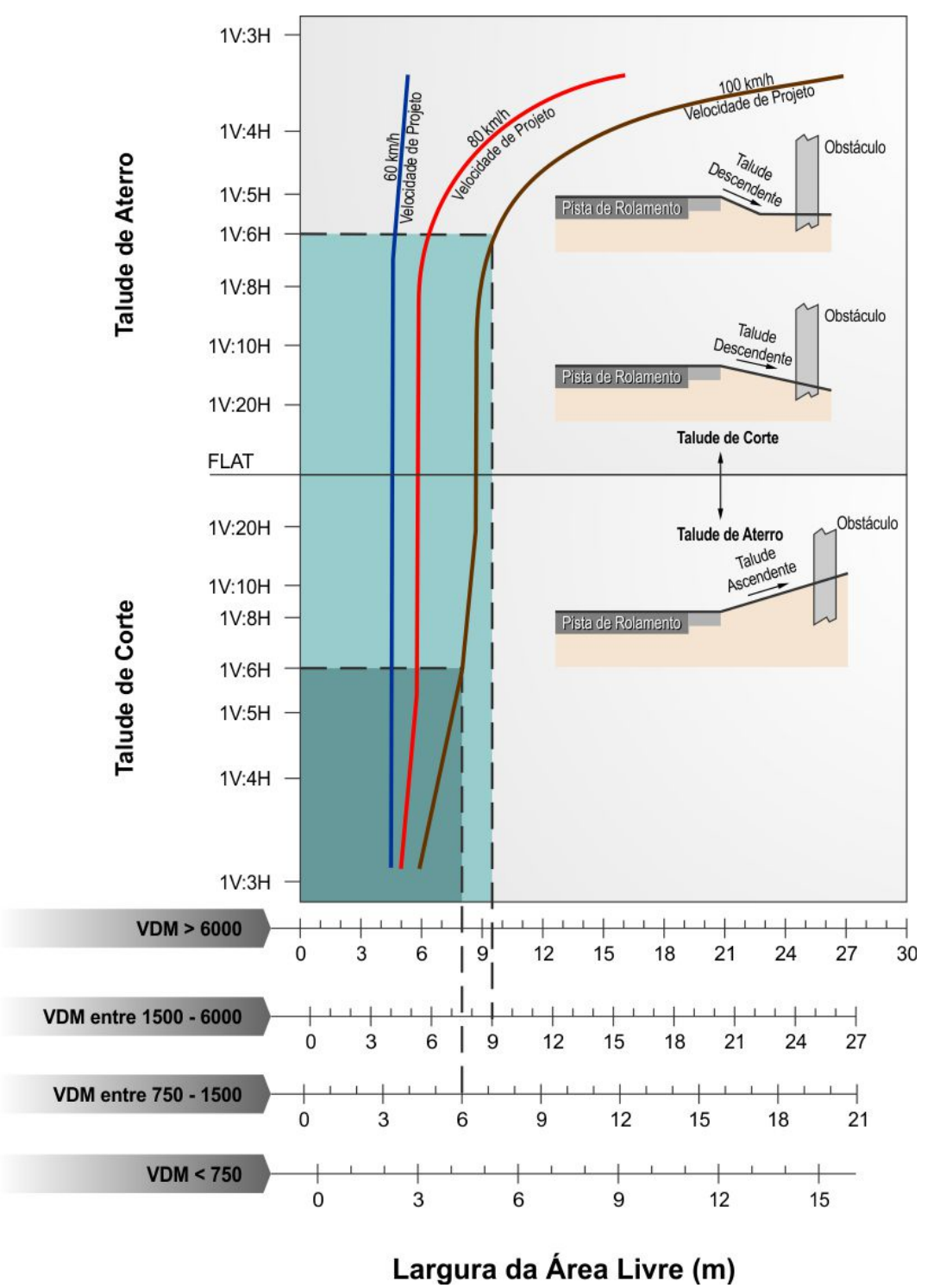

Figura 2-4- Ábaco para valores sugeridos de largura da área livre (Adaptado de RDG 2006) 
Tabela 2-2 - Valores sugeridos para largura da área livre (RDG 2006)

\begin{tabular}{|c|c|c|c|c|c|c|c|}
\hline \multicolumn{8}{|c|}{ Valores sugeridos para a largura da área livre (m) } \\
\hline \multirow[b]{2}{*}{$\begin{array}{c}\text { Velocidade de } \\
\text { projeto }\end{array}$} & \multirow[b]{2}{*}{ VDM de projeto } & \multicolumn{3}{|c|}{ taludes descendentes } & \multicolumn{3}{|c|}{ Taludes ascendentes } \\
\hline & & $\begin{array}{c}1 \mathrm{~V}: 6 \mathrm{H} \text { ou } \\
\text { mais suave }\end{array}$ & $\begin{array}{c}1 \mathrm{~V}: 5 \mathrm{H} \text { até } \\
1 \mathrm{~V}: 4 \mathrm{H}\end{array}$ & $1 \mathrm{~V}: 3 \mathrm{H}$ & $1 \mathrm{~V}: 3 \mathrm{H}$ & $\begin{array}{c}1 \mathrm{~V}: 5 \mathrm{H} \text { até } \\
1 \mathrm{~V}: 4 \mathrm{H}\end{array}$ & $\begin{array}{c}1 \mathrm{~V}: 6 \mathrm{H} \text { ou } \\
\text { mais suave }\end{array}$ \\
\hline \multirow{4}{*}{$\begin{array}{l}60 \mathrm{~km} / \mathrm{h} \text { ou } \\
\text { menos }\end{array}$} & até 750 & $2.0-3.0$ & $2.0-3.0$ & ** & $2.0-3.0$ & $2.0-3.0$ & $2.0-3.0$ \\
\hline & $750-150$ & $3.0-3.5$ & $3.5-4.5$ & ** & $3.0-3.5$ & $3.0-3.5$ & $3.0-3.5$ \\
\hline & $1500-6000$ & $3.5-4.5$ & $4.5-5.0$ & ** & $3.5-4.5$ & $3.5-4.5$ & $3.5-4.5$ \\
\hline & acima de 6000 & $4.5-5.0$ & $5.0-5.5$ & ** & $4.5-5.0$ & $4.5-5.0$ & $4.5-5.0$ \\
\hline \multirow{4}{*}{$70-80 \mathrm{~km} / \mathrm{h}$} & até 750 & $3.0-3.5$ & $3.5-4.5$ & ** & $2.5-3.0$ & $2.5-3.0$ & $3.0-3.5$ \\
\hline & $750-150$ & $4.5-5.0$ & $5.0-6.0$ & ** & $3.0-3.5$ & $3.5-4.5$ & $4.5-5.0$ \\
\hline & $1500-6000$ & $5.0-5.5$ & $6.0-8.0$ & ** & $3.5-4.5$ & $4.5-5.0$ & $5.0-5.5$ \\
\hline & acima de 6000 & $6.0-6.5$ & $7.5-8.5$ & ** & $4.5-5.0$ & $5.5-6.0$ & $6.0-6.5$ \\
\hline \multirow{4}{*}{$90 \mathrm{~km} / \mathrm{h}$} & até 750 & $3.5-4.5$ & $4.5-5.5$ & ** & $2.5-3.0$ & $3.0-3.5$ & $3.0-3.5$ \\
\hline & $750-150$ & $5.0-5.5$ & $6.0-7.5$ & ** & $3.0-3.5$ & $4.5-5.0$ & $5.0-5.5$ \\
\hline & $1500-6000$ & $6.0-6.5$ & $7.5-9.0$ & ** & $4.5-5.0$ & $5.0-5.5$ & $6.0-6.5$ \\
\hline & acima de 6000 & $6.5-7.5$ & $8.0-10.0^{*}$ & ** & $5.0-5.5$ & $6.0-6.5$ & $6.5-7.5$ \\
\hline \multirow{4}{*}{$100 \mathrm{~km} / \mathrm{h}$} & até 750 & $5.0-5.5$ & $6.0-7.5$ & ** & $3.0-3.5$ & $3.5-4.5$ & $4.5-5.0$ \\
\hline & $750-150$ & $6.0-7.5$ & $8.0-10.0^{*}$ & ** & $3.5-4.5$ & $5.0-5.5$ & $6.0-6.5$ \\
\hline & $1500-6000$ & $8.0-9.0$ & $10.0-12.0^{*}$ & ** & $4.5-5.5$ & $5.5-6.5$ & $7.5-8.0$ \\
\hline & acima de 6000 & $9.0-10.0^{*}$ & $11.0-13.5^{*}$ & ** & $6.0-6.5$ & $7.5-8.0$ & $8.0-8.5$ \\
\hline \multirow{4}{*}{$110 \mathrm{~km} / \mathrm{h}$} & até 750 & $5.5-6.0$ & $6.0-8.0$ & ** & $3.0-3.5$ & $4.5-5.0$ & $4.5-5.0$ \\
\hline & $750-150$ & $7.5-8.0$ & $8.5-11.0^{*}$ & ** & $3.5-5.0$ & $5.5-6.0$ & $6.0-6.5$ \\
\hline & 1500 - 6000 & $8.5-10.0^{*}$ & $10.5-13.0^{*}$ & ** & $5.0-6.0$ & $6.5-7.5$ & $8.0-8.5$ \\
\hline & acima de 6000 & $9.0-10.5^{*}$ & $11.5-14.0^{*}$ & ** & $6.5-7.5$ & $8.0-9.0$ & $8.5-9.0$ \\
\hline
\end{tabular}

* Onde uma investigação específica local indicar alta probabilidade de acidentes, ou tais ocorrências forem indicadas através de um histórico de acidentes, o projetista deve prover distâncias de área livre maiores do que as indicadas na tabela. Áreas livres podem ser limitadas a $9 \mathrm{~m}$ por praticidade e prover uma configuração consistente da rodovia caso experiência prévia com projetos similares tenham indicado performance satisfatória.

* * Como a recuperação é menos provável em taludes traspassáveis $1 \mathrm{~V}: 3 \mathrm{H}$, objetos fixos não devem estar presentes nas proximidades do pé desses taludes. A recuperação de veículos com velocidades elevadas que saíram da pista além da borda do acostamento pode ser esperada que ocorra além do pé do talude. A determinação da largura da área de recuperação no pé do talude deve levar em consideração a faixa de domínio disponível, problemas ambientais, fatores econômicos, necessidades de segurança e histórico de acidentes. Além disso, a distância entre a borda da faixa de rolamento e o início do talude $1 \mathrm{~V}: 3 \mathrm{H}$ pode influenciar a área de recuperação provida no pé do talude. Enquanto a aplicação pode estar limitada por diversos fatores, os parâmetros do talude descendente aos quais podem entrar na determinação da área de recuperação máxima desejável estão ilustrados na figura 2.1 .

Tabela 2-3 - Fatores de majoração em curvas horizontais (m)

\begin{tabular}{ccccccc}
\hline \multirow{2}{*}{ Raio $(\mathrm{m})$} & \multicolumn{6}{c}{ Velocidade de Projeto $(\mathrm{km} / \mathrm{h})$} \\
& 60 & 70 & 80 & 90 & 100 & 110 \\
\hline 900 & 1,1 & 1,1 & 1,1 & 1,2 & 1,2 & 1,2 \\
700 & 1,1 & 1,1 & 1,2 & 1,2 & 1,2 & 1,3 \\
600 & 1,1 & 1,2 & 1,2 & 1,2 & 1,3 & 1,4 \\
500 & 1,1 & 1,2 & 1,2 & 1,3 & 1,3 & 1,4 \\
450 & 1,2 & 1,2 & 1,3 & 1,3 & 1,4 & 1,5 \\
400 & 1,2 & 1,2 & 1,3 & 1,3 & 1,4 & - \\
350 & 1,2 & 1,2 & 1,3 & 1,4 & 1,5 & - \\
300 & 1,2 & 1,3 & 1,4 & 1,5 & 1,5 & - \\
250 & 1,3 & 1,3 & 1,4 & 1,5 & - & - \\
200 & 1,3 & 1,4 & 1,5 & - & - & - \\
150 & 1,4 & 1,5 & - & - & - & - \\
100 & 1,5 & - & - & - & - & - \\
\hline
\end{tabular}

Diversos órgãos seguem as recomendações tradicionais do RDG (2006, 2002, 1996; pretensamente também a primeira edição de 1989) para a determinação da largura da área livre e os fatores de majoração em curvas, entre eles o TAC (1999) e a ABNT (na NBR 6971:1999, que 
repete as curvas do RDG, sem detalhamento dos critérios de aplicação). O manual do DNER (1999), por sua vez, não apresenta este conceito.

Os estudos que originaram as recomendações não puderam ser identificados. A revisão histórica de MCLEAN (2002) remete a adoção do conceito de área livre às versões originais do Yellow Book (AASHO, 1967, 1974) e menciona que o valor inicialmente fixado (em 9,0m com perfil suave, aceitando declividade transversal até $3 \mathrm{H}: 1 \mathrm{~V}$ ou $4 \mathrm{H}: 1 \mathrm{~V}$, mas recomendando até $6 \mathrm{H}: 1 \mathrm{~V}$ ) não foi resultado de pesquisas extensas, mas considerou os estudos sobre saídas de pista e o contexto do sistema de vias expressas interestaduais americano. A extensão dos critérios para vias de menor velocidade de projeto e menor fluxo de tráfego teria sido resultado de discussões internas aos comitês da AASHTO durante a produção do Barrier Guide (AASHTO, 1977) e da primeira edição do RDG (1989), incluindo o fator de ajustamento para áreas livres no lado externo de curvas horizontais. Desde então o critério do RDG (1989) viria sendo reproduzido sem melhor análise. Uma exceção seria o estudo de investigação de GRAHAM e HARWOOD (1982).

É possível ver que os critérios atuais deixam de lado diversos aspectos relevantes. O mais evidente é relacionado com a influência das rampas (a declividade longitudinal da via, especialmente nos trechos descendentes) na necessidade de área livre. Este fator deveria normalmente ser combinado com a influência dos raios das curvas existentes.

No entanto, tanto o RDG (2006) quanto o TAC (1999) destacam que estes critérios são meramente indicativos e fazem menção do uso de procedimentos de análise custo-benefício na avaliação da área livre, e que poderá ser utilizado na avaliação de alternativas, como o uso de dispositivo de proteção lateral, caso a área livre requerida não for viável. Estes métodos serão analisados no capítulo seguinte.

Os critérios de outros países parecem ser ainda menos adequados. Na Austrália e Nova Zelândia, o AUSTROADS (2003) adota como valores de largura da área livre um ábaco diferente daquele apresentado pelo RDG (2006), bem como os fatores de correção para o lado externo das curvas, como mostram a Figura 2-5 e Figura 2-6. No entanto, a adoção dos critérios tradicionais do RDG tem sido proposta também na Austrália e Nova Zelândia (MCLEAN, 2002; ROPPER et al., 2002). 


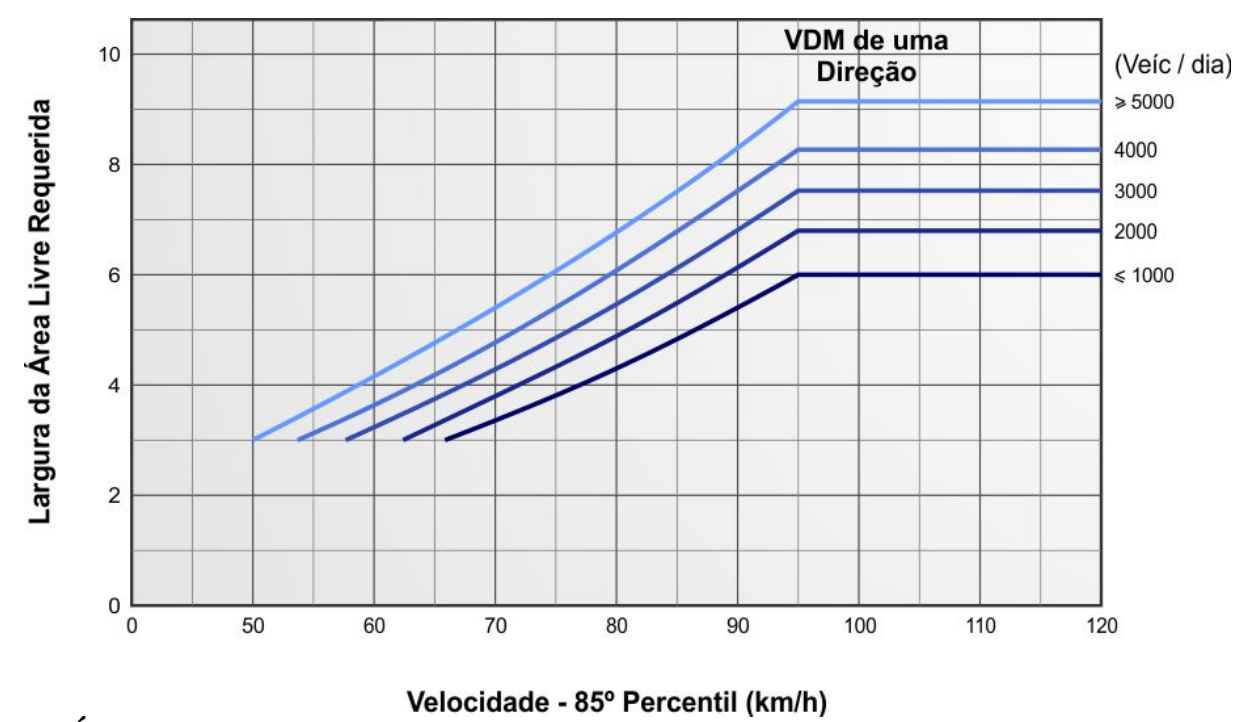

Figura 2-5 - Ábaco apresentado pelo Rural Road Design para determinação da área livre (adaptado)

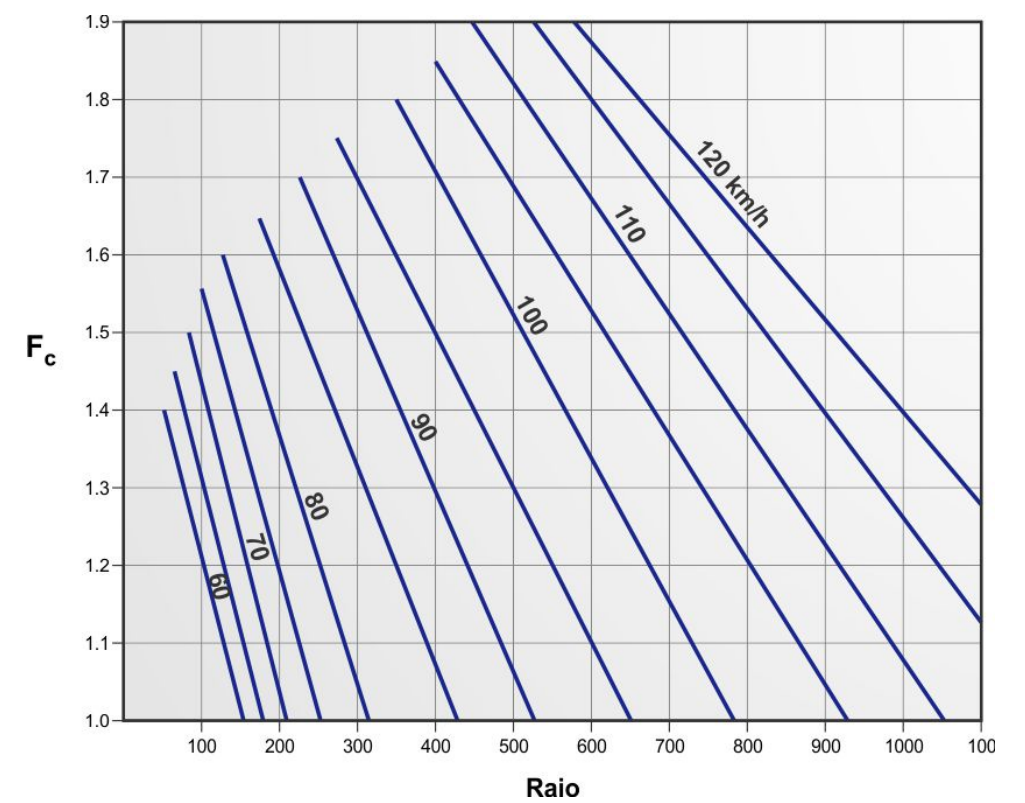

Figura 2-6 - Fator de correção da largura da área livre em curvas (AUSTROADS, 2003)

Comparando as recomendações para os exemplos do RDG (2006), a rodovia com velocidade de projeto de $100 \mathrm{~km} / \mathrm{h}$, em um trecho em aterro com declive lateral $1 \mathrm{~V}: 6 \mathrm{H}$ e VDM de 5000 veículos, que requereria uma área livre de 9,0 m, manteria o requisito de 9,0 $\mathrm{m}$ de área livre pelo critério australiano (mas independente do tipo de seção e declive lateral), enquanto que em um trecho em corte com aclive lateral 1V:6H e VDM de 700 veículos, que requereria 4,5m pelo RDG (2006), seria elevado para cerca de $6 \mathrm{~m}$ pelo critério australiano (independente do tipo de seção e declive lateral). Na presença de uma curva de 700 metros em um trecho descendente com rampa de 3\%, o fator de correção seria igual a 1,2 segundo o RDG (2006) e passaria a 1,15 no critério australiano (ambos independentes da rampa longitudinal). 


\subsection{CRITÉRIOS GERAIS PARA O USO DE PROTEÇÃO LATERAL}

Um primeiro aspecto que motiva o uso de dispositivos contínuos de proteção lateral decorre das características das áreas adjacentes à via, especialmente as declividades transversais. A aplicação mais usual dos dispositivos de proteção lateral está associada a este tipo de característica e será discutido a seguir. Também serão apresentadas brevemente a aplicação dos dispositivos de proteção lateral no caso da presença de obstáculos fixos nas laterais da via, contidos na área livre requerida.

Como mencionado anteriormente, a função dos dispositivos de proteção lateral é evitar que o veículo desgovernado venha a chocar-se com um objeto fixo localizado nas laterais da via ou venha a atravessar uma condição de terreno que possa causar danos graves aos ocupantes do veículo (terrenos não traspassáveis como, por exemplo, os taludes íngremes de aterro), e isso é feito contendo o veículo e redirecionando-o com desaceleração aceitável.

Vale ressaltar que a barreira, por si só, constitui um obstáculo fixo às margens da rodovia e, devido a sua proximidade e extensão, pode aumentar a freqüência dos acidentes. Portanto, como ação principal deve-se, sempre que possível, eliminar as causas da necessidade do uso da proteção lateral, com medidas de suavização de taludes de aterro e remoção de obstáculos ou sua transformação em elementos deformáveis/colapsíveis, como serão mencionados no item 2.7. É recomendável que os dispositivos de proteção lateral sejam instalados apenas em locais onde a gravidade do impacto com o dispositivo seja inferior à gravidade das conseqüências na ausência dele. Todavia, há locais em que não é tão clara a comparação das conseqüências.

Segundo o RDG (2006), uma análise benefício-custo deve ser realizada para avaliar a necessidade de proteção lateral considerando fatores como a velocidade de projeto e o volume de tráfego, comparando custos associados à barreira (instalação, manutenção e custo do acidente) com os custos alternativos sem a barreira. Assim, por exemplo, rodovias de baixa velocidade de projeto e baixo volume de tráfego, ou com pouca probabilidade de acidentes, não necessitariam de proteção lateral, na presença de obstáculos fixos. Nos critérios usuais do RDG, esta ponderação aparece na definição da área livre requerida (que é função da velocidade de projeto 
da via e do seu volume de tráfego), visto que a motivação para proteção decorre da presença de elementos na extensão lateral definida.

Ainda de acordo com o RDG (2006), a necessidade para o uso de dispositivos de proteção lateral pode ser agrupada em duas categorias: taludes de aterro e obstáculos laterais, sendo que a proteção de pedestres e ciclistas também pode justificar o uso da proteção lateral em locais com grande presença deste tipo de usuário. No entanto, apenas para os dois primeiros aspectos existem critérios explícitos propostos no RDG (2006), revisados a seguir.

\subsubsection{Uso de proteção lateral devido à presença de aterros}

No Brasil, existem duas recomendações distintas no que se refere ao uso de dispositivos de proteção lateral na presença de aterros.

O Manual de Projeto Viário do antigo DNER (1999), ainda adotado pelo DNIT, recomenda o critério apresentado na Figura 2-7 a seguir. Embora não haja referência explícita à fonte da recomendação, o RDG (1989) está entre as referências do manual citado.

A NBR 15486:2007 da ABNT, por sua vez, recomenda o critério apresentado na Figura 2-8 a seguir, que é o atualmente adotado pelo RDG (1996, também 2002 e 2006) e foi proposto em substituição ao critério anterior, adotado pela NBR 6971:1999.

Portanto, a fonte de ambas as recomendações é comum e será discutida a seguir com base na apresentação do RDG (2006) e suas fontes de informação.

No caso de proteção devido ao talude de aterro, o RDG (2006) expõe um critério com dois fatores básicos de decisão, a saber, altura e inclinação do talude. Este critério, cuja origem não foi mencionada no manual americano, é a fonte do apresentado acima pela ABNT. Tal critério não considera a probabilidade de saída de pista, tampouco a relação benefício/custo de se utilizar ou não a proteção lateral. 


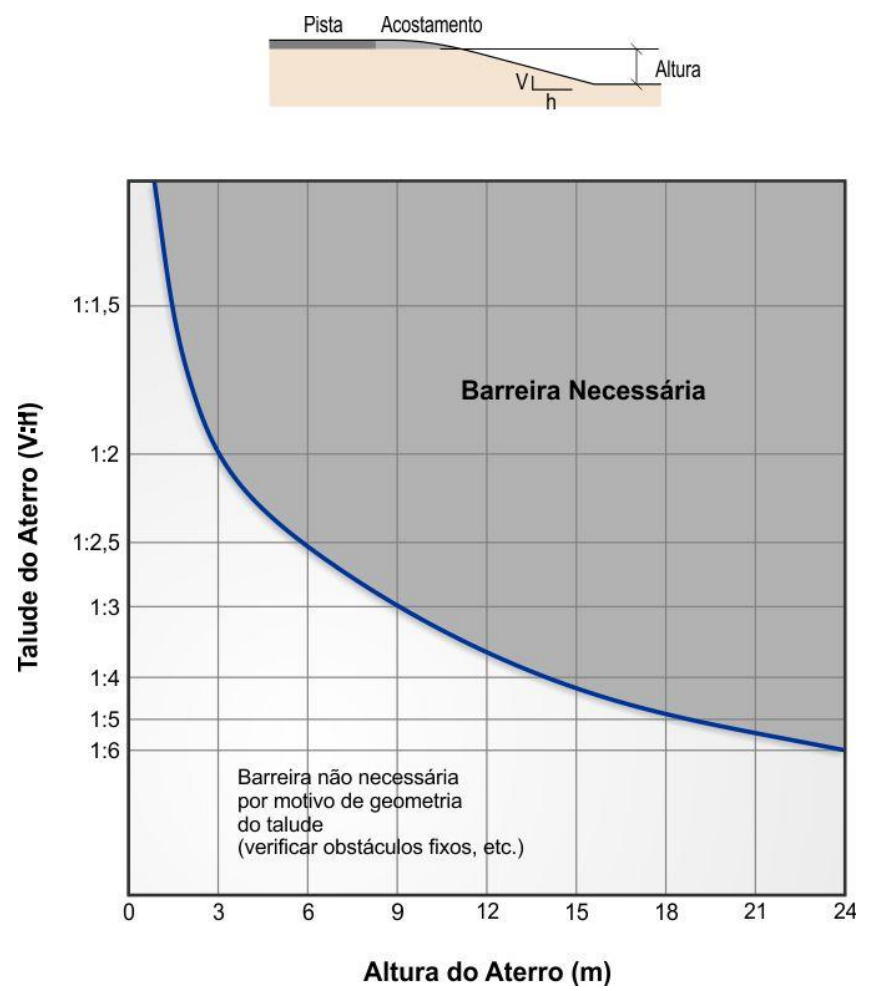

Figura 2-7-Necessidade de proteção lateral de taludes de aterro em função da altura e inclinação do talude (adaptado DNER, 1999)
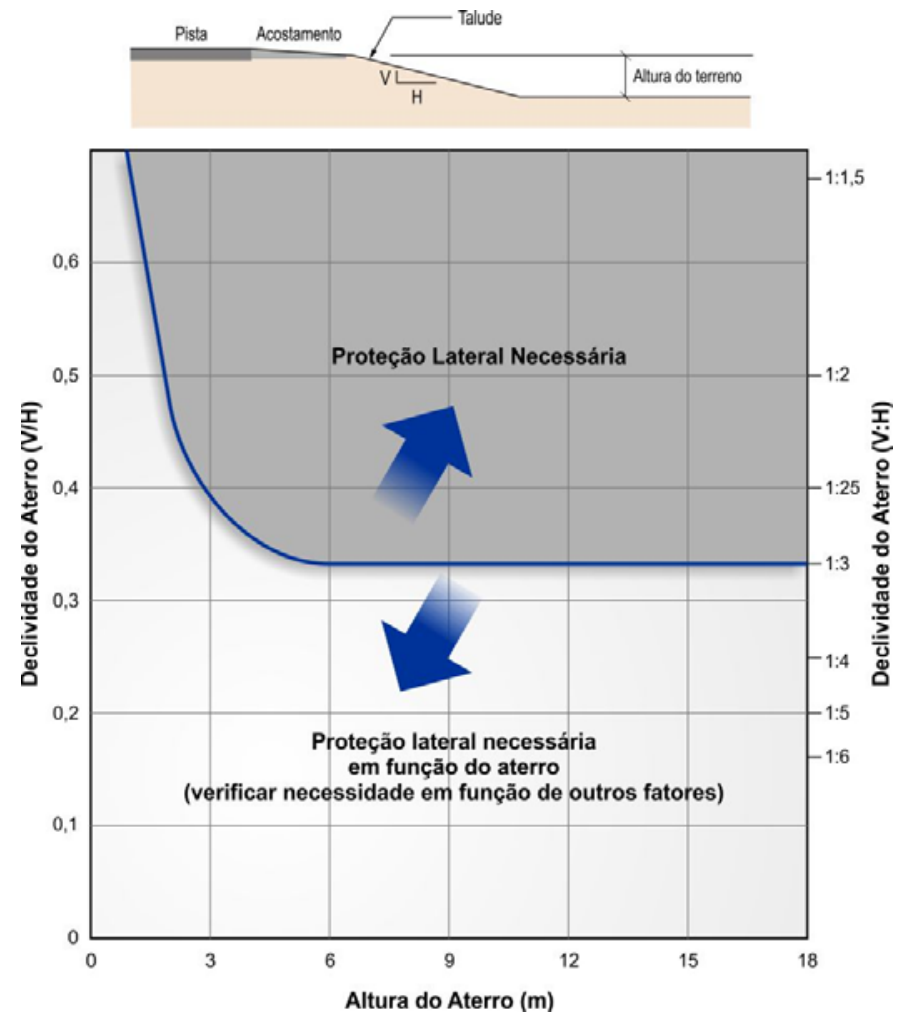

Figura 2-8 - Necessidade de proteção lateral de taludes de aterro em função da altura e inclinação do talude (NBR 15486:2007) 
Nota-se que o gráfico da Figura 2-8 é horizontal na sua parte inferior, indicando que para taludes mais suaves que $3 \mathrm{H}: 1 \mathrm{~V}$, independente da altura, não se exige proteção lateral, exceto se outros fatores vierem a exigí-la, como presença de objetos fixos ou históricos de acidentes. Esta característica está coerente com o conceito de taludes críticos, situação em que o veículo pode vir a tombar ou capotar, adotado na definição atual do conceito de área livre. Na versão do RDG (1989), entretanto, o gráfico deste mesmo critério (o da Figura 2-7), não era horizontal em sua parte inferior, indicando que taludes mais suaves que $3 \mathrm{H}: 1 \mathrm{~V}$ justificam o uso de barreiras dependendo da altura de aterro. O critério recomendado pelo DNER (1999) corresponderia, portanto, ao do RDG (1989). Ambos seriam menos consistentes com o critério de área livre.

Nota-se que no Brasil, por questões de custo de implantação, aterros de alturas consideráveis não são associados às inclinações mais suaves, pois esta combinação resulta em extensa largura de aterro, ocupando demasiadamente o espaço lateral, impactando a largura da faixa de domínio e variáveis ambientais, além de exigir movimento de volumes de terra bastante significativos. $\mathrm{O}$ projeto seguro exigiria, portanto, a utilização de dispositivos de proteção lateral.

Segundo GLENNON (2004), estes critérios muito provavelmente têm sua origem nos estudos de GLENNON E TAMBURRI (1967), cujo propósito foi determinar critérios objetivos para a instalação de defensas metálicas (guardrails) na presença de taludes de aterro ou objetos fixos. Os critérios propostos no estudo referido foram obtidos através da comparação entre a severidade do choque com a defensa metálica e a severidade de se atravessar um talude de aterro, com determinadas características, ou a severidade do choque com obstáculo fixo. Em outras palavras, o estudo buscou avaliar o que seria menos grave: chocar-se com a defensa metálica ou atravessar um barranco/chocar-se com objeto fixo às margens da rodovia.

A primeira parte do estudo de GLENNON E TAMBURRI (1967) trata do critério para uso de defensas metálicas na presença de aterros e a segunda parte, trata do critério na presença de obstáculos fixos.

O índice de severidade utilizado no estudo baseou-se na ponderação de três níveis de gravidade dos acidentes, quais sejam, com vítima fatal (fatal accidents), com vítima não fatal (injury accidents) e sem vítima (property-damage-only accidents, ou PDO), e os pesos atribuídos a estas classes foram 25, 6 e 1, respectivamente, baseados em custos diretos destes tipos de acidentes em estudo do Illinois Division of Highway (1962), apud GLENNON e TAMBURRI (1967). Assim, 
o índice de severidade do obstáculo, seja ele o talude ou a defensa metálica, é calculado da seguinte forma:

$$
S I=\frac{25 F+6 I+P}{N}
$$

onde

$\mathrm{F}=$ número de acidentes com vítimas fatais,

$\mathrm{I}$ = número de acidentes com vítimas não fatais,

$\mathrm{P}=$ número de acidentes sem vítimas, e

$\mathrm{N}=$ número total de acidentes.

Os autores do estudo ressaltam que mudanças moderadas nos pesos relativos dos acidentes com vítimas fatais e não fatais têm pouca influência no índice de severidade. Entretanto, se for considerado o sofrimento humano e a produtividade futura que a vítima deixa de realizar, os pesos atribuídos aos acidentes com vítimas fatais e não fatais crescem consideravelmente, influenciando a necessidade do uso de defensas metálicas em taludes de aterro.

O índice de severidade do talude de aterro foi estimado no referido estudo por técnicas de regressão múltipla relacionando a severidade com as variáveis representativas das condições do talude (altura do aterro, inclinação do talude, material utilizado no aterro, condições no pé do talude, presença de cursos d'água no pé do talude, presença de obstáculos fixos e velocidade do veículo), e o índice de severidade da defensa metálica pode ser obtido por uma grande amostragem de acidentes classificados por severidade.

A Tabela 2-4 mostra o número de acidentes, separados por severidade, envolvendo choque de veículos com defensas metálicas entre 1963 e 1964, e a Tabela 2-5 mostra o número de acidentes envolvendo veículos atravessando taludes de aterro, classificados por severidade e condições do aterro (altura e inclinação do talude de aterro). Os autores desconsideraram as seguintes variáveis: material utilizado no aterro, condições no pé do talude, presença de cursos d'água no pé do talude, presença de obstáculos fixos e velocidade do veículo (por serem de complexa obtenção, ter baixa correlação com o índice de severidade ou por considerarem a variável separadamente). 
No estudo foram avaliadas equações de regressão linear múltipla e transformações log-log e semi-log, ilustradas na Tabela 2-6, para diversas combinações de pesos atribuídos as classes de severidade. Assim, para se determinar qual condição de talude de aterro o uso da defensa metálica irá reduzir a severidade, basta igualar os índices de severidade do talude de aterro e da defensa metálica, encontrando a curva de igual severidade. A Figura 2-9 mostra o resultado das equações linear, log-log e semi-log para a combinação de pesos 1-6-25. A curva consagrada e utilizada no RDG é a de melhor ajuste das três ilustradas na Figura 2-9: a forma log-log, com $\mathrm{R}=0,8$ e desvio padrão 0,91 . $\mathrm{O}$ uso de defensa metálica seria necessário se as características do aterro fossem aquelas representadas acima desta curva.

Tabela 2-4 - Número de acidentes do tipo choque com defensa metálica (GLENNON E TAMBURRI, 1967)

\begin{tabular}{ccccc}
\hline Com vítima fatal & Com vítima não fatal & Sem vítima (PDO) & Total & SI (1-6-25) \\
\hline 14 & 147 & 170 & 331 & 4,24 \\
\hline
\end{tabular}

Tabela 2-5 - Número de acidentes com atravessamento de aterro (GLENNON E TAMBURRI, 1967)

\begin{tabular}{|c|c|c|c|c|c|c|c|}
\hline \multicolumn{3}{|c|}{ Categoria de aterro } & \multicolumn{4}{|c|}{ Número de acidentes } & \multirow[b]{2}{*}{$\begin{array}{c}\text { SI } \\
(1-6-25)\end{array}$} \\
\hline $\begin{array}{c}\text { Faixa de } \\
\text { altura do } \\
\text { aterro }\end{array}$ & $\begin{array}{l}\text { Categoria } \\
\text { de altura }\end{array}$ & $\begin{array}{c}\text { Inclinação do } \\
\text { talude de } \\
\text { aterro }\end{array}$ & Fatal & $\begin{array}{l}\text { Com vítima } \\
\text { não fatal }\end{array}$ & PDO & Total & \\
\hline \multirow{6}{*}{0,3 à 1,5} & 0,9 & $0,200(5: 1)$ & 0 & 2 & 9 & 11 & 1,91 \\
\hline & 0,9 & $0,250(4: 1)$ & 0 & 2 & 7 & 9 & 2,11 \\
\hline & 0,9 & $0,333(3: 1)$ & 0 & 4 & 6 & 10 & 3,00 \\
\hline & 0,9 & $0,500(2: 1)$ & 0 & 22 & 20 & 42 & 3,62 \\
\hline & 0,9 & $0,667(1,5: 1)$ & 0 & 10 & 7 & 17 & 3,94 \\
\hline & 0,9 & 1 & 0 & 1 & 3 & 4 & 2,25 \\
\hline \multirow{6}{*}{1,8 à 3} & 2,4 & 0,200 & 0 & 2 & 2 & 4 & 3,50 \\
\hline & 2,4 & 0,250 & 1 & 4 & 3 & 8 & 6,50 \\
\hline & 2,4 & 0,333 & 0 & 5 & 5 & 10 & 3,50 \\
\hline & 2,4 & 0,500 & 1 & 34 & 31 & 66 & 3,94 \\
\hline & 2,4 & 0,667 & 2 & 42 & 27 & 71 & 4,63 \\
\hline & 2,4 & 1,000 & 1 & 19 & 5 & 25 & 5,76 \\
\hline \multirow{5}{*}{3,3 à 6} & 4,5 & 0,250 & 1 & 1 & 3 & 5 & 6,80 \\
\hline & 4,5 & 0,333 & 0 & 6 & 3 & 9 & 4,33 \\
\hline & 4,5 & 0,500 & 5 & 75 & 44 & 124 & 4,98 \\
\hline & 4,5 & 0,667 & 3 & 73 & 41 & 117 & 4,73 \\
\hline & 4,5 & 1,000 & 1 & 14 & 9 & 24 & 4,88 \\
\hline \multirow{5}{*}{6,3 à 9} & 7,5 & 0,250 & 0 & 1 & 1 & 2 & 3,50 \\
\hline & 7,5 & 0,333 & 0 & 0 & 2 & 2 & 1,00 \\
\hline & 7,5 & 0,500 & 1 & 33 & 22 & 56 & 4,38 \\
\hline & 7,5 & 0,667 & 8 & 42 & 28 & 78 & 6,17 \\
\hline & 7,5 & 1,000 & 1 & 21 & 5 & 27 & 5,78 \\
\hline \multirow{3}{*}{9,3 à 12} & 10,5 & 0,500 & 1 & 22 & 5 & 28 & 5,80 \\
\hline & 10,5 & 0,667 & 1 & 20 & 8 & 29 & 5,65 \\
\hline & 10,5 & 1,000 & 1 & 5 & 4 & 10 & 5,90 \\
\hline \multirow{3}{*}{12,3 à 15} & 13,5 & 0,500 & 0 & 3 & 3 & 6 & 3,50 \\
\hline & 13,5 & 0,667 & 2 & 18 & 7 & 27 & 6,12 \\
\hline & 13,5 & 1,000 & 0 & 10 & 1 & 11 & 5,55 \\
\hline \multirow{3}{*}{15,3 à 21} & 18 & 0,500 & 0 & 8 & 4 & 12 & 4,33 \\
\hline & 18 & 0,667 & 3 & 25 & 6 & 34 & 6,80 \\
\hline & 18 & 1,000 & 2 & 3 & 2 & 7 & 10,00 \\
\hline \multirow{3}{*}{21,3 à 30} & 25,5 & 0,500 & 1 & 6 & 3 & 10 & 6,40 \\
\hline & 25,5 & 0,667 & 0 & 20 & 3 & 23 & 5,37 \\
\hline & 25,5 & 1,000 & 1 & 4 & 2 & 7 & 7,28 \\
\hline \multirow{3}{*}{30,3 à 45} & 37,5 & 0,500 & 0 & 1 & 1 & 2 & 3,50 \\
\hline & 37,5 & 0,667 & 0 & 16 & 3 & 19 & 5,22 \\
\hline & 37,5 & 1,000 & 1 & 7 & 1 & 9 & 7,68 \\
\hline \multirow{3}{*}{45,3 à 60} & 52,5 & 0,500 & 0 & 2 & 0 & 2 & 6,00 \\
\hline & 52,5 & 0,667 & 1 & 7 & 3 & 11 & 6,36 \\
\hline & 52,5 & 1,000 & 3 & 8 & 0 & 11 & 11,20 \\
\hline \multirow{2}{*}{60,3 à 150} & 105 & 0,667 & 1 & 6 & 1 & 8 & 7,75 \\
\hline & 105 & 1,000 & 5 & 7 & 0 & 12 & 13,90 \\
\hline
\end{tabular}


Tabela 2-6 - Equações de regressão múltiplas (GLENNON E TAMBURRI, 1967)

\begin{tabular}{|c|c|c|c|c|}
\hline Pesos & $\begin{array}{c}\text { Tipo de } \\
\text { equação }\end{array}$ & Equação de regressão & $\begin{array}{c}\text { Erro } \\
\text { padrão }\end{array}$ & $\begin{array}{c}\text { Coeficiente de } \\
\text { correlação } \\
\text { multipla }\end{array}$ \\
\hline \multirow{3}{*}{$1-4-17$} & Linear & $S I=1,988+0,012 h+1,933 s$ & 0,656 & 0,791 \\
\hline & Semi-log & $\mathrm{SI}=2,250+1,433 \log (\mathrm{h})+2,061 \log (\mathrm{s})$ & 0,705 & 0,753 \\
\hline & Log-log & $\log (\mathrm{SI})=0,413+0,149 \log (\mathrm{h})+0,278 \log (\mathrm{s})$ & 0,440 & 0,794 \\
\hline \multirow{3}{*}{$1-5-25$} & Linear & $S I=2,189+0,017 \mathrm{~h}+2,851 \mathrm{~s}$ & 0,970 & 0,788 \\
\hline & Semi-log & $\mathrm{SI}=2,679+2,020 \log (\mathrm{h})+3,064 \log (\mathrm{s})$ & 1,071 & 0,734 \\
\hline & Log-log & $\log (S I)=0,505+0,164 \log (h)+0,329 \log (s)$ & 1,070 & 0,785 \\
\hline \multirow{3}{*}{$1-6-25$} & Linear & $\mathrm{SI}=2,649+0,018 \mathrm{~h}+3,075 \mathrm{~s}$ & 0,966 & 0,804 \\
\hline & Semi-log & $\mathrm{SI}=3,146+2,185 \log (\mathrm{h})+3,316 \log (\mathrm{s})$ & 1,032 & 0,772 \\
\hline & Log-log & $\log (S I)=0,566+0,160 \log (h)+0,324 \log (s)$ & 0,913 & 0,804 \\
\hline \multirow{3}{*}{$1-6-28$} & Linear & $S I=2,565+0,019 h+3,341 s$ & 1,108 & 0,785 \\
\hline & Semi-log & $\mathrm{SI}=3,151+2,326 \log (\mathrm{h})+3,566 \log (\mathrm{s})$ & 1,190 & 0,747 \\
\hline & Log-log & $\log (S I)=0,572+0,164 \log (h)+0,336 \log (s)$ & 1,272 & 0,79 \\
\hline \multirow{3}{*}{$1-10-100$} & Linear & $S I=2,787+0,068 h+9,578 s$ & 4,163 & 0,75 \\
\hline & Semi-log & $\mathrm{SI}=3,618+7,625 \log (\mathrm{h})+9,773 \log (\mathrm{s})$ & 4,690 & 0,667 \\
\hline & Log-log & $\log (S I)=0,806+0,235 \log (h)+0,467 \log (s)$ & 18,841 & 0,738 \\
\hline
\end{tabular}

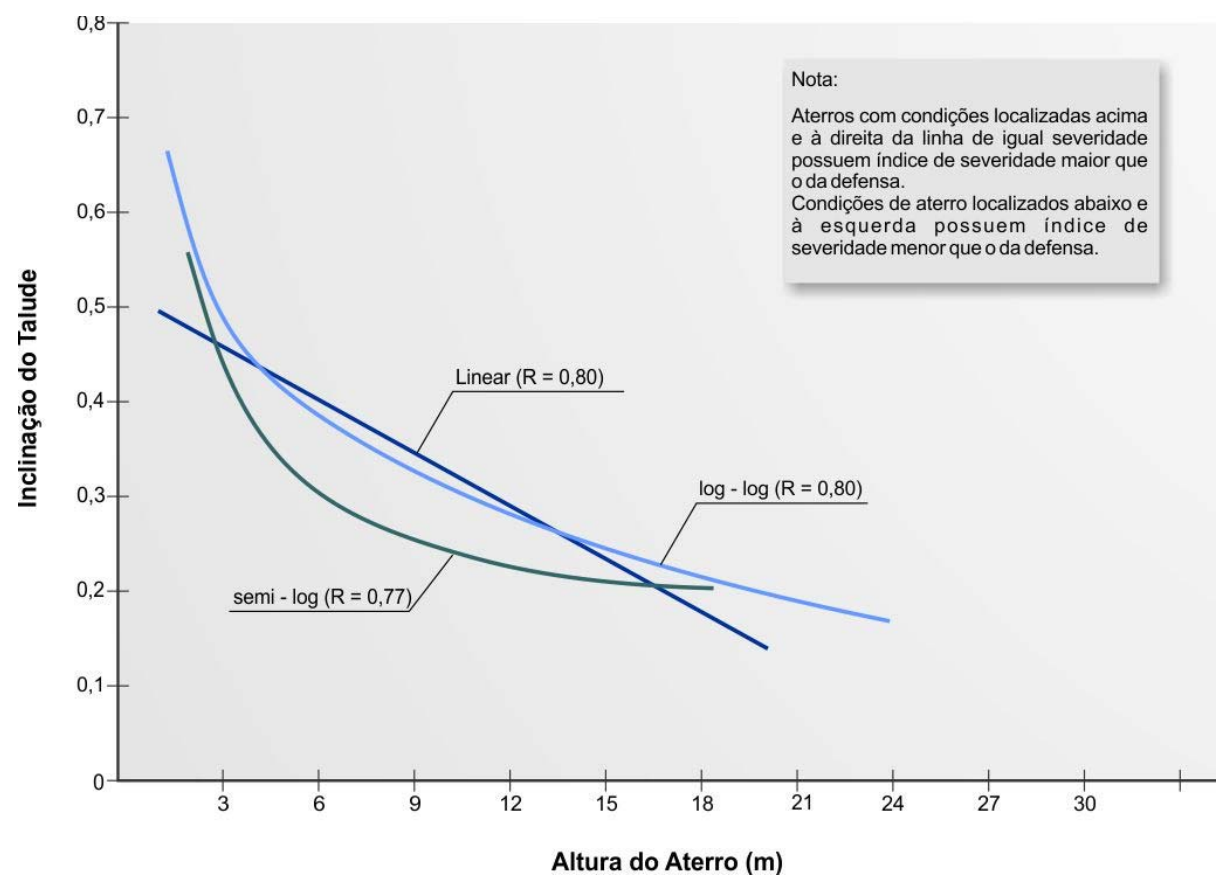

Figura 2-9 - Três tipos de equações estudadas na análise de regressão para os pesos de severidade 1-6-25. (adaptado GLENNON E TAMBURRI, 1967)

Nota-se que o RDG menciona o critério de GLENNON E TAMBURRI (1967) sem, no entanto, fazer distinção do uso de barreiras rígidas ou flexíveis. Viu-se que, no estudo original, a curva de igual severidade foi obtida a partir de dados de acidentes envolvendo choques com defensas metálicas e não com barreiras rígidas, que pode ter índice de severidade maior que a defensa metálica. Outro ponto importante é que a curva foi obtida a partir de custos diretos de nível de 
gravidade (com vítima fatal, com vítima não fatal e sem vítima) na relação 25-6-1, que pode variar com o tempo e de local para local.

Portanto, o Manual de Projeto Geométrico de Rodovias Rurais do DNER (1999) e da ABNT, através da NBR 6971:1999, baseiam-se na curva apresentada pelo RDG (1989), enquanto que a NBR 15486:2007 baseia-se na curva apresentada pelo RDG (2006), todas estas mantendo a indistinção entre os tipos de barreiras. Um aspecto surpreendente a notar é que a relação de pesos 25-6-1 atribuídos aos níveis de gravidade do acidente do estudo de GLENNON E TAMBURRI (1967) é coerente com os valores de custos sociais apresentados pelo estudo do IPEA (2006).

De acordo com TAC (1999), a determinação da necessidade do uso de proteção lateral baseada na comparação de severidades entre chocar-se com a proteção e atravessar um talude de aterro, dado sua altura e inclinação, é inadequado, pois não consideram a probabilidade da ocorrência do acidente e a comparação do custo de instalação da barreira e o custo da não utilização da barreira. TAC (1999) exemplifica um procedimento similar, inadequado, porém mais sofisticado que o descrito acima (veja Figura 2-10), e ainda, destaca que o desenvolvimento de novas técnicas de análise custo-benefício provê o projetista com uma opção melhor na avaliação da necessidade do uso de proteção lateral, pois possibilita considerar fatores específicos de cada local na análise. Estes últimos seriam os modelos compreensivos, discutidos no capítulo seguinte.

Pode-se notar que o RDG (2006) faz ponderações similares, com menor destaque, e cita a existência de critérios alternativos (como os ábacos apresentados no seu capítulo 5). O exemplo apresentado pelo TAC (1999) é mais compreensivo e baseado em estudos locais. Um método clássico similar, apesar de proposto em um estudo americano, do Special Report 81 do antigo Highway Research Board, não foi adotado pelo RDG (2006). Este procedimento foi proposto no Brasil através do manual de Defensas Rodoviárias, de 1979, do antigo DNER.

Outros países apresentam critérios similares (e igualmente criticáveis, portanto). O critério do AUSTROADS (2003) está apresentado na Figura 2-11. No entanto, como anteriormente observado, existe também a tendência a adotar os critérios americanos também na Austrália e Nova Zelândia (MCLEAN, 2002; ROPPER et al., 2002). 


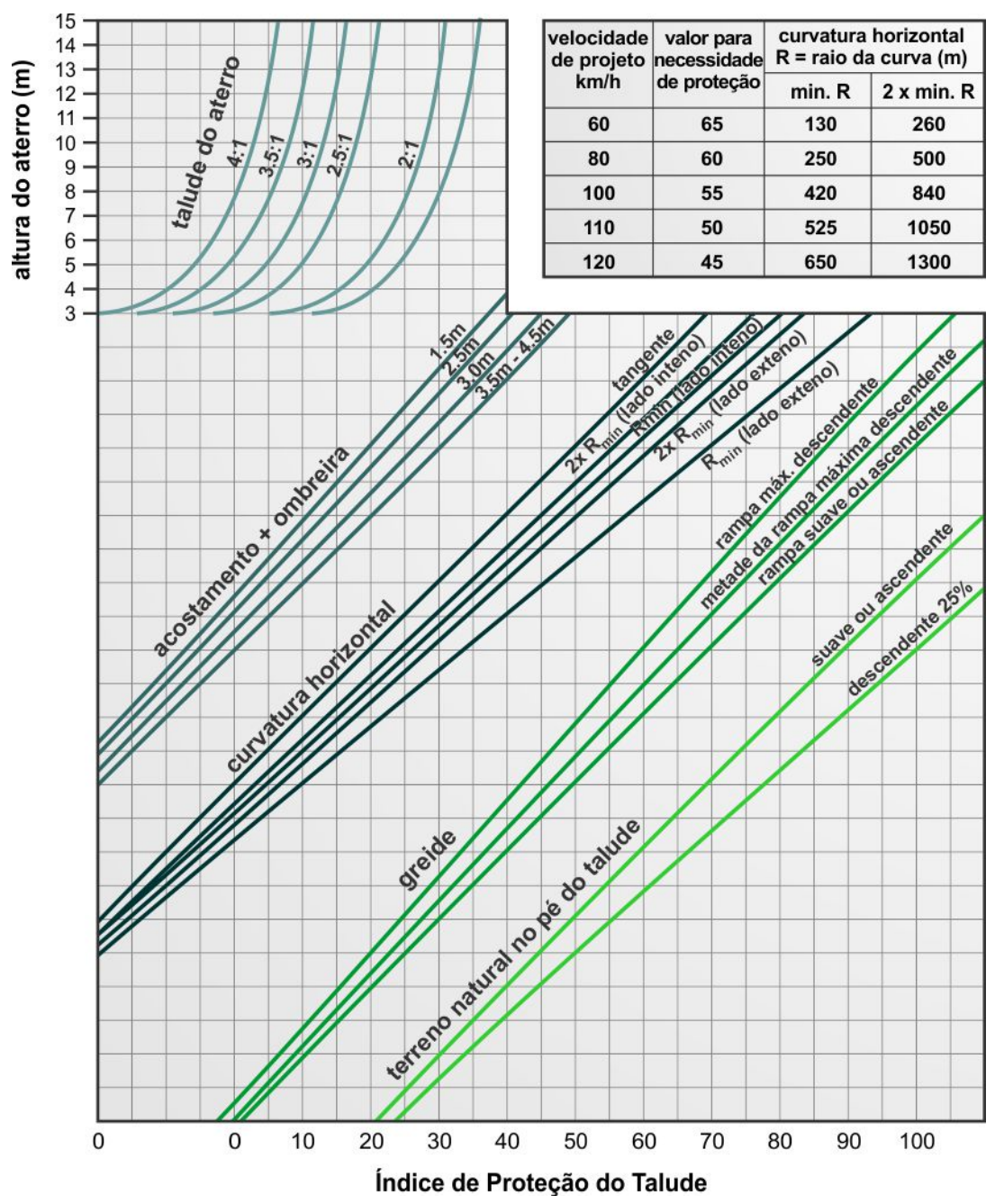

Figura 2-10 - Necessidade de proteção em aterros (TAC 1999)

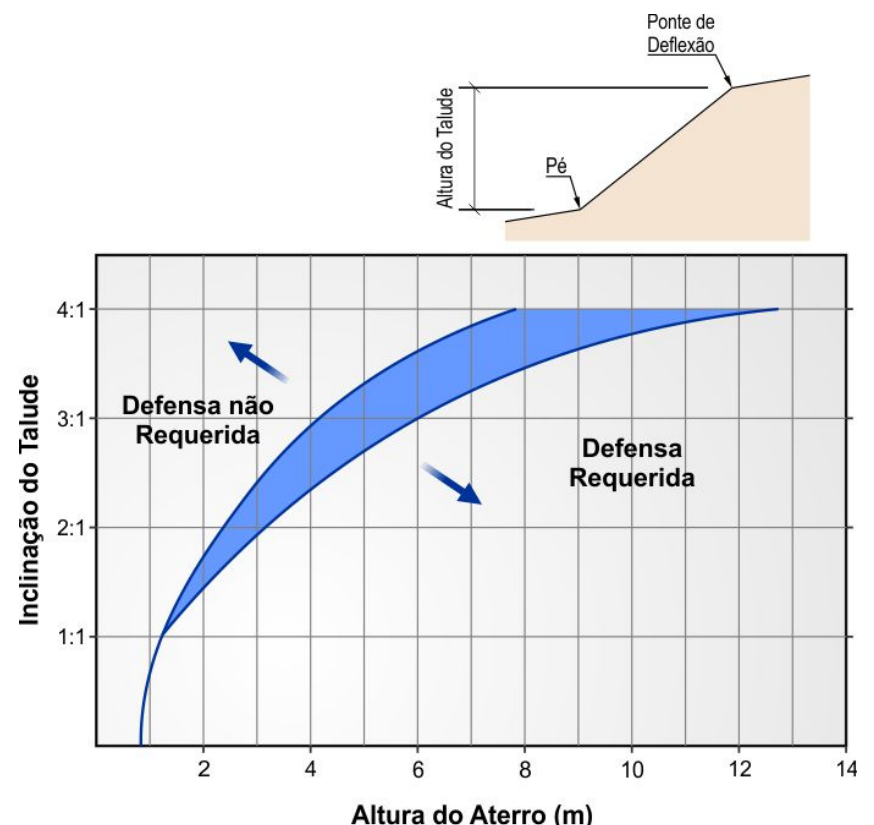

Figura 2-11 - Necessidade de proteção lateral (adaptado: AUSTROADS, 2003) 


\subsubsection{Uso de proteção lateral devido à presença de obstáculos laterais}

Os obstáculos laterais podem ser tanto objetos fixos, feitos ou não pelo homem, como terrenos não traspassáveis. A necessidade do uso de proteção lateral a fim de proteger o motorista dos danos causados pelo impacto com um obstáculo lateral depende do tipo de obstáculo e da probabilidade de atingi-lo (RDG, 2006). A remoção, relocação, modificação ou uso de proteção lateral para obstáculos próximos à via são mais fáceis de avaliar. No entanto, de acordo com o RDG (2006), à medida que o afastamento do obstáculo em relação à via aumenta torna-se menos evidente a melhor solução. As extensões de área livre recomendadas anteriormente podem orientar o profissional na determinação se o obstáculo constitui ou não perigo para o motorista.

O RDG (2006) apresenta uma lista de obstáculos laterais que normalmente exigem o uso de dispositivos de proteção lateral, e está reproduzida na Tabela 2-1.

O TAC (1999) propõe a aplicação de heurística na consideração do uso de proteção lateral com os seguintes passos:

a. Proteger um terreno não traspassável ou um objeto fixo somente é justificável quando estão localizados dentro da área livre e não podem ser economicamente removidos, relocados, substituídos por materiais quebráveis, e se o impacto com a barreira for menos severo que a condição sem barreira.

b. Experiências de acidentes no local ou em local semelhante devem ser usadas para ajudar na decisão de instalação ou omissão em casos secundários.

c. Com relação os sinais de tráfego, na prática, poucos são protegidos.

No entanto, o TAC (1999) também menciona que a necessidade de proteção lateral deveria ser desenvolvida por análise quantitativa de custo-benefício em função do tipo de obstáculo e da probabilidade de atingi-lo.

Percebe-se, então, que as recomendações são similares: que se deve avaliar a remoção, relocação ou substituição de obstáculos rígidos presentes na área livre definida e, se isto não for possível, que se devem avaliar dispositivos para proteção lateral dos obstáculos. Em ambos os casos, uma análise de benefício-custo é recomendada para confirmar a decisão a tomar. 


\subsection{CRITÉRIOS DE SELEÇÃO DO TIPO DE PROTEÇÃO LATERAL CONTÍNUA}

A escolha do tipo de proteção lateral consiste na determinação das características relacionadas à deflexão dinâmica, nível de contenção da proteção e a gravidade do impacto sentido pelos ocupantes do veículo.

Parece não haver um critério claro para a escolha do tipo de proteção lateral. Talvez a peculiaridade e a complexidade de cada local tornem única a solução do projeto de segurança, fazendo com que o processo de seleção não seja uma tarefa simples. Atualmente, a decisão para a escolha de um sistema de contenção baseia-se em experiência de campo e bom senso. Por exemplo, em locais onde há restrição de espaço entre a pista e o obstáculo fixo, opta-se por utilizar sistemas rígidos ou semi-rígidos; o custo de manutenção e reparo também favorece a opção por utilizar sistemas rígidos ou semi-rígidos; o custo de instalação e a capacidade de absorção de energia do impacto (protegendo os ocupantes dos veículos) favorecem a utilização de sistemas flexíveis com defensas metálicas. Outros fatores são levados em conta, como a predominância de certos tipos de veículos (veículos pesados em velocidades média ou elevada podem normalmente romper defensas metálicas) e o efeito de restrição à visibilidade (maior com o uso de barreiras de concreto) ou a necessidade de instalar dispositivos anti-ofuscantes (mais fácil de fixar sobre barreiras de concreto).

Um exemplo da escolha incorreta da utilização de dispositivo de proteção lateral é o da Figura 2-12, que mostra o uso de defensa metálica no canteiro central da Av. 23 de Maio, sob o viaduto Pedro de Toledo. Na figura é possível ver que a defensa metálica está bastante próxima aos pilares do viaduto e, nesta condição, se um veículo desgovernado vir a se chocar neste ponto, certamente o impacto com o pilar ocorrerá, resultando em taxa de desaceleração elevada. Outra questão observada na Figura 2-12 e que será tratado no item 2.5 é o posicionamento da defensa metálica com relação à guia. A recomendação é que a defensa metálica esteja posiciona com a face alinhada à guia, caso contrário, o impacto do veículo com a guia pode provocar sua “decolagem", levando a condições inadequadas de impacto. Com relação à fixação, nota-se que o sistema é engastado ao solo por meio de postes e que as lâminas dos sentidos opostos de circulação do tráfego são interligadas por meio de espaçadores. Uma alternativa a esta instalação seria a utilização de barreiras rígidas no trecho central, em último caso, e uma transição para um sistema flexível nos terminais de barreira deveria ser utilizada (defensas metálicas independentes 
e alinhadas às guias, uma para cada pista, exigiriam um maior espaço para a deflexão do sistema na aproximação com os pilares do viaduto).

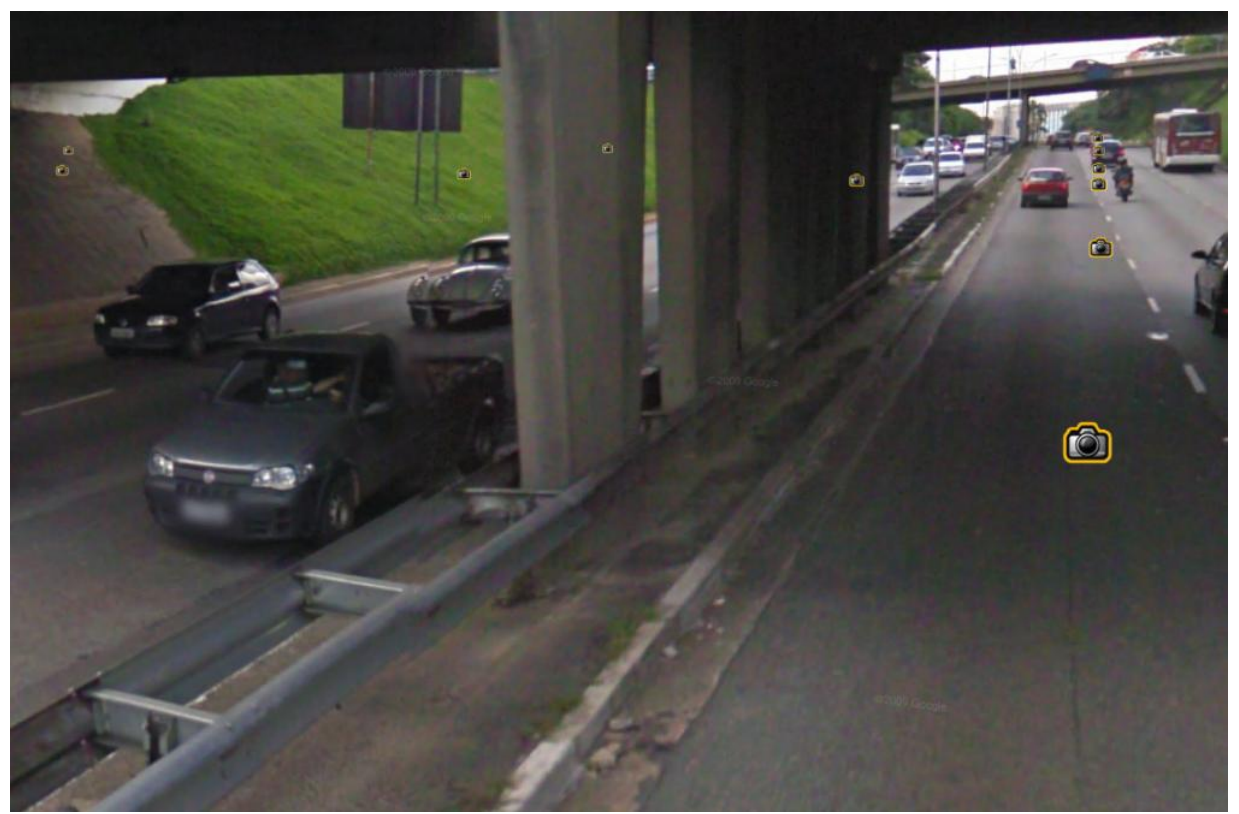

Figura 2-12 - Sistema flexível instalado próximo ao obstáculo. Nota-se que se a defensa fosse instalada alinhada a guia e se a rigidez fosse aumentada localmente, o sistema poderia ser aceitável (foto: Google Earth, Av. 23 de maio, acessado em 09/01/2011)

Segundo a terminologia da NBR 6971:1999, uma deflexão menor de até 0,60m qualificaria o dispositivo como rígido. Os dispositivos flexíveis são classificados em maleáveis, semimaleáveis e semi-rígidos. São fixadas somente as disposições construtivas básicas para cada tipo de dispositivo, sem mencionar sua deflexão típica ou máxima. As defensas podem ser também simples ou duplas (recomendadas apenas em canteiros centrais estreitos) e ter altura de $0,65 \mathrm{~m}$ ou $0,75 \mathrm{~m}$ (destinada a locais com tráfego significativo de veículos pesados).

As barreiras de concreto usualmente são tratados como sistemas rígidos. Estes sistemas proporcionam deflexão lateral quase nula e impõe as maiores taxas de desaceleração. São utilizados em locais onde praticamente não há espaço para a deformação ou em locais onde a penalidade pela penetração na barreira é elevada. Diversos perfis transversais estão disponíveis, inclusive a versão mais alta destinada aos locais com grande porcentagem de caminhões. A NBR 14885:2004 recomenda o perfil New Jersey e o perfil F, fixando suas dimensões básicas (sem especificar características de armação, ligação ou fundação). As barreiras podem também ser simples ou duplas e a altura recomendada é de $0,81 \mathrm{~m}$ ou $1,00 \mathrm{~m}$ (destinada a locais com tráfego significativo de veículos pesados) 
Segundo o TAC (1999), para que os objetivos da proteção lateral sejam alcançados deve-se balancear a necessidade de prevenir a deformação da barreira com a necessidade de proteção dos ocupantes do veículo. Em outras palavras, um sistema flexível é mais tolerante que um sistema rígido, porém a necessidade de espaço para a deflexão do sistema é maior. Ainda segundo o TAC (1999), diversos sistemas alcançam este balanceamento de formas distintas, mas todos podem ser agrupados em três grupos distintos: sistemas flexíveis, semi-rígidos e rígidos, e serão descritos na sequência.

Os sistemas flexíveis resultam em grandes deformações laterais, porém produzem menores taxas de desaceleração nos veículos durante o impacto (o que pode resultar em menor impacto interno sobre os ocupantes dos veículos). Tais sistemas são utilizados em locais onde pode ser provido um espaço suficiente entre o dispositivo de proteção e os desníveis adjacentes ou obstáculos fixos protegidos. Como relata o TAC (1999), este tipo de sistema pode ter deflexões típicas na faixa de 3,2 m a 3,7 m. Os sistemas semi-rígidos fornecem deflexões laterais reduzidas, mas com altas taxas de desaceleração. Estes sistemas são utilizados em áreas onde há restrição de espaço lateral e onde as deflexões devem ser limitadas. Deflexões típicas de projeto variam entre 0,5 m e 1,7 m. Entende-se que deflexões menores que $0,5 \mathrm{~m}$ caracterizam sistemas rígidos.

A tendência atual é a de classificar os dispositivos de proteção lateral segundo suas características de desempenho (níveis de contenção, distância de trabalho, etc.). A ABNT, na NBR 15486:2007, cita ambos os padrões americano e europeu.

Por exemplo, para a designação da capacidade de contenção, o RDG (2006) adota os critérios propostos pelo NCHRP Report 350, que faz uma classificação segundo os níveis de teste (test level) que variam de TL-1, TL-2, TL-3, TL-4, TL-5, TL-6. Assim, barreiras certificadas com nível de proteção TL-2 foram desenvolvidas para veículos de passeio e pequenos caminhões em situações de baixa gravidade de impacto. Para esse nível, as barreiras possuem proteção limitada quando impactadas por veículos maiores com velocidades elevadas e grandes ângulos de impacto. Deve-se, portanto, escolher o dispositivo de proteção que melhor se enquadra ao nível de proteção, considerando o tipo de tráfego, velocidade e volume da via, conseqüências da penetração no sistema e custo. Por exemplo, a escolha de um dispositivo de proteção que satisfaz o TL-4 pode não ser economicamente viável em rodovias de baixo volume de tráfego ou baixa velocidade diretriz. A normatização européia adotou níveis de contenção distintos e introduziu 
classes de distância de trabalho (ou deflexão ao impacto) W1, E2, W3, W4, W5, W6, W7, W8. Maiores detalhes serão discutidos na seção 2.8 adiante.

O nível de contenção e a classe de deflexão ao impacto estão diretamente relacionados à seleção do tipo de proteção lateral, em particular em função do espaço disponível além do dispositivo de proteção. Como mencionado anteriormente, em locais onde a distância entre o dispositivo de proteção e o obstáculo a ser "protegido" é generoso, os sistemas flexíveis podem ser a melhor opção, dado a pequena taxa de desaceleração a que os ocupantes do veículo são submetidos. Alguns sistemas semi-flexíveis podem ter a rigidez aumentada localmente através da redução do espaçamento dos postes de apoio, adoção de postes mais rígidos ou elementos de enrijecimento, se a nova configuração permitir evitar o uso de dispositivos rígidos.

O RDG (2006) apresenta diversos fatores que devem ser considerados antes da escolha final do tipo de sistema de contenção a ser utilizados: capacidade de contenção e redirecionamento, deflexão, condições do terreno, compatibilidade, custos, manutenção, estética e ambiente, e experiência de campo.

As condições do terreno geralmente influenciam a escolha do tipo de sistema. Segundo o RDG (2006), se a proteção lateral for instalada em locais com inclinação maiores que $10 \mathrm{H}: 1 \mathrm{~V}$, um sistema flexível ou semi-rígido deve ser usado. Em locais onde a inclinação superar 1V:6H o uso de proteção lateral deve ser evitada. O tipo e a largura de solo disponível para a fixação dos suportes também devem ser considerados. Os custos iniciais de instalação geralmente são maiores para sistemas rígidos. Por outro lado, os custos de manutenção são menores. Para sistemas flexíveis, o raciocínio inverso é verificado.

O fator compatibilização está relacionado com a uniformização dos tipos de proteção já adotados na região, isto é, quando se tem poucos tipos de proteção em operação em uma determinada rodovia ou região, surgem vantagens tais como a simplicidade na geração do inventário, a familiaridade da equipe de manutenção e construção, a validação da eficácia do dispositivo pela comparação com os outros adotados, etc. A facilidade, o custo e a conveniência da manutenção rotineira, do reparo em caso de danos, do estoque de material de reposição e da futura disponibilidade de peças, também pesam na decisão. Sistemas mais simples e padronizados necessitam de menos peças para serem estocadas e repostas. 
Normalmente o fator estético não é considerado na escolha do tipo de dispositivo de proteção. Entretanto, segundo o RDG (2006), em locais como parques e áreas de recreação, um sistema de contenção que se integra visualmente ao ambiente pode ser selecionado. Fatores ambientais como chuvas (ligadas a questões de drenagem), regiões com concentração de indústrias (ligadas à problemas de corrosão) e locais com restrição de visibilidade, devem ser considerados.

Por fim, ainda segundo o RDG (2006), a experiência de campo pode fornecer elementos para tomada de decisão do tipo de proteção a ser implantada. Dispositivos de proteção que já estão em operação e que se mostraram satisfatórios em diversos requisitos são grandes candidatos a serem utilizados. O NCHRP Report 350 (Ross et al., 1993) recomenda um procedimento complementar de avaliação em serviço dos dispositivos de proteção que pode ser utilizado para avaliar o desempenho dos dispositivos de proteção instalados.

Em resumo, parece razoável admitir que a visão corrente seja a de utilizar dispositivos flexíveis sempre que possível. Entre estes, pode-se optar por configurações de menor maleabilidade em função da distância de trabalho disponível, desde que seja possível garantir e eficácia do dispositivo de contenção. Os dispositivos rígidos seriam utilizados em último caso, onde a distância de trabalho ou a necessidade de contenção são mais críticos. A exceção seria a sua utilização onde a redução do esforço de manutenção for relevante (onde o tráfego é reduzido ou onde a presteza da manutenção não pode ser adequadamente garantida). No entanto, no Brasil, pode-se conjecturar se esta exceção não corresponde à regra da prática observada (além de serem negligenciados os requisitos de distância de trabalho e eficácia da contenção).

\subsection{CRITÉRIOS PARA O POSICIONAMENTO E ARRANJO DA PROTEÇÃO CONTÍNUA}

\subsubsection{Afastamento lateral com relação à pista}

De acordo com o RDG (2006), a proteção contínua (lateral ou central) deve ser posicionada tão afastada da faixa de rolamento quanto possível, para que o motorista do veículo desgovernado possa ter mais chance de retomar o controle do veículo sem vir a se chocar com a barreira. Além disso, afastamentos laterais maiores proporcionam distâncias de visibilidade maiores. Afastamentos uniformes com relação à borda da pista, tanto da proteção lateral, quanto de outros 
elementos, reduzem a reação e a preocupação do motorista com estes elementos. Quando possível, a barreira deverá ser posicionada além da linha fictícia que o RDG (2006) denomina shy line ("linha de intimidação" ou, segundo a NBR 15486:2007, "linha de preocupação").

Valores sugeridos do afastamento da linha de intimidação em função da velocidade de projeto estão listados na tabela a seguir.

Tabela 2-7-Valores do afastamento da linha de intimidação (shy line, RDG, 2006)

\begin{tabular}{llllllllll}
\hline Velocidade de projeto $(\mathrm{km} / \mathrm{h})$ & 130 & 120 & 110 & 100 & 90 & 80 & 70 & 60 & 50 \\
\hline $\begin{array}{l}\text { Afastamento lateral da linha de } \\
\text { preocupação }(\mathrm{m})\end{array}$ & 3,7 & 3,2 & 2,8 & 2,4 & 2,2 & 2 & 1,7 & 1,4 & 1,1 \\
\hline
\end{tabular}

Segundo o RDG (2006), para o dispositivo de proteção longo e contínuo, este efeito não é tão crítico, especialmente quando este é introduzido além da linha de intimidação e aproximando-o gradualmente da pista.

Além do acima exposto, o TAC (1999) acrescenta que o uso de dispositivos de proteção laterais não é recomendável com afastamento superior a $4 \mathrm{~m}$, discordando do critério do RDG (2006). Segundo o TAC (1999), quanto mais distante o posicionamento da barreira, maior a chance do veículo desgovernado atingi-la com ângulo maior. Em coerência com o TAC (1999), a NBR 14885:2004 menciona que deve ser observada uma distância livre entre a borda da barreira e a linha demarcatória da borda da faixa de rolamento de no máximo 3,6 m.

Segundo o RDG (2006), se o dispositivo de proteção for utilizado para proteger o motorista de um objeto rígido, o afastamento deve ser tal que, após o impacto, o veículo não atinja o objeto devido à deformação do dispositivo. Assim, a deflexão dinâmica é um fator a ser considerado, tanto na escolha do tipo de dispositivo, quando ao seu posicionamento em relação ao objeto. Portanto, torna-se necessário a avaliação do espaço entre a pista de rolamento e o objeto rígido para a determinação da rigidez da proteção lateral e de seu posicionamento com relação à via. Ainda segundo o RDG (2006), quando for o caso de veículos de elevado centro de gravidade, atenção especial deve ser dada na consideração da rotação do veículo sobre a proteção lateral, situação na qual o objeto rígido pode ser atingido mesmo considerando-se a amplitude de deflexão dinâmica. 
Se um aterro necessitar ser protegido, a distância entre o dispositivo de proteção lateral e o início do talude deve ser também suficiente para garantir o suporte adequado do sistema e permitir o seu correto funcionamento. O RDG (2006) sugere o valor de 0,60 m para o suporte adequado, mas ressalta que este valor depende do tipo de solo, da inclinação do talude, condição de impacto esperado, seção e ancoragem do poste.

Tanto o RDG (2006) quando o TAC (1999) não mencionam a distância mínima entre a proteção lateral e a borda da faixa de rolamento na ausência de acostamento. A NBR 14885:2004, item 4.2.5.1, diz que "deve ser observada uma distância livre entre a borda da barreira e a linha demarcatória da faixa de rolamento de no mínimo $1 \mathrm{~m}$ e no máximo 3,6 m, admitindo-se excepcionalmente o mínimo de 0,6 m". Esclarece-se que "barreira" para esta norma é barreira de concreto. Já a NBR 6971:1999, que trata de defensas metálicas, diz que "as lâminas de uma defensa não podem ser instaladas a menos de $0,50 \mathrm{~m} \pm 0,02 \mathrm{~m}$ da borda de pista”. Entretanto, tanto NBR 14885:2004 como a NBR 6971:1999, não esclarecem a razão de este valor mínimo existir ou justificam sua recomendação. Os valores mínimos são exíguos para instalação de sinais de trânsito usuais (com dimensões transversais da ordem de $1 \mathrm{~m}$ ) e para permitir a realização de serviços de manutenção ou limpeza (exigindo a utilização de dispositivos de sinalização temporária para afastar o fluxo de veículos e proteger os operadores).

\subsubsection{Influência da superfície do terreno}

O RDG (2006) informa que, seja qual for o tipo de proteção lateral utilizado, as condições do terreno entre a pista de rolamento e a proteção lateral têm efeitos significativos no desempenho da proteção, e por isso, essas condições devem ser tais que, no momento do impacto, todos os eixos do veículo devem estar em contato com o chão e sua suspensão não deve estar nem comprimida tampouco estendida.

Assim, atenção especial deve ser dada na utilização de guias e rampas precedentes à proteção lateral, pois estes elementos influenciam a posição de impacto do veículo na proteção.

No caso de impacto com guias, a trajetória do veículo dependerá de fatores como o peso e as características da suspensão do veículo, velocidade e ângulo de impacto, além da altura e forma da guia. No item 5.6.2.1 do RDG (2006), é mencionado que testes de impacto mostraram que 
deve ser desencorajado o uso da combinação de guias e defensas metálicas onde altas velocidades e grandes ângulos de impacto são esperados. Quando não há alternativas factíveis, o projetista deve considerar o uso de guias não superiores que $100 \mathrm{~mm}$ e considerar o aumento da rigidez da defensa a fim de reduzir a deflexão potencial. No item 3.4.1, o RDG (2006) afirma que guias não são desejáveis em rodovias de alta velocidade, e não devem ser utilizadas em frente às barreiras de concreto com face inclinada (sloping faced concrete barriers), pois tal posicionamento resulta em desempenho insatisfatório da barreira. Se a guia for utilizada em conjunto com defensa metálica, deve-se posicioná-la alinhada com a defensa ou atrás dela.

Ambos os itens do RDG (2006) supracitados recomendam que se o uso da combinação guia/barreira for usado ou vier a ser usado extensamente, testes de impacto específicos devem ser realizados.

A ABNT, através da NBR 15486:2007, item 4.2.1.8.2 cita que "a combinação de barreiras com sarjetas em trechos com alta velocidade, onde ângulos de impacto elevados podem ser esperados, deve ser evitada". Desta afirmação e da comparação com o segundo parágrafo do item 5.6.2.1 do RDG (2006), reproduzido anteriormente, pode-se supor que provavelmente houve uma tradução equivocada da ABNT, que fez confusão entre guias e sarjetas (curbs e gutter), no desejo de recomendar, neste aspecto, o mesmo princípio do RDG (2006). Por outro lado, o item 4.2.5.3 da NBR 14885 diz que "não deve existir meio fio entre a barreira e a borda do pavimento", onde o termo "barreira" se refere à barreira de concreto para esta norma.

Com relação a esta mesma questão, a NBR 6971:1999, que trata de defensas metálicas, menciona que "é vedado o projeto e emprego de guias, sarjetas ou qualquer outro elemento, em posição que possa alterar as alturas de impacto nas lâminas de defensas, especificadas em 4.3.5 e 4.3.6." e "estes elementos, quando existirem, devem ser colocados atrás da linha de postes das defensas". Os itens 4.3.5 e 4.3.6 desta norma referem-se à altura da defensa de $75 \mathrm{~cm}$ e $65 \mathrm{~cm}$, medida do bordo superior ao solo, para o trânsito de caminhões maior ou igual a 30\% do VDM e menor que $30 \%$ do VDM, respectivamente.

Além da presença e características das guias, outra característica do terreno precedente à barreira que influencia seu desempenho é a inclinação deste terreno. Muitas barreiras são projetadas e testadas em terrenos planos e suaves. Como cita o RDG (2006), quando a barreira é posicionada em terrenos com inclinações maiores que $1 \mathrm{~V}: 10 \mathrm{H}$, estudos têm mostrado que para certos ângulos 
e velocidades de saídas de pista, o veículo desgovernado pode passar por cima de muitos tipos de barreiras ou impactá-las em pontos abaixo do esperado. Durante o percurso de um veículo desgovernado que atravessou o acostamento e o aterro, o para-choque dianteiro do veículo descreve uma trajetória vertical que não é paralela ao terreno sendo que, em um primeiro momento, o para-choque percorre uma altura superior à sua altura normal com relação ao terreno, e em seguida, o pára-choque percorre uma altura menor. A Figura 2-13, retirada do RDG (2006), mostra a trajetória do para-choque nesta condição, bem como os parâmetros relevantes na avaliação do posicionamento lateral da barreira. De acordo com o RDG (2006), os parâmetros mais importantes são $\Delta \mathrm{H}_{\mathrm{S}}$ (a diferença de altura no limite do acostamento) e $\Delta \mathrm{H}_{2}$ (a diferença de altura a $0,60 \mathrm{~m}$, ou $2 \mathrm{ft}$, além do limite do acostamento), pois muitos dispositivos de proteção lateral são posicionados entre a extremidade do acostamento e $0,60 \mathrm{~m}$ além dele. No entanto, não são fornecidas recomendações práticas a serem utilizadas.

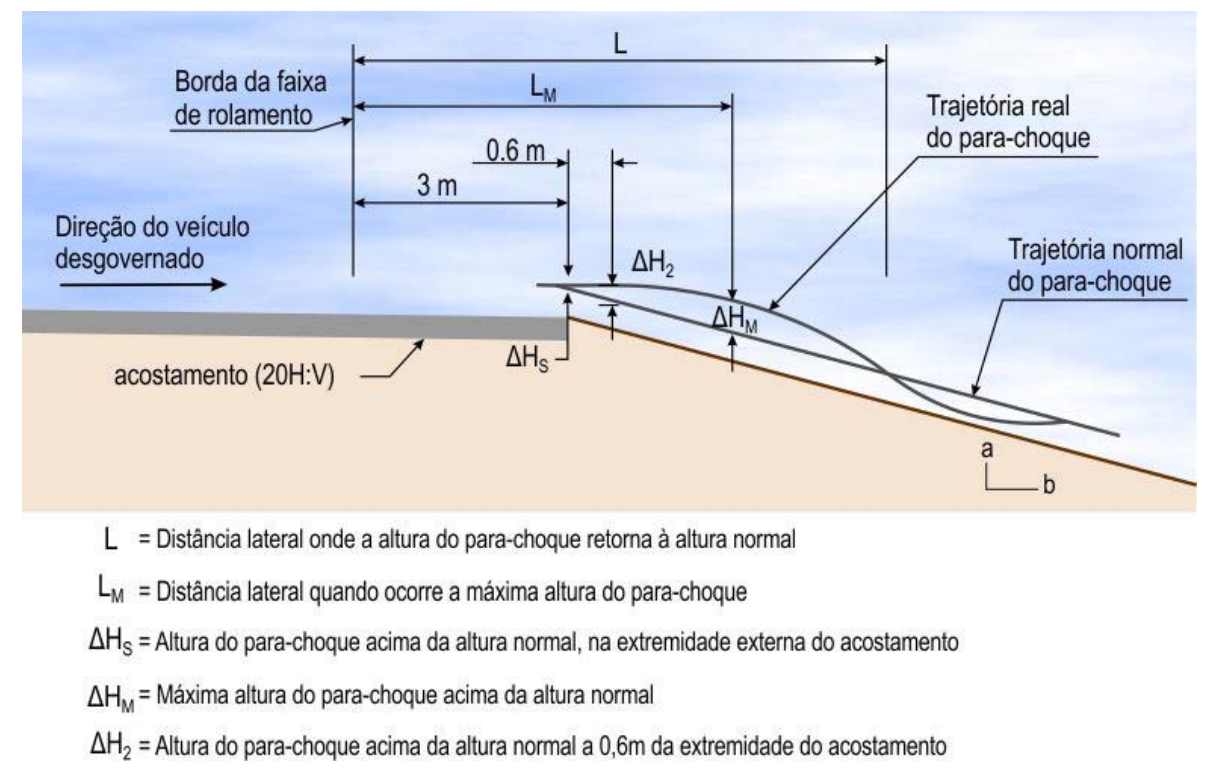

Figura 2-13 - Trajetória do pára-choque do veículo durante a saída de pista (RDG, 2006)

Enquanto o RDG (2006) informa que a proteção lateral tem melhor desempenho quando instaladas em declividades iguais ou mais suaves que $10 \mathrm{H}: 1 \mathrm{~V}$, e que no caso da consideração de instalações em declividades de $6 \mathrm{H}: 1 \mathrm{~V}$ ou mais íngremes, o afastamento lateral da proteção deve ser tal que no momento do impacto o veículo esteja em sua altura normal, o TAC (1999) é mais conservador, mencionando que a instalação de proteção lateral deve ser evitada para declividades iguais ou mais íngremes que $6 \mathrm{H}: 1 \mathrm{~V}$, e que o uso de proteção lateral em declividades maiores que 10H:1V somente devem ocorrer se o dispositivo for posicionado onde o veículo esteja em sua altura normal no momento do impacto. 
Com relação à superelevação da pista, vale destacar que a ABNT, por meio da NBR 14885:2004, diz que "o eixo vertical de referência do perfil da barreira deve permanecer para inclinações transversais da pista até 10\%" (10H:1V) e que "para superelevações maiores, o eixo de referência do perfil deve ser normal ao plano do pavimento em todo o trecho superelevado". Lembra-se novamente que, para esta norma, "barreira” é o mesmo que barreira de concreto.

\subsubsection{Segmento defletido de transição da proteção lateral}

O segmento defletido de transição da proteção lateral é o trecho da proteção não paralelo à via que geralmente situa-se no início da proteção, com os objetivos, de acordo com o RDG (2006) e TAC (1999), de posicionar os terminais da proteção mais afastados da via, reduzir a reação do motorista ao dispositivo de proteção, pela introdução gradual do dispositivo quando da sua aproximação, reduzir o comprimento total necessário do dispositivo de proteção e fazer a transição do dispositivo até um obstáculo que esteja mais próximo à via, como os parapeitos das obras de arte especiais. Das funções acima, a NBR 15486:2007 cita apenas duas: "reduzir o comprimento total da barreira e minimizar a reação dos motoristas ao início da barreira dentro da distância de preocupação".

De acordo com o RDG (2006), existem duas desvantagens no uso do segmento defletido de transição. A primeira é que quanto mais defletido for o segmento de transição, ou seja, quanto maior o ângulo do segmento de transição em relação à direção paralela à via, maior o ângulo de impacto que pode ocorrer com a barreira e, por conseguinte, maior a gravidade do acidente, particularmente para sistemas de contenção rígidos e semi-rígidos. A segunda desvantagem é que caso o veículo desgovernado venha a chocar-se com o segmento defletido da proteção lateral, a probabilidade do veículo ser redirecionado para a pista ou mesmo atravessá-la é maior, sendo que tal situação é especialmente indesejável em rodovias de pista simples de duplo sentido, onde o veículo pode ser redirecionado para o sentido oposto. Estas desvantagens também são mencionadas pelo TAC (1999) e pela ABNT (2007).

A Tabela 2-8, retirada do RDG (2006), mostra os valores máximos sugeridos para as taxas de deflexão em função da velocidade de projeto, do tipo e da posição da barreira com relação à linha de preocupação. Nota-se que quanto maior a velocidade, mais suave é a deflexão do segmento de transição, e que para proteção lateral posicionada além da linha de intimidação, o segmento pode ser feita com transição menos suave. Nota-se também, que para sistemas rígidos, a deflexão da 
transição é mais suave se comparada com a deflexão para sistemas semi-rígidos, no caso dos sistemas estarem posicionados além da linha de intimidação.

A Tabela 2-9, apresenta as taxas de deflexão, indicadas pelo TAC (1999), para dispositivos de proteção posicionados além do acostamento, em função da velocidade de projeto. Vê-se que os valores apresentados pelo TAC (1999) são similares aos apresentados pelo RDG (2006) para dispositivos posicionados dentro da linha de intimidação (são mais conservadores que aqueles adotados pelo RDG, 2006, para dispositivos posicionados além da linha de intimidação). No TAC (1999) não se distingue o posicionamento da proteção antes ou depois da linha de intimidação, como no RDG (2006), apenas mencionando a aplicação a dispositivos posicionados além do acostamento, sem, no entanto, indicar os valores da largura do acostamento requeridos.

Nota-se também, que para sistemas rígidos, a deflexão da transição é mais suave se comparada com a deflexão para sistemas semi-rígidos, no caso dos sistemas estarem posicionados além da linha de intimidação.

Tabela 2-8 - Valor de deflexão apresentado pelo RDG (2006)

\begin{tabular}{|c|c|c|c|}
\hline \multirow[t]{2}{*}{$\begin{array}{l}\text { Velocidade de } \\
\text { projeto }(\mathrm{km} / \mathrm{h})\end{array}$} & \multirow[t]{2}{*}{$\begin{array}{c}\text { Taxa de deflexão para } \\
\text { proteção antes da lin ha de } \\
\text { preocu pação }\end{array}$} & \multicolumn{2}{|c|}{$\begin{array}{c}\text { Taxa de deflexão para proteção além da } \\
\text { linha de preocupação }\end{array}$} \\
\hline & & * & ** \\
\hline 110 & $30: 1$ & $20: 1$ & $15: 1$ \\
\hline 100 & $26: 1$ & $18: 1$ & $14: 1$ \\
\hline 90 & $24: 1$ & $16: 1$ & $12: 1$ \\
\hline 80 & $21: 1$ & $14: 1$ & $11: 1$ \\
\hline 70 & $18: 1$ & $12: 1$ & $10: 1$ \\
\hline 60 & $16: 1$ & $10: 1$ & $8: 1$ \\
\hline 50 & $13: 1$ & 8:1 & $7: 1$ \\
\hline
\end{tabular}

Tabela 2-9 - Valor de deflexão apresentado pelo TAC (1999)

\begin{tabular}{ccc}
\hline $\begin{array}{l}\text { Velocidade de } \\
\text { projeto }(\mathbf{k m} / \mathbf{h})\end{array}$ & $\begin{array}{c}\text { Sistemas flexíveis e } \\
\text { semi-rígidos }\end{array}$ & Sistemas rígidos \\
\hline 130 & $25: 1$ & $50: 1$ \\
120 & $25: 1$ & $40: 1$ \\
110 & $25: 1$ & $30: 1$ \\
100 & $20: 1$ & $25: 1$ \\
80 & $15: 1$ & $20: 1$ \\
65 & $10: 1$ & $15: 1$ \\
50 & $10: 1$ & $10: 1$ \\
\hline
\end{tabular}

Para a NBR 14885:2004, os trechos iniciais das barreiras, sempre que possível, "devem ser construídos com início a uma distância de pelo menos 3,6 $\mathrm{m}$ da borda do pavimento, para posteriormente ser executada a transição até no máximo $1 \mathrm{~m}$ da linha demarcatória da borda da faixa de rolamento, admitindo-se a exceção de 4.2.5.1”. A exceção a que se refere o ítem 4.2.5.1 
é o mínimo excepcional de $0,6 \mathrm{~m}$. Com relação ao ângulo de deflexão da proteção no trecho inicial, para a NBR 14885:2004, deve ser de no máximo 2²0’' (1:25), independente da velocidade de projeto e da rigidez do dispositivo de proteção lateral.

\subsubsection{Comprimento necessário de proteção lateral}

Tanto o RDG (2006) como a ABNT não fazem a definição de comprimento necessário, expondo apenas a forma de calculá-lo. Porém, segundo o TAC (1999), o comprimento necessário de proteção lateral é definido como sendo aquele requerido para fornecer proteção a um veículo desgovernado de um obstáculo, excluindo o comprimento dos terminais, e é função da distância do obstáculo à faixa de rolamento, da distância do dispositivo de proteção ao obstáculo e à faixa de rolamento e da velocidade de projeto.

O comprimento necessário, ainda segundo o TAC (1999), é a soma do comprimento adjacente ao obstáculo "Lh", do comprimento na aproximação à montante "La" e do comprimento à jusante "Lb" (ver Figura 2-15), sendo que este último pode ser considerado nulo quando se tratar de rodovia de pista dupla, rodovias de único sentido ou quando o obstáculo estiver fora da área livre na referência do fluxo oposto (caso contrário, a extensão "Lb" seria calculada como "La" em função das saídas de pista geradas pelo tráfego do sentido oposto existente).

Tanto no RDG (2006) quanto no TAC (1999), o cálculo de "La" necessário é baseado no valor da distância da saída de pista " $L_{R}$ " ou "E", que pode ser definido como a distância percorrida por um veículo desgovernado, medida paralelamente à pista. Ambos adotam um valor baseado na distância percorrida até sua parada, que é função da velocidade de projeto da via, para definir " $L_{R}$ " ou "E". Nota-se que os valores recomendados de " $L_{R}$ " ou "E" adotados pelo TAC (1999), apresentados na Tabela 2-11, em função apenas da velocidade de projeto, são similares, mas diferentes dos valores de " $L_{R}$ " sugeridos pelo RDG (2006), apresentados na Tabela 2-10 que variam em função da velocidade de projeto e do volume de tráfego. 
Tabela 2-10- Distância $L_{R}$ percorrida na saída de pista (RDG)

\begin{tabular}{|c|c|c|c|c|}
\hline \multirow{2}{*}{$\begin{array}{c}\text { Velocidade } \\
\text { de projeto } \\
(\mathrm{km} / \mathrm{h})\end{array}$} & Acima de 6000 veíc/dia & $\begin{array}{c}\text { Entre } 2000 \text { e } 6000 \\
\text { veíc/dia }\end{array}$ & $\begin{array}{c}\text { Entre } 800 \text { e } 2000 \\
\text { veíc/dia }\end{array}$ & Abaixo de 800 veíc/dia \\
\cline { 2 - 5 } & $\begin{array}{c}\text { Comprimento de saída } \\
\text { de pista } \mathrm{Lr}(\mathrm{m})\end{array}$ & $\begin{array}{c}\text { Comprimento de saída } \\
\text { de pista } \operatorname{Lr}(\mathrm{m})\end{array}$ & $\begin{array}{c}\text { Comprimento de saída } \\
\text { de pista } \mathrm{Lr}(\mathrm{m})\end{array}$ & $\begin{array}{c}\text { Comprimento de saída } \\
\text { de pista } \operatorname{Lr}(\mathrm{m})\end{array}$ \\
\hline 110 & 145 & 135 & 120 & 110 \\
100 & 130 & 120 & 105 & 100 \\
90 & 110 & 105 & 95 & 85 \\
80 & 100 & 90 & 80 & 75 \\
70 & 80 & 75 & 65 & 60 \\
60 & 70 & 60 & 55 & 50 \\
50 & 50 & 50 & 45 & 40 \\
\hline
\end{tabular}

Tabela 2-11 - Distância E percorrida na saída de pista (TAC, 1999)

\begin{tabular}{|cc|}
\hline $\begin{array}{c}\text { Velocidade de projeto } \\
(\mathrm{km} / \mathrm{h})\end{array}$ & $\begin{array}{c}\text { Distância de saída de pista }(\mathrm{E}) \\
(\mathrm{m})\end{array}$ \\
\hline 120 ou superior & 160 \\
110 & 140 \\
100 & 120 \\
90 & 110 \\
80 & 95 \\
70 & 75 \\
60 ou inferior & 60 \\
\hline
\end{tabular}

Os valores de $L_{R}$ baseiam-se no ajuste dos resultados obtidos por Hutchinson e Kennedy em estudo de saídas de pista pelo canteiro central, e em características de tempos de reação dos motoristas e frenagem de veículos em saídas de pista com baixa velocidade. Os valores de E são baseados em estudos canadenses.

O RDG (2006) e o TAC (1999) adotam formas similares para o cálculo do comprimento necessário de proteção lateral. Ambos resumem-se a um problema geométrico, como mostra a Figura 2-14, consideradas as suposições admitidas (discutidas a seguir). Há algumas diferenças de critério que também serão esclarecidas aqui.

No RDG (2006), o comprimento necessário "X" e o afastamento lateral "Y" do início do comprimento necessário à borda da pista, podem ser calculados pelas seguintes expressões:

$$
X=\frac{L_{A}+(b / a)\left(L_{1}\right)-L_{2}}{(b / a)+\left(L_{A} / L_{R}\right)}
$$




$$
Y=L_{A}-\frac{L_{A}}{L_{R}}(X)
$$

onde todas as variáveis estão mostradas na Figura 2-14. Portanto, "X" é a distância entre a face mais próxima do obstáculo e o limite do comprimento de proteção necessário ao longo da via (ao qual deve ser acrescentado o comprimento do terminal do dispositivo) e "Y" é o afastamento transversal do dispositivo de proteção no ponto limite do comprimento de proteção necessário. $\mathrm{O}$ afastamento do objeto em relação ao bordo da pista de rolamento é " $L_{3}$ " e o afastamento correspondente do dispositivo de proteção é " $\mathrm{L}_{2}$ " (sujeito aos mínimos anteriormente comentados), devendo a diferença " $\mathrm{L}_{3}-\mathrm{L}_{2}$ " ser maior que a deflexão dinâmica " $\mathrm{D}$ ". A extensão " $\mathrm{L}_{1}$ " corresponde a um trecho de transição e/ou em tangente eventualmente necessário ou adotado (não defletido).

Segundo o RDG (2006), uma alternativa à determinação do comprimento necessário utilizando o $\mathrm{L}_{\mathrm{R}}$ seria a adoção do comprimento de proteção que intercepte a direção representada pela trajetória de saída de pista sob certo ângulo, determinado por análise custo-benefício. No procedimento normal, o ângulo de saída de pista é decorrente da posição do obstáculo (ou limite da área livre) considerado e da distância de saída de pista adotada, não avaliado explicitamente. No procedimento alternativo, o ângulo de saída selecionado determina o valor correspondente da distância de recuperação (tga $=\mathrm{L}_{\mathrm{A}} / \mathrm{L}_{\mathrm{R}}$ ), seguindo-se então o mesmo procedimento corresponde ao da ABNT (comentado adiante).

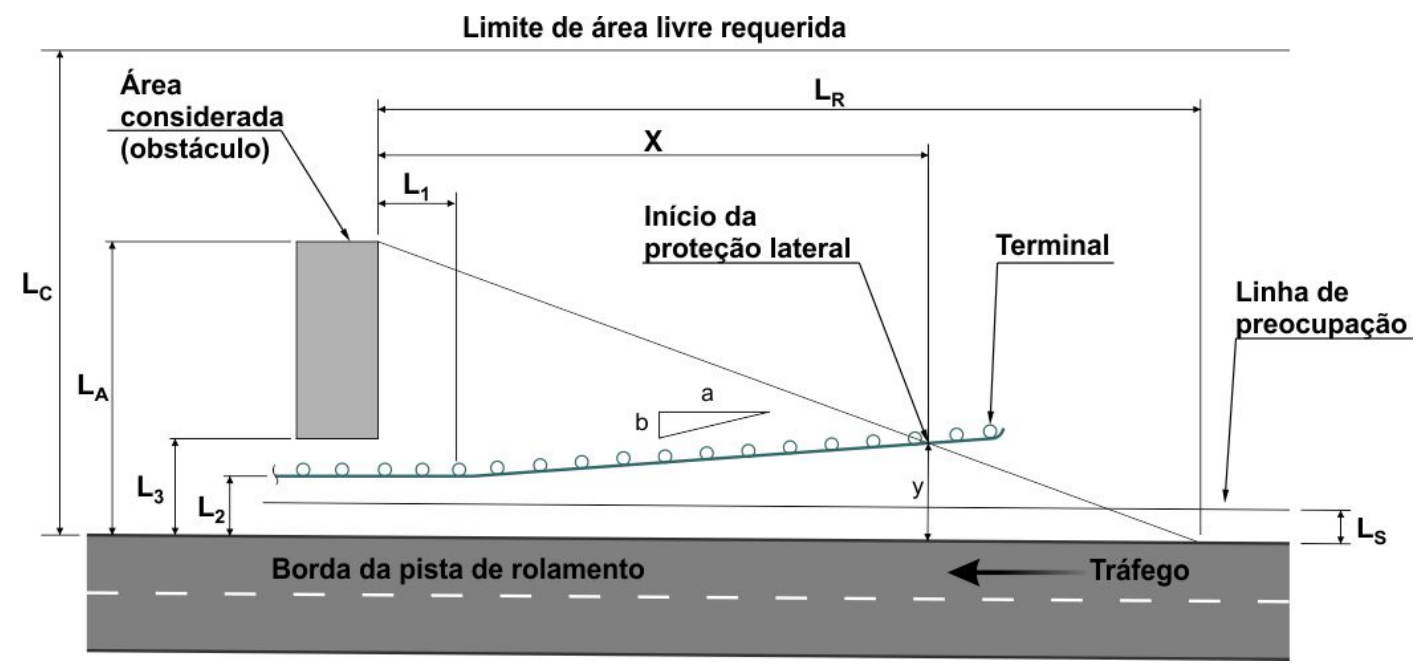

Figura 2-14 - Ilustração do comprimento necessário (adaptado: RDG 2006) 
No TAC (1999), as fórmulas mostradas são as mesmas, mas a forma algébrica adotada não considera a deflexão do dispositivo de proteção (corresponde a admitir b/a=0), tendo-se:

$$
L_{a}=\left(1-\frac{A}{B}\right) \cdot E
$$

(neste caso, $\mathrm{Y}=\mathrm{A}$; na verdade, o TAC, 1999, calcula $\mathrm{X}_{\mathrm{t}}=\mathrm{L}_{\mathrm{a}}+\mathrm{L}_{\mathrm{h}}$ ). As variáveis correspondentes estão mostradas na Figura 2-15 a seguir. Os valores $L_{A}, L_{R}, L_{2}$ e $L_{C}$, do RDG (2006) são, respectivamente, análogos as dimensões B, E, A e largura da área livre do TAC (1999). O caso de dispositivos defletidos pode ser analisado graficamente, segundo o TAC (1999).

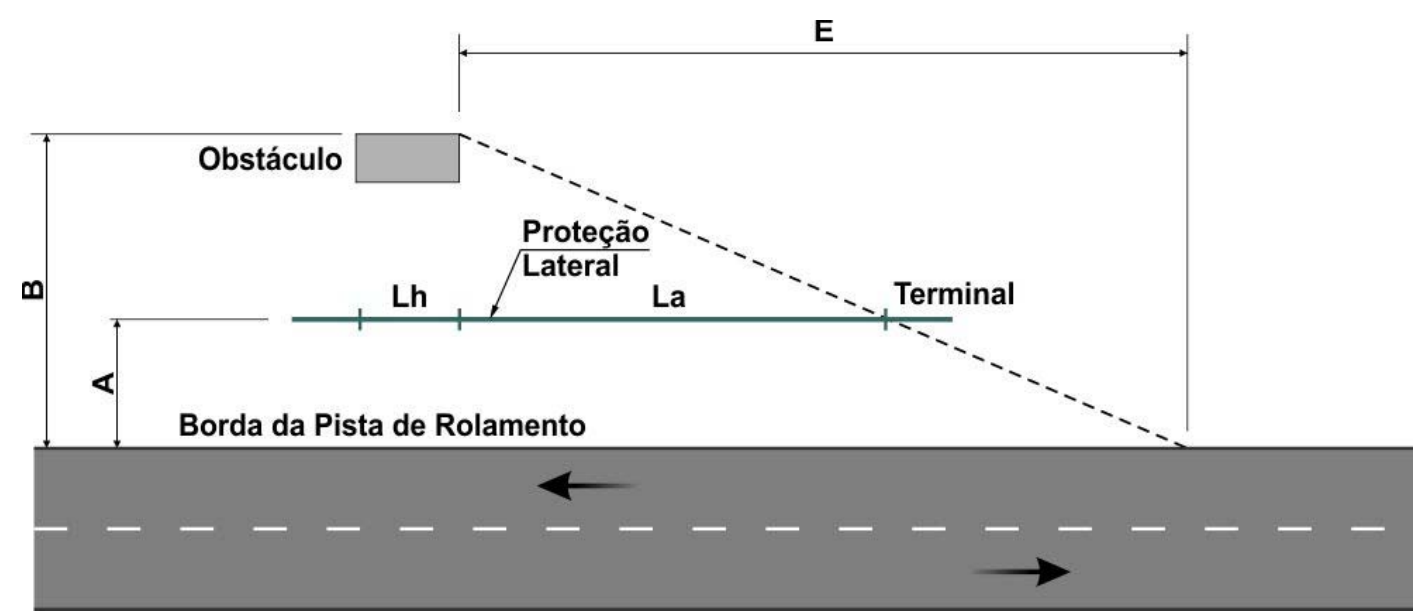

Figura 2-15 - Ilustração do comprimento necessário (adaptado: TAC 1999)

Nota-se que ambos os trabalhos referem-se ao comprimento necessário (lenght of need) com significado distinto. No RDG (2006), o valor do comprimento necessário " $\mathrm{X}$ " é apenas a dimensão a montante do obstáculo, enquanto no TAC (1999) o conceito refere-se à dimensão total (soma da dimensão adjacente ao obstáculo, da dimensão à montante e da dimensão à jusante). A fórmula obtém somente uma parcela do comprimento necessário na definição do TAC (1999), que é o de aproximação "La" (o valor de "Lb" é calculado examinando as saídas de pista do sentido oposto, de forma similar). Convém, portanto, referir-se ao comprimento necessário de aproximação $(\mathrm{X})$ ou total $\left(\mathrm{X}_{\mathrm{t}}=\mathrm{L}_{\mathrm{a}}+\mathrm{L}_{\mathrm{h}}\right)$, para distinguir o conceito do RDG (2006) e do TAC (1999) 
Para que as expressões 2-1 e 2-3 acima possam ser utilizadas, é necessário definir ainda as variáveis $\mathrm{L}_{1}, \mathrm{~L}_{2}$, e o ângulo de deflexão. $\mathrm{Na}$ escolha destes dois últimos, deve-se observar o disposto nos itens 2.5.1, 2.5.2 e 2.5.3. O valor da variável $\mathrm{L}_{1}$ deve ser escolhido pelo projetista levando-se em conta a necessidade de transição ou trecho tangente ou restrições locais.

No caso da determinação do comprimento necessário de proteção lateral para o tráfego de sentido oposto, o procedimento acima se mantém, porém considerando todas as dimensões laterais em relação à borda esquerda da faixa de rolamento do sentido oposto.

Como suplemento, o TAC (1999) ainda recomenda a aplicação das seguintes heurísticas:

1. Terminais são adicionados ao comprimento necessário na extremidade do trecho à montante do obstáculo.

2. Utilizando deflexão com as taxas indicadas na Tabela 2-9, reduzir-se-á o comprimento necessário (o que pode ser determinado graficamente).

3. No trecho defletido do dispositivo de proteção, a área entre a proteção e a via deve ser suavizada.

4. Se há o trecho defletido do dispositivo de proteção, um trecho tangente (entende-se paralelo) imediatamente anterior ao obstáculo deve ser considerado, especialmente se um trecho com dispositivo semi-rígido é conectado ao um dispositivo rígido, com comprimento pelo menos igual ao trecho de transição entre eles;

5. Quando o obstáculo se estende além da área livre, a distância a ser considerada para o ponto mais afastado do obstáculo (ver dimensão "B" da Figura 2-15) é a própria largura da área livre, que é função da velocidade de projeto da via.

6. Todo sistema de proteção deve ter suas extremidades ancoradas por terminais ou fixação em objetos fixos (como encontro de pontes), ou deve ter suas extremidades estendidas além do comprimento necessário a fím de prover estabilidade. Este último tratamento deve ser feito de maneira que seja pouco provável o impacto de um veículo desgovernado na extremidade do sistema de contenção. 
7. Sistemas de proteção que terminam nas proximidades de objetos rígidos, como encontros de pontes, muros de contenção, rochas de face lisa, devem ser estendidas e conectadas a eles.

De acordo com a ABNT, através da NBR 15486:2007, "para se determinar o comprimento necessário de um sistema de contenção lateral, o método mais simples é o de se determinar graficamente um comprimento de barreira que intercepte a trajetória do veículo, tendo estabelecido um ângulo de impacto de no máximo $15^{\circ}$, e de modo que o veículo não atinja o obstáculo" (portanto, $\mathrm{L}_{\mathrm{R}}=\mathrm{L}_{\mathrm{A}} / \operatorname{tg} \alpha$, com $\alpha_{\operatorname{máx}}=15^{\circ}$ ). As Figura 2-16 e Figura 2-17 ilustram este procedimento para tráfego unidirecional e bidirecional, respectivamente.

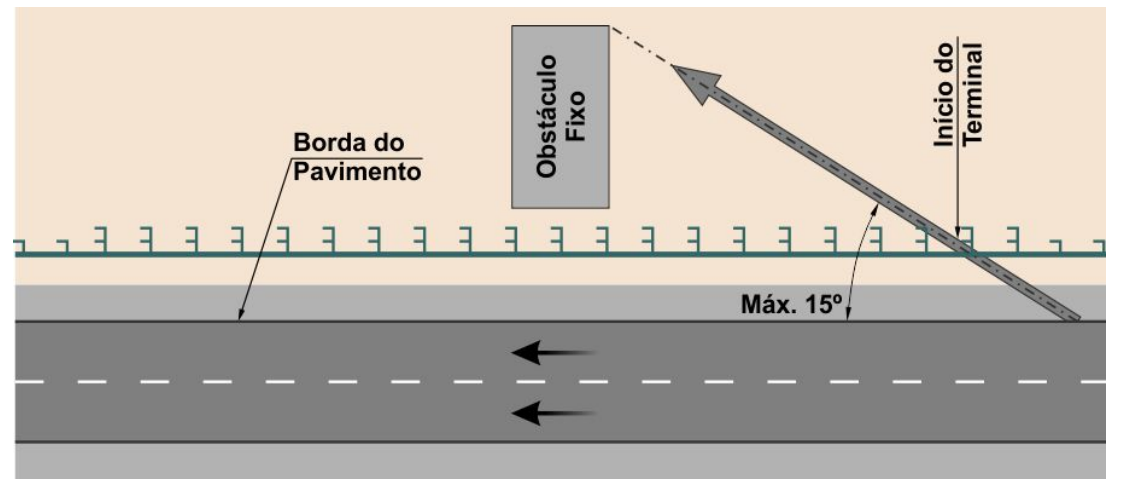

Figura 2-16 - Comprimento da barreira em tráfego unidirecional (adaptado NBR 15486:2007)

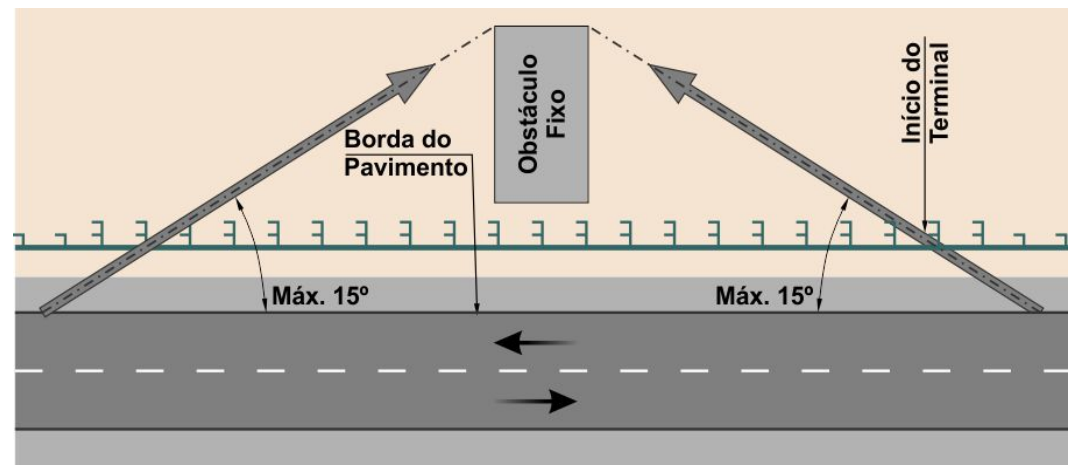

Figura 2-17 - Comprimento da barreira em tráfego bidirecional (adaptado NBR 15486:2007)

Portanto, no procedimento recomendado pela ABNT, adota-se um ângulo de saída de pista recomendado e, dada a posição do obstáculo (ou de forma correspondente de um limite da área livre considerada), a distância de saída de pista não é avaliada explicitamente. Embora o procedimento adicional não seja detalhado, pode-se supor a mesma forma de aplicação. As taxas de deflexão recomendadas no RDG (2006) são inclusive igualmente sugeridas. 


\subsection{TERMINAIS}

A presença dos dispositivos de proteção lateral contínuos na proteção de taludes ou objetos fixos impõe, inevitavelmente, a presença de outro obstáculo: as extremidades do próprio dispositivo de proteção (sejam barreiras de concreto ou defensas metálicas).

Portanto, para que a segurança do entorno viário seja alcançado, as extremidades das proteções laterais devem possuir características que as tornam seguras, reduzindo a gravidade do impacto do veículo desgovernado com estas extremidades que, por si só, constituem obstáculos perigosos para os motoristas, especialmente quando localizados dentro da área livre recomendada ou em locais com grande probabilidade de serem atingidos.

Assim, definem-se os terminais como dispositivos de proteção pontuais, utilizados nas extremidades das barreiras, com o objetivo de torná-las seguras. Para que isso seja alcançado, os terminais não podem impor aos veículos desgovernados o esmagamento, o descontrole, a decolagem do veículo, a penetração de partes do sistema no veículo, o capotamento e desacelerações abruptas, que podem provocar danos graves aos ocupantes do veículo. Outro requisito importante é que o veículo seja redirecionado com segurança no caso de impacto na lateral do terminal (ou, alternativamente, capturado pelo dispositivo).

Nem sempre os terminais são elementos projetados com as características acima citadas (terminais absorvedores de energia), recebendo simplesmente um tratamento das extremidades dos dispositivos de proteção lateral (como os terminais abatidos e ancorados em taludes de corte).

O RDG (2006) dedica o capítulo 8 aos terminais e atenuadores de impacto (sendo que este último não será tratado nesta dissertação), onde são listadas diversas soluções para terminais (algumas patenteadas, outras não), atendendo aos requisitos da NCHRP Report 350.

O RDG (2006) classifica os terminais em dois grupos: não-redirecionadores ou abrigadores (nonredirective ou gating, também penetráveis/atravessáveis) e redirecionadores ou nãoabrigadores (redirective ou nongating, também não-penetráveis/não-atravessáveis). A NBR 
15486:2007 também faz esta mesma classificação, porém, com os termos "de abertura" e "de não-abertura". Os terminais não-redirecionadores permitem que um veículo atravesse o dispositivo, quando o impacto ocorre de forma oblíqua na região do nariz, enquanto que os terminais redirecionadores são capazes de reconduzir o veículo nestas mesmas condições. Para os terminais não-redirecionadores o comprimento útil inicia a 3,81 $\mathrm{m}$ da cabeça da unidade, mas pode variar de dispositivo para dispositivo.

Constam no NCHRP Report 350 definições similares para terminais abrigadores (nãoredirecionadores) e não-abrigadores (redirecionadores). O primeiro é definido como sendo aqueles projetados para permitir uma penetração controlada em parte do comprimento do dispositivo. O segundo é definido como terminais projetados para terem total capacidade de redirecionamento ao longo de todo o seu comprimento.

De acordo com o RDG (2006), a grande maioria dos terminais são não-redirecionadores e, por essa razão, a área atrás de todos os terminais deve ser traspassável e livre de objetos fixos relevantes, com uma área mínima recomendável de $23 \mathrm{~m}$ x $6 \mathrm{~m}$ paralela ao dispositivo. $\mathrm{O}$ terreno entre a pista e o terminal deve ser suave, com inclinação não superior a $10 \mathrm{H}: 1 \mathrm{~V}$ em qualquer direção

O TAC (1999) define terminal (end treatment) como o método pelo qual a extremidade da barreira exposta frontalmente ao tráfego é tratada para minimizar sua ameaça intrínseca aos veículos desgovernados. O TAC (1999), no que tange ao assunto, propõe uma série de heurísticas, algumas delas semelhantes aos tratamentos e observações feitas pelo RDG (2006), e outras podem ser destacadas por acrescentar pontos importantes ou diferenciar-se dos demais manuais, como as descritas abaixo.

Em uma de suas heurísticas, o TAC (1999) menciona que se houver espaço disponível, a proteção lateral pode ser introduzida longe o suficiente da corrente de tráfego de tal forma que sua extremidade não seja caracterizada como um obstáculo perigoso e, desta forma, não necessitaria de terminal.

Em outra heurística, o TAC (1999) destaca que todos os sistemas devem ser instalados em superfície suave. Menciona também que o uso de guias e sarjetas não é recomendado, mas se forem realmente necessárias, somente as do tipo inclinadas devem ser utilizadas. 
Em coerência com o citado no RDG (2006), o TAC(1999) destaca que o uso do terminal abatido para barreiras de concreto devem ser utilizadas somente onde as velocidades são inferiores ou iguais a $60 \mathrm{~km} / \mathrm{h}$, e onde o espaço é restrito. O TAC (1999) menciona também o terminal abatido para defensas metálicas com restrição de uso para vias de velocidades altas ou volumes de tráfego elevados. O terminal abatido para defensas metálicas não é mencionado na versão de 2006 do RDG (foi retirado após a versão de 1996). No texto de GLENNON (2004), apesar de ser mencionado, fica claro de que este tipo de terminal não é mais recomendado.

A NBR 15486:2007 não define claramente o conceito de terminal, embora utilize a denominação e distinga os tipos correspondentes aos direcionadores (de não-abertura) e não-direcionadores (de abertura). Menos ainda são definidos na NBR 6971:1999 e a NBR 14885:2004. As duas últimas expõem termos diferentes como "trecho inicial da barreira", "perfil de transição" e "conjunto de ancoragem".

O item 4.2.8 "Trecho inicial da barreira", da NBR 14885:2004, menciona que o trecho inicial da barreira deve ter o "perfil de transição", isto é, a "transição deve ser feita por um plano inclinado de $15^{\circ} \pm 2^{\circ}$ em relação à horizontal desde o topo até a guia da barreira" e, sempre que possível adotar o trecho em deflexão abordada anteriormente no item 2.5.3. E ainda acrescenta a seguinte nota: "Para trechos com velocidades superiores a $70 \mathrm{~km} / \mathrm{h}$, devem ser estudados terminais mais apropriados." Ainda na mesma norma, no item 4.2.9 "Amortecedores de impacto", descreve: "Onde não for possível executar a transição do trecho inicial mais afastado da pista, conforme 4.2.8, o terminal deve ser protegido por amortecedores de impacto". Percebe-se, portanto, que a expressão "terminal" desta última oração não possui a idéia de dispositivo de proteção pontual anteriormente tratada, pois, em caso contrário, não necessitaria ser protegido por amortecedores de impacto.

Já o termo "conjunto de ancoragem" contido na NBR 6971:1999, parece referir-se ao conceito de terminal de que trata este item, porém de uma forma pouco clara e sem citar as características necessárias para a redução da gravidade do impacto de um veículo desgovernado. Outro termo encontrado nesta mesma norma é o "terminal aéreo" que seria a "peça terminal de seção de defensa, empregada quando, por algum motivo, não é possível efetuar a ancoragem enterrada". Nota-se também que não se menciona os fundamentos de segurança necessários para garantir o conceito de terminal, objeto deste item. 
A ABNT NBR 15486:2007 destaca três tipos de terminais, que serão descritos abaixo: terminais abatidos, terminais ancorados em taludes de corte e terminais absorvedores de energia. Para todos os terminais não-redirecionadores, o terreno entre a pista e o terminal deve ser suave, com inclinação não superior a 10H:1V em qualquer direção.

Os terminais abatidos, utilizados tanto para defensas metálicas quanto para barreiras de concreto, consistem na introdução do dispositivo de proteção lateral, de forma gradual, variando desde a altura do solo até a altura normal do dispositivo, semelhante a uma rampa. A NBR 15486:2007 menciona que "este tipo de tratamento somente deve ser utilizado em trechos com baixa velocidade, abaixo de $60 \mathrm{~km} / \mathrm{h}$, e com limitação de espaço disponível para outras soluções.

Para defensas metálicas, de acordo com a NBR 6971:1999, as ancoragens "devem ter uma extensão mínima de 16,00 m antes de atingirem sua altura de projeto”. E ainda: “As mudanças de altura de uma defensa, seja por razões de projeto ou devido à ancoragem, não devem ser bruscas. Devem observar um ângulo menor ou igual a 4³0', entre o eixo superior das lâminas e o plano da pista, o que corresponde a uma relação aproximada de 1:12.”

Os terminais ancorados em taludes de corte são executados quando o aterro a ser protegido é precedido de talude de corte, onde a ancoragem do dispositivo de proteção lateral é feita. Este tratamento elimina a possibilidade de um choque frontal com a extremidade da barreira, além de impossibilitar o veículo de alcançar a parte de trás do dispositivo. As Figuras 2-18 e 2-19 mostram tratamentos usuais no Brasil.

Conforme a NBR 15486:2007, "sua correta execução inclui manter uma altura uniforme da lâmina em relação à pista até cruzar a linha de drenagem superficial, utilizar uma deflexão lateral apropriada para a velocidade de projeto, adicionar lâmina adicional ou barra auxiliar e utilizar uma ancoragem capaz de desenvolver a tensão total do sistema. O terreno frontal ao terminal não deve ser mais inclinado que 4H:1V. Caso estes princípios não possam ser aplicados, então outra solução deve ser estudada”. 


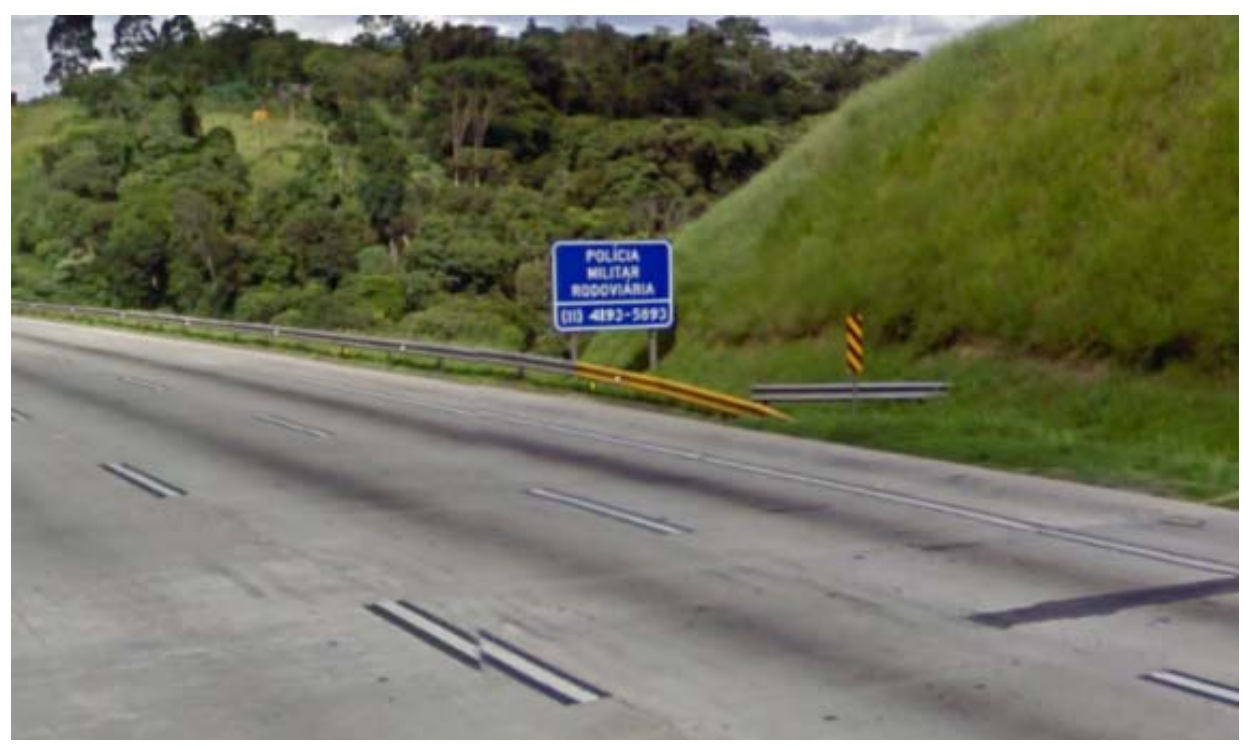

Figura 2-18 - Defensa metálica com terminal abatido. Nota-se que neste caso houve oportunidade para a ancoragem no talude de corte precedente (fonte: Google Earth, Rodoanel de São Paulo, trecho oeste, acessado em mar/2011)

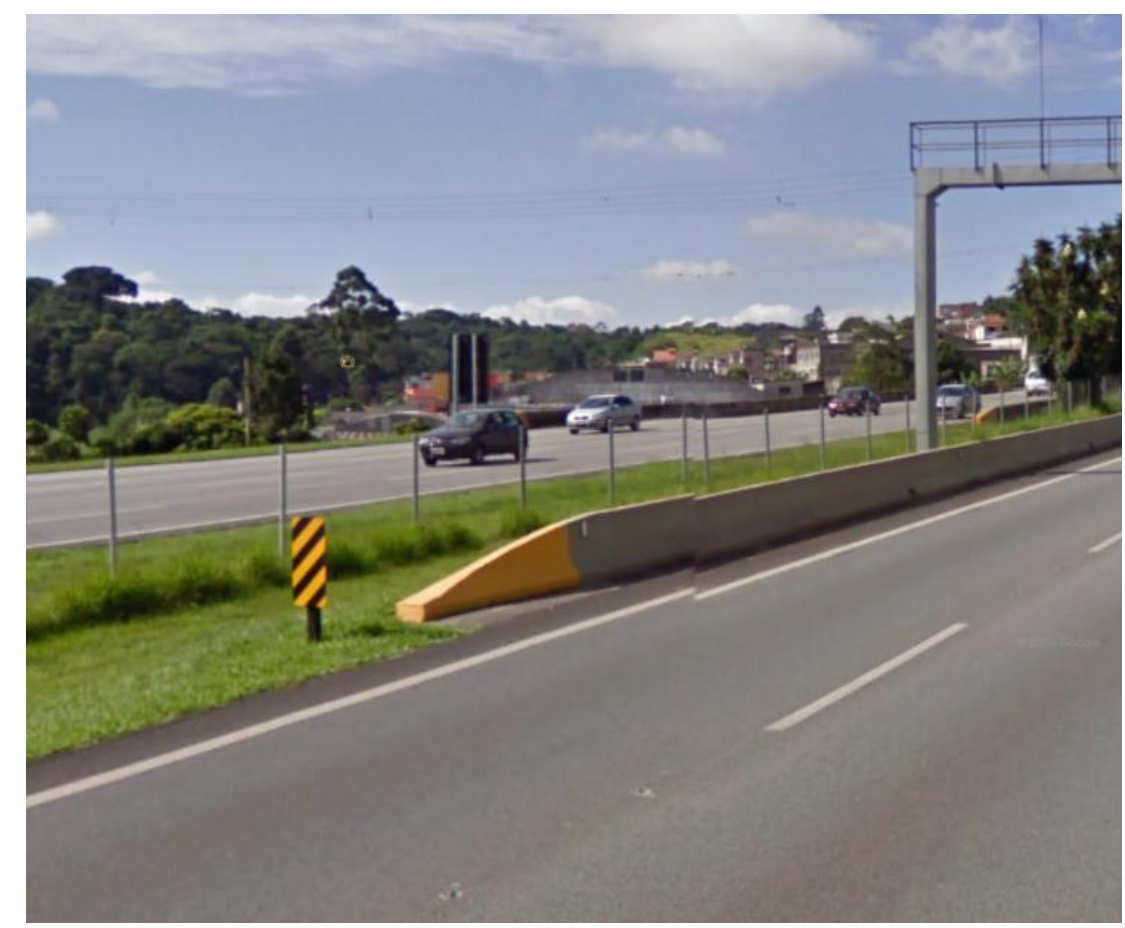

Figura 2-19 - Barreira de concreto com terminal abatido (fonte: Gloogle Earth, Rodovia dos Imigrantes, acessado em mar/2011)

Por fim, de acordo com a NBR 15486:2007, “os terminais absorvedores de energia consistem em um cabeçal de impacto acoplado a um sistema de lâminas ou tubos, adequadamente ancorado, que ao serem impactados frontalmente absorvem a energia cinética do veículo impactante, conduzindo-o a uma parada segura. Quando o impacto ocorre na lateral do corpo do terminal, 
fora do cabeçal, o terminal, através da sua ancoragem, permite desenvolver tensão e redirecionar o veículo."

A NBR 15486:2007, apesar de não ter clareza na definição de terminal, trata de uma forma mais relevante as aplicações, as funções e os requisitos do terminal. Também, segundo a NBR 15486:2007, os terminais devem atender aos critérios de avaliação do NCHRP Report 350 ou da norma européia EN 1317.

Não foi possível identificar os trabalhos científicos que embasaram as recomendações usuais (com exceção das similares às recomendações correspondentes para proteção geral de obstáculos e dispositivos de drenagem, que serão discutidos no próximo item). Pode-se perceber, no entanto, que as recomendações para terminação das barreiras e defensas vêm sofrendo mudanças recentes, visto que muitas práticas tradicionais têm sido hoje condenadas (ou estão em revisão) e novos dispositivos ou técnicas estão sendo buscados atualmente.

\subsection{TRATAMENTO PARA OBSTÁCULOS E DISPOSITIVOS DE DRENAGEM}

A garantia de uma área livre ampla, e pela própria definição, livre de obstáculos, nem sempre é possível, tendo em vista que muitos dos obstáculos são conseqüências do projeto viário.

A seguir serão apresentados alguns tratamentos típicos para obstáculos situados dentro da área livre requerida, baseados em critérios atualmente aceitos dos manuais nacionais e internacionais, que contribuem para o alcance do conceito de entorno tolerante.

Estes obstáculos estão divididos em dois grupos, discutidos a seguir, a saber:

(1) dispositivos de drenagem e

(2) postes, árvores e suportes de sinalização.

\subsubsection{Dispositivos de drenagem}


Além dos aspectos hidráulicos, hidrológicos, estruturais e construtivos, os dispositivos de drenagem devem ser projetados para atender aos requisitos de segurança viária, pois muitas vezes podem oferecer riscos aos veículos que involuntariamente saíram da pista.

Em geral, conforme expõe o RDG (2006), em ordem de preferência, algumas opções são aplicáveis aos dispositivos de drenagem:

- Eliminar estruturas não essenciais;

- Projetar ou modificar estruturas de drenagem para torná-la traspassável ou mínima obstrução possível para um veículo desgovernado;

- Se a estrutura de drenagem de maior porte em local vulnerável não puder ser reprojetada ou relocada, deve-se utilizar dispositivos de proteção lateral.

Não há uma extensa discussão destes aspectos de segurança viária na literatura técnica nacional (manuais do DNER/DNIT, normas da ABNT, etc.), razão pela qual a discussão a seguir vai limitar-se às recomendações da literatura internacional. Em alguns aspectos, os manuais nacionais de projeto de rodovias repetem as fontes clássicas, como observado a seguir, particularmente na recomendação de critérios de projeto.

\subsubsection{Tratamento para canais}

Canais são dispositivos de drenagem abertos, geralmente paralelos à via e localizados dentro da faixa de domínio. Além da sua função primária de coleta e condução das águas da chuva, é importante que estes dispositivos contribuam também para o entorno tolerante. Assim é importante que a seção transversal do canal não o torne um obstáculo perigoso para um veículo desgovernado que vier a atravessá-lo.

O RDG (2006) apresenta dois ábacos para a determinação de seções transversais desejáveis de canais e estão apresentados na Figura 2-20. O ábaco da Figura 2-20a se aplica em todos os canais com seção triangular "V", canais arredondados com largura da base menor que 2,4 m e canais trapezoidais com largura da base menor que 1,2 m. Já o ábaco da Figura 2-20b se aplica em canais arredondados com largura de base maior ou igual a $2,4 \mathrm{~m}$ e canais trapezoidais com largura da base igual ou superior a 1,2 $\mathrm{m}$. 
Canais com configuração de seção dentro da área hachurada são considerados traspassáveis. Canais com seções situadas fora da área hachurada são considerados menos desejáveis e seu uso deve ser limitado onde maiores ângulos de saída de pista são esperados, como o lado externo de curvas fechadas. Entretanto, estas seções podem ser aceitáveis em projetos com restrita faixa de domínio, em terrenos acidentados, projetos de recapeamento, restauração e reabilitação, em rodovias com baixo volume de tráfego ou baixa velocidade de projeto, particularmente se o fundo e talude ascendente do canal forem livres de obstáculos.

Se for prático, canais com seção transversal fora da área hachurada e situadas em locais vulneráveis devem ter sua seção modificada, de modo a torná-los traspassáveis, ou convertidos em sistemas fechados, ou em alguns casos, deve-se utilizar dispositivos de proteção lateral.

Estes critérios têm sido repetidos nas sucessivas versões do RDG (2006 e 2002, 1996, pelo menos). As recomendações que o TAC (1999) faz sobre estes elementos são as mesmas apresentadas pelo RDG (2006). A ABNT repete os ábacos do RDG (2006) na NBR 15486:2007, mas neste aspecto, é lacônica. Não há recomendação correspondente nos manuais de projeto geométrico ou de drenagem de rodovias do DNER/DNIT.
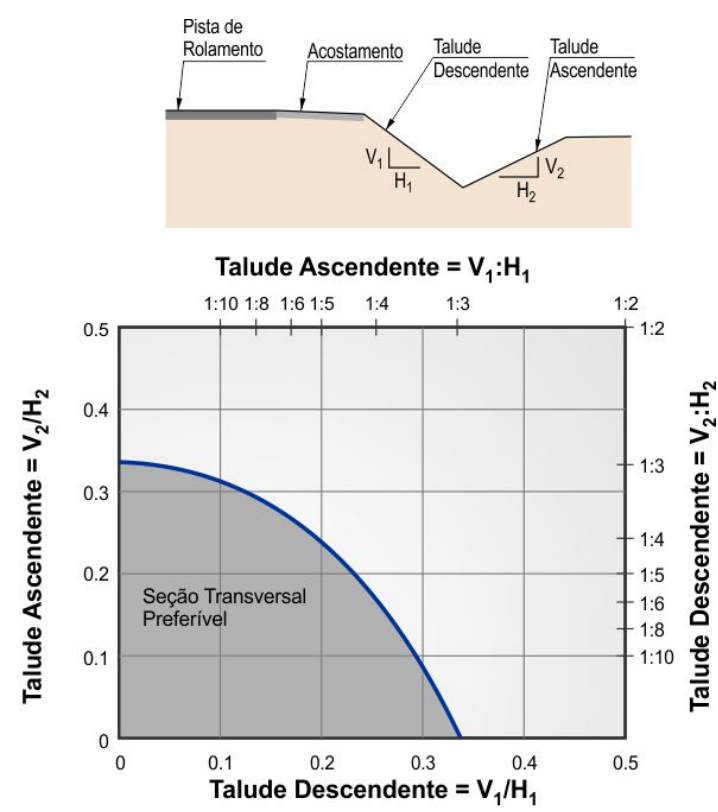

(a)

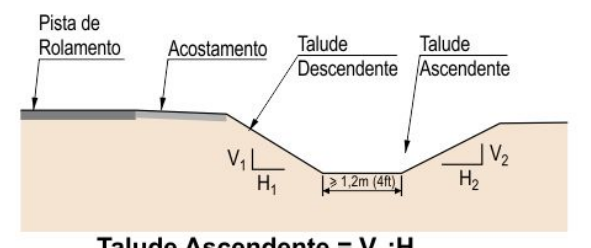

Talude Ascendente $=\mathrm{V}_{1}: \mathrm{H}_{1}$

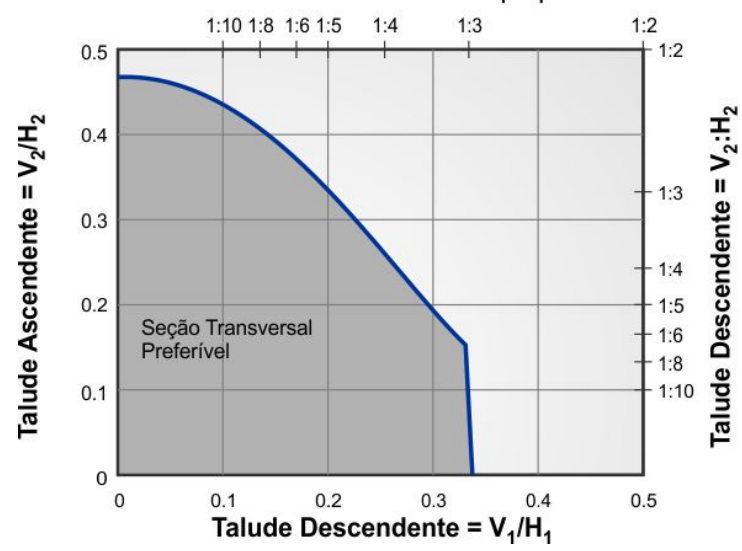

(b)

Figura 2-20 - Seções transversais preferenciais de canais (adaptado: RDG, 2006) 
Embora o RDG (2006) não tenha citado a fonte dos ábacos apresentados na Figura 2-20, segundo GLENNON (2004) estas informações provêm do estudo de WEAVER, MARQUIS, OLSON (1975).

Neste estudo os autores utilizaram um modelo de simulação computacional da dinâmica do movimento veicular, o HVOSM (Highway Vehicle Objective Simulation Model), para investigar o comportamento do veículo desgovernado durante o atravessamento de três regiões críticas do talude de aterro no entorno da via: o ponto de interseção dos planos do acostamento com o talude do aterro (daqui por diante referido como ombreira), o talude descendente e o pé do talude (ver Figura 2-21). Também foram testadas seções transversais com diversas combinações de inclinação dos taludes que formam as laterais do canal, bem como quatro configurações de fundo do canal: canal em "V", canal trapezoidal, canal com fundo arredondado e canal trapezoidal com cantos arredondados.

As condições de atravessamento foram caracterizadas pela velocidade do veículo e o ângulo de saída de pista. A velocidade do veículo no estudo variou de $40 \mathrm{mph}$ (aproximadamente $60 \mathrm{~km} / \mathrm{h}$ ) à $80 \mathrm{mph}$ (aproximadamente $120 \mathrm{~km} / \mathrm{h}$ ) e os ângulos de saída de pista utilizados foram 7, $15 \mathrm{e}$ $25^{\circ}$. Foram simulados saídas de pista sem tentativa de retorno a via e com tentativa do motorista retornar a via. Inclinações de taludes testadas variaram de $3 \mathrm{H}: 1 \mathrm{~V}$ à $10 \mathrm{H}: 1 \mathrm{~V}$. Para a validação do modelo, os autores utilizaram 24 testes em escala real.

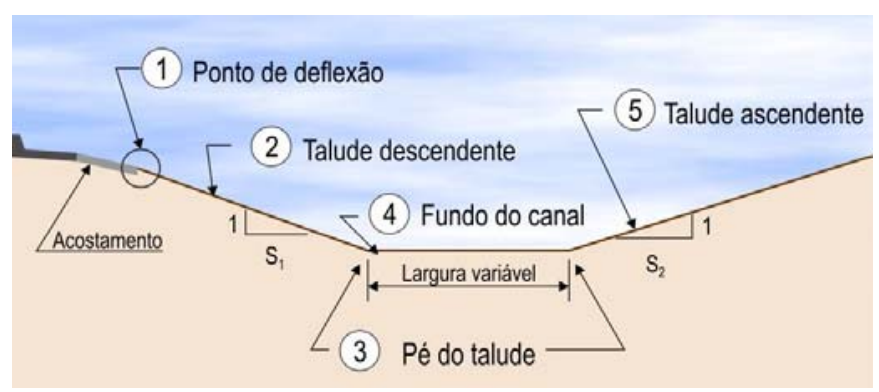

Figura 2-21 - Regiões críticas da seção transversal

Os critérios adotados para avaliar a severidade do atravessamento do talude pelo veículo desgovernado foram a ocorrência de capotamento/tombamento e a aceleração do veículo nos três eixos principais. Segundo os autores do estudo, o capotamento/tombamento somente ocorre em condições muito severas. Na ombreira, apesar de ocorrerem os máximos ângulos relacionados ao capotamento, nenhuma simulação resultou neste evento. Nota-se que existe coerência entre os 
resultados do estudo e as definições de taludes recuperáveis e não-recuperáveis definidos anteriormente, dado que os autores simularam taludes de 3H:1V a 10H:1V (o estudo é inclusive citado por GLENNON, 2004, como origem teórica do limite para taludes críticos em 1V:3H).

Entretanto, os autores do estudo destacam que existe a possibilidade de capotamento no talude durante a tentativa de retorno à via por parte do motorista, dependendo do tipo ou estado do solo que compõe o talude. Outra observação importante é que para permitir a recuperação do veículo na região do talude, um coeficiente de atrito de pelo menos 0,6 deve existir, e a superfície deve ser uniforme. Na definição de talude recuperável previamente mencionada (item 2.1.3), nenhum manual se refere a coeficiente de atrito como condicionante fundamental para o retorno à pista pelo veículo desgovernado.

WEAVER, MARQUIS, OLSON (1975) utilizaram a aceleração resultante nos três eixos principais (lateral, longitudinal e vertical), baseado no critério proposto por HYDE (1968) apud WEAVER, MARQUIS, OLSON (1975), para a determinação do índice de severidade do atravessamento de veículo desgovernado em determinadas condições, caracterizadas pela geometria do talude, velocidade e ângulo de saída de pista e tentativa ou não de retorno à pista pelo motorista. Esse critério corresponde ao índice de severidade do acidente (ASI-Acceleration Severity Index) que veio a ser amplamente adotado na definição do limiar de resistência humana em acidentes. A equação utilizada no estudo para a determinação do ASI:

$$
\text { ASI }=\sqrt{\left(\frac{G_{\text {lon }}}{G_{x}}\right)^{2}+\left(\frac{G_{\text {lat }}}{G_{y}}\right)^{2}+\left(\frac{G_{\text {ver }}}{G_{z}}\right)^{2}}
$$

Onde,

ASI = Índice de severidade do acidente;

$\mathrm{G}_{\text {lon }}=$ acelereção ocorrida segundo o eixo longitudinal;

$\mathrm{G}_{\text {lat }}=$ acelereção ocorrida segundo o eixo lateral;

$\mathrm{G}_{\mathrm{ver}}=$ acelereção ocorrida segundo o eixo vertical;

$\mathrm{G}_{\mathrm{x}}=$ acelereção tolerável segundo o eixo longitudinal;

$\mathrm{G}_{\mathrm{y}}=$ acelereção tolerável segundo o eixo lateral;

$\mathrm{G}_{\mathrm{z}}=$ acelereção tolerável segundo o eixo vertical; 
com os valores de aceleração definidos em termos de "g" (aceleração da gravidade).

Os valores limite de $G_{x}, G_{y}$ e $G_{z}$ adotados no estudo foram 5,7 e 6 , respectivamente, o que corresponde a valores de aceleração toleráveis para ocupantes sem restrições de movimento, isto é, sem utilização de cinto de segurança. A Tabela 2-12 mostra valores limites toleráveis para acelerações nas condições sem cinto de segurança, com cinto de segurança apenas na cintura (cinto de 2 pontos) e com cinto de segurança na cintura e no ombro (cinto de 3 pontos).

Tabela 2-12 - Valores toleráveis para acelerações (HYDE, 1968 apud WEAVER, MARQUIS, OLSON, 1975)

\begin{tabular}{lccc}
\hline \multirow{2}{*}{ Restrição } & \multicolumn{3}{c}{ Aceleração máxima (G's) } \\
\cline { 2 - 4 } & $\begin{array}{c}\text { LAT. } \\
\text { Gy }\end{array}$ & $\begin{array}{c}\text { LONG. } \\
\text { GX }\end{array}$ & $\begin{array}{c}\text { VERT. } \\
\text { Gz }\end{array}$ \\
\hline Sem restrição & 5 & 7 & 6 \\
Com cinto de segurança 2 pontos & 9 & 12 & 10 \\
Com cinto de segurança 3 pontos & 15 & 20 & 17 \\
\hline
\end{tabular}

A partir das simulações de diversas combinações de inclinação de taludes e configurações do fundo dos canais, os autores obtiveram as curvas ilustradas nas Figura 2-22, Figura 2-23 e Figura 2-24, para ASI iguais a 1,0 e 1,6, valores que representam acelerações resultantes toleráveis para ocupantes sem cinto de segurança e com cinto de segurança, respectivamente. As curvas foram obtidas para $60 \mathrm{mph}(96 \mathrm{~km} / \mathrm{h})$ e ângulo de saída de pista de $25^{\circ}$

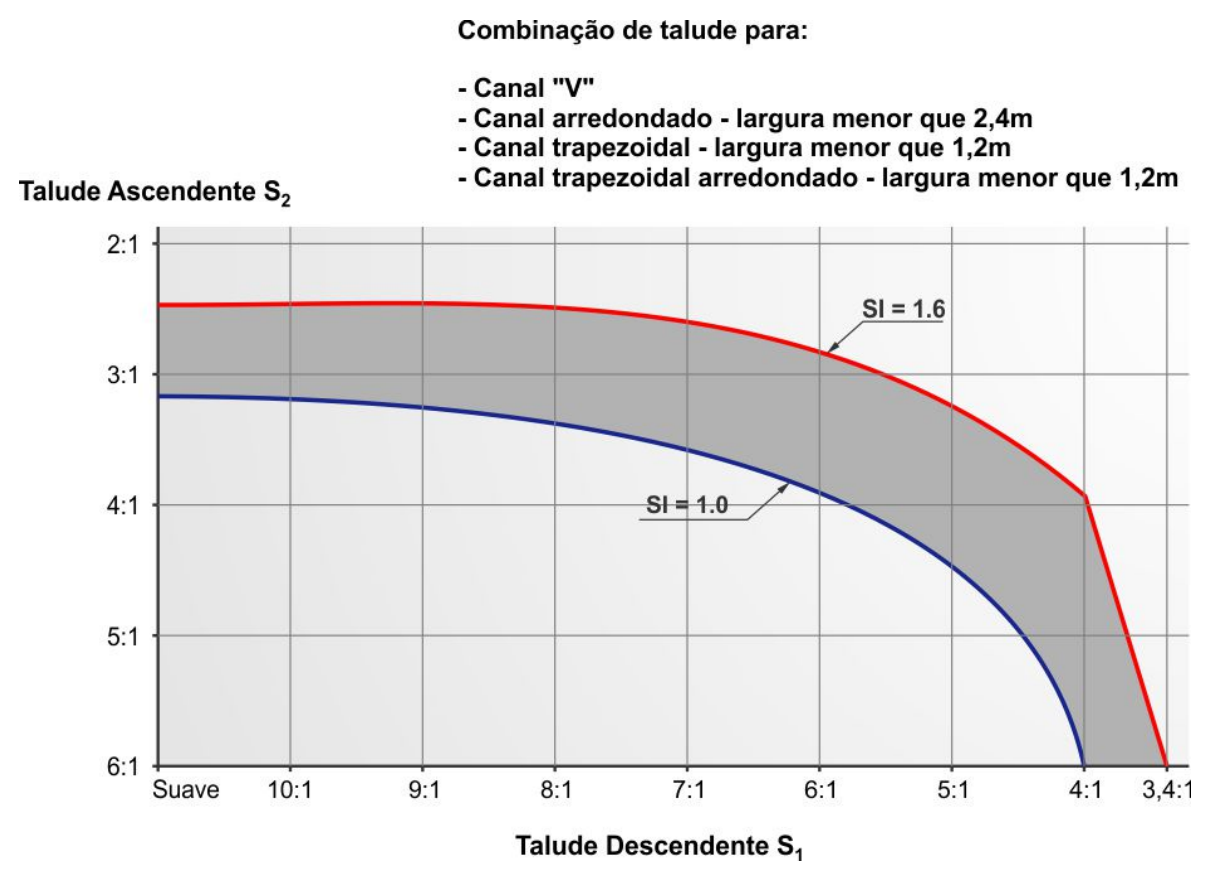

Figura 2-22 - Seção transversal de canal em V, arredondado com até 2,4m e trapezoidal até 1,2m (arredondado ou não) 


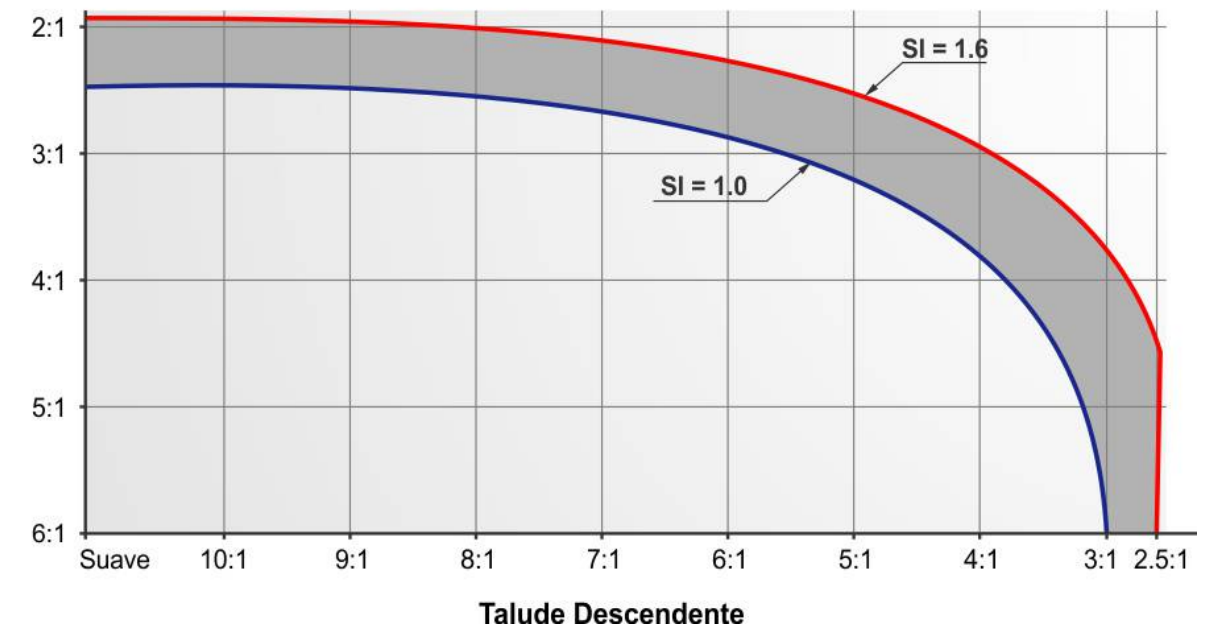

Figura 2-23 - Seção transversal de canal arredondado com 1,8m a 3,6m e trapezoidal com 1,2m a 2,4m

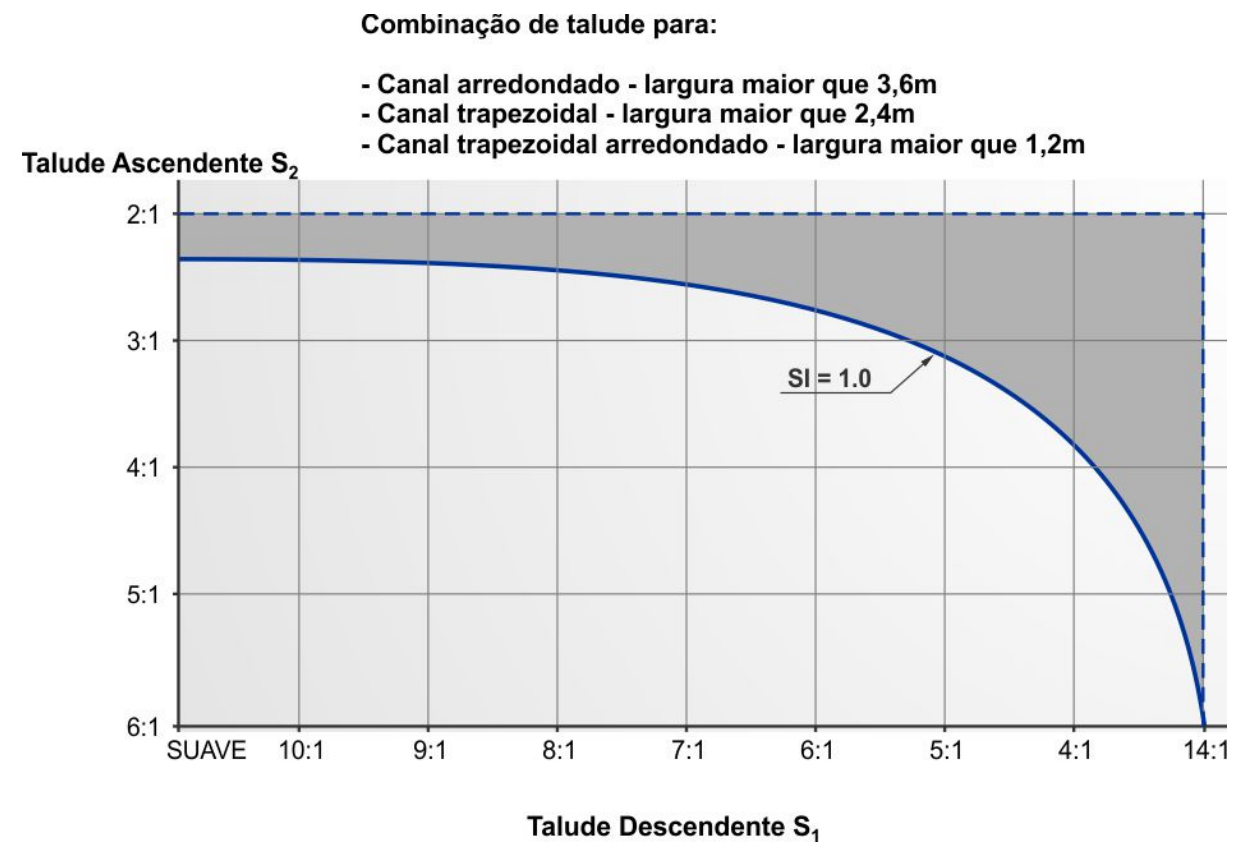

Figura 2-24 - Seção transversal de canal arredondado com mais de 3,6m, trapezoidal com mais de 2,4m, e arredondado e trapezoidal com mais de $1,2 \mathrm{~m}$

Comparando com os ábacos adotados no RDG (2006), pode-se ver que os critérios atualmente adotados seriam conservativos mesmo em relação ao caso sem cinto de segurança.

Outras conclusões do estudo foram: 
- Apesar dos maiores ângulos relacionados ao tombamento/capotamento ocorrerem no atravessamento da região da ombreira, estes dois eventos não constituem um problema para taludes de inclinações iguais ou mais suaves que $2 \mathrm{H}: 1 \mathrm{~V}$, para saídas de pista com ângulos maiores que $25^{\circ}$ e velocidade de $80 \mathrm{mph}$ (aproximadamente $120 \mathrm{~km} / \mathrm{h}$ ) se não ocorrer tentativa de manobra de retorno à pista. Do ponto de vista do tombamento/capotamento o arredondamento da ombreira não é necessário, porém, este tipo de tratamento reduzirá a tendência de decolagem do veículo ao passar por este ponto.

- Se existir distancia de recuperação disponível, manobras de retorno à pista podem ser executadas em taludes com inclinações iguais ou mais suaves que $3 \mathrm{H}: 1 \mathrm{~V}$, à velocidade de $80 \mathrm{mph}(120 \mathrm{~km} / \mathrm{h})$ e ângulo de saídas de pista de $15^{\circ}$ sem que haja tombamento/capotamento.

- Canais trapezoidais representam as seções transversais mais desejáveis do ponto de vista da segurança, especialmente os que possuem larguras superiores a 2,4 m. Taludes descendentes com inclinações de $4 \mathrm{H}: 1 \mathrm{~V}$ ou mais íngremes não são desejáveis, pois limitam a escolha da inclinação do talude ascendente. Inclinações maiores que 3H:1V são indicadas somente onde as condições do local não permitirem o uso de inclinações mais suaves.

Pode-se ver que o uso dos resultados qualitativos do estudo teórico predominou no RDG (provavelmente gerando uma versão correspondente mais conservativa dos ábacos), o que pode ser em parte atribuído à inconsistência dos seus resultados com os obtidos com os estudos empíricos, como, por exemplo, o estudo sobre tombamentos de VINER (1995).

\subsubsection{Guias (ou meios-fios)}

Guias são dispositivos de drenagem associados a sarjetas, geralmente paralelos à via e localizados lateralmente à área pavimentada, particularmente no meio urbano (onde delimitam as calçadas reservadas aos pedestres) ou na delimitação de canteiros físicos (áreas elevadas que excluem o tráfego veicular). Existe uma unanimidade entre os manuais com relação ao uso de guias em rodovias de altas velocidades, cuja recomendação é evitar esta combinação. Os manuais relatam que o choque de um veículo desgovernado em alta velocidade com a guia, desencadeará 
eventos secundários graves, como capotamento ou a "decolagem" do veículo resultando em perda do controle por parte do motorista. O termo "altas velocidades" não é quantificado no RDG (2006) tampouco na ABNT (2007), enquanto que o TAC (1999) quantifica em 90km/h a velocidade para se limitar o uso de guias, tanto as verticais, quanto as inclinadas.

Segundo RDG (2006), como as guias não tem capacidade de direcionamento, obstruções atrás delas devem ser posicionadas além da área livre quando possível. $\mathrm{O}$ efeito da combinação de guias e dispositivos de proteção lateral é um aspecto relevante e foi anteriormente tratado no item 2.5.2.

\subsubsection{Bueiros transversais à rodovia}

Os bueiros transversais têm a função de transportar água de um lado para outro da rodovia, podendo chegar, os de maior porte, a mais de $3 \mathrm{~m}$ de altura/diâmetro. Suas extremidades (entrada e saída d'água) são formadas por muros de ala e muros de testa, em geral de concreto, e dependendo da sua localização, vêm a constituir obstáculo ao veículo desgovernado, tanto devido à protuberância das estruturas dos muros de ala/testa, quando pela própria abertura existente nas extremidades de entrada/saída d'água, que resulta em um buraco por onde o veículo pode cair.

Assim, como recomenda o RDG (2006) e TAC (1999), para minimizar as ameaças criadas por estes elementos, deve-se considerar o uso de desenhos traspassáveis, estender a estrutura de forma que o choque com suas extremidades fique menos provável, usar proteção lateral ou, se nenhuma desta alternativas forem apropriadas, delinear os obstáculos da estrutura, tornando-a mais previsível.

Como sugere o RDG (2006), se o talude de aterro for traspassável, o tratamento preferido para os bueiros transversais é estendê-los ou encurtá-los de modo que as extremidades de entrada e a saída se conformem com o talude de aterro. Para pequenos bueiros, (bueiros circulares simples com diâmetro de $0,90 \mathrm{~m}$ ou menos, ou bueiros circulares múltiplos, cada um com diâmetro de 0,75m ou menos) nada, além disso, é necessário. Para estruturas maiores, da ordem de 1,0m ou mais, o uso de grades de barras de aço pode reduzir o vão livre da abertura da estrutura, tornando-a traspassável. A Figura 2-25 ilustra tal solução. Se a capacidade hidráulica for comprometida ou problema de obstrução for provável com grades, então o uso de dispositivos de proteção lateral deve ser considerado. 
Segundo o RDG (2006), testes de impacto em escala real mostraram que veículos podem atravessar as extremidades da estrutura associadas com barras de ferro, em inclinações até $3 \mathrm{H}: 1 \mathrm{~V}$, tanto para velocidades baixas $(30 \mathrm{~km} / \mathrm{h})$ quanto para velocidade altas $(100 \mathrm{~km} / \mathrm{h})$, para espaçamento entre as barras de $0,75 \mathrm{~m}$. Este espaçamento não muda de forma significativa a capacidade de escoamento do dispositivo, a menos que folhas e galhos obstruam parcialmente a entrada. Assim, é importante avaliar o potencial acúmulo de sujeira na entrada e a limpeza do dispositivo.

Outra opção que o RDG (2006) recomenda para o aumento da segurança no caso de bueiros de médio tamanho, se torná-los traspassável for impraticável, é estender a estrutura de modo que as extremidades fiquem além da área livre, reduzindo a probabilidade do veículo desgovernado atingi-las. No caso de estruturas de drenagem de grande porte, que tornam as soluções anteriores inviáveis, o uso de dispositivo de proteção lateral é, em geral, mais eficiente.

As recomendações do TAC (1999) são as mesmas.
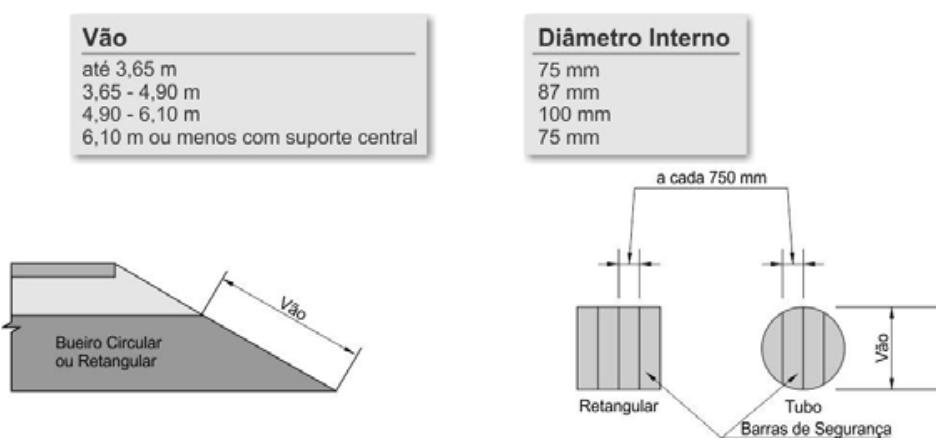

Figura 2-25 - Uso de barras como tratamento de segurança para extremidades de bueiros transversais (adaptado: RDG, 2006)

\subsubsection{Bueiros paralelos à rodovia}

Os bueiros paralelos à via são encontrados principalmente em canteiros centrais, em acessos a outras rodovias ou a propriedades, em alças de acesso, etc., e geralmente são de pequeno porte. Porém, dada a sua orientação com relação ao fluxo de tráfego, este tipo de estrutura pode ser chocado frontalmente por um veículo que eventualmente saia da pista, podendo este evento ter conseqüências graves. Assim, sempre que possível, deve-se projetar o dispositivo de tal forma 
que o torne traspassável, conformando-o ao talude, que também deverá ter inclinação tão suave quanto possível.

De acordo com o RDG (2006), para localidades susceptíveis a impactos com altas velocidades, deve-se utilizar taludes transversais de aterro com inclinações iguais ou mais suaves que $6 \mathrm{H}: 1 \mathrm{~V}$. Para rodovias de baixa velocidade ou baixo volume de tráfego, onde o histórico de acidentes mostrar baixa freqüência de acidentes com saídas de pista pode-se usar taludes mais íngremes, como medida de melhor efetividade. O RDG (2006) sugere ainda as seguintes medidas, em ordem de preferência:

- Eliminar a estrutura;

- Utilizar formas traspassáveis;

- Mover a estrutura lateralmente para um local menos provável de ser atingido;

- Utilizar dispositivos de proteção lateral;

- Delinear a estrutura se as alternativas acima não forem adequadas.

Apesar dos bueiros paralelos à via serem menores se comparado aos bueiros transversais, o uso de barras perpendiculares ao tráfego pode ajudar a tornar a estrutura traspassável, que evitariam o enganchamento das rodas do veículo. Conforme RDG (2006), estudos mostraram que, para estruturas paralelas, uma grade formada por barras espaçadas em $600 \mathrm{~mm}$ reduzem significativamente o enganchamento das rodas, sendo recomendado que a barra mais baixa deve ser colocada de $100 \mathrm{~mm}$ a $200 \mathrm{~mm}$ da base da estrutura. Em geral, estruturas menores que 600 mm de diâmetro não necessitam de grades.

As Figura 2-26 e Figura 2-27, obtidas do RDG (2006), mostram respectivamente as soluções do uso de barras nas entradas e saídas dos bueiros e a solução de deslocamento lateral. Se as soluções listadas acima não forem viáveis, o uso de dispositivo de proteção lateral deve ser considerado.

O TAC (1999) faz uma observação importante acerca da solução com uso de barras em áreas urbanas ou em proximidades de escolas e parques, onde se deve ter cuidado com a possibilidade das crianças caírem ou ficarem presas. 

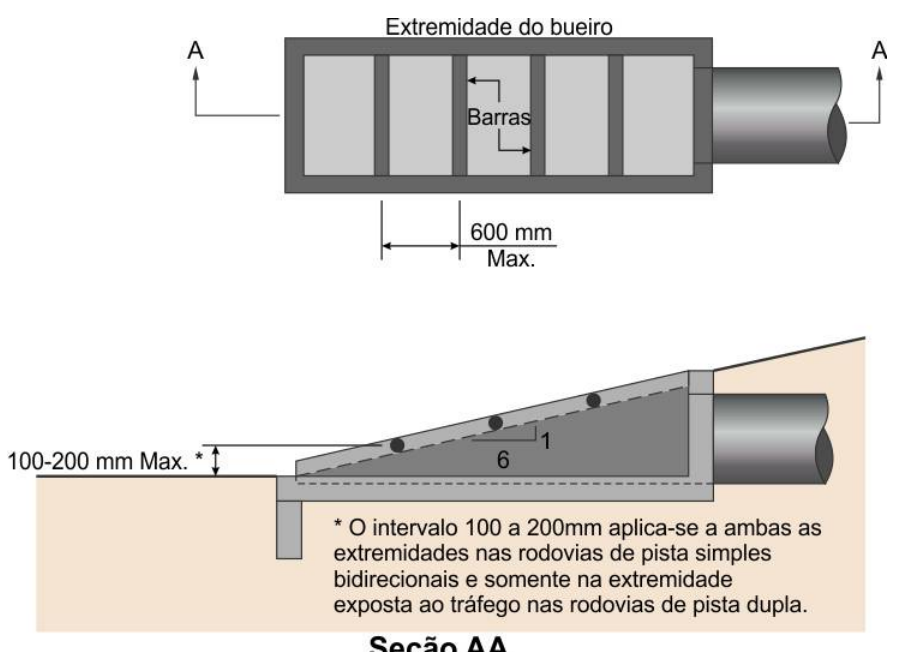

Seção AA

Figura 2-26 - Uso de barras como tratamento de segurança para extremidades de bueiros paralelos (RDG, 2006)

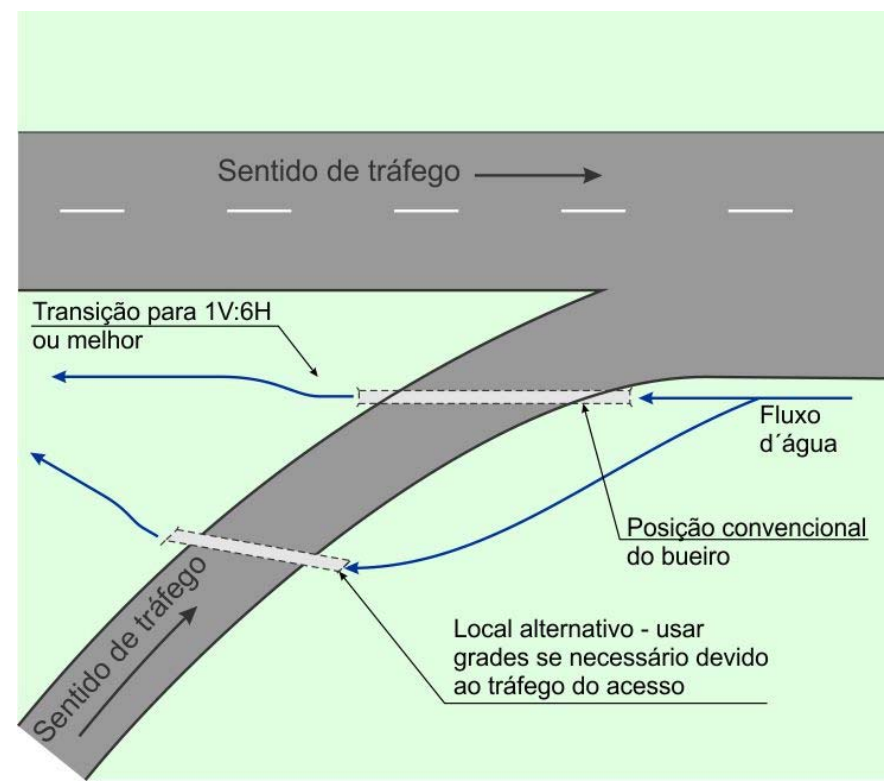

Figura 2-27 - Deslocamento lateral do bueiro para uma região menos provável de ser atingido (RDG, 2006)

Parece claro que o uso de espaçamentos menores seria recomendado pela segurança viária. A eficiência hidráulica seria reduzida e teria de ser avaliada, redimensionando-se os elementos pelo alargamento das seções (pelo menos nas entradas e saídas) preferindo-se barras de menor diâmetro e menor espaçamento (implicando em maior cuidado de manutenção).

\subsubsection{Caixas de captação}

Caixas de captação são dispositivos de drenagem cuja função é retirar água das valetas ou sarjetas, desviando-a para outros dispositivos condutores. As caixas de captação geralmente não 
apresentam problemas com relação à segurança de veículos desgovernados, visto que estes dispositivos são instalados rente ao pavimento ou a valeta. Devem ser dimensionados, além do aspecto hidráulico, para resistir à carga imposta pelas rodas do veículo e não devem constituir obstáculos para ciclistas e pedestres. Segundo o RDG (2006), não deve haver nenhuma parte saliente da caixa de captação superior a $100 \mathrm{~mm}$ e a sua abertura deve ser tratada para que não prenda as rodas dos veículos.

\subsubsection{Obstáculos rígidos (árvores, pilares, postes e suportes de sinalização)}

Em se tratando do entorno na via, o ideal seria que a área livre disponível fosse igual à área livre necessária, isto é, seria desejável que o entorno da via fosse traspassável e livre de obstáculos por uma largura baseada entre o equilíbrio dos custos associados a este espaço e a redução de acidentes associada à largura desta área. Entretanto, muitos dos obstáculos são resultantes do projeto da via e alguns são essenciais para a sua operação e segurança, portanto, sua presença no que seria a área livre é fundamental. Como exemplo pode-se citar os postes de sinalização, que devem estar ali para regular, advertir ou orientar os usuários, e os postes de iluminação, que devem estar localizados próximos à borda da via para dar sentido à sua função.

Assim, nem sempre é possível remover ou reposicionar estes elementos. Especialmente para os elementos verticais, também nem sempre é possível redesenhar estes tipos de obstáculos para serem traspassáveis. As medidas de engenharia, neste caso, podem seguir a idéia da redução da gravidade do acidente caso um choque ocorra, com uso de dispositivos colapsíveis, observando além da insegurança promovida pela presença do obstáculo, a insegurança gerada pela ausência dele ou redução da sua eficiência. Em outras palavras, o tratamento a ser feito para este tipo de dispositivo deve levar em conta as conseqüências da ausência da informação. Por exemplo, se o suporte de uma placa indicando curva perigosa à frente for do tipo colapsível, o choque de um veículo com esta placa removerá temporariamente a informação para os demais usuários da via, resultando em aumento da insegurança. Neste caso, o uso de proteção lateral pode ser considerado ao invés do dispositivo colapsível. Este tipo de análise está presente no manual britânico (U.K.DfT, 2006)

Segundo o RDG (2006), sempre que possível, os postes ou suportes de sinalização devem ser locados em áreas inacessíveis como, por exemplo, atrás de dispositivos de proteção lateral 
existentes (observando a distância de deflexão dinâmica do dispositivo de proteção) ou fixados em obras-de-arte especiais. Se estas medidas não forem possíveis, o uso de dispositivos colapsíveis deve ser considerado, observando o disposto no parágrafo anterior. De acordo com o RDG (2006), as partes remanescentes do dispositivo colapsível atingido não devem superar 100 $\mathrm{mm}$ acima do solo, a fim de não provocar o enganchamento do veículo, e o terreno nas proximidades do dispositivo não deve provocar desvios na altura de impacto do veículo, para não comprometer as condições de impacto para o qual o dispositivo foi projetado.

De acordo com RDG (2006), pórticos de sinalização não podem ser colapsíveis, devido ao seu peso e necessidade de suportes robustos. O RDG (2006) também chama a atenção para limitação de dispositivos colapsíveis em locais com grande concentração de pedestre, como zonas urbanas ou paradas de ônibus.

\subsection{CONSIDERAÇÕES SOBRE OS TESTES DE IMPACTO E CRITÉRIOS DE DESEMPENHO}

A NBR 15486:2007 traz em seu Anexo A informações acerca dos níveis de contenção e níveis de ensaio a que devem atender os sistemas de contenção, terminais e atenuadores de impacto. No anexo são comparados os critérios contidos no NCHRP Report 350 e no EN 1317 (1 à 5).

O NCHRP Report 350 traz os procedimentos recomendados para a avaliação do desempenho dos dispositivos de segurança. As avaliações são feitas com base em teste de impacto real e na análise do dispositivo durante sua operação na via. Nos EUA, qualquer dispositivo de contenção deve atender aos requisitos contidos no NCHRP Report 350, cujo objetivo é padronizar os testes realizados com os diversos dispositivos de segurança, bem como a avaliação do desempenho destes dispositivos com relação à adequação estrutural, risco para os ocupantes e o comportamento do veículo após o impacto.

Os testes de impacto são realizados em condições específicas de velocidade, ângulo de impacto, ponto de impacto no dispositivo e massa do veículo. Para dispositivos longitudinais, as velocidades variam de $35 \mathrm{~km} / \mathrm{h}$ à $100 \mathrm{~km} / \mathrm{h}$ e o ângulo de impacto varia de 0 e $25^{\circ}$.

Os veículos utilizados são os carros pequenos designados por 700C e 820C, camionetes pickup designados por 2000P, caminhões simples designados por $8000 \mathrm{~S}$ e caminhões com unidades tratoras e reboques designados por $36000 \mathrm{~V}$ e $36000 \mathrm{~T}$. As Tabela 2-13 e 
Tabela 2-14 mostram resumidamente as propriedades dos veículos utilizados nos testes de impacto. É fácil notar que os números nas designações referem-se às massas dos veículos em kg. Percebe-se que o veículo motocicleta não é utilizado para avaliar os dispositivos de proteção.

O NCHRP Report 350 classifica os testes em seis níveis (abreviados por TL, de test level): TL-1, TL-2, TL-3, TL-4, TL-5 e TL-6. Geralmente, os menores TLs são aplicados para avaliar sistemas usados em rodovias de baixo volume ou zonas de manutenção, enquanto que TLs maiores são aplicados para avaliar sistemas a serem utilizados em rodovias de maior volume de tráfego ou em locais que demandam condições elevadas de segurança (por exemplo, em locais com grandes proporções de veículos pesados ou locais onde as conseqüências de penetração no dispositivo de proteção não são toleráveis). Os testes de 4 a 6 (TL-4, TL-5 e TL-6), são aplicados somente para dispositivos de proteção longitudinais.

Tabela 2-13 - Propriedade dos veículos 700C, 820C e 2000P (fonte: NCHRP Report 350)

\begin{tabular}{|c|c|c|c|}
\hline Propriedades & $\begin{array}{c}700 \mathrm{C} \text { (carro } \\
\text { pequeno) }\end{array}$ & $\begin{array}{c}820 \mathrm{C} \text { (carro } \\
\text { pequeno) }\end{array}$ & $\begin{array}{c}2000 \mathrm{P} \\
\text { (caminhão com } \\
\text { caçamba) }\end{array}$ \\
\hline \multicolumn{4}{|l|}{$\overline{\text { Massa }(\mathrm{kg})}$} \\
\hline Teste inercial & $\begin{array}{c}700+/-25 \\
75\end{array}$ & $820+/-25$ & $2000+/-45$ \\
\hline $\begin{array}{c}\text { Modelo } \\
\text { Lastro máximo }\end{array}$ & $\begin{array}{l}75 \\
70\end{array}$ & $\begin{array}{l}75 \\
80\end{array}$ & $\begin{array}{l}\cdots \\
200\end{array}$ \\
\hline Bruto estático & $775+/-25$ & $895+/-25$ & $2000+/-45$ \\
\hline \multicolumn{4}{|l|}{ Dimensões (cm) } \\
\hline Distância entre eixos & $230+/-10$ & $230+/-10$ & $335+/-25$ \\
\hline Balanço dianteiro & $75+/-10$ & $75+/-10$ & $80+/-10$ \\
\hline Comprimento total & $370+/-20$ & $370+/-20$ & $535+/-25$ \\
\hline Distância lateral entre rodas (ver nota b) & $135+/-10$ & $135+/-10$ & $165+/-15$ \\
\hline \multicolumn{4}{|l|}{ Localização do centro de massa $(\mathrm{cm})$ (ver nota a) } \\
\hline Além do eixo frontal & $80+/-15$ & $80+/-15$ & $140+/-15$ \\
\hline Acima do solo & $55+/-5$ & $55+/-5$ & $70+/-5$ \\
\hline Posicionamento do motor & Frontal & Frontal & Frontal \\
\hline Posicionamento do eixo de tração & Frontal & Frontal & Traseiro \\
\hline Tipo de transmissão & $\begin{array}{l}\text { Manual ou } \\
\text { automática }\end{array}$ & $\begin{array}{l}\text { Manual ou } \\
\text { automática }\end{array}$ & $\begin{array}{l}\text { Manual ou } \\
\text { automática }\end{array}$ \\
\hline
\end{tabular}

Notas:

a) Massa para o "teste inercial"

b) Média entre os eixos frontal e traseiro 
Tabela 2-14 - Propriedade dos veículos 8000S, 36000V e 36000T

\begin{tabular}{|c|c|c|c|c|c|c|c|}
\hline \multirow{2}{*}{ Propriedade } & \multirow{2}{*}{$\begin{array}{l}8000 \text { S (Caminhão } \\
\text { simples) }\end{array}$} & \multicolumn{3}{|c|}{ 36000V (cavalo mecânico/reboque baú) } & \multicolumn{3}{|c|}{36000 (cavalo mecânico / reboque tipo tanque) } \\
\hline & & Trator & Trailer & Combinação & Trator & Trailer & Combinação \\
\hline \multicolumn{8}{|c|}{ Massa (kg) } \\
\hline Em ordem de marcha & $5,4500+/-450$ & $\mathrm{~N} / \mathrm{S}$ & NS & $13,200+/-1,400$ & NS & NS & $13,200+/-1,400$ \\
\hline Lastro & Conforme necessário & N/A & Conforme necessário & NA & NA & Conforme necessário & $\mathrm{N} / \mathrm{A}$ \\
\hline Teste de inércia & $8,000+/-200$ & $\mathrm{~N} / \mathrm{S}$ & NS & $36,000+/-500$ & NS & NS & $36,000+/-500$ \\
\hline \multicolumn{8}{|c|}{ Dimensões (cm) } \\
\hline Distância entre eixos & 535 (máx) & 480 (máx) & NS & NA & 480 (máx) & NS & $\mathrm{N} / \mathrm{A}$ \\
\hline Comprimento total & 870 (máx) & N/S & 1,525 (máx) & 1,985 (máx) & NS & NS & 1,985 (máx) \\
\hline Balanço do trailer & NA & $\mathrm{N} / \mathrm{A}$ & 220 (máx) & NA & NA & 185 (máx) & N/A \\
\hline Peso da carroceria & $130+/-5$ & $\mathrm{~N} / \mathrm{A}$ & $132+/-5$ & NA & NA & NA & $\mathrm{N} / \mathrm{A}$ \\
\hline \multicolumn{8}{|c|}{ Localização do centro de massa (cm) } \\
\hline Lastro & $170+/-5$ & $\mathrm{~N} / \mathrm{A}$ & $185+/-5$ & NA & NA & $205+/-10$ & $\mathrm{~N} / \mathrm{S}$ \\
\hline Teste de inércia & $125+/-5$ & $\mathrm{~N} / \mathrm{S}$ & NS & NS & NS & NS & $\mathrm{N} / \mathrm{S}$ \\
\hline
\end{tabular}

É oportuno frisar que os testes mencionados no NCHRP Report 350 refletem condições padronizadas de impacto, tipo de veículo, posicionamento da proteção lateral, condições do terreno onde o dispositivo de proteção está localizado e, portanto, não abrangem todas as condições possíveis de ocorrer. Para a avaliação de dispositivos em condições não idealizadas como, por exemplo, uso de barreiras atrás de guias, caberia ao responsável pelo projeto, instalação, operação ou fiscalização, a aplicação de testes específicos para tal avaliação.

A Tabela 2-15 mostra a matriz de testes para dispositivos de proteção longitudinais. Na coluna nomeação do teste, a primeira parte da nomenclatura refere-se ao TL e a segunda parte, ao número do teste, que se relaciona com o tipo de veículo, tipo de dispositivo e local de impacto. A designação do teste precedida por "S" refere-se ao teste opcional 700C.

O NCHRP Report 350 utiliza três critérios para a avaliação do desempenho dos dispositivos de proteção submetidos às condições padronizadas de velocidade, ângulo de impacto, ponto de impacto no dispositivo e massa do veículo: adequação estrutural, risco para os ocupantes e trajetória do veículo após o impacto.

\subsubsection{Adequação estrutural}

Os critérios de avaliação da adequação estrutural estão relacionados aos requisitos estruturais associados ao impacto, e não se relacionam a outras solicitações como, por exemplo, a carga gerada pelo vento no caso de suportes de sinalização. Os dispositivos de proteção devem satisfazer os requisitos A, B e C, indicados na Tabela 2-16. Por exemplo, dependendo da função, o dispositivo deve satisfazer a adequação estrutural pelo redirecionamento do veículo, pela parada do veículo de maneira controlada ou permitindo a penetração ao longo do dispositivo. 
Nota-se que os requisitos estão relacionados ao número do teste, que por sua vez relacionam-se com o tipo de veículo, tipo de dispositivo e local de impacto.

Tabela 2-15 - Matriz de testes para dispositivos de proteção longitudinais (NCHRP Report 350)

\begin{tabular}{|c|c|c|c|c|c|c|c|}
\hline \multirow[b]{2}{*}{$\begin{array}{l}\text { Teste de } \\
\text { Nível }\end{array}$} & \multirow[b]{2}{*}{$\begin{array}{c}\text { Seção da } \\
\text { Barreira }\end{array}$} & \multirow[b]{2}{*}{$\begin{array}{c}\text { Nomeação do } \\
\text { teste }\end{array}$} & \multicolumn{3}{|c|}{ Condições de Impacto } & \multirow[b]{2}{*}{$\begin{array}{l}\text { Ponto de } \\
\text { impacto }\end{array}$} & \multirow[b]{2}{*}{$\begin{array}{l}\text { Critério de } \\
\text { avaliação }\end{array}$} \\
\hline & & & Veículo & $\begin{array}{c}\text { Velocidade } \\
\text { nominal } \\
(\mathrm{km} / \mathrm{h})\end{array}$ & $\begin{array}{c}\text { Ângulo } \\
\text { Nominal, } \\
\theta \text { (graus) }\end{array}$ & & \\
\hline \multirow{6}{*}{1} & \multirow{3}{*}{$\begin{array}{c}\text { Comprimento } \\
\text { necessário }\end{array}$} & $1-10$ & $820 \mathrm{C}$ & 50 & 20 & (b) & $\mathrm{A}, \mathrm{D}, \mathrm{F}, \mathrm{H}, \mathrm{I},(\mathrm{J}), \mathrm{K}, \mathrm{M}$ \\
\hline & & $\mathrm{S} 1-10$ & $700 \mathrm{C}$ & 50 & 20 & (b) & $\mathrm{A}, \mathrm{D}, \mathrm{F}, \mathrm{H}, \mathrm{I},(\mathrm{J}), \mathrm{K}, \mathrm{M}$ \\
\hline & & $1-11$ & $2000 \mathrm{P}$ & 50 & 25 & (b) & $\mathrm{A}, \mathrm{D}, \mathrm{F}, \mathrm{K}, \mathrm{L}, \mathrm{M}$ \\
\hline & \multirow{3}{*}{ Transição } & $1-20$ & $820 \mathrm{C}$ & 50 & 20 & (b) & $\mathrm{A}, \mathrm{D}, \mathrm{F}, \mathrm{H}, \mathrm{I},(\mathrm{J}), \mathrm{K}, \mathrm{M}$ \\
\hline & & $\mathrm{S} 1-20$ & $700 \mathrm{C}$ & 50 & 20 & (b) & $\mathrm{A}, \mathrm{D}, \mathrm{F}, \mathrm{H}, \mathrm{I},(\mathrm{J}), \mathrm{K}, \mathrm{M}$ \\
\hline & & $1-21$ & $2000 P$ & 50 & 25 & (b) & $\mathrm{A}, \mathrm{D}, \mathrm{F}, \mathrm{K}, \mathrm{L}, \mathrm{M}$ \\
\hline \multirow{6}{*}{2} & \multirow{3}{*}{$\begin{array}{c}\text { Comprimento } \\
\text { necessário }\end{array}$} & $2-10$ & $820 \mathrm{C}$ & 70 & 20 & (b) & $\mathrm{A}, \mathrm{D}, \mathrm{F}, \mathrm{H}, \mathrm{I},(\mathrm{J}), \mathrm{K}, \mathrm{M}$ \\
\hline & & S2-10 & $700 \mathrm{C}$ & 70 & 20 & (b) & $\mathrm{A}, \mathrm{D}, \mathrm{F}, \mathrm{H}, \mathrm{I},(\mathrm{J}), \mathrm{K}, \mathrm{M}$ \\
\hline & & $2-11$ & $2000 P$ & 70 & 25 & (b) & $\mathrm{A}, \mathrm{D}, \mathrm{F}, \mathrm{K}, \mathrm{L}, \mathrm{M}$ \\
\hline & \multirow{3}{*}{ Transição } & $2-20$ & $820 \mathrm{C}$ & 70 & 20 & (b) & $\mathrm{A}, \mathrm{D}, \mathrm{F}, \mathrm{H}, \mathrm{I},(\mathrm{J}), \mathrm{K}, \mathrm{M}$ \\
\hline & & $\mathrm{S} 2-20$ & $700 \mathrm{C}$ & 70 & 20 & (b) & $\mathrm{A}, \mathrm{D}, \mathrm{F}, \mathrm{H}, \mathrm{I},(\mathrm{J}), \mathrm{K}, \mathrm{M}$ \\
\hline & & $2-21$ & $2000 P$ & 70 & 25 & (b) & $\mathrm{A}, \mathrm{D}, \mathrm{F}, \mathrm{K}, \mathrm{L}, \mathrm{M}$ \\
\hline \multirow{6}{*}{$\begin{array}{c}3 \\
\text { Nível } \\
\text { básico }\end{array}$} & \multirow{3}{*}{$\begin{array}{c}\text { Comprimento } \\
\text { necessário }\end{array}$} & $3-10$ & $820 \mathrm{C}$ & 100 & 20 & (b) & $\mathrm{A}, \mathrm{D}, \mathrm{F}, \mathrm{H}, \mathrm{I},(\mathrm{J}), \mathrm{K}, \mathrm{M}$ \\
\hline & & S3-10 & $700 \mathrm{C}$ & 100 & 20 & (b) & $\mathrm{A}, \mathrm{D}, \mathrm{F}, \mathrm{H}, \mathrm{I},(\mathrm{J}), \mathrm{K}, \mathrm{M}$ \\
\hline & & $3-11$ & $2000 P$ & 100 & 25 & (b) & $\mathrm{A}, \mathrm{D}, \mathrm{F}, \mathrm{K}, \mathrm{L}, \mathrm{M}$ \\
\hline & \multirow{3}{*}{ Transição } & $3-20$ & $820 \mathrm{C}$ & 100 & 20 & (b) & $\mathrm{A}, \mathrm{D}, \mathrm{F}, \mathrm{H}, \mathrm{I},(\mathrm{J}), \mathrm{K}, \mathrm{M}$ \\
\hline & & S3-20 & $700 \mathrm{C}$ & 100 & 20 & (b) & $\mathrm{A}, \mathrm{D}, \mathrm{F}, \mathrm{H}, \mathrm{I},(\mathrm{J}), \mathrm{K}, \mathrm{M}$ \\
\hline & & $3-21$ & $2000 \mathrm{P}$ & 100 & 25 & (b) & $\mathrm{A}, \mathrm{D}, \mathrm{F}, \mathrm{K}, \mathrm{L}, \mathrm{M}$ \\
\hline \multirow{8}{*}{4} & \multirow{4}{*}{$\begin{array}{c}\text { Comprimento } \\
\text { necessário }\end{array}$} & $4-10$ & $820 \mathrm{C}$ & 100 & 20 & (b) & $\mathrm{A}, \mathrm{D}, \mathrm{F}, \mathrm{H}, \mathrm{I},(\mathrm{J}), \mathrm{K}, \mathrm{M}$ \\
\hline & & $S 4-10$ & $700 \mathrm{C}$ & 100 & 20 & (b) & $\mathrm{A}, \mathrm{D}, \mathrm{F}, \mathrm{H}, \mathrm{I},(\mathrm{J}), \mathrm{K}, \mathrm{M}$ \\
\hline & & $4-11$ & $2000 P$ & 100 & 25 & (b) & $\mathrm{A}, \mathrm{D}, \mathrm{F}, \mathrm{K}, \mathrm{L}, \mathrm{M}$ \\
\hline & & $4-12$ & $8000 \mathrm{~s}$ & 80 & 15 & (b) & $\mathrm{A}, \mathrm{D}, \mathrm{G}, \mathrm{K}, \mathrm{M}$ \\
\hline & \multirow{4}{*}{ Transição } & $4-20$ & $820 \mathrm{C}$ & 100 & 20 & (b) & $\mathrm{A}, \mathrm{D}, \mathrm{F}, \mathrm{H}, \mathrm{I},(\mathrm{J}), \mathrm{K}, \mathrm{M}$ \\
\hline & & S4-20 & $700 \mathrm{C}$ & 100 & 20 & (b) & $\mathrm{A}, \mathrm{D}, \mathrm{F}, \mathrm{H}, \mathrm{I},(\mathrm{J}), \mathrm{K}, \mathrm{M}$ \\
\hline & & $4-21$ & $2000 P$ & 100 & 25 & (b) & $\mathrm{A}, \mathrm{D}, \mathrm{F}, \mathrm{K}, \mathrm{L}, \mathrm{M}$ \\
\hline & & $4-22$ & $8000 \mathrm{~s}$ & 80 & 15 & (b) & $\mathrm{A}, \mathrm{D}, \mathrm{G}, \mathrm{K}, \mathrm{M}$ \\
\hline \multirow{8}{*}{5} & \multirow{4}{*}{$\begin{array}{c}\text { Comprimento } \\
\text { necessário }\end{array}$} & $5-10$ & $820 \mathrm{C}$ & 100 & 20 & (b) & $\mathrm{A}, \mathrm{D}, \mathrm{F}, \mathrm{H}, \mathrm{I},(\mathrm{J}), \mathrm{K}, \mathrm{M}$ \\
\hline & & S5-10 & $700 \mathrm{C}$ & 100 & 20 & (b) & $\mathrm{A}, \mathrm{D}, \mathrm{F}, \mathrm{H}, \mathrm{I},(\mathrm{J}), \mathrm{K}, \mathrm{M}$ \\
\hline & & $5-11$ & $2000 \mathrm{P}$ & 100 & 25 & (b) & $\mathrm{A}, \mathrm{D}, \mathrm{F}, \mathrm{K}, \mathrm{L}, \mathrm{M}$ \\
\hline & & $5-12$ & $36000 \mathrm{~V}$ & 80 & 15 & (b) & $\mathrm{A}, \mathrm{D}, \mathrm{G}, \mathrm{K}, \mathrm{M}$ \\
\hline & \multirow{4}{*}{ Transição } & $5-20$ & $820 \mathrm{C}$ & 100 & 20 & (b) & $\mathrm{A}, \mathrm{D}, \mathrm{F}, \mathrm{H}, \mathrm{I},(\mathrm{J}), \mathrm{K}, \mathrm{M}$ \\
\hline & & S5-20 & $700 \mathrm{C}$ & 100 & 20 & (b) & $\mathrm{A}, \mathrm{D}, \mathrm{F}, \mathrm{H}, \mathrm{I},(\mathrm{J}), \mathrm{K}, \mathrm{M}$ \\
\hline & & $5-21$ & $2000 P$ & 100 & 25 & (b) & $\mathrm{A}, \mathrm{D}, \mathrm{F}, \mathrm{K}, \mathrm{L}, \mathrm{M}$ \\
\hline & & $5-22$ & $36000 \mathrm{~V}$ & 80 & 15 & (b) & $\mathrm{A}, \mathrm{D}, \mathrm{G}, \mathrm{K}, \mathrm{M}$ \\
\hline \multirow{8}{*}{6} & \multirow{4}{*}{$\begin{array}{c}\text { Comprimento } \\
\text { necessário }\end{array}$} & $6-10$ & $820 \mathrm{C}$ & 100 & 20 & (b) & $\mathrm{A}, \mathrm{D}, \mathrm{F}, \mathrm{H}, \mathrm{I},(\mathrm{J}), \mathrm{K}, \mathrm{M}$ \\
\hline & & S6-10 & $700 \mathrm{C}$ & 100 & 20 & (b) & $\mathrm{A}, \mathrm{D}, \mathrm{F}, \mathrm{H}, \mathrm{I},(\mathrm{J}), \mathrm{K}, \mathrm{M}$ \\
\hline & & $6-11$ & $2000 P$ & 100 & 25 & (b) & $\mathrm{A}, \mathrm{D}, \mathrm{F}, \mathrm{K}, \mathrm{L}, \mathrm{M}$ \\
\hline & & $6-12$ & $36000 \mathrm{~T}$ & 80 & 15 & (b) & $\mathrm{A}, \mathrm{D}, \mathrm{G}, \mathrm{K}, \mathrm{M}$ \\
\hline & & $6-20$ & $820 \mathrm{C}$ & 100 & 20 & (b) & $\mathrm{A}, \mathrm{D}, \mathrm{F}, \mathrm{H}, \mathrm{I},(\mathrm{J}), \mathrm{K}, \mathrm{M}$ \\
\hline & Transicão & S6-20 & $700 \mathrm{C}$ & 100 & 20 & (b) & $\mathrm{A}, \mathrm{D}, \mathrm{F}, \mathrm{H}, \mathrm{I},(\mathrm{J}), \mathrm{K}, \mathrm{M}$ \\
\hline & & $6-21$ & $2000 P$ & 100 & 25 & (b) & $\mathrm{A}, \mathrm{D}, \mathrm{F}, \mathrm{K}, \mathrm{L}, \mathrm{M}$ \\
\hline & & $6-22$ & $36000 T$ & 80 & 15 & (b) & $\mathrm{A}, \mathrm{D}, \mathrm{G}, \mathrm{K}, \mathrm{M}$ \\
\hline
\end{tabular}

Tabela 2-16 - Requisitos para a adequação estrutural (NCHRP Repor 350)

\begin{tabular}{|c|c|c|c|}
\hline Fatores de avaliação & & Critério de avaliação & $\begin{array}{c}\text { Testes aplicáveis } \\
\text { (ver nota a) }\end{array}$ \\
\hline \multirow{3}{*}{ Adequação estrutural } & A. & $\begin{array}{l}\text { O dispositivo testado deve conter e } \\
\text { redirecionar o veículo; o veículo não } \\
\text { deve penetrar, passar por cima ou por } \\
\text { baixo da instalação apesar da deflexão } \\
\text { lateral do dispositivo ser aceitável }\end{array}$ & $\begin{array}{l}10,11,12,20,21, \\
22,35,36,37,38\end{array}$ \\
\hline & B. & $\begin{array}{l}\text { O dispositivo deve ser prontamente } \\
\text { ativado de uma forma previsível através } \\
\text { de sua quebra, fratura ou contenção }\end{array}$ & $\begin{array}{c}60,61,70,71,80 \\
81\end{array}$ \\
\hline & & $\begin{array}{c}\text { A performance aceitável do dispositivo } \\
\text { pode ser o redireciomento, a penetração } \\
\text { controlada, ou a parada controlada do } \\
\text { veículo. }\end{array}$ & $\begin{array}{l}30,31,32,33,34 \\
39,40,41,42,43 \\
44,50,51,52,53\end{array}$ \\
\hline
\end{tabular}

Notas

a) Os números dos testes referem-se aos últimos dois dígitos da designação do teste para cada nível de teste exceto quando outra orientação for indicada. 


\subsubsection{Risco para os ocupantes}

$\mathrm{Na}$ avaliação do risco para os ocupantes do veículo é desconsiderada a resistência ao impacto do compartimento dos ocupantes, dada a grande variabilidade de elementos de projeto que influenciam a resistência desta parte do veículo (e que variam de veículo para veículo). O risco para os ocupantes é avaliado pela aceleração do veículo, cujo valor também é utilizado como parâmetro de projeto do dispositivo de segurança e da estrutura externa do veículo.

Os requisitos a serem atendidos na avaliação do desempenho dos dispositivos de proteção estão listados na Tabela 2-17 e aplicam-se a números de teste específicos. Um dos requisitos, por exemplo, é que o dispositivo de proteção avaliado não deve ter elementos desprendidos ou qualquer tipo de fragmento que possa penetrar ou mostrar-se com potencial de penetração no compartimento dos ocupantes do veículo, ou apresentar ameaça indevidas para o tráfego, pedestres ou trabalhadores presentes no local. Outro requisito é que o veículo permaneça "de cabeça para cima" durante e após o choque, sendo aceitáveis moderados giros em torno dos três eixos. Fatores de desempenho como a velocidade do ocupante no impacto com a superfície interior do veículo e a resultante da aceleração veicular também são considerados.

\subsubsection{Trajetória do veículo após o impacto}

A tabela 2-18 lista os requisitos que devem ser atendidos na avaliação do dispositivo de proteção com relação à trajetória do veículo após o impacto. $\mathrm{O}$ dispositivo deve proporcionar uma trajetória pós-impacto que não provoque eventos secundários perigosos, que ponham em risco os ocupantes do veículo e demais usuários da via. Em geral, quando o ângulo de saída após o impacto é menor que $60 \%$ do ângulo de impacto, o redirecionamento do veículo é considerado suave. Características aceitáveis pós-impacto também são alcançadas se o veículo é desacelerado até a parada total quando o contato veículo-dispositivo é mantido. 
Tabela 2-17 - Requisitos do risco para os ocupantes (NCHRP Report 350)

\begin{tabular}{|c|c|c|c|c|c|}
\hline $\begin{array}{l}\text { Fatores de } \\
\text { avaliação }\end{array}$ & \multicolumn{4}{|c|}{ Critério de avaliação } & Testes aplicáveis \\
\hline \multirow{14}{*}{$\begin{array}{l}\text { Risco dos } \\
\text { ocupantes }\end{array}$} & \multicolumn{4}{|c|}{$\begin{array}{l}\text { Elementos soltos, fragme } \\
\text { não devem penetrar ou ir } \\
\text { compartimento do ocupa } \\
\text { outros motoristas, pedest } \\
\text { Deformações ou invasõe } \\
\text { poderão causar sérios d }\end{array}$} & Todos \\
\hline & $\mathrm{E}$. & \multicolumn{3}{|c|}{$\begin{array}{l}\text { Elementos soltos, fragmentos ou outras partículas do dispositivo } \\
\text { testado, ou danos veiculares não devem bloquear a visão do } \\
\text { motorista ou causar a perda do controle do veículo pelo motorista }\end{array}$} & 70,71 \\
\hline & $\mathrm{F}$. & \multicolumn{3}{|c|}{$\begin{array}{c}\text { O veículo deve permanecer em pé durante e após a colisão } \\
\text { apesar de manobras moderadas, afastamentos e desvios serem } \\
\text { aceitáveis }\end{array}$} & $\begin{array}{l}\text { Todos com exc eção } \\
\text { daqueles listados no } \\
\text { criterio G }\end{array}$ \\
\hline & G. & \multicolumn{3}{|c|}{$\begin{array}{c}\text { É preferível, apesar de não essencial, que o veículo permaneça } \\
\text { em pé durante e após a colisão }\end{array}$} & $\begin{array}{l}\text { 12, 22, 30(b), 31(b), } \\
\text { 32(b), 33(b), 34(b), 35(b), } \\
\text { 36(b), 37(b), 38(b), 39(b), } \\
\text { 40(b), 41(b), 42(b), 43(b), } \\
\text { 44(b) }\end{array}$ \\
\hline & \multirow[t]{5}{*}{$\mathrm{H}$. } & \multicolumn{3}{|c|}{$\begin{array}{l}\text { Os limites da velocidade de impacto ao ocupante devem satisfazer } \\
\text { ao seguinte: }\end{array}$} & \\
\hline & & \multicolumn{3}{|c|}{ Limites da velocidade de impacto $(\mathrm{m} / \mathrm{s})$} & \\
\hline & & Componentes & Preferível & Máxima & \\
\hline & & Longitudinal e lateral & 9 & 12 & $\begin{array}{c}10,20,30,31,32,33,34 \\
36,40,41,42,43,50,51 \\
52,53,80,81\end{array}$ \\
\hline & & Longitudinal & 3 & 5 & $60,61,70,71$ \\
\hline & \multicolumn{4}{|c|}{$\begin{array}{l}\text { I. Os limites de desacelerações para os ocupantes dos veículos } \\
\text { devem satisfazer ao seguinte: }\end{array}$} & \\
\hline & & \multicolumn{3}{|c|}{ Limites de desac eleração (G's) } & \\
\hline & & Componentes & Preferível & Máxima & \\
\hline & & Longitudinal e lateral & 15 & 20 & $\begin{array}{c}10,20,30,31,32,33,34 \\
36,40,41,42,43,50,51 \\
52,53,60,61,70,71,80 \\
81\end{array}$ \\
\hline & \multicolumn{4}{|c|}{$\begin{array}{ll}\text { J. } & \\
\text { (Opcional) Modelo hibrido III. }\end{array}$} & $\begin{array}{c}10,20,30,31,32,33,34 \\
36,40,41,42,43,50,51 \\
52,53,60,61,70,71,80 \\
81\end{array}$ \\
\hline
\end{tabular}


Tabela 2-18 - Requisitos para a trajetória do veículo após o impacto (NCHRP Report 350)

\begin{tabular}{|c|c|c|c|}
\hline $\begin{array}{l}\text { Fatores de } \\
\text { avaliação }\end{array}$ & & Critério de avaliação & Testes aplicáveis (a) \\
\hline \multirow{5}{*}{$\begin{array}{l}\text { Trajetória do } \\
\text { veículo }\end{array}$} & $\mathrm{K}$. & $\begin{array}{c}\text { Após a colisão é preferível que a trajetória do veículo não invada } \\
\text { as faixas de tráfego adjacentes }\end{array}$ & Todos \\
\hline & L. & & $11,21,35,37,38,39$ \\
\hline & & $\begin{array}{l}\text { A velocidade de impacto ao ocupante não deve exceder } 12 \mathrm{~m} / \mathrm{s} \text { e a } \\
\text { desaceleração na direção longitudinal não deve exceder a } 20 \mathrm{G} \text { 's }\end{array}$ & \\
\hline & M & $\begin{array}{c}\text { O ângulo de saída para o dispositivo em teste deve ser } \\
\text { preferencialmente menor do que } 60 \% \text { do ângulo do teste de } \\
\text { impacto, medido no momento em que o veículo perde contato com } \\
\text { o dispositivo de teste. }\end{array}$ & $\begin{array}{l}10,11,12,20,21,22,35 \\
36,37,38,39\end{array}$ \\
\hline & $\mathrm{N}$. & A trajetória do veículo atrás do dispositivo testado é aceitável & $\begin{array}{l}30,31,32,33,34,39,42, \\
43,44,60,61,70,71,80 \\
81\end{array}$ \\
\hline
\end{tabular}

a) Os números dos testes referem-se aos ultimos dois dígitos na designação do teste para cada teste de nível exceto quando indicado o contrário

Os critérios de avaliação acima sintetizados relacionam-se ao desempenho de dispositivos de segurança ao impacto e fatores como custo, estética, durabilidade e manutenção, não são levados em conta.

De acordo com o NCHRP Report 350, para que sejam possíveis e práticos, os valores limites recomendados para os critérios de avaliação são baseados na tecnologia atual e, quando necessário, no julgamento coletivo de especialistas da área. O estabelecimento dos critérios de desempenho baseia-se na filosofia de que se as condições econômicas e tecnológicas permitirem, maiores níveis de segurança devem ser esperados para certos dispositivos do que outros. Além disso, devido à natureza complexa da colisão veicular, da maneira como os ocupantes do veículo respondem dinamicamente à colisão e a complexidade da tolerância humana ao impacto, os critérios recomendados devem ser tratados como diretrizes gerais e não como critérios absolutos. 


\section{MODELOS COMPREENSIVOS}

O objetivo deste capítulo é o de revisar métodos de análise que tratam de forma mais explícita as saídas de pista e a presença dos dispositivos de proteção lateral. A apresentação do capítulo anterior pretendeu deixar claro o que é recomendado, mas também buscou verificar a origem das recomendações. Muitas vezes, os estudos originais são antigos e simplificados.

Os modelos compreensivos constituem-se em um conjunto de algoritmos que auxiliam na tomada de decisão de intervenções de segurança viária, baseados em análise custo-benefício ou outro critério de análise, levando em consideração diversos aspectos tais como, o volume de tráfego, presença e localização dos obstáculos, a freqüência dos acidentes, a severidade e os custos associados a eles e o custo de implantação das intervenções.

Neste capítulo, os métodos serão apresentados com base na estrutura de dois programas de computador que incorporam os modelos compreensivos, a saber, os americanos Roadside Safety Analysis Program (RSAP) e o seu predecessor ROADSIDE.

O RSAP e o ROADSIDE são oficialmente recomendados pelo RDG (2002, e sua atualização de 2006) e pelo RDG (1996), respectivamente. A documentação básica do ROADSIDE é o Apêndice A do RDG (1996). Para o RSAP, além do Apêndice A do RDG (2006), foi consultado o relatório do projeto de desenvolvimento, publicado como NCHRP Report 492 (2003). 
A mesma estrutura básica também é proposta para cálculos manuais em GLENNON (2004) e no TAC (1999). Há também o britânico RRRAP, baseado em planilhas eletrônicas do programa de computador Microsoft Excel $\mathbb{R}$, que muito provavelmente incorporam modelos compreensivos. Porém, o RRRAP não foi revisado nesta dissertação. É importante ressaltar que os modelos compreensivos não são necessariamente programas de computador, mas sim modelos matemáticos que incorporam os aspectos relevantes para a análise do obstáculo nas laterais da via. Portanto, os modelos compreensivos podem ser aplicados manualmente, como o proposto por GLENNON (2004). Todavia, a aplicação manual pode ser desgastante dependendo da quantidade de informações que se quer agregar.

Um exemplo comparativo para ilustrar a diferença de abordagem dos métodos compreensivos dos métodos expostos no capítulo anterior seria a tomada de decisão de colocar ou não defensa metálica na lateral da via com a presença de um talude de aterro de $4 \mathrm{~m}$ de altura e inclinação de 1,5H:1V. O método ilustrado na Figura 2-8 recomenda que, em tal situação, a defensa deve ser utilizada, independente de fatores como o afastamento lateral do talude em relação à via, a presença ou não de curvas horizontais, o volume de tráfego, etc. Já os métodos compreensivos responderiam de formas diferentes dependendo de cada um destes fatores. Se o afastamento lateral do talude em relação à via for de $20 \mathrm{~m}$, talvez não seja necessário a defensa. Se a distância do talude à via for bastante próxima, mas se o volume de veículos for irrisório, talvez também não seja necessária a defensa. São nestas situações que os modelos compreensivos seriam potencialmente melhores que os métodos recomendados no capítulo 2.

\subsection{ESTRUTURA DOS MODELOS COMPREENSIVOS}

Os modelos compreensivos descritos a seguir estão incorporados aos programas computacionais previamente citados. O programa RSAP trabalha em plataforma Microsoft Windows ${ }^{\circledR}$, sendo de fácil uso e assimilação por parte do usuário, enquanto que o ROADSIDE é um programa que roda em plataforma DOS e a entrada dos dados é feita pelo teclado, de forma seqüencial, ou por arquivos de dados.

Ambos baseiam-se em análise custo-benefício incremental, isto é, dado uma situação qualquer (ou situação inicial, ou ainda, situação "1") do entorno viário, caracterizado pela presença de obstáculos laterais, dispositivos de segurança, geometria da via, volume de tráfego, etc., e dado 
outra situação com intervenção de melhoria a ser proposta (situação "2"), analisa-se se a situação "2" é melhor ou pior que a situação "1" em termos de eficiência de alocação de recursos financeiros. É possível ainda analisar diversas situações ou alternativas de projeto e escolher a que possui o maior incremento benefício/custo.

A análise incremental benefício/custo por ser útil em situações não óbvias, na qual se pode tomar diversas medidas, ou até mesmo "não fazer nada", para uma dada situação, e que o uso dos critérios apresentados no capítulo 2 não convém ou não fornecem a melhor resposta para tal situação, dado o alcance limitado ou deficiência do critério.

A taxa incremental benefício/custo utilizada no RSAP é expressa da seguinte maneira:

$$
B / C_{(2-1)}=\frac{\left(A C_{1}-A C_{2}\right)}{\left(D C_{2}-D C_{1}\right)}
$$

onde:

$\mathrm{B} / \mathrm{C}_{(2-1)}$ : taxa incremental beneficio/custo na comparação da alternativa 2 com a alternativa 1 .

$\mathrm{AC}_{1}, \mathrm{AC}_{2}$ : custo social anualizado associado aos acidentes das alternativas 1 e 2.

$\mathrm{DC}_{1}, \mathrm{DC}_{2}$ : custo direto anualizado das alternativas 1 e 2.

Vê-se, portanto, que o benefício é definido em termos de redução dos custos sociais dos acidentes decorrentes da redução do número e/ou severidade do acidente. Os custos diretos são aqueles relacionados ao custo inicial de instalação da alternativa, o custo de manutenção e custos de reparos resultante dos acidentes.

A avaliação dos custos sociais dos acidentes é o ponto mais delicado, em particular a previsão dos acidentes. $\mathrm{Na}$ grande parte dos modelos compreensivos, esta avaliação utiliza um modelo sequencial que pode receber uma interpretação probabilística. Os modelos compreensivos (e, portanto, os programas computacionais RSAP e o ROADSIDE) baseiam-se em modelo de saídas de pista e no risco de acidente decorrente de uma série de probabilidades condicionais:

$$
E(C)=Q A \cdot P(E) . P(C \mid E) \cdot P(I \mid C) \cdot C(I)
$$

onde: 
E(C): Custo estimado dos acidentes (relacionados com saídas de pista).

QA: Número de veículos, por ano, que passam em determinado trecho; pode ser interpretado como exposição veicular.

$\mathrm{P}(\mathrm{E})$ : Probabilidade de saída de pista em um determinado trecho da via, geralmente medida em saídas de pista por veículo circulante. É influenciada pela geometria da via.

$\mathrm{P}(\mathrm{C} \mid \mathrm{E})$ : Probabilidade de choque dado que ocorreu uma saída de pista, medida em choques por saídas de pista. É função do ângulo de saída de pista, da extensão da saída, da posição lateral do obstáculo com relação à via, e das dimensões do obstáculo.

$\mathrm{P}(\mathrm{I} \mid \mathrm{C})$ : Probabilidade de severidade dado que ocorreu um choque, medida em números de acidentes de determinada gravidade pelo número total de acidentes.

$\mathrm{C}(\mathrm{I})$ : custo do acidente associada à determinada gravidade.

A fórmula acima pressupõe uma somatória para os acidentes por grau de severidade; nas formulações mais detalhadas, a somatória distingue também outros aspectos que influenciam os resultados como o tipo de veículo, velocidade e ângulo de saída, orientação do veículo, etc.

Nesta formulação, o valor de $\mathrm{E}(\mathrm{C})$ é a medida de (des)benefício da alternativa considerada. Traduzindo a expressão acima em palavras, para a determinação do custo dos acidentes é necessário saber primeiro qual é a probabilidade de saída de pista. Uma vez ocorrida uma saída de pista, não necessariamente ocorre um choque com obstáculo, pois no local da saída de pista pode não haver um obstáculo, ou ainda, se houver obstáculo, este pode estar suficientemente longe para o veículo não alcançá-lo. Portanto, dado que ocorreu uma saída de pista, é necessário saber a probabilidade de haver o choque, que é função do afastamento lateral do obstáculo em relação à pista e da localização deste obstáculo ao longo da via. A última etapa é associar o choque ao custo e, para isso, é necessário saber a magnitude dos danos causados ao veículo e aos seus ocupantes, pois cada magnitude de dano está associada a um custo diferente. Por exemplo, se o choque resultou em uma vítima fatal, certamente o custo deste acidente é muito maior que um choque resultado em apenas danos materiais. Vale lembrar que o termo custo do acidente refere-se ao custo social do acidente de trânsito.

GLENNON (2004), originalmente GLENNON (1974), adota um conceito muito parecido, porém sem a associação com o custo do acidente de determinada gravidade e, portanto, não representa o custo social do acidente de trânsito, mas representa uma indicação do quanto um local é perigoso, 
auxiliando na tomada de decisão para intervenções de melhoria da segurança viária. Este conceito poderia ser traduzido como índice de periculosidade e é expressa da seguinte forma:

$$
\mathrm{H}=\mathrm{QA} . \mathrm{P}(\mathrm{E}) . \mathrm{P}(\mathrm{C} \mid \mathrm{E}) . \mathrm{P}(\mathrm{I} \mid \mathrm{C})
$$

onde:

H: Índice de periculosidade (hazard), expresso em tipo de acidente por ano. QA, $\mathrm{P}(\mathrm{E}), \mathrm{P}(\mathrm{C} \mid \mathrm{E})$ e $\mathrm{P}(\mathrm{I} \mid \mathrm{C})$ : definidos anteriormente.

A menos de detalhes de formulação que serão discutidos adiante, as estruturas do RSAP e do ROADSIDE são similares. Algumas hipóteses básicas adotadas para os dados de entrada e a estratégia de cálculo é a principal diferença entre eles.

Para a determinação de $\mathrm{E}(\mathrm{C})$, o RSAP trabalha com três módulos, quais sejam, módulo de saídas de pista, módulo de previsão de acidentes e módulo de previsão da severidade do acidente. O quarto módulo, módulo de análise custo-benefício, junto com os outros três, completa a estrutura do RSAP, e finaliza a análise custo-benefício da alternativa em questão. A peculiaridade do RSAP é que os eventos a analisar são gerados aleatoriamente a partir de uma amostragem por importância baseada na distribuição das variáveis relevantes.

O ROADSIDE tem a mesma estrutura, mas a estratégia de cálculo corresponde a definir faixas de valores para cada variável relevante (determinando uma matriz de intervalos discretos e seus valores característicos) e avaliar o caso típico de cada célula (depois ponderada pela frequência correspondente).

Portanto, inicialmente, a maior diferença entre os programas é o método de determinação da solução. Enquanto o ROADSIDE obtém a solução de forma determinística, o RSAP a obtém de forma estocástica, utilizando simulação de Monte Carlo.

$\mathrm{Na}$ determinação dos custos associados aos acidentes, a forma determinística de solução busca primeiramente a probabilidade de cada característica da saída de pista, tais como a velocidade do veículo, o ângulo de saída, tipo de veículo, localização, etc., e os valores possíveis destas características para encontrar o valor médio a ser utilizado no cálculo. Desta forma, como sabido, o resultado será sempre o mesmo. 
Já no modelo estocástico, as saídas de pista são simuladas uma de cada vez, com cada característica (velocidade do veículo, o ângulo de saída, tipo de veículo, localização, etc) atribuída de forma aleatória, baseada em distribuições estabelecidas dentro do programa. Assim, por exemplo, assume-se que as saídas de pista são distribuídas uniformemente ao longo de uma determinada seção homogênea e que sua quantidade é função da freqüência de saídas de pista. A faixa de onde se originou a saída de pista e a direção é função do volume de tráfego distribuído por faixa. A velocidade, ângulo e orientação são determinados a partir de distribuições estimadas de dados de acidentes reais. Na medida em que as hipóteses de distribuição sejam similares, os resultados deveriam também ser compatíveis. No entanto, devido à natureza estocástica, na simulação de Monte Carlo nem sempre a resposta é a mesma, mas se um grande número de simulações é realizado, a resposta converge para um valor com nível de exatidão determinada.

A vantagem básica do método adotado no RSAP é a de poder avaliar o efeito da aleatoriedade (por exemplo, construindo intervalos de confiança para os resultados) e a desvantagem básica é o maior "custo" computacional (cada simulação é mais demorada e mais simulações são necessárias se o efeito da aleatoriedade deve ser avaliado). Além disso, a adoção de uma amostragem por importância permite analisar com mais detalhe eventos mais críticos (ponderando os resultados de forma conveniente para que o resultado global não seja viesado).

Estes aspectos computacionais não interessam a este trabalho, visto que normalmente os resultados obtidos devem ser consistentes e semelhantes.

A seguir, as hipóteses e procedimentos de cálculo serão descritos e analisados.

\subsection{CARACTERÍSTICAS DAS SAÍDAS DE PISTA}

Como se viu na estrutura dos modelos compreensivos, um dos primeiros passos na determinação da previsão do custo do acidente associado a uma condição do entorno viário é conhecer as características das saídas de pista, isto é, a frequência, extensão lateral e ângulo de saída de pista. A probabilidade de saída de pista $\mathrm{P}(\mathrm{E})$ é a primeira etapa na estrutura dos modelos compreensivos, enquanto que a extensão lateral e o ângulo de saída de pista serão úteis na determinação da probabilidade de choques $\mathrm{P}(\mathrm{C} \mid \mathrm{E})$, que será discutido no próximo item. 
Dois estudos clássicos acerca da natureza das saídas de pista foram desenvolvidos por COOPER (1980) e HUTCHINSON e KENNEDY (1967), que servem de base, até hoje, para estudos relacionados ao assunto. Infelizmente, o estudo de COOPER (1980) não foi encontrado para revisão, sendo que alguns comentários sobre o estudo foram extraídos do NCHRP Report 492.

\subsubsection{Frequência básica de saídas de pista}

O RSAP, de acordo com NCHRP Report 492, utiliza os dados do estudo de COOPER (1980) para relacionar a taxa de saída de pista e o volume de tráfego. A Figura 3-1 ilustra a taxa de saídas de pista em função do volume de tráfego utilizada no RSAP. O ROADSIDE utiliza uma taxa de saídas de pista constante igual a 0,0003 saídas/km/ano por veículos/dia (portanto, 3,0 saídas/km/ano para VDM de 10000 e 6,0 saídas/km/ano para VDM de 20000). Pretensamente são saídas para os dois lados da pista, com base no VDM bidirecional.

Em ambos os casos, estes são os valores básicos para a frequência de saídas de pista.

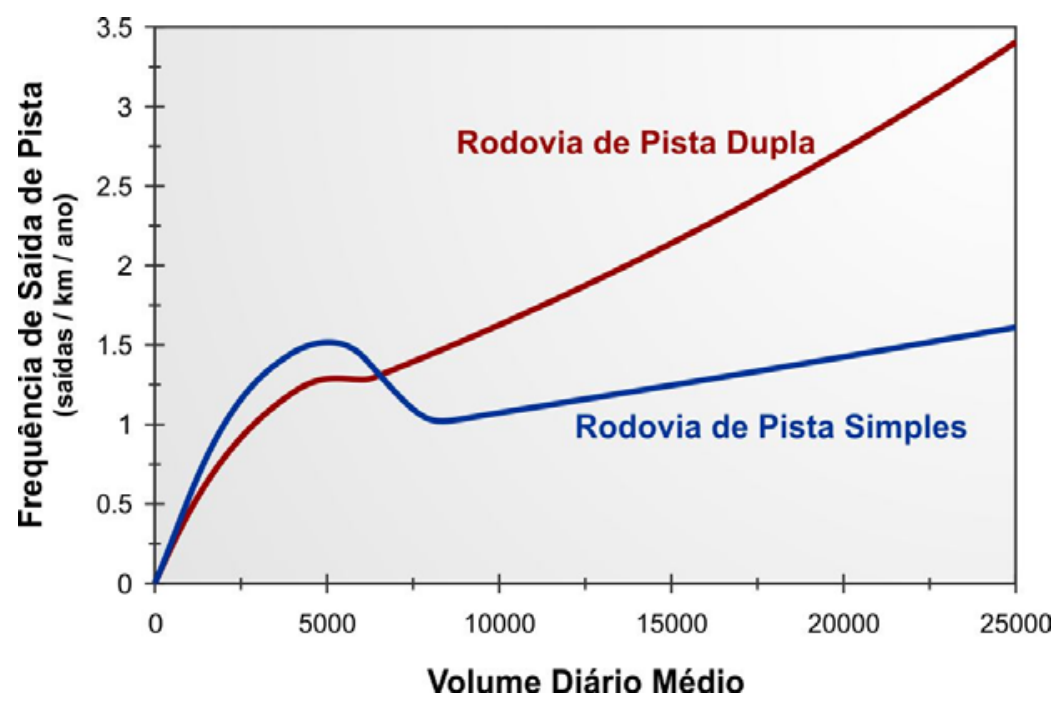

Figura 3-1 - Frequência de saída de pista em função do volume de tráfego adotado pelo RSAP (adaptado NCHRP Report 492) 
Segundo o NCHRP Report 492, o estudo de COOPER (1980), realizado no Canadá no final da década de 70, envolveu observações de trilhas de roda no canteiro central e na lateral da rodovia. Alguns ajustes foram realizados nos valores encontrados por COOPER (1980) para o RSAP. Como o estudo baseou-se na observação de trilhas de rodas, a presença de acostamentos pavimentados dificultava esta observação, e acredita-se que as saídas de pista inferiores a $4 \mathrm{~m}$ foram subestimados. Assim, os dados de saídas de pista de COOPER (1980) foram re-analisados e estimou-se que as saídas estavam subestimadas por uma taxa de 2,466 para rodovias de pista simples e 1,878 para rodovias de pista dupla com múltiplas faixas. Outra limitação do estudo de COOPER (1980), de acordo com NCHRP Report 492, é a dificuldade de se distinguir entre saídas de pista voluntárias e involuntárias, pois alguns motoristas poderiam sair da pista intencionalmente para, por exemplo, revezarem a vez de dirigir. Assim, no RSAP, a freqüência de saídas de pista de COOPER (1980) é multiplicada por 0,60 para considerar esta deficiência.

Além do estudo de COOPER (1980), vale a pena mencionar o estudo de HUTCHINSON e KENNEDY (1967), que investigaram a freqüência e a natureza das saídas de pista em canteiros centrais de duas rodovias expressas, a Interstate 74 e a Kingery Expressway, localizadas em Illinois, Estados Unidos, e também se basearam na observação de marcas de pneus no canteiro central (portanto, não se referem a saídas laterais mas centrais).

Os trechos das rodovias selecionadas para o estudo caracterizavam-se por possuírem duas faixas por sentido, segmentos em tangente e canteiros centrais de larguras de $12 \mathrm{~m}$ e $5,4 \mathrm{~m}$ para a I74 e Kingery Expressway, respectivamente. A rodovia Interstate 74 possuía delineadores refletivos, enquanto que a Kingery Expressway possuía um pequeno grau de delineamento gerado pela presença de barreira a cabos no canteiro central. Durante a coleta de dados (período de 3 anos), os volumes de tráfego variaram de 1700 à 6000 veíc/dia na 174 e de 18000 à 31000 veíc/dia na Kingery Expressway. A

Tabela 3-1 e a Figura 3-2 mostram, respectivamente, os dados coletados no estudo e a relação entre saídas de pista e o volume de tráfego. Nota-se que, para a Kingery Expressway, os dados foram coletados durante o inverno. 
Tabela 3-1 - Frequência e taxa de saída de pista (HUTCHINSON e KENNEDY, 1967)

\begin{tabular}{|c|c|c|c|c|c|c|}
\hline $\begin{array}{l}\text { Período de } \\
\text { obser vação }\end{array}$ & $\begin{array}{c}\text { Dias de } \\
\text { observação }\end{array}$ & $\begin{array}{l}\text { Volume de } \\
\text { tráfego } \\
\text { (veículo/dia) }\end{array}$ & Veículo-km & $\begin{array}{c}\text { Saídas } \\
\text { observadas }\end{array}$ & $\begin{array}{c}\text { Frequencia de saídas } \\
\text { de pista } \\
\text { (saídas/km/ano) }\end{array}$ & $\begin{array}{l}\text { Taxa de saídas de } \\
\text { pista (saídas } 100 \mathrm{x} \\
10^{\wedge} 6 \text { veiculo- } \mathrm{km} \text { ) }\end{array}$ \\
\hline \multicolumn{7}{|c|}{ I74 (39,4 km) } \\
\hline $\begin{array}{c}\text { Out. 4, } 1960-\text { Dez. } \\
22,1960\end{array}$ & 79 & 1900 & $5.913 .940,00$ & 16 & 1,9 & 271 \\
\hline $\begin{array}{c}\text { Dez. 22, } 1960 \text { - } \\
\text { Mar. 29, } 1961\end{array}$ & 97 & 3000 & $11.465 .400,00$ & 31 & 3,0 & 270 \\
\hline $\begin{array}{c}\text { Mar. 29, } 1961 \text { - Jul. } \\
\text { 12, } 1961\end{array}$ & 105 & 4000 & $16.548 .000,00$ & 58 & 5,1 & 350 \\
\hline $\begin{array}{c}\text { Jul. 12, } 1961 \text { - Dez } \\
\text { 2, } 1961\end{array}$ & 143 & 4150 & $23.381 .930,00$ & 30 & 1,9 & 128 \\
\hline $\begin{array}{c}\text { Dez. 2, } 1961 \text { - Mar. } \\
\text { 31, } 1962\end{array}$ & 119 & 4350 & $20.395 .410,00$ & 32 & 2,5 & 157 \\
\hline $\begin{array}{c}\text { Mar. 31, } 1962- \\
\text { Jun. 26, } 1962\end{array}$ & 87 & 5250 & $17.995 .950,00$ & 17 & 1,8 & 94 \\
\hline $\begin{array}{c}\text { Jun. 26, } 1962 \text { - } \\
\text { Out. 13, } 1962\end{array}$ & 109 & 5750 & $24.693 .950,00$ & 16 & 1,4 & 65 \\
\hline $\begin{array}{c}\text { Out. 13, } 1962 \text { - Abr. } \\
16,1963\end{array}$ & 185 & 5950 & $43.369 .550,00$ & 50 & 2,5 & 115 \\
\hline $\begin{array}{l}\text { Abr. 16, } 1963 \text { - } \\
\text { Jun. 27, } 1963\end{array}$ & 72 & 5950 & $16.878 .960,00$ & 5 & 0,6 & 30 \\
\hline $\begin{array}{c}\text { Jun. 27, } 1963 \text { - } \\
\text { Abr. 6, } 1964\end{array}$ & 284 & 5700 & $63.780 .720,00$ & 47 & 1,5 & 74 \\
\hline \multicolumn{7}{|c|}{ Kingery Expressway (4,8 km) } \\
\hline $\begin{array}{c}\text { Dez. 1, } 1957 \text { - Mar. } \\
\text { 31, } 1958\end{array}$ & 120 & 18195 & $10.480 .320,00$ & 7 & 4,4 & 67 \\
\hline $\begin{array}{c}\text { Dez. 1, } 1958 \text { - Mar. } \\
\text { 31, } 1959\end{array}$ & 120 & 20490 & $11.802 .240,00$ & 9 & 5,7 & 76 \\
\hline $\begin{array}{c}\text { Dez. 1, } 1959 \text { - Mar. } \\
\text { 31, } 1960\end{array}$ & 121 & 31253 & $18.151 .742,40$ & 14 & 8,8 & 77 \\
\hline
\end{tabular}

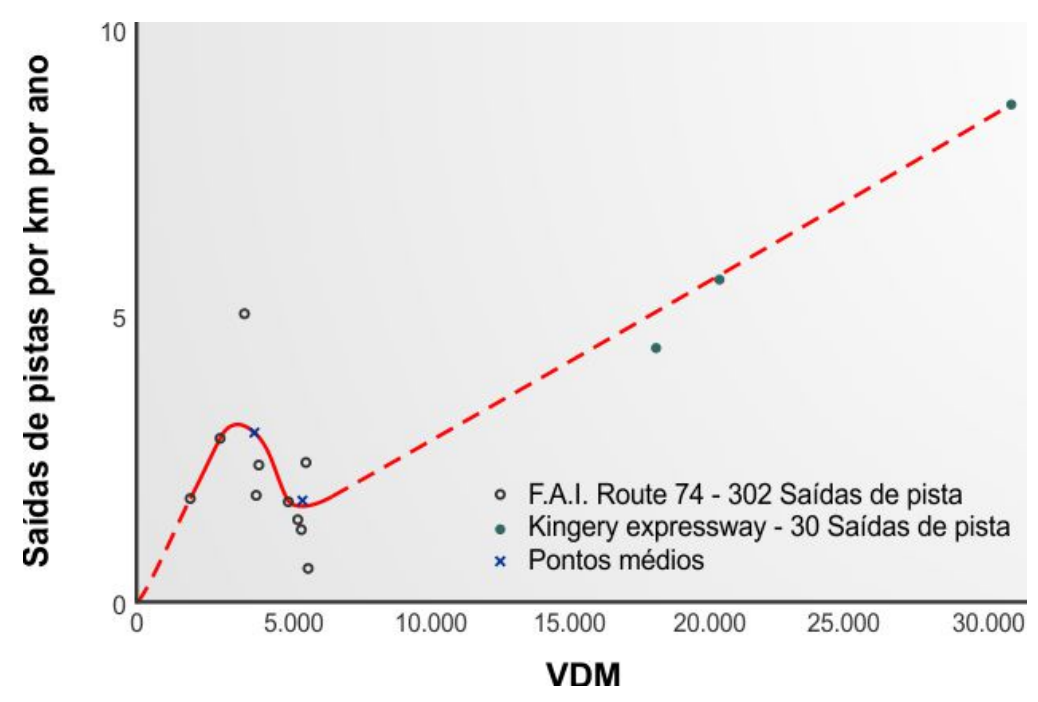

Figura 3-2 - Frequência de saída de pista (HUTCHINSON e KENNEDY, 1967)

É possível perceber que a aparência do gráfico da Figura 3-2 obtida por HUTCHINSON e KENNEDY (1967) é muito parecida com o da Figura 3-1, obtida por COOPER (1980). Ambos os gráficos mostram que para valores pequenos de volume de tráfego, a frequência de saída de 
pista aumenta com o aumento do volume de tráfego e, quando o volume de tráfego atinge certo valor, em torno de 4000 veíc/dia, para o estudo de HUTCHINSON e KENNEDY (1967), e em torno de 5000 veíc/dia, para o estudo de COOPER (1980), a frequência de saídas de pista passa a decrescer. Em torno de 6000 veíc/dia, para o estudo de HUTCHINSON e KENNEDY (1967), e em torno de 8000 veíc/dia, para o estudo de COOPER (1980), as freqüências de saídas de pista voltam a crescer com o aumento do volume de tráfego, em ambas as curvas.

A explicação de HUTCHINSON e KENNEDY (1967) para o formato da curva está relacionada às condições de dirigibilidade associadas às mudanças no volume de tráfego. Para pequenos volumes de tráfego, os motoristas agem de forma independente uns dos outros, isto é, nestas condições, existe maior liberdade de movimento e as restrições são impostas apenas pela geometria da via. Além disso, com a baixa densidade do tráfego, o delineamento gerado pelos próprios veículos na via é menor, situação na qual o balizamento entre veículos praticamente inexiste e a freqüência de saída de pista é função primariamente da quantidade de veículos sujeitos as saídas de pista. Portanto, a freqüência de saídas de pista aumenta com o aumento do volume de tráfego.

Conforme aumenta o volume de veículos, os espaços entre eles diminuem, exigindo maior atenção dos motoristas, que passam a ficar mais alertas. Com maior quantidade de veículos, o delineamento da via gerado por eles aumenta, e os motoristas tendem, conscientemente ou não, a se balizarem pelos veículos da frente. Portanto, para volumes de 4000 veíc/dia à 6000 veíc/dia, a freqüência de saídas de pista diminui com o aumento do volume de tráfego.

Por outro lado, com mais veículos na via, o conflito entre eles aumenta, aumentando a probabilidade de contato entre eles ou de manobras evasivas. O motorista precisa dividir sua atenção voltada para a pista com as manobras realizadas por outros motoristas. Portanto, conforme aumenta o volume de tráfego, a freqüência de saídas de pista também aumenta. Além disso, as saídas de pista se tornam mais severas, pois as manobras evasivas geram ângulos de saídas maiores, aumentando a porcentagem de veículos que cruzam o canteiro central.

É importante destacar que a taxa de saída de pista, definida pela tangente do ângulo da curva da freqüência de saída de pista com a abscissa, é constante para volumes de tráfego inferiores a 4000 veíc/dia e superiores a 6000 veíc/dia, mas maior para volumes de tráfego menores. 


\subsubsection{Fatores de ajuste da frequência básica de saídas de pista}

Em ambos os programas de computador estudados, em relação aos valores básicos, as estimativas de frequência de saídas de pista adotadas incluem ajustes para o efeito de curvas horizontais e rampas verticais. Estes fatores majoram a frequência de saídas de pista em curvas mais acentuadas e em rampas mais íngremes. A Figura 3-3 ilustra os fatores de ajuste considerados no RSAP e no ROADSIDE. Segundo o NCHRP Report 492, estes ajustes baseiamse nos estudos de WRIGHT e ROBERTSON (1976).

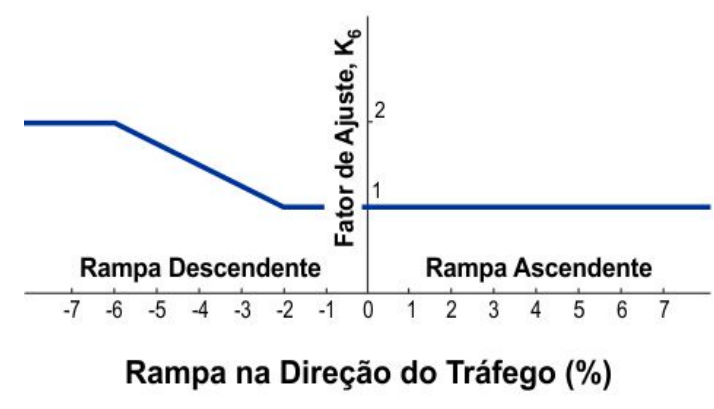

Rampa na Direção do Tráfego (\%)

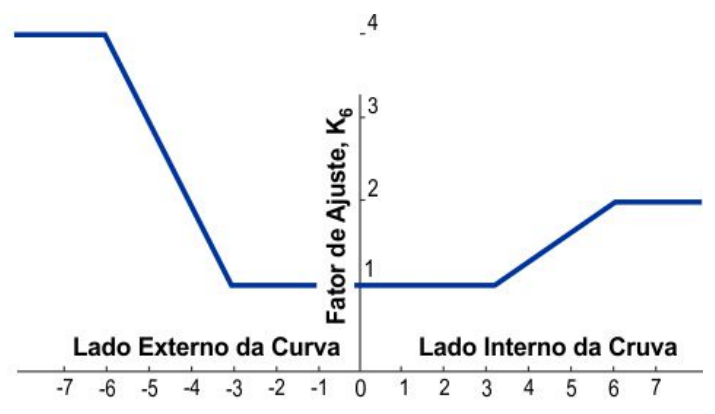

Curvatura (graus)

Figura 3-3 - Fatores de ajuste para curvas horizontais e rampas verticais (adaptado NCHRP Report 492)

Além deste ajuste, o RSAP permite que o usuário entre com outro fator de ajuste manual para incorporar efeitos como, por exemplo, a presença constante de policiamento em uma dada seção, que pode induzir a uma freqüência menor de saídas de pista.

Portanto, pelo menos um aspecto negligenciado nas recomendações tradicionais do RDG (2006 ou suas versões anteriores) e nos que o seguem é introduzido: o efeito das rampas verticais na frequência das saídas de pista. Note-se que é relevante apenas em declives superiores a $2 \%$, majorando a taxa de saídas de pista em até $100 \%$ nos declives iguais ou superiores a $6 \%$ (variando o efeito na taxa de saídas de pista linearmente entre $2 \%$ e $6 \%$ ).

\subsubsection{Características das saídas de pista}

Além da freqüência de saídas de pista, HUTCHINSON e KENNEDY (1967) estudaram as características das saídas de pista definidas em termos do ângulo e da extensão lateral e longitudinal das saídas de pista. A análise das características das saídas de pista considerou os 
dados das rodovias Interstate 74 e Interstate 57 limitados às saídas não intencionais com movimentos laterais superiores a $0,9 \mathrm{~m}$. As distribuições dos ângulos de saídas de pista, da extensão longitudinal e lateral das saídas de pista encontradas pelos autores estão representadas nas Figura 3-4, Figura 3-5, Figura 3-6, respectivamente. Na Tabela 3-2 estão os parâmetros estatísticos associadas às características das saídas de pista do estudo.

Tabela 3-2 - Parâmetros estatísticos associados às características das saídas de pista (HUTCHINSON e KENNEDY, 1967)

\begin{tabular}{|c|c|c|c|c|c|c|c|c|c|c|c|c|}
\hline \multirow{2}{*}{ Parâmetros } & \multicolumn{3}{|c|}{ Números } & \multicolumn{3}{|c|}{ Média } & \multicolumn{3}{|c|}{ Desvio Padrão } & \multicolumn{3}{|c|}{$\begin{array}{l}\text { Intervalo de confiança } \\
\text { (Coef. Conf. }=0,96)\end{array}$} \\
\hline & 157 & 174 & $\begin{array}{c}157 \mathrm{e} \\
174\end{array}$ & 157 & 174 & $\begin{array}{l}157 \text { e } \\
174\end{array}$ & 157 & 174 & $\begin{array}{c}157 \mathrm{e} \\
174\end{array}$ & 157 & 174 & 157 e 174 \\
\hline Ângulo de saída de pista $\left({ }^{\circ}\right)$ & 25 & 289 & 314 & 10,2 & 11,0 & 10,9 & 9,6 & 11,1 & 11,0 & $\begin{array}{c}6,2 \text { até } \\
14,1\end{array}$ & $\begin{array}{c}9,7 \text { até } \\
12,2\end{array}$ & $\begin{array}{c}9,7 \text { até } \\
12,1\end{array}$ \\
\hline Extensão da saída de pista $(\mathrm{m})$ & 25 & 290 & 315 & 87,6 & 87,3 & 87,3 & 60,6 & 65,1 & 64,8 & $\begin{array}{l}63 \text { até } \\
113\end{array}$ & $\begin{array}{l}80 \text { até } \\
95\end{array}$ & 80 até 95 \\
\hline $\begin{array}{l}\text { Extensão lateral da saída de } \\
\text { pista }(m)\end{array}$ & 25 & 296 & 321 & 6,9 & 6,9 & 6,9 & 3 & 3,3 & 3,3 & $\begin{array}{c}5,7 \text { até } \\
8,1\end{array}$ & $\begin{array}{c}6,6 \text { até } \\
7,2\end{array}$ & $\begin{array}{c}6,6 \text { até } \\
7,2\end{array}$ \\
\hline
\end{tabular}

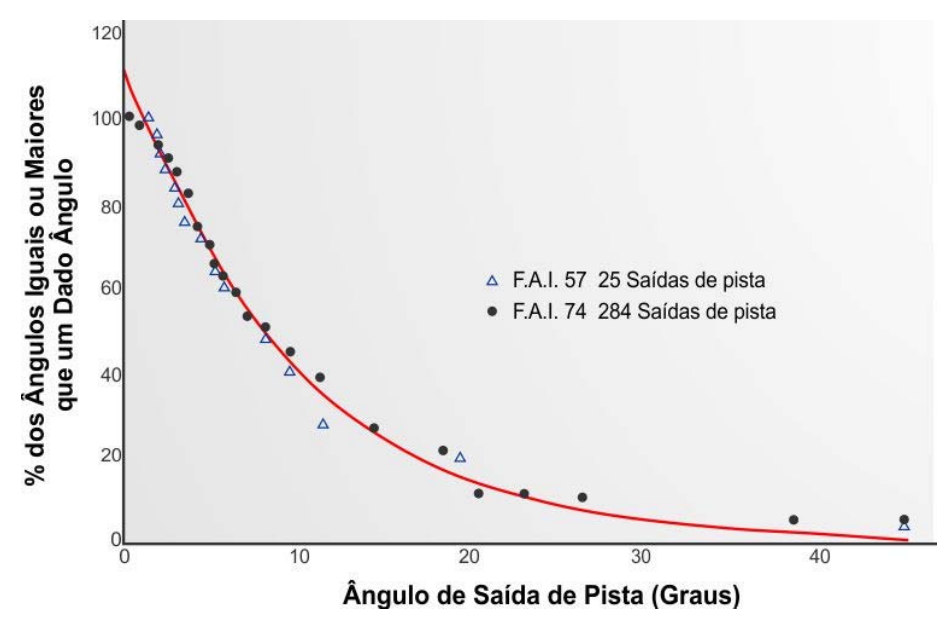

Figura 3-4 - Distribuição do ângulo de saída de pista (HUTCHINSON e KENNEDY, 1967)

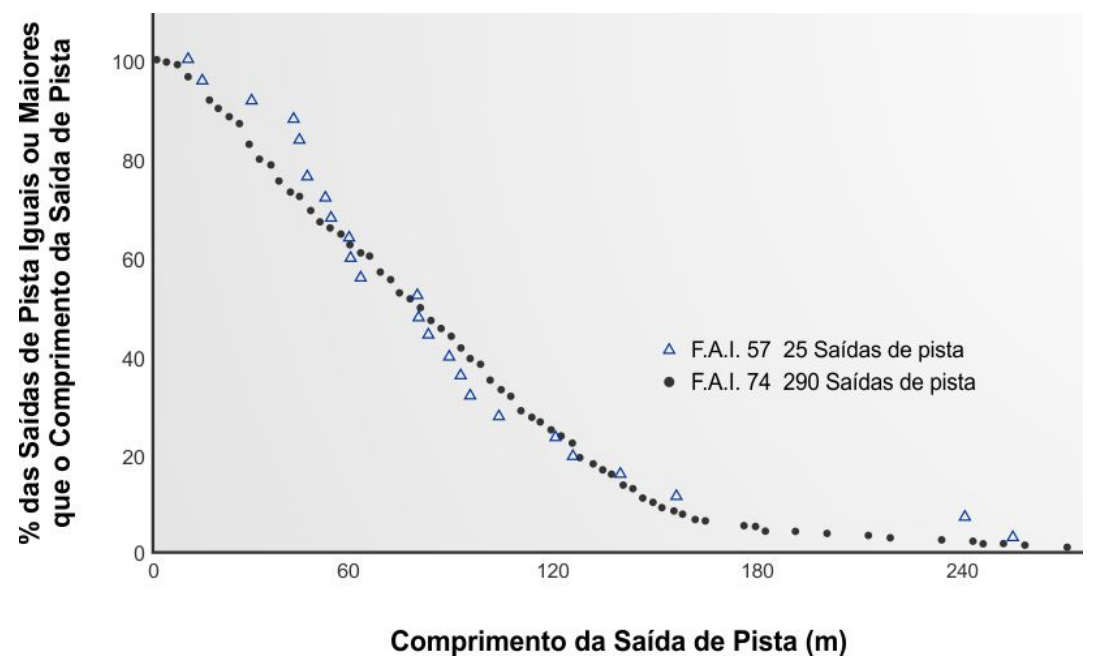

Figura 3-5 - Distribuição da extensão longitudinal de saída de pista (HUTCHINSON e KENNEDY, 1967) 


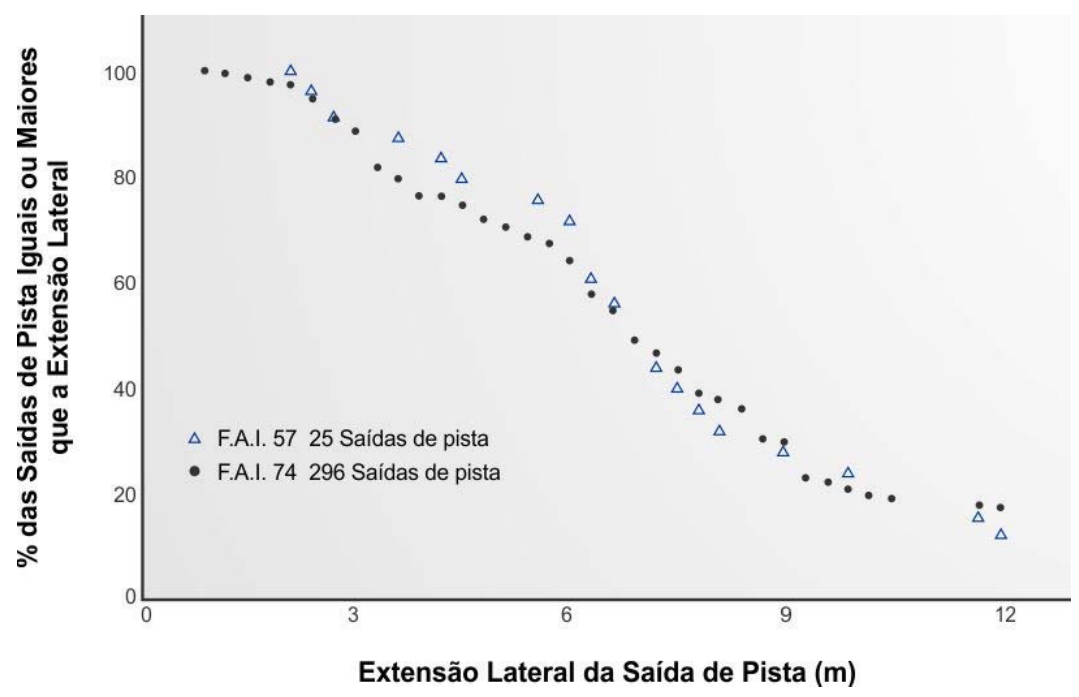

Figura 3-6 - Distribuição da extensão lateral de saída de pista (HUTCHINSON e KENNEDY, 1967)

HUTCHINSON e KENNEDY (1967) observaram que mudanças na inclinação da curva de distribuição da extensão lateral ocorriam aproximadamente na mesma distância lateral que as mudanças de inclinação das seções transversais, como ilustrado na Figura 3-7. Quando um veículo move-se para a esquerda da sua trajetória intencional, o motorista esterça o volante de modo a impor uma curva horizontal para a direita, na tentativa da recuperação da trajetória, porém defronta-se com a primeira metade do canteiro central, que impõe uma superelevação negativa para esta manobra.

Como mostra a Figura 3-7, para o intervalo de 1,0m à 2,4m, a curva de distribuição da extensão lateral da saída de pista é praticamente horizontal, indicando que poucos motoristas conseguem retomar o controle do veículo uma vez que a roda dianteira esquerda deixa os 1,0m do refúgio.

Para o intervalo de $1,0 \mathrm{~m}$ a $3,5 \mathrm{~m}$, região da transição da ombreira para o talude descendente do canteiro central, percebe-se pela figura que muitos motoristas conseguem controlar o veículo, apesar da mudança de inclinação na seção transversal para uma situação mais desfavorável.

A explicação, segundo HUTCHINSON e KENNEDY (1967), está associada ao tempo de reação do motorista. Supondo velocidade de $95 \mathrm{~km} / \mathrm{h}$, ângulo de saída de pista de 7,5 e $1 \mathrm{~s}$ de tempo de reação, o veículo percorreria lateralmente uma distância de aproximadamente $3,5 \mathrm{~m}$. 
Para o intervalo de 3,5 m a 6,0 m, a curva de distribuição da extensão lateral é mais suave, indicando que poucos veículos conseguem retomar o controle do veículo na região de maior superelevação negativa formada pelo talude do canteiro central.

Após os 6,0 m, a inclinação da curva de distribuição torna-se mais inclinada, devido à superelevação positiva formada pelo talude ascendente do canteiro central, provendo oportunidade aos motoristas de retomarem o controle do veículo.

Por fim, na distância superior a mudança de inclinação do talude ascendente do canteiro central para a ombreira da pista oposta, a curva de distribuição da extensão lateral torna-se mais suave devido à menor superelevação positiva provida pela ombreira da pista de sentido oposto.

Na Figura 3-7, a reta tracejada indica a curva teórica que estima a distribuição da extensão lateral da saída de pista se a inclinação transversal da ombreira fosse estendida. Considerando a curva teórica, praticamente todos os veículos recuperariam o controle em uma distância de até $9 \mathrm{~m}$.
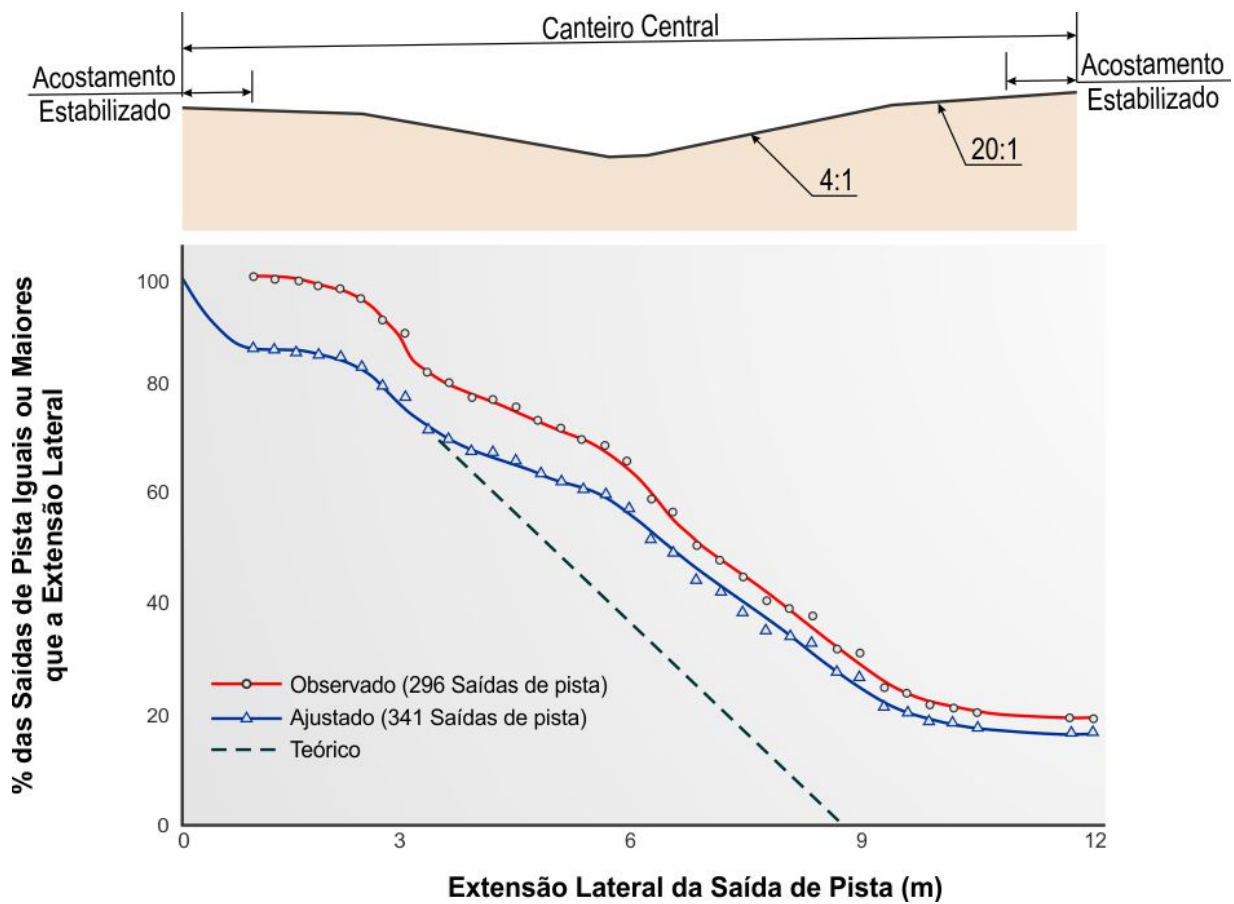

Figura 3-7 - Distribuição da extensão lateral e seção tranversal do canteiro central (HUTCHINSON e KENNEDY, 1967)

No ROADSIDE, a velocidade e o ângulo de saída de pista são baseados em distribuições hipotéticas convenientes. As Figura 3-8, Figura 3-9 e Figura 3-10 mostram respectivamente as curvas de distribuição das velocidades, dos ângulos de saídas de pista inicial e remodelado. 
A distribuição de velocidades de saída de pista é relacionada com a velocidade de projeto. Define-se uma velocidade de referência (RS) igual a $90 \%$ da velocidade de projeto e uma distribuição linear esquemática em 12 células de $4 \mathrm{~km} / \mathrm{h}$ (de RS-16km/h a RS+24km/h).

A distribuição do ângulo de saída de pista adota uma curva hipotética de distribuição de probabilidade onde a máxima probabilidade ocorre para ângulo de saída igual a zero, e as probabilidades decrescem linearmente até o valor $39^{\circ}$, definindo células de $3^{\circ}$ (até 13 células). Entretanto, o valor máximo do ângulo de saída é limitado pela velocidade de saída de pista, baseado no modelo de massa pontual representado na Figura 3-11, e para um determinado valor máximo de ângulo, toda a curva de distribuição do ângulo de saída é remodelada. Pode-se ver que este perfil inicial é compatível com a Figura 3-4, com a simplificação decorrente da hipótese de variação linear. No entanto, o ROADSIDE ajusta o perfil inicial (Figura 3-11) baseado na hipótese de um ângulo máximo de saída (compatível com o atrito limite com o pavimento).

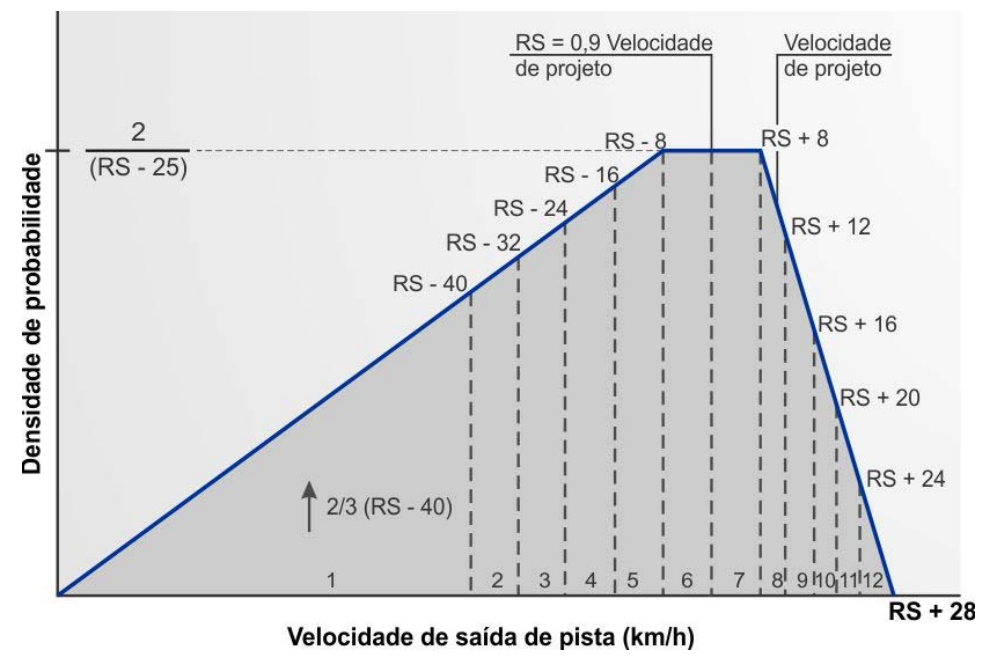

Figura 3-8 - Distribuição hipotética da velocidade adotada pelo ROADSIDE

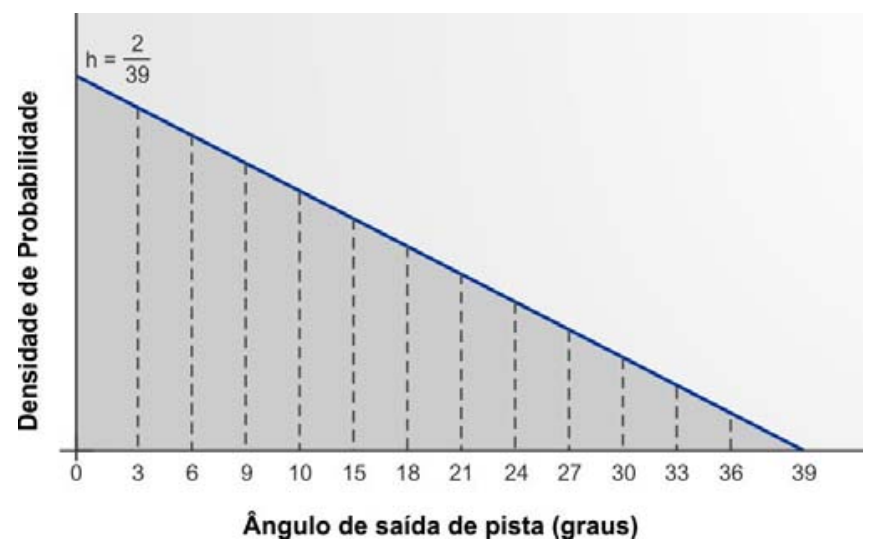

Figura 3-9 - Distribuição do ângulo de saída de pista adotada pelo ROADSIDE 


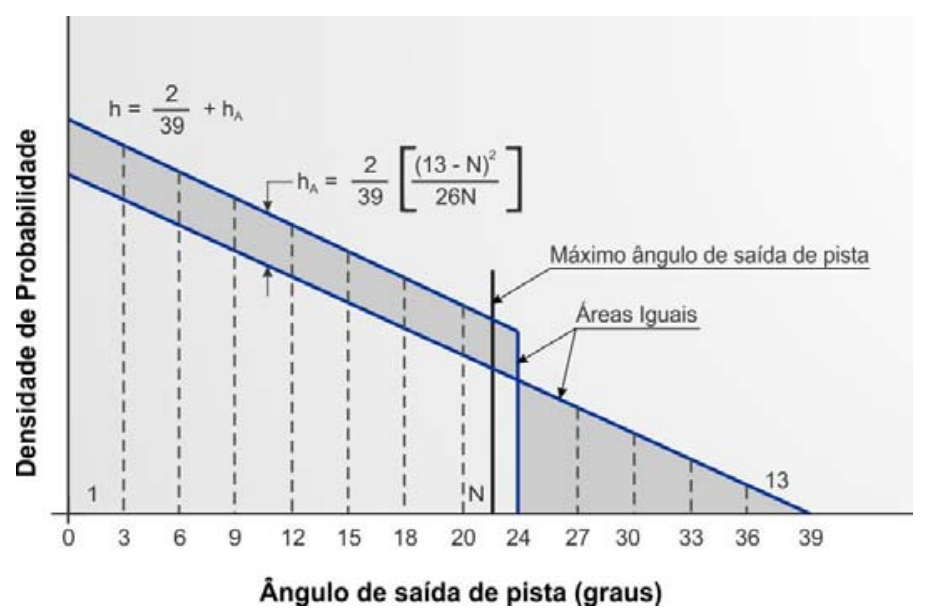

Figura 3-10 - Distribuição remodelada do ângulo de saída de pista adotada pelo ROADSIDE

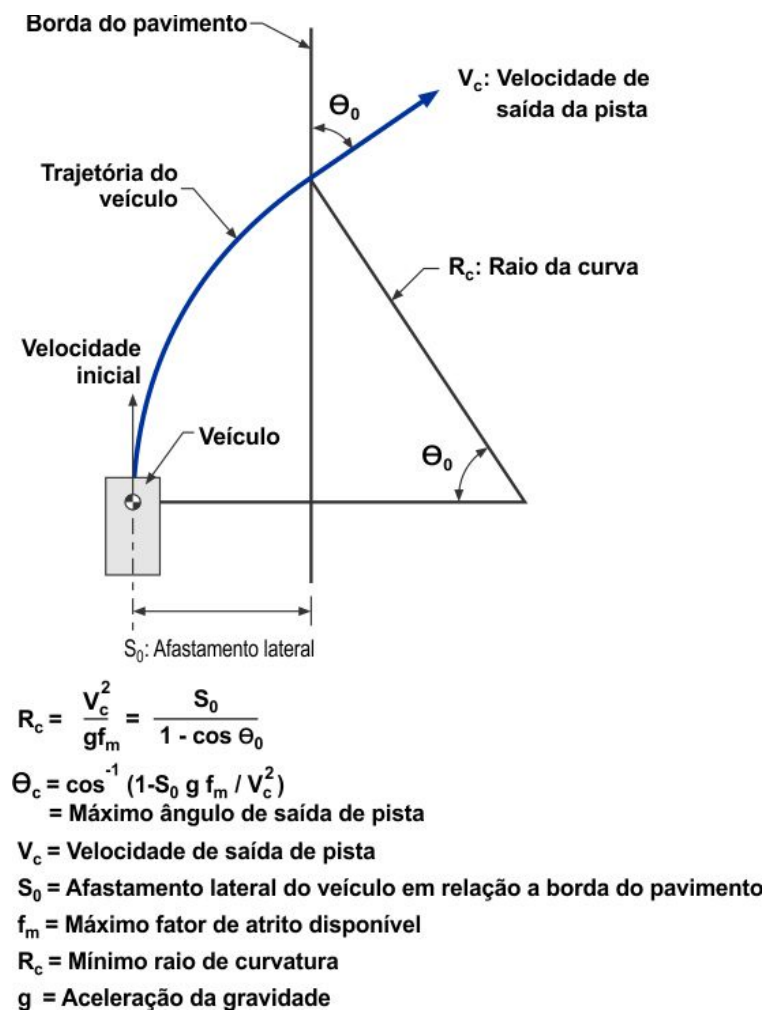

Figura 3-11 - Ângulo máximo de saída no modelo de massa pontual (adaptado NCHRP 492)

Devido à consideração de trajetória retilínea durante a saída de pista, o ângulo de impacto é considerado igual ao ângulo de saída. Em trechos curvos da via, adota-se uma correção igual ao grau de curva $\left(+/-\mathrm{c} / \mathrm{R}^{*} 180^{\circ} / \pi\right)$ para $\mathrm{c}=100 \mathrm{ft}$ ( ou $30 \mathrm{~m}$ ).

Para a velocidade de impacto, o ROADSIDE considera uma desaceleração de $3,92 \mathrm{~m} / \mathrm{s}^{2}(0,4 . \mathrm{g})$ a partir da velocidade de saída de pista. Com relação à extensão lateral da saída de pista, o ROADSIDE, através da combinação da velocidade e ângulo de saída de pista e da presunção de desaceleração de $3,9 \mathrm{~m} / \mathrm{s}^{2}$, considera que a máxima extensão de saída é: 


$$
Y_{m}=L_{m} \operatorname{sen} \phi_{e}
$$

onde,

$$
\mathrm{L}_{\mathrm{m}}=\mathrm{V}_{\mathrm{e}}^{2} / 2 \cdot \mathrm{b}
$$

$\mathrm{V}_{\mathrm{e}}=$ velocidade de saída de pista,

$\mathrm{b}=$ desaceleração $\left(3,9 \mathrm{~m} / \mathrm{s}^{2}\right)$,

$\phi_{\mathrm{e}}=$ ângulo de saída de pista.

A partir deste valor máximo, o ROADSIDE utiliza uma distribuição cossenoidal para atribuir probabilidade para cada extensão lateral entre a borda da faixa de rolamento e o valor máximo:

$$
P\left[Y>Y_{d}\right]=0,5+0,5 \cos \left(\frac{\pi Y_{d}}{Y_{m}}\right) \text { para } \mathrm{Y}_{\mathrm{d}}<\mathrm{Y}_{\mathrm{m}} \text {, e } P\left[Y>Y_{d}\right]=0 \text { para } \mathrm{Y}_{\mathrm{d}} \geq \mathrm{Y}_{\mathrm{m}}
$$

Onde:

$Y_{\mathrm{d}}$ : afastamento lateral do obstáculo em relação à borda da pista. Esta equação deve ser vista como uma aproximação dos dados mostrados na Figura 3-6, que permite fazer com que a extensão de saída seja função da velocidade de saída (como também do atrito de rolamento, caso adote-se uma hipótese alternativa em relação à frenagem assumida de $3,9 \mathrm{~m} / \mathrm{s}^{2}$ ).

No ROADSIDE, considera-se apenas um veículo alinhado com a velocidade de saída. A orientação do veículo no momento do impacto não é considerada (admitindo implicitamente a mesma orientação do veículo na pista). Apesar do ROADSIDE não considerar a orientação do veículo durante a saída de pista, o programa permite que seja inserido a largura do arraste diretamente pelo usuário.

No RSAP, tanto a distribuição de velocidades quanto de ângulos de impacto é obtida de dados empíricos. Conforme NCHRP Report 492, reconstruções de acidentes mostraram que os ângulos de impacto em condições reais podem exceder o valor limite determinados pelo modelo de massa pontual por uma grande margem. Assim, o RSAP incorpora curvas de distribuição de velocidade 
e ângulo de impacto geradas a partir de dados de reconstrução de acidentes, relatados em MAK, SICKING e ROSS (1986).

No RSAP, a distribuição lateral da saída de pista é baseada na re-análise do estudo de Cooper, com a exclusão dos dados referentes à extensão de 0 à $4 \mathrm{~m}$. Esta exclusão se deve à subestimação das saídas de pista devido a dificuldade de se observar trilhas de roda em acostamentos pavimentados. Assim, a curva de distribuição da extensão lateral foi obtida da re-análise dos dados de Cooper e da premissa de que esta distribuição pode ser representada pelo modelo de regressão abaixo:

$$
\ln (Y)=a+b X
$$

onde,

$\mathrm{Y}=$ porcentagem que excede a distância lateral $\mathrm{X}$

$\mathrm{X}=$ distância lateral

$a, b=$ coeficientes da regressão

Os valores de extensão lateral de 0 à $4 \mathrm{~m}$ foram extrapolados a partir do modelo acima. A Figura 3-12 ilustra a curva de distribuição de probabilidade da extensão lateral utilizada no RSAP.

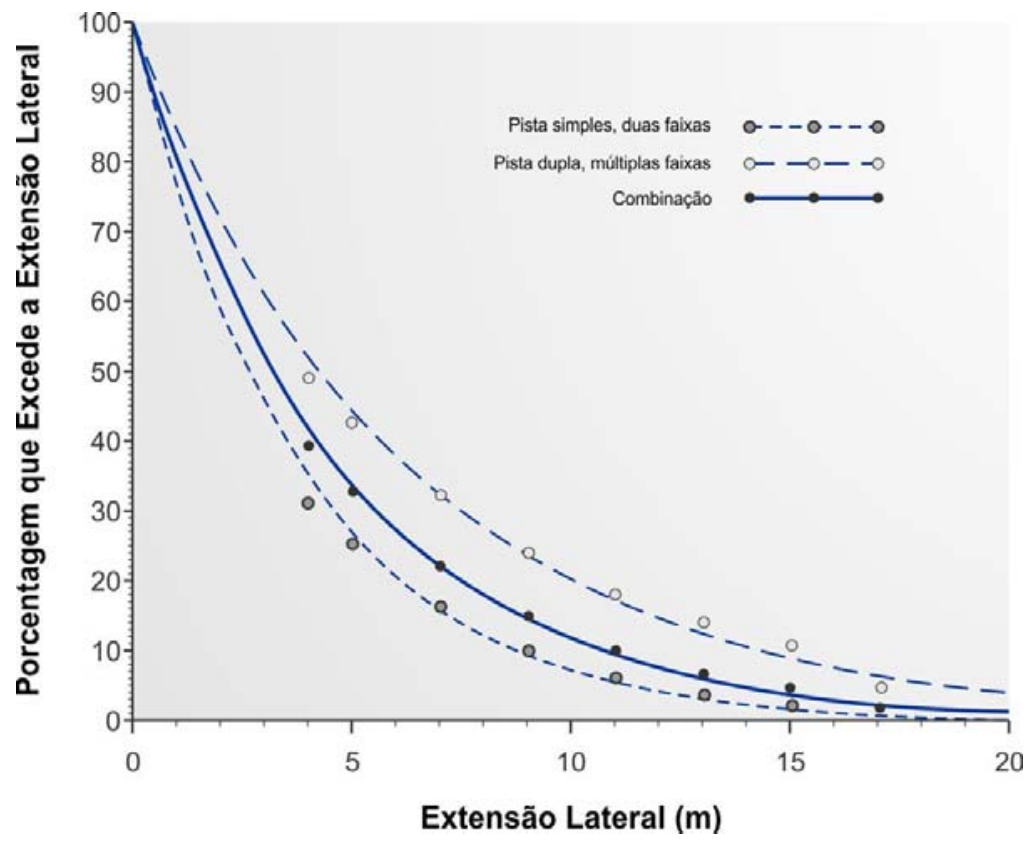

Figura 3-12 - Curva de distribuição da extensão lateral (RSAP) 
Por outro lado, o RSAP considera o ângulo e a velocidade de saída de pista igual às da condição de impacto. Uma crítica que poderia ser feita ao RSAP é que, se a velocidade de impacto é admitida como sendo igual à velocidade de saída de pista, isto implicaria na desconsideração da tentativa de frenagem por parte do motorista. E se também é considerado que o ângulo de saída de pista é igual ao ângulo de impacto, isto implica em trajetória retilínea e, portanto, não há tentativa de manobra de retorno à pista. Estes dois aspectos tornariam incoerente o formato da curva de distribuição da extensão lateral da saída de pista adotada pelo RSAP. As hipóteses podem ser consideradas conservativas (prevendo acidentes mais graves).

No RSAP, são considerados 12 tipos de veículos, desde carros pequenos de passeio até caminhões com semi-reboques. São consideradas também diversas orientações do veículo na trajetória da saída de pista, baseado em dados de acidentes envolvendo choque com postes, luminárias e suportes de sinalização. A Figura 3-13 ilustra a distribuição das orientações do veículo na trajetória da saída de pista. Estas orientações são medidas com relação à direção da saída de pista, conforme esclarece a Figura 3-14.

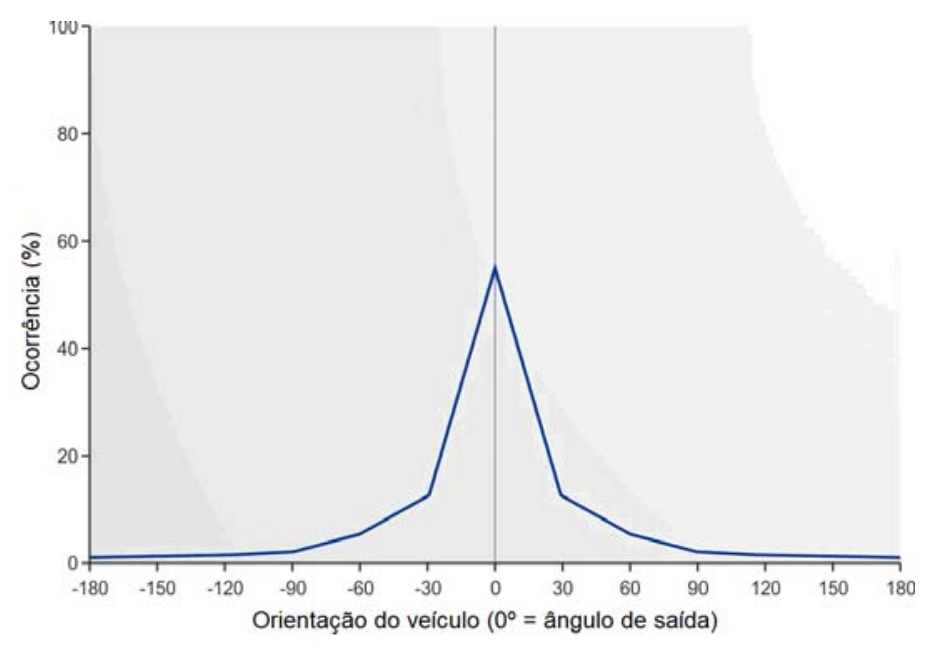

Figura 3-13 - Distribuição da orientação do veículo 


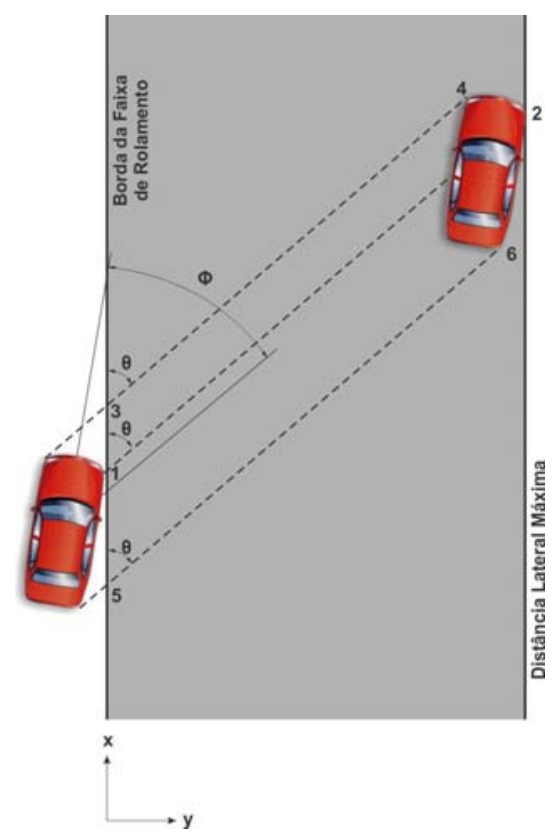

Figura 3-14 - Orientação do veículo em relação ao ângulo de saída de pista

A orientação do veículo é útil para se determinar o arraste do veículo, que por sua vez é utilizada para se determinar a probabilidade do veículo desgovernado chocar-se com um obstáculo. Em outras palavras, se existe sobreposição da envoltória de risco (definida no tópico a seguir) com a mancha de arraste do veículo, poderá haver choque, dependendo da extensão lateral da saída de pista e da posição do obstáculo em relação à pista. Outra importância relacionada à orientação do veículo é a sua relação com a severidade do impacto. Todavia, esta relação não está incorporada no RSAP.

As diversas características das saídas de pista (velocidade, o ângulo de saída, o tipo e orientação do veículo) são também consideradas na determinação da velocidade de impacto e da energia decorrente, contrapondo-as às características dos obstáculos existentes ou dos dispositivos de proteção interpostos. Este aspecto será discutido adiante.

\subsection{PREVISÃO DA PROBABILIDADE DE CHOQUE}

Nos modelos compreensivos, a previsão da probabilidade de choque decorrente das saídas de pista é obtida aplicando o conceito de envoltória de risco.

A envoltória de risco é a área definida pela projeção geométrica do obstáculo sobre a via, considerando o ângulo de saída de pista e a orientação do veículo. Todavia, para ocorrer o 
choque, não basta que o veículo desgovernado saia da pista dentro da envoltória de risco. Outra condição necessária para ocorrência do choque é que o veículo desgovernado percorra uma extensão suficiente para alcançar o obstáculo. Portanto, a probabilidade de um choque ocorrer é a probabilidade de existir uma saída de pista dentro da envoltória de risco e da saída de pista ter uma extensão suficiente para atingir o obstáculo.

A formulação baseada no conceito na envoltória de risco está ilustrada na Figura 3-15 tendo sido originalmente proposta por GLENNON (1974). Nesta formulação a envoltória de risco é subdividida em três zonas; a zona 1 abrange a área correspondente à face do obstáculo, perpendicular a pista; a zona 2 corresponde ao canto do obstáculo; e a zona 3 corresponde a lateral do obstáculo, paralela à pista.

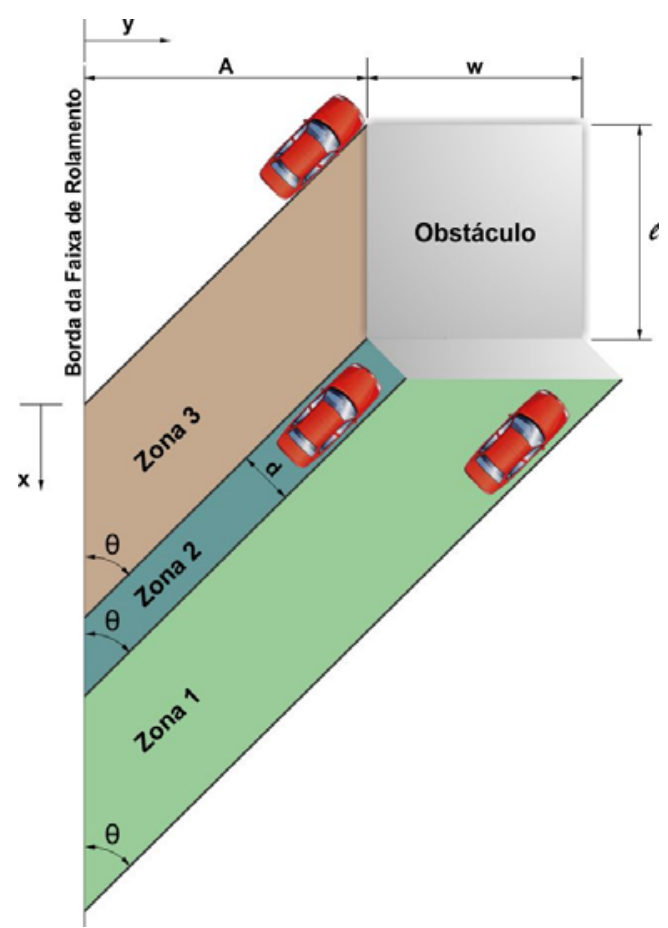

Figura 3-15 - Envoltória de risco

Desta forma, o cálculo da probabilidade de ocorrer o choque, dado uma saída de pista, é a somatória das probabilidades de ocorrer o choque dentro de cada uma das três zonas que constituem a envoltória de risco. Portanto, se $\mathrm{P}_{\mathrm{Zi}}$ é a probabilidade de ocorrer o choque na zona $\mathrm{i}$, então a probabilidade de ocorrer o choque, dado uma saída de pista é:

$$
P(C \mid E)=\sum_{i=1}^{3} P_{Z i}
$$


Adotando uma função genérica $\mathrm{f}(\mathrm{y})$ para a probabilidade de ocorrer uma determinada extensão lateral de saída de pista, perpendicular a ela, e supondo um obstáculo pontual, apenas para efeito de simplificação, então a probabilidade de ocorrer um choque considerando que o veículo está na envoltória de risco é a probabilidade da extensão lateral da saída de pista ser maior ou igual à distância “a” do obstáculo à pista:

$$
p=\int_{a}^{\infty} f(y) d y
$$

A seguir, será mostrado o cálculo da probabilidade de choque, dado uma saída de pista, para cada uma das três zonas isoladamente, apenas por questão de entendimento, e posteriormente será apresentada a formulação completa do modelo proposto por GLENNON (1974). Para isso, admitir-se-á que o afastamento lateral do obstáculo em relação à borda da faixa de rolamento é "A" e que as saídas de pista ocorrem sob um ângulo $\theta$.

O modelo adota como premissa que a saída de pista ocorre em linha reta. A adoção de uma trajetória curvilínea tornaria o modelo demasiadamente complexo, e ainda, a falta de informação sobre o comportamento do veículo e do motorista após a saída de pista não permitiram o desenvolvimento de modelos mais completos. A dedução será feita da zona 3 para a zona 1, por questão de complexidade progressiva.

\section{$\underline{\text { Zona } 3}$}

Supondo que o ponto de saída de pista do veículo desgovernado é o ponto genérico $\mathrm{P}_{3}$ da Figura 3-16 distante " $\mathrm{x}$ " da origem, com $0<\mathrm{x}<1$, então a probabilidade $\mathrm{P}_{\mathrm{Z3}}$ :

$$
P_{Z 3}=\int_{0}^{l} \int_{A}^{\infty} f(y) \cdot d y \cdot d x=l \cdot \int_{A}^{\infty} f(y) \cdot d y
$$

Nota-se que como a distância do obstáculo à pista é constante, então a probabilidade do ocorrer o choque resume-se a probabilidade do veículo atingir a extensão lateral maior ou igual a $A$ multiplicado pelo lado do obstáculo de comprimento $l$. 


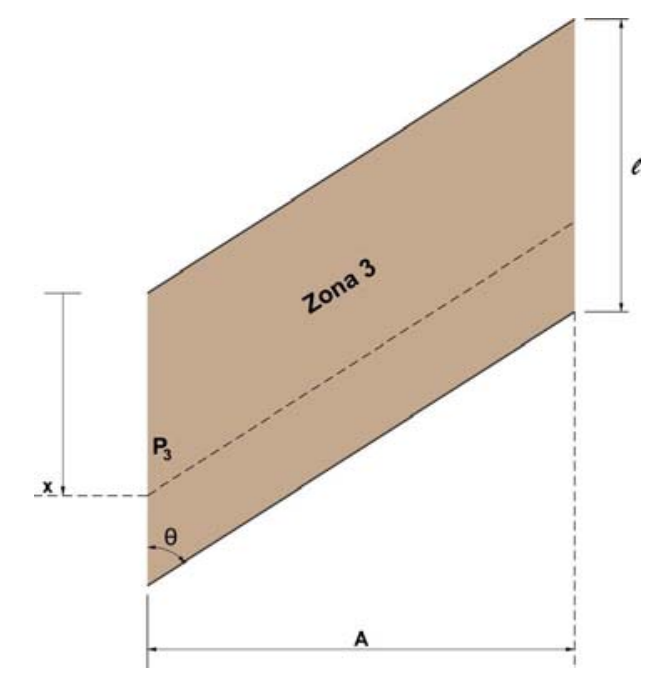

Figura 3-16 - Zona 3 da envoltória de risco

\section{$\underline{\text { Zona } 2}$}

Se o veículo desgovernado sair da pista no ponto $\mathrm{P}_{2}$ (ver Figura 3-17) distante $x$ da origem, com 1 $<\mathrm{x}<1+\mathrm{d} / \operatorname{sen} \theta$, o ponto correspondente no limite superior direito da zona 2 estará distante de $A+(x-l) \cdot \operatorname{sen} \theta \cdot \cos \theta$. Portanto, a probabilidade $\mathrm{P}_{\mathrm{Z} 2}$ é:

$$
P_{Z 2}=\int_{l}^{l+\frac{d}{\operatorname{sen} \theta}} \int_{A+(x-l) \operatorname{sen} \theta \cdot \cos \theta}^{\infty} f(y) \cdot d y \cdot d x
$$

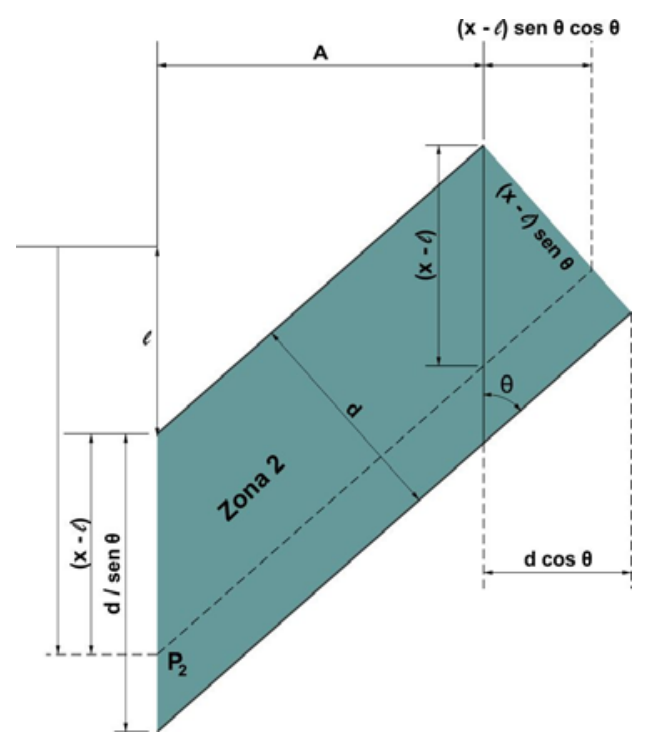

Figura 3-17 - Zona 2 da envoltória de risco

\section{Zona 1}


Se o veículo desgovernado sair no ponto $\mathrm{P}_{1}$ (ver Figura 3-18) distante " $\mathrm{x}$ " da origem, com $1+$ $\mathrm{d} / \operatorname{sen} \theta<\mathrm{x}<[1+\mathrm{d} / \operatorname{sen} \theta+\mathrm{w} / \operatorname{tg} \theta]$, o ponto correspondente no limite superior da zona 1 estará a uma distância de "A+d.cos $\theta+[\mathrm{x}-(1+\mathrm{d} / \operatorname{sen} \theta)] \cdot \operatorname{tg} \theta$ ". Portanto, a probabilidade $\mathrm{P}_{\mathrm{Zl}} \mathrm{e}:$

$$
P_{Z 1}=\int_{l+\frac{d}{\operatorname{sen} \theta}}^{l+\frac{d}{\operatorname{sen} \theta}+\frac{w}{\operatorname{tg} \theta}} \int_{A+d \cdot \cos \theta+\left(x-l-\frac{d}{\operatorname{sen} \theta}\right) \cdot \operatorname{tg} \theta}^{\infty} f(y) \cdot d y \cdot d x
$$

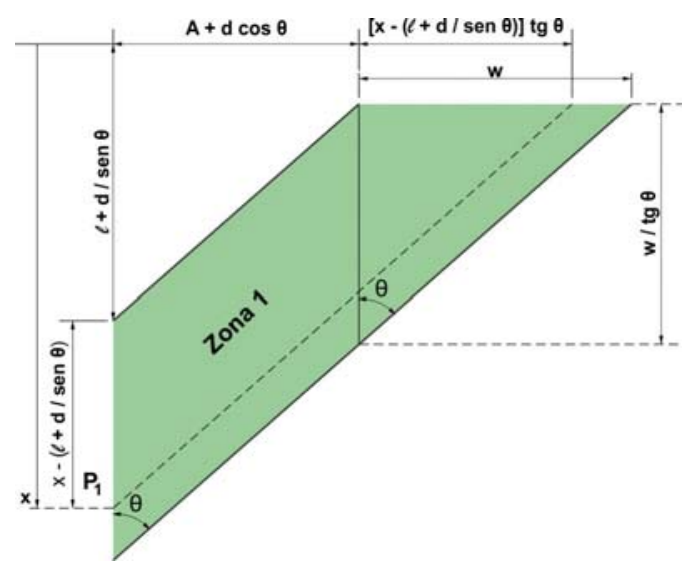

Figura 3-18 - Zona 1 da envoltória de risco

Assim, a probabilidade de choque, dado uma saída de pista, é:

$$
P(C \mid E)=l \cdot \int_{A}^{\infty} f(y) \cdot d y+\int_{l}^{l+\frac{d}{\operatorname{sen} \theta}} \int_{A+(x-l) \operatorname{sen} \theta \cdot \cos \theta}^{\infty} f(y) \cdot d y \cdot d x+\int_{l+\frac{d}{\operatorname{sen} \theta}}^{l+\frac{d}{\operatorname{sen} \theta}+\frac{w}{\operatorname{tg} \theta}} \int_{A+d \cdot \cos \theta+\left(x-l-\frac{d}{\operatorname{sen} \theta}\right) \cdot \operatorname{tg} \theta}^{\infty} f(y) \cdot d y \cdot d x
$$

Versões operacionais dessa formulação são incorporadas em procedimentos de cálculo manual como o proposto por GLENNON (2004) e pelo TAC (1999).

O conceito de índice de periculosidade, adotado por GLENNON (1974), baseado na formulação acima, resulta em: 


$$
H=\frac{E_{f} \cdot S}{5280}\left(l \cdot \int_{A}^{\infty} f(y) \cdot d y+\int_{l}^{l+\frac{d}{\operatorname{sen} \theta}} \int_{A+(x-l) \operatorname{sen} \theta \cdot \cos \theta}^{\infty} f(y) \cdot d y \cdot d x+\int_{l+\frac{d}{\operatorname{sen} \theta}}^{l+\frac{d}{\operatorname{sen} \theta}+\frac{w}{\operatorname{tg} \theta}} \int_{A+d \cdot \cos \theta+\left(x-l-\frac{d}{\operatorname{sen} \theta}\right) \cdot \operatorname{tg} \theta}^{\infty} f(y) \cdot d y \cdot d x\right)
$$

onde:

$\mathrm{H}$ : índice de periculosidade.

Ef: frequência de saídas de pista, em números de saídas por ano por milha.

S: índice de severidade (ou SI, como será visto adiante).

(Obs: o valor 5280 é a conversão de pés para milhas, pois as dimensões do obstáculo estão em pés)

Note-se que $\mathrm{E}_{\mathrm{f}}=\mathrm{QA} . \mathrm{P}(\mathrm{E})$ para um trecho L da rodovia, que neste caso é uma milha $(1,609 \mathrm{~km})$, com V separado por sentido, e $\mathrm{S}=\mathrm{P}(\mathrm{I} \mid \mathrm{C})$, definido anteriormente. GLENNON (1974) adota S como sendo o número de acidentes com vítima fatal e vítima não fatal pelo total de acidentes (ou seja, desconsidera os acidentes sem vítimas). Entretanto, o autor chama a atenção para o fato de que outras formas de mensurar a severidade do obstáculo podem ser utilizadas, dependendo do objetivo da análise.

Outro ponto interessante a ser destacado é a divisão, em zonas, da envoltória de risco. Obviamente, a separação da envoltória correspondente ao lado (zona 3) e face (zona 1) do obstáculo é necessária devido ao cálculo das probabilidades de choque ser diferente em cada zona, visto que o afastamento lateral de cada ponto da face não é constante em relação a borda da faixa de rolamento. Com relação à separação da parte da envoltória correspondente ao canto do obstáculo (zona 2), presume-se que o motivo é a gravidade do impacto, que intuitivamente é maior que o impacto contra o lado ou a face. Entretanto, GLENNON (1974), na expressão do índice de periculosidade, multiplica pelo mesmo índice de severidade as três parcelas da probabilidade de choque, muito provavelmente por falta de dados detalhados sobre a severidade do impacto para cada parte do obstáculo. Todavia, quando disponível, cada $\mathrm{P}_{\mathrm{Zi}}$ deve ser multiplicado pelo respectivo $\mathrm{S}_{\mathrm{i}}$, onde i é a zona em questão.

GLENNON (1974), para tornar o modelo matematicamente aplicável, faz algumas simplificações. Para a primeira integral dupla da equação (3-13), a simplificação consiste em considerar a extensão lateral do ponto de impacto como sendo aquele correspondente ao ponto médio do limite da zona 2 adjacente a borda da pista de rolamento. Assim, o valor $x$ - $l$ passa a ser 
$d /(2 \operatorname{sen} \theta)$ e a probabilidade da extensão lateral é multiplicada pela extensão paralela à pista correspondente a $d$, ou seja, $d / \operatorname{sen} \theta$. Então:

$$
P_{Z 2}=\frac{d}{\operatorname{sen} \theta} \cdot \int_{A+\frac{d \cdot \cos \theta}{2}}^{\infty} f(y) \cdot d y
$$

Outra simplificação ocorre com a segunda integral dupla da equação (3-13). O comprimento por onde pode ocorrer a saída de pista na zona 1, w / tg $\theta$, é subdividido em "n" pequenos incrementos e, por conseqüência, a dimensão "w" na zona 1 também é subdividida em " $n$ ". Assim, a probabilidade de choque relativo a zona 1 é a somatória das probabilidades de choque para cada subdivisão j.

Considerando o ponto médio, projetada em w, da subdivisão $\mathrm{j}$, para representar o local de impacto, a extensão lateral da saída de pista seria a média dos comprimentos relativos às subdivisões $\mathrm{j}$ e $\mathrm{j}-1, \frac{1}{2}\left(\frac{j w}{n}+\frac{(j-1) w}{n}\right)$, acrescida de $\mathrm{A}+\mathrm{d} \cdot \cos \theta$. Portanto, a probabilidade de choque relativo a zona 1 torna-se:

$$
P_{Z 1}=\frac{w}{n \cdot \operatorname{tg} \theta} \sum_{j=1}^{n} \int_{A+d \cdot \cos \theta+\frac{w(2 j-1)}{2 n}}^{\infty} f(y) \cdot d y
$$

Adotando um ângulo de saída de pista de $11^{\circ}$, largura do veículo de 6 pés $(1,8 \mathrm{~m})$ e que $\mathrm{E}_{\mathrm{f}}$ é a freqüência de saídas de pista por milha por ano, considerando cada sentido (QA=365.VDM/2), GLENNON (1974) propôs o seguinte modelo simplificado, em unidades imperiais, para a determinação do índice de periculosidade para uma direção da rodovia:

$$
H=\frac{E_{f} S}{10560}\left\{l \cdot P[y \geq A]+31,4 \cdot P[y \geq A+3]+\frac{5,14 w}{n} \sum_{j=1}^{n} P\left[y \geq A+6+\frac{w(2 j-1)}{2 n}\right] \cdot\right\}
$$

O modelo abaixo, apresentado no TAC (1999), é muito parecido com o modelo proposto por GLENNON (1974). O modelo proposto pelo TAC (1999) é utilizado para a determinação da freqüência de acidentes, enquanto que o proposto por GLENNON (1974) equivaleria à medida de perigo do local, pois incorpora a severidade do acidente. 


$$
C_{f}=\left(E_{f} / 2000\right)\left[(L+19,2) \cdot P[Y \geq A]+5,14 \sum_{J}^{W} P[Y \geq(A+1,8+(2 J-1) / 2)]\right]
$$

onde,

$\mathrm{C}_{\mathrm{f}}=$ freqüência de choques (choques/ano, por km)

$\mathrm{E}_{\mathrm{f}}=$ número de saídas de pista/ano.direção

$\mathrm{L}=$ comprimento do obstáculo $(\mathrm{m})$

$\mathrm{W}=$ largura do obstáculo $(\mathrm{m})$

$\mathrm{A}=$ distância lateral do obstáculo à extremidade da faixa de rolamento $(\mathrm{m})$

$\mathrm{P}[\mathrm{Y} \geq \ldots]=$ probabilidade da extensão lateral da saída de pista ser maior que certo valor

$\mathrm{J}=$ número arredondado de $1 \mathrm{~m}$ que cabem na largura do obstáculo.

(onde adotou-se $\mathrm{w} / \mathrm{n}=1 \mathrm{~m}$, tendo-se $31,4 \mathrm{ft}=19,2 \mathrm{~m}$ e $6 \mathrm{ft}=1,8 \mathrm{~m}$, desprezando-se a parcela de choques de canto, com base no fator de conversão $1 \mathrm{ft}=0,3048 \mathrm{~m}$ para $1 \mathrm{mi}=5280 \mathrm{ft} \mathrm{e} 1 \mathrm{~km}=1000 \mathrm{~m}$ ).

Nota-se que o modelo acima não separa a parcela da envoltória de risco referente ao canto do objeto como no modelo de GLENNON (1974). Além disso, o TAC (1999) simplifica o modelo fazendo $\mathrm{n}=\mathrm{w}$, resultando em incrementos de $1 \mathrm{~m}$ no cálculo da probabilidade na face do obstáculo. Ambos os modelos podem ser aplicados manualmente.

Ambos os programas de computador revisados utilizam formulações semelhantes, incorporando o cálculo a cada acidente característico (ROADSIDE) ou aleatorizado (RSAP) analisado.

O ROADSIDE caracteriza um obstáculo através do afastamento lateral com relação à borda da pista, o comprimento do obstáculo paralelo a pista e a largura do obstáculo perpendicular a pista. O ROADSIDE não é capaz de analisar a situação em que um obstáculo pode constituir um escudo para outro, e quando existem diversos obstáculos, cada um é analisado separadamente e os custos dos acidentes devem ser somados manualmente.

Cada célula da matriz de condições de saída define-se pela velocidade e ângulo de saída (com a hipótese de frenagem, define-se a extensão da saída) e pelo tipo de veículo (a orientação do veículo é paralela ao sentido normal de tráfego ou é definida pelo analista). Portanto, para cada ponto potencial de saída pode-se avaliar se o obstáculo está na envoltória de risco da saída de pista e se a saída de pista alcançará a posição do obstáculo, resultando um acidente (ou não). 
A forma como o RSAP analisa o obstáculo é mais complexa. O RSAP além de analisar múltiplos obstáculos, ainda é capaz de determinar qual obstáculo é atingido primeiro, se o veículo pode penetrar e atravessar o obstáculo e ainda, determinar os impactos subseqüentes.

O RSAP determina qual obstáculo é atingido primeiro, de dois ou mais obstáculos localizados próximos uns dos outros, elegendo o mais próximo a faixa de rolamento. Entretanto, o fato do obstáculo estar mais próximo da faixa de rolamento não garante que será atingido primeiro, pois se deve considerar o ângulo de orientação do veículo.

O RSAP determina o atravessamento de um obstáculo por uma energia cinética limite de resistência ao impacto. Para considerar a penetração do veículo em uma barreira, por exemplo, o RSAP compara a severidade do impacto IS com o limite de contenção desta barreira.

O IS é análogo à energia cinética (transversal) e é calculado da seguinte forma:

$$
I S=\frac{1}{2} m(V \cdot \operatorname{sen} \theta)^{2}
$$

onde,

IS $=$ severidade do impacto

$\mathrm{m}=$ massa do veículo

$\mathrm{V}=$ velocidade do veículo

$\theta=$ ângulo de saída de pista.

Assim, se o IS for maior que a capacidade de contenção da barreira, em termos de limite de contenção, considera-se que o veículo penetrou na barreira. A análise da penetração de outros obstáculos seria obtida de forma análoga.

Após a penetração do primeiro obstáculo, o RSAP determina a velocidade do veículo após este impacto subtraindo a energia necessária para rompê-lo da energia total inicial, resultando na velocidade associada à energia remanescente. Assim, inicia-se novamente o ciclo de análise até que não haja mais obstáculos ou até que não haja penetração. 
A determinação da envoltória de risco de cada saída de pista (sorteada aleatoriamente ou correspondente a uma célula da matriz de características) é a parte mais trabalhosa do procedimento de cálculo. Os procedimentos simplificados para aplicação manual normalmente assumem uma velocidade, um ângulo de saída, um tipo de veículo e uma orientação (alguns poucos casos podem naturalmente ser analisados e a ponderação deve então considerar a frequência relativa de cada tipo de evento).

\subsection{PREVISÃO DA SEVERIDADE E CUSTO DO ACIDENTE}

Uma vez que a saída de pista resultou em choque, a severidade deste evento deve ser estimada. A severidade é talvez o mais importante parâmetro em uma análise custo-benefício, pois está intimamente relacionada aos custos dos acidentes. Em princípio, em ambos os programas, a questão pode ser representada pela transformação da severidade de impacto (IS) em um índice de severidade (SI) do choque decorrente, considerando a rigidez e outras características do obstáculo (ou dispositivo de proteção) atingido. O índice de severidade (SI) é uma variável intermediária da qual ambos os programas derivam a severidade dos acidentes decorrentes, e está relacionado ao tipo de obstáculo e as condições de impacto.

O propósito do SI é comparar as conseqüências do acidente dentre diversos obstáculos, auxiliando na avaliação de medidas para a redução dos custos dos acidentes de trânsito. Como cada SI está relacionado à probabilidade de danos (por exemplo, fatal, não fatal e sem vítima) e cada dano está associado à um custo social, a troca de um obstáculo com SI menor que o outro como, por exemplo, colocar uma defensa metálica em frente a uma árvore, pode resultar em redução do custo social dos acidentes de trânsito, apesar de haver um aumento na freqüência de acidentes.

Uma discussão e revisão de valores para o SI foi realizada por TURNER e HALL (1994). O índice de severidade associado a um tipo de obstáculo em determinada condição de impacto pode ser determinada através do julgamento de especialistas, dados de acidentes ou análise cinemática, dependendo da conveniência e disponibilidade de dados ou recursos.

A determinação do SI através do julgamento de especialistas consiste na atribuição do SI a cada tipo de obstáculo ou característica da via, de acordo com a intuição e experiência dos especialistas (engenheiro rodoviário, policial rodoviário ou pesquisador), que podem ter como 
base a comparação entre as conseqüências de impacto com diversos obstáculos. Segundo TURNER e HALL (1994), esta é a base para os valores de SI adotados pelo RDG (1989). Depreende-se também que foram a base dos estudos que levaram aos valores de SI tabelados no RDG (1996).

Serão apresentadas a seguir algumas das diferentes definições e métodos para determinar o SI .

A primeira definição seria a proposta por GLENNON (1974), onde o SI é obtido diretamente da proporção dos acidentes com vítimas para cada tipo de obstáculo (expresso como porcentagem).

A determinação do SI através dos dados de acidentes pode ser feita calculando-se a soma do número de acidentes fatais, com vítimas não fatais e sem vítimas, em termos de acidentes equivalentes sem vítima, onde o fator de equivalência pode ser relacionado ao custo social gerado por cada nível de gravidade. Portanto, pode ser expresso como:

$$
S I=\frac{c_{F} \cdot F+c_{I} \cdot I+P}{N}
$$

onde,

SI: índice de severidade;

F: número de acidentes com vítima fatal;

I: número de acidentes com vítima não fatal (ferido);

P: número de acidentes sem vítimas (ilesos);

$\mathrm{N}$ : número total de acidentes;

$\mathrm{c}_{\mathrm{F}}$ : fator de equivalência entre acidentes com vítimas fatais e sem vítimas;

c : fator de equivalência entre acidentes com vítimas não fatais e sem vítimas;

Esta foi a alternativa utilizada no estudo original de GLENNON e TAMBURRI (1967), que utilizaram os valores $c_{\mathrm{F}}=25$ e $c_{\mathrm{I}}=6$. GLENNON (1974) optou pela simplificação de adotar o SI como sendo igual à proporção de acidentes fatais e com feridos $(\mathrm{S})$, dispensando a ponderação pelos custos específicos:

$$
S=\frac{n^{\mathrm{o}} \text { de acidentes com vítimas fatais }+n^{\mathrm{o}} \text { de acidentes com vítimas não fatais }}{n^{\mathrm{o}} \text { total de acidentes }}
$$


O SI pode ainda ser obtido por análise dinâmica do acidente, baseado em limites toleráveis de aceleração, que são diferentes para cada um dos três eixos x, y e z (ou longitudinal, lateral e vertical, respectivamente). Através da determinação das acelerações nos eixos x, y e z em simulação computacional ou teste de impacto em escala real, pode-se determinar o SI do impacto com o obstáculo pela seguinte expressão, onde as acelerações são em termos de g (aceleração da gravidade) ou outra unidade consistente:

$$
\text { ASI }=\sqrt{\left(\frac{G_{\text {lon }}}{G_{x}}\right)^{2}+\left(\frac{G_{\text {lat }}}{G_{y}}\right)^{2}+\left(\frac{G_{\text {ver }}}{G_{z}}\right)^{2}}
$$

Onde,

ASI $=$ Índice de severidade de aceleração

$\mathrm{G}_{\text {lon }}=$ acelereção ocorrida segundo o eixo longitudinal;

$\mathrm{G}_{\text {lat }}=$ acelereção ocorrida segundo o eixo lateral;

$\mathrm{G}_{\mathrm{ver}}=$ acelereção ocorrida segundo o eixo vertical;

$\mathrm{G}_{\mathrm{x}}=$ acelereção tolerável segundo o eixo longitudinal;

$\mathrm{G}_{\mathrm{y}}=$ acelereção tolerável segundo o eixo lateral;

$\mathrm{G}_{\mathrm{z}}=$ acelereção tolerável segundo o eixo vertical;

Esta expressão segue o critério proposto por HYDE (1968) apud WEAVER, MARQUIS, OLSON (1975), onde os valores limites por eixo e o valor limite de severidade (chamado de índice de severidade de aceleração) foram obtidos de estudos de resistência humana em acidentes ou situações semelhantes (considerando o uso ou não de cintos de segurança ou outros dispositivos de proteção ao ocupante do veículo).

Os valores de aceleração teriam de ser obtidos da análise da dinâmica do acidente. A simplificação básica deste critério é a de utilizar as acelerações do veículo no acidente, dispensando a análise da dinâmica produzida sobre os ocupantes do veículo. Naturalmente, a incorporação deste outro aspecto pode ser buscada, se considerada viável. No entanto, os dados de aceleração apenas estão disponíveis quando fornecidos por resultados de modelos computacionais ou medidas de testes de impacto.

Os modelos de análise da dinâmica veicular nos acidentes de trânsito da literatura da área de reconstrução de acidentes, com hipóteses e dados convenientes, podem ser uma fonte alternativa, 
embora normalmente orientem-se a avaliar a severidade dos acidentes pelo $\Delta \mathrm{V}$ (e não pelo ASI). Por exemplo, LIMPERT (1994) faz uma análise do choque de um veículo com uma parede rígida, com atrito. A variação do momento linear $\Delta \mathrm{p}_{\mathrm{x}}$ na direção normal à parede é igual ao impulso normal $\mathrm{I}_{\mathrm{x}}$ :

$$
I_{x}=\Delta p_{x} \Rightarrow F_{x} \cdot t=m \Delta V_{x}
$$

onde,

$\mathrm{F}_{\mathrm{X}}$ : força de contato veículo-parede

m: massa do veículo

$\Delta \mathrm{V}_{\mathrm{x}}=\mathrm{V}_{2 \mathrm{x}}-\mathrm{V}_{1 \mathrm{x}}$ : variação da velocidade na direção perpendicular à parede, igual a $-\mathrm{V}_{2} \operatorname{sen} \alpha_{2^{-}}$ $\mathrm{V}_{1} \operatorname{sen} \alpha_{1}$

$\mathrm{V}_{1}, \mathrm{~V}_{2}$ : velocidade antes do impacto e após o impacto, respectivamente

O coeficiente de restituição $e$, lembrando que a parede permanece parada antes e depois do choque, é:

$$
e=\frac{-V_{2} \operatorname{sen} \alpha_{2}}{V_{1} \operatorname{sen} \alpha_{1}}
$$

Então, com (3-21) e (3-22) tem-se:

$$
F_{x} \cdot t=-m V_{1} \operatorname{sen} \alpha_{1}(1-e)
$$

$\mathrm{O}$ impulso $\mathrm{I}_{\mathrm{y}}=\mathrm{F}_{\mathrm{y}} \cdot \mathrm{t}$ paralelo à parede é:

$$
F_{x} \cdot t=F_{x} \cdot t \cdot f=-m V_{1} \operatorname{sen} \alpha_{1}(1-e) f
$$

onde $f$ é o coeficiente de atrito entre o veículo e a parede.

Então:

$$
m V_{1} \cos \alpha_{1}-m V_{1} \operatorname{sen} \alpha_{1}(1-e) f=m V_{2} \cos \alpha_{2}
$$

E a velocidade final $V_{2}$ é: 


$$
V_{2}=\frac{V_{1} \cos \alpha_{1}-V_{1} \operatorname{sen} \alpha_{1}(1-e) f}{\cos \alpha_{2}}
$$

Obtém-se assim o $\Delta \mathrm{V}$ para o veículo (em cada componente).

Além dos coeficientes de atrito e restituição, a previsão das forças e acelerações normal e tangencial depende da estimativa do tempo de duração do acidente (que por sua vez depende do coeficiente de rigidez do veículo e da parede "rígida"). Neste caso, existe a alternativa de utilizar softwares de reconstrução de acidentes (como o $\mathrm{PC}$-Crash) que possuem um razoável banco de dados sobre características relevantes nos acidentes de diferentes tipos de veículos e obstáculos.

Por fim, o valor previsto para ASI teria de ser relacionado com a severidade dos acidentes. Uma relação deste tipo está proposta, por exemplo, no Apêndice G do NCHRP Report 350, usando $\Delta \mathrm{V}$ ao invés de ASI. A deficiência de se utilizar o $\Delta \mathrm{V}$ é que, tanto para barreiras rígidas, quanto para defensas maleáveis, o $\Delta \mathrm{V}$ seria o mesmo, sendo ignorada a deformação do conjunto veículo-proteção lateral. Este fato resulta em severidades iguais para os dois tipos de proteção lateral.

No entanto, vê-se que a análise tradicional não incorpora as características dos dispositivos de proteção. Por exemplo, associando uma barreira ou defensa a um amortecedor de impacto em regime linear, que poderia ser caracterizado por sua rigidez $\mathrm{K}$ (isto é, que reage com uma força $\mathrm{R}=\mathrm{K}$.d ao atingir uma deformação $\mathrm{d}$, com $\mathrm{K}$ em N/m), a fase de compressão de um impacto com velocidade $\mathrm{V}$ terminaria transformando a energia cinética $\mathrm{m} \cdot \mathrm{V}^{2} / 2$ em energia de deformação $\mathrm{K} . \mathrm{d}_{\text {máx }}{ }^{2} / 2$, tendo-se a deformação máxima dada por $\mathrm{d}_{\text {máx }}=\mathrm{V} .(\mathrm{m} / \mathrm{K})^{1 / 2}$. Admitindo que a reação média na fase de deformação seja $\mathrm{R}=\mathrm{K} \cdot \mathrm{d}_{\text {máx }} / 2$, a desaceleração média seria $\mathrm{a}=\mathrm{R} / \mathrm{m}$, de forma que um mesmo $\Delta \mathrm{V}$ ocorreria em um tempo de duração distinta $\mathrm{t}=\Delta \mathrm{V} / \mathrm{a}$ e poderia ser avaliado um índice de severidade $\mathrm{ASI}=\mathrm{a} / \mathrm{a}_{\text {máx }}$ distinto para cada dispositivo de proteção (em um choque oblíquo, seria usada a componente transversal da velocidade). Por exemplo, o RDG (2006) indica que uma defensa convencional tem deflexão máxima $\mathrm{d}_{\text {máx }}=0,9 \mathrm{~m}$ (corresponde à deformação para o impacto de um veículo de massa $2000 \mathrm{~kg}$, com velocidade de $100 \mathrm{~km} / \mathrm{h}$ e ângulo de impacto de $25^{\circ}$ ), o que corresponderia a $\mathrm{K}=340 \mathrm{kN} / \mathrm{m}$ e $\mathrm{ASI}=0,52$ para $\mathrm{a}_{\operatorname{máx}}=15 \mathrm{~g}$, enquanto uma barreira de concreto tem uma deflexão máxima desprezível (admitindo $\mathrm{d}_{\operatorname{máx}}=0,05 \mathrm{~m}$, isto corresponderia a $\mathrm{K}=110000 \mathrm{kN} / \mathrm{m}$ e $\mathrm{ASI}=9,4$ para o mesmo impacto). Desta forma, pode-se prever severidade 
distinta para diferentes tipos de dispositivos (dadas suas características). Em SZULADZINSKI (2010), diversas outras formulações para problemas de impacto são apresentadas. Sendo $\Delta \mathrm{V}=35 \mathrm{~km} / \mathrm{h}$, o critério do Apêndice G do NCHRP R350 indicaria 29\% de acidentes graves em ambos os casos, enquanto o critério alternativo indicaria que um caso não produziria ferimentos graves (a defensa) e outro (a barreira) tornaria os acidentes fatais quase certamente.

Nos softwares correspondentes ao RDG, o índice de severidade representa a intensidade dos danos causados aos ocupantes do veículo em uma escala de 0 a 10. Assim, por exemplo, para uma dada condição de impacto caracterizada pela velocidade e ângulo de impacto, se um obstáculo possui SI próximo ao valor 10 significa que o impacto com este obstáculo tem chances altíssimas de produzir uma fatalidade, enquanto que, se outro obstáculo possuir SI próximo a zero, o impacto com este obstáculo, nas mesmas condições, dificilmente resultará em fatalidade. Portanto, cada valor de SI está associado à probabilidade de ocorrer um determinado nível de danos aos ocupantes do veículo. Uma classificação americana em cinco níveis é: K (fatal), A (ferimento incapacitante), B (ferimento moderado ou não incapacitante), C (pequenos ferimentos) e PDO (abreviação de Property-damage-only, ou apenas danos materiais, eventualmente separado em PDO1 e PDO2, segundo o montante do dano). No Brasil, os boletins de ocorrência de acidentes de trânsito classificam o evento, segundo a gravidade, em três níveis: com vítima fatal, com vítima não fatal e sem vítima.

A Tabela 3-3 mostra a relação entre o SI e as probabilidades de ocorrem cada um dos níveis de danos, classificados em seis níveis. Com essa relação é possível mensurar o custo do acidente, somando-se o produto da probabilidade do dano com o custo associado a este dano.

Tabela 3-3 - Relação entre o SI e a probabilidade de danos no RSAP

\begin{tabular}{|c|c|c|c|c|c|c|c|}
\hline \multicolumn{8}{|c|}{ Nível de danos (\%) } \\
\hline $\begin{array}{c}\text { Indice de } \\
\text { Severidade } \\
\text { (SI) }\end{array}$ & Nenhum & PDO1 & PDO2 & C & B & A & $\mathbf{K}$ \\
\hline 0 & 100.0 & - & - & - & - & - & - \\
\hline 0.5 & - & 100.0 & - & - & - & - & - \\
\hline 1 & - & 66.7 & 23.7 & 7.3 & 2.3 & - & - \\
\hline 2 & - & - & 71.0 & 22.0 & 7.0 & - & - \\
\hline 3 & - & - & 43.0 & 34.0 & 21.0 & 1.0 & 1.0 \\
\hline 4 & - & - & 30.0 & 30.0 & 32.0 & 5.0 & 3.0 \\
\hline 5 & - & - & 15.0 & 22.0 & 45.0 & 10.0 & 8.0 \\
\hline 6 & - & - & 7.0 & 16.0 & 39.0 & 20.0 & 18.0 \\
\hline 7 & - & - & 2.0 & 10.0 & 28.0 & 30.0 & 30.0 \\
\hline 8 & - & - & - & 4.0 & 19.0 & 27.0 & 50.0 \\
\hline 9 & - & - & - & - & 7.0 & 18.0 & 75.0 \\
\hline 10 & - & - & - & - & - & - & 100.0 \\
\hline \multirow[t]{5}{*}{ Nota: } & $\mathrm{K}=$ & \multicolumn{6}{|c|}{ danos fatais } \\
\hline & $A=$ & \multicolumn{6}{|c|}{ danos incapacitantes ou severos } \\
\hline & $B=$ & \multicolumn{6}{|c|}{ danos moderados ou não incapacitantes } \\
\hline & $\mathrm{C}=$ & \multicolumn{6}{|c|}{ danos mínimos } \\
\hline & $\mathrm{PDO}=$ & \multicolumn{6}{|c|}{ apenas danos materiais } \\
\hline
\end{tabular}


O ROADSIDE utiliza valores médios de índice de severidade (SI) para cada tipo de obstáculo em função da velocidade de projeto da rodovia. Estes índices de severidade estão listadas no Apêndice A do RDG (1996), em função do tipo de elemento colidido e da velocidade de projeto da via (portanto, não diretamente da severidade do impacto).

O RSAP também utiliza os índices de severidade, entretanto, relacionando o SI com a velocidade de impacto do acidente e não à velocidade de projeto da via. Para cada obstáculo, um modelo de regressão linear é usado para a obtenção da reta SI x V. A Figura 3-19 mostra o exemplo dado pelo NCHRP Report 492 para o obstáculo árvore de diâmetro superior a $300 \mathrm{~mm}$. A determinação da reta possibilita relacionar o SI com uma velocidade específica de impacto para cada obstáculo, ao invés de utilizar valores médios.

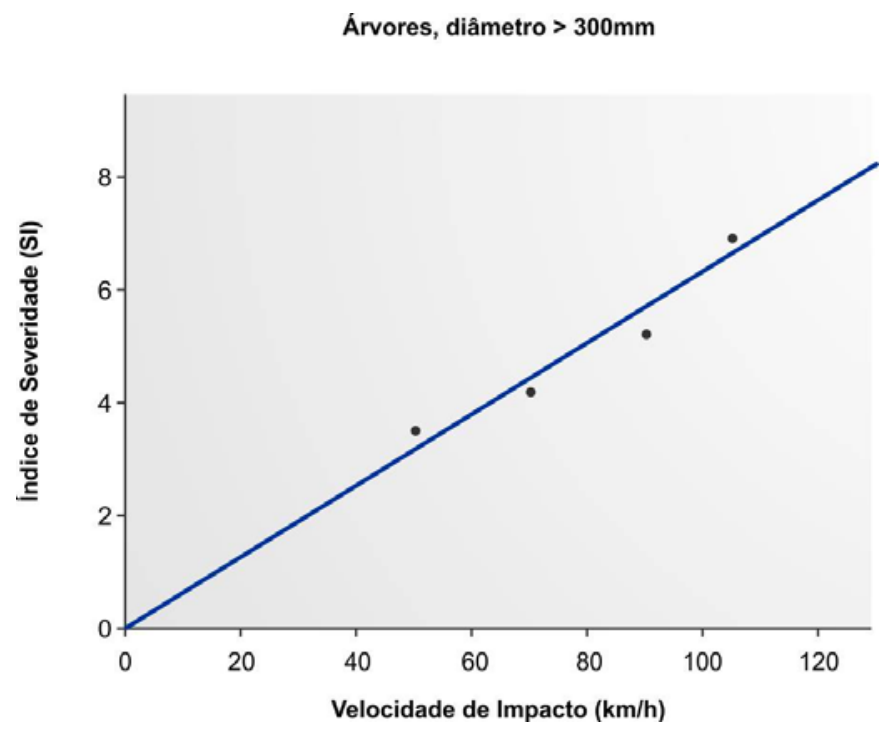

Figura 3-19 - Indice de severidade no RSAP

Embora teoricamente superior, os estudos que determinaram as curvas de severidade do RSAP não puderam ser identificados, tampouco são fornecidos os dados completos assumidos (e a fonte dos estudos específicos) para cada tipo de elemento colidido, na documentação do RSAP. As fontes alternativas seriam do ROADSIDE ou de outros estudos. A observação de que a matriz de transformação do SI na proporção de acidentes por nível de severidade sugere que houve algum tipo de calibração para manter a validade da Tabela 3-3. Portanto, os dados do ROADSIDE seriam consistentes (embora inadequados teoricamente). Qualquer outra versão para o SI implicaria em obter ou calibrar sua relação com a severidade dos acidentes. 


\subsection{EXEMPLO DE APLICAÇÃO NUMÉRICA DE MODELO COMPREENSIVO PARA UM CASO HIPOTÉTICO E COMPARAÇÃO COM OS CRITÉRIOS CONVENCIONAIS}

Para o melhor entendimento da aplicação dos modelos compreensivos, será apresentado um exemplo hipotético, ilustrado na Figura 3-20. Também serão apresentadas algumas comparações das respostas dos modelos compreensivos com os resultados da aplicação dos critérios existentes convencionais, destacando a diferença de abordagem entre ambos.

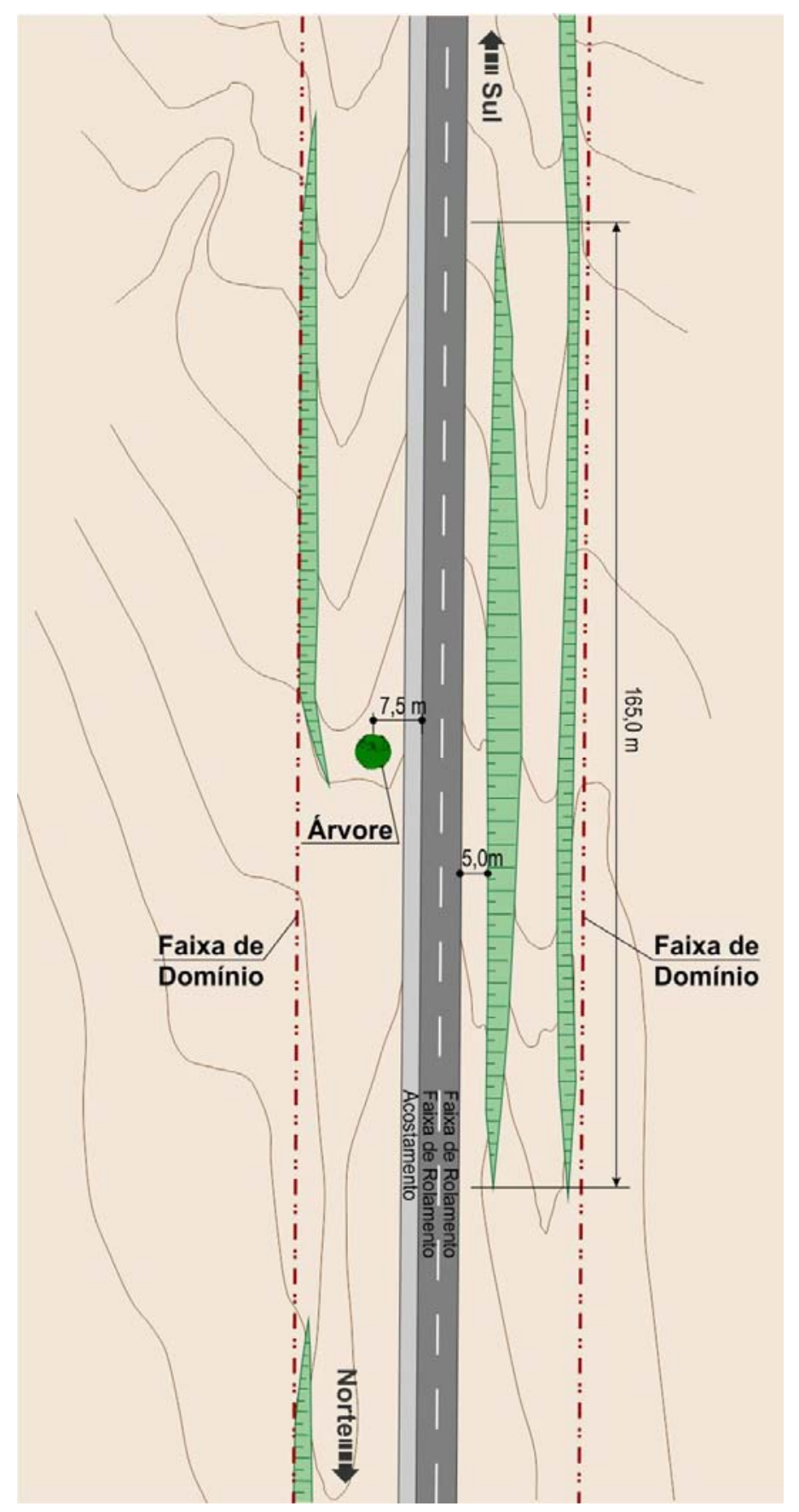

Figura 3-20 - Ilustração do caso hipotético 
O trecho hipotético de rodovia consiste em um segmento em tangente, com a presença de uma árvore com 0,30 $\mathrm{cm}$ de diâmetro ao lado esquerdo da rodovia, e com a presença de um talude de aterro, ao lado direito. O trecho é de pista simples, com faixas de 3,5m de largura e com acostamento somente para o sentido norte com largura de 3,0m. Supõe-se que o VDM do trecho é de 15.000, sendo metade deste volume para cada sentido. Considera-se que a velocidade sinalizada é de $100 \mathrm{~km} / \mathrm{h}$ e que o local não apresenta histórico de acidentes graves. O limite da faixa de domínio é representado pela linha "traço-ponto-ponto".

\subsubsection{Aplicação dos critérios convencionais}

\subsubsection{A presença da árvore}

Pela Figura 3-20, o afastamento da árvore com relação à faixa de rolamento da pista de sentido norte é igual à 7,5 m e com relação a faixa de rolamento da pista de sentido sul é igual a $11 \mathrm{~m}$. Para esta condição, a priori, será verificada a largura recomendada de área livre.

Pelo ábaco da Figura 2-4, entra-se com as três informações necessárias: velocidade de $100 \mathrm{~km} / \mathrm{h}$ (supondo velocidade de projeto igual à sinalizada, na falta da primeira informação), talude da ordem de 12H:1V (obtida das curvas de nível) e VDM igual a 15.000 v/dia. Portanto, encontra-se o valor de 8,5 m, e verifica-se que as árvores estão dentro da área livre recomendada no caso do fluxo que se dirige para o norte, e fora, para o fluxo que se dirige para o sul.

Vale lembrar que, os valores obtidos do ábaco não são valores precisos e sim uma referência e, portanto, poderia ser considerada a atitude de "não fazer nada" já que o local não apresenta histórico relevante de acidentes.

Baseado nos critérios recomendados (expostos no capitulo 2), a referida árvore deveria ser tratada como obstáculo a proteger e algum tratamento deveria ser feito. Pode-se remover a árvore ou utilizar dispositivo de proteção lateral. Por se tratar de uma árvore isolada, poderia ser tomada a decisão de remover a árvore.

\subsubsection{A presença do talude}


Como pode ser visto na Figura 3-20, o comprimento do talude de aterro é de $165 \mathrm{~m}$, e a altura no ponto mais alto estima-se ter $3,5 \mathrm{~m}$, considerando a largura de $5 \mathrm{~m}$ e talude com inclinação de 1,5H:1,0V. Nota-se que o talude de aterro está afastado lateralmente de $5 \mathrm{~m}$ da borda da faixa do sentido sul e $8,5 \mathrm{~m}$ da borda da faixa de sentido norte e, portanto, dentro da área livre requerida, para ambos os sentidos. Poder-se-ia conjecturar sobre a irrelevância do obstáculo para os motoristas que trafegam pelo sentido norte, tomando-se a decisão de não fazer a proteção para tal sentido.

Pelo critério do RDG (2006), o talude necessitaria ser protegido por dispositivo de proteção lateral (ver Figura 2-8). Além disso, um talude com inclinação desta magnitude é considerado crítico pelas definições usuais (ver item 2.1.3) e, portanto, um obstáculo para os veículos desgovernados.

Percebe-se pela Figura 3-20 que mais adiante, próximo ao limite da faixa de domínio (linha “traço-ponto-ponto") à direita da figura, há um talude de corte, que cria uma depressão junto com o talude de aterro. Se houver terra disponível na região, pode-se preencher este espaço e suavizar o talude, tornando-o traspassável e recuperável, descartando a necessidade de uso de dispositivo de proteção lateral.

\subsubsection{Aplicação dos modelos compreensivos}

Neste tópico serão feitas aplicações manuais dos modelos compreensivos baseadas no trecho hipotético e nos obstáculos descritos anteriormente.

Para análise, será utilizado o método manual de análise com o critério de benefício-custo incremental apresentado no TAC (1999). Ressalta-se que, para o exercício, não importa o algoritmo utilizado, e sim a estrutura e os parâmetros necessários para a aplicação dos modelos compreensivos. O modelo adotado pelo TAC (1999) está representado na equação (3-17).

Serão adotadas, para o exemplo numérico, a taxa de saídas de pista e a curva de probabilidade de extensão lateral utilizadas no ROADSIDE, conforme equações (3-4) e (3-6) apresentadas anteriormente. Então: 
- Taxa de saída de pista: $\mathrm{t}_{\mathrm{f}}=0,0003$ saídas/(km.ano.VDM)

- Equação de probabilidade de extensão lateral: $P\left[Y \geq Y_{d}\right]=0,5+0,5 \cdot \cos \left(\frac{\pi Y_{d}}{18,87}\right)$

O valor $18,87 \mathrm{~m}$ é resultante da adoção da velocidade de saída de pista igual à velocidade sinalizada de $100 \mathrm{~km} / \mathrm{h}$ e ângulo médio de saída de pista igual a $11^{\circ}$, obtido do estudo de HUTCHINSON e KENNEDY (1967), ângulo também utilizado no modelo do TAC (1999).

Será considerado 10 anos de vida útil de projeto, uma taxa de desconto de $6 \%$ e taxa de crescimento do volume de tráfego de $0 \%$.

\subsubsection{A presença da árvore}

Para a realização da análise benefício/custo incremental é necessário haver pelo menos duas alternativas. Neste exemplo, a primeira alternativa será a de "não fazer nada" e a segunda, a utilização de defensa metálica.

Para ambas as alternativas, a freqüência de saídas de pista é:

$E_{f}=t_{f} . V D M=(0,0003) .(15000)=4,5$ saídas $/(k m . a n o)$, somando os dois sentidos.

\subsection{Alternativa 1: Não fazer nada}

A freqüência de choques para a alternativa 1 é:

$C_{f}^{\text {NORTE }}=\frac{4,5}{2000}[(0,3+19,2) \cdot P[Y \geq 7,5]+5,14 \cdot P[Y \geq(7,5+1,8+0,5)]]=\frac{4,5}{2000}[19,5 \cdot 0,658+5,14 \cdot 0,47]$

$=0,0343$ choques/ano

$C_{f}^{S U L}=\frac{4,5}{2000}[(0,3+19,2) \cdot P[Y \geq 11]+5,14 \cdot P[Y \geq(11+1,8+0,5)]]=\frac{4,5}{2000}[19,5 \cdot 0,372+5,14 \cdot 0,20]$

$=0,0186$ choques/ano

Portanto, $\mathrm{C}_{\mathrm{f}}=0,0343+0,0186=0,0529$ choques/ano ( 1 choque a cada 19 anos $)$ 
Para saber o custo anual dos choques é preciso saber o custo unitário do choque, que depende da gravidade do impacto com uma árvore. Essa gravidade pode ser relacionada com o SI da árvore, para as dadas condições de impacto. De acordo com o Anexo A do RDG (1996), para o impacto com uma árvore de diâmetro $300 \mathrm{~mm}$ e velocidade de $100 \mathrm{~km} / \mathrm{h}$, o SI é aproximadamente 6.

O custo médio do choque será obtido da relação entre o SI e a probabilidade de ocorrência de cada dano (conforme Tabela 3-3), e para cada tipo de dano, associa-se seu custo. Serão utilizados, para efeito de exemplo, os custos apresentados no estudo do IPEA (2006). Como a Tabela 3-3 baseia-se em seis níveis de severidade (K, A, B, C, PDO1 e PDO2) e os custos do IPEA são classificados em apenas três (vítima fatal, com vítima não fatal e sem vítima), será agrupado os níveis de severidade da seguinte forma:

Tabela 3-4 - Equivalência dos tipos de danos e respectivos custos

\begin{tabular}{c|c|c}
\hline \multicolumn{2}{c|}{ Equivalência do tipo de danos } & Custo IPEA(2006) \\
\cline { 1 - 1 } $\mathrm{K}$ & Com vítima fatal & $\mathrm{R} \$ 418.341,00$ \\
\hline $\mathrm{A}$ & \multirow{2}{*}{ Com vítima não fatal } & $\mathrm{R} \$ 86.032,00$ \\
\cline { 1 - 1 } $\mathrm{B}$ & & $\mathrm{R} \$ 16.849,00$ \\
\hline $\mathrm{yDO} 1$ & Sem vítimas & $\mathrm{R}$ \\
\cline { 1 - 1 } $\mathrm{PDO} 2$ & &
\end{tabular}

Com as informações da tabela acima e da Tabela 3-3, os custos sociais associados aos SIs estão representados na Tabela 3-5

Tabela 3-5 - Relação entre SI, probabilidade de danos e custo social

\begin{tabular}{c|c|c|c|c}
\hline \multirow{2}{*}{$\mathbf{S I}$} & \multicolumn{3}{|c|}{ Probabilidade de danos } & \multirow{2}{*}{ Custo social } \\
\cline { 2 - 5 } & Sem vítimas & Com vítima não fatal & Fatal & \\
\hline \multicolumn{5}{|c|}{} \\
\hline $\mathbf{0 , 5}$ & 1,00 & 0,00 & 0,00 & $\mathrm{R} \$ 16.849,00$ \\
\hline $\mathbf{1}$ & 0,90 & 0,10 & 0,00 & $\mathrm{R} \$ 23.490,57$ \\
\hline $\mathbf{2}$ & 0,71 & 0,29 & 0,00 & $\mathrm{R} \$ 36.912,07$ \\
\hline $\mathbf{3}$ & 0,43 & 0,56 & 0,01 & $\mathrm{R} \$ 59.606,40$ \\
\hline $\mathbf{4}$ & 0,30 & 0,67 & 0,03 & $\mathrm{R} \$ 75.246,37$ \\
\hline $\mathbf{5}$ & 0,15 & 0,77 & 0,08 & $\mathrm{R} \$ 102.239,27$ \\
\hline $\mathbf{6}$ & 0,07 & 0,75 & 0,18 & $\mathrm{R} \$ 141.004,81$ \\
\hline $\mathbf{7}$ & 0,02 & 0,68 & 0,30 & $\mathrm{R} \$ 184.341,04$ \\
\hline $\mathbf{8}$ & 0,00 & 0,50 & 0,50 & $\mathrm{R} \$ 252.186,50$ \\
\hline $\mathbf{9}$ & 0,00 & 0,25 & 0,75 & $\mathrm{R} \$ 335.263,75$ \\
\hline $\mathbf{1 0}$ & 0,00 & 0,00 & 1,00 & $\mathrm{R} \$ 418.341,00$ \\
\hline
\end{tabular}

Assim, o custo social relacionado ao SI igual a 6 é R\$141.004,81 e o custo social anual devido a presença da árvore é: $\mathrm{R} \$ 141.004,81$ x $0,0529=\mathrm{R} \$ 7.459,00 / \mathrm{ano}$ 
Considerando um período de 10 anos, com uma taxa de 6\%, tem-se:

$$
A C_{1}=7.459 \cdot \sum_{n=1}^{10} \frac{1}{(1+0,06)^{n}}=\mathrm{R} \$ 54.899,00
$$

\subsection{Alternativa 2: Utilização de defensa metálica}

Naturalmente, a freqüência de choques para esta alternativa irá aumentar devido ao comprimento da defensa e a proximidade em relação à via.

Para o cálculo do comprimento necessário de defensa metálica para a proteção da árvore será adotado o critério da ABNT NBR 15486:2007, sem adoção de segmento defletido. Então, para um ângulo de saída de pista de $11^{\circ}$ e defensa posicionada no limite do acostamento, o comprimento necessário para um sentido é:

$$
X=\frac{7,5-3,0}{\operatorname{tg} 11^{\circ}}=23 m
$$

e para os dois sentidos é $46 \mathrm{~m}$.

Assim, a freqüência de choques para a alternativa 2 é:

$C_{f}^{\text {NORTE }}=\frac{4,5}{2000}[(46+19,2) \cdot P[Y \geq 3]+5,14 \cdot P[Y \geq(3+1,8+0,5)]]=\frac{4,5}{2000}[65,2 \cdot 0,939+5,14 \cdot 0,818]$

$=0,1472$ choques/ano

$$
\begin{aligned}
& C_{f}^{S U L}=\frac{4,5}{2000}[(46+19,2) \cdot P[Y \geq 6,5]+5,14 \cdot P[Y \geq(6,5+1,8+0,5)]]=\frac{4,5}{2000}[65,2 \cdot 0,735+5,14 \cdot 0,553] \\
& =0,1142 \text { choques/ano }
\end{aligned}
$$

Portanto, $\mathrm{C}_{\mathrm{f}}=0,1472+0,1142=0,2614$ choques/ano ( 1 choque a cada 4 anos $)$

O SI do impacto com a defensa, segundo RDG(1996) é aproximadamente 3. Assim, o custo social associado à presença da defensa é $\mathrm{R} \$ 59.606,40$ x 0,2614 = R \$ 15.581,00/ano. Então:

$$
A C_{2}=15.581 \cdot \sum_{n=1}^{10} \frac{1}{(1+0,06)^{n}}=\mathrm{R} \$ 114.677,00
$$


Percebe-se que, neste caso, apesar do SI ser menor para a barreira de concreto, a previsão de choques contra a proteção lateral resultou em número maior deste evento, contribuindo para o aumento de custo social se comparado com a alternativa "não fazer nada".

\subsection{Análise benefício/custo incremental das alternativas}

Naturalmente, a ausência de benefício indicaria que a proteção é inadequada. No entanto, prossegue-se a aplicação a título ilustrativo. Para uma análise benefício/custo, podem-se adotar os custos de instalação da defensa metálica constantes na TPU/DER-SP.

Entretanto, uma dificuldade a ser enfrentada em um caso real é determinar o custo de manutenção e reparos da defensa metálica, ou de qualquer outro dispositivo. Neste exemplo, não será considerado o custo de manutenção, e o custo de reparo será proporcional a freqüência de choques com a defensa metálica.

Abaixo será calculado o benefício/custo incremental da alternativa 1 para a alternativa 2 . De acordo com a TPU/DER-SP de março de 2010, o custo por metro de defensa metálica é R\$ 352,03 , o custo de remoção para reinstalação é R \$ 84,48 e o custo de implantação é R \$49,56.

Então o custo total de instalação é: 352,03 x $46=\mathrm{R} \$ 16.193,00$

O custo de reparo é $(84,48+49,56)$ x 10 x $0,2614=\mathrm{R} \$ 350,40 /$ ano (foi considerado $10 \mathrm{~m}$ de danos na defensa metálica devido ao impacto, porém esta análise deveria levar em conta a energia cinética do veículo e o módulo de deformação da defensa metálica para estimar o comprimento a ser reparado). Então:

$$
D C_{2}=16.193+350,40 \cdot \sum_{n=1}^{10} \frac{1}{(1+0,06)^{n}}=\mathrm{R} \$ 18.772,00
$$

A análise benefício/custo incremental é:

$$
B / C_{(2-1)}=\frac{\left(A C_{1}-A C_{2}\right)}{\left(D C_{2}-D C_{1}\right)}
$$


onde:

$\mathrm{B} / \mathrm{C}_{(2-1)}$ : taxa incremental beneficio/custo na comparação da alternativa 2 com a alternativa 1 .

$\mathrm{AC}_{1}, \mathrm{AC}_{2}$ : custo social anualizado associado aos acidentes das alternativas 1 e 2 .

$\mathrm{DC}_{1}, \mathrm{DC}_{2}$ : custo direto anualizado das alternativas 1 e 2 .

Portanto,

$$
\mathrm{B} / \mathrm{C}_{2-1}=(54.899-114.677) /(18.772-0)=-3,18
$$

Com base no valor acima, não se tomaria a decisão da instalação da defensa metálica.

Poder-se-ia conjecturar a utilização da defensa metálica na proteção do fluxo em sentido norte apenas, como uma alternativa 3. Então:

$$
C_{f}^{\text {NORTE }}=\frac{4,5}{2000}[(23+19,2) \cdot P[Y \geq 3]+5,14 \cdot P[Y \geq(3+1,8+0,5)]]=\frac{4,5}{2000}[42,2 \cdot 0,939+5,14 \cdot 0,818]
$$

$=0,0986$ choques/ano (para a defensa metálica)

$$
C_{f}^{S U L}=\frac{4,5}{2000}[(23+19,2) \cdot P[Y \geq 6,5]+5,14 \cdot P[Y \geq(6,5+1,8+0,5)]]=\frac{4,5}{2000}[42,2 \cdot 0,735+5,14 \cdot 0,553]
$$

$=0,0762$ choques/ano (para a defensa metálica)

$C_{f}^{S U L}=\frac{4,5}{2000}[(0,3+19,2) \cdot P[Y \geq 11]+5,14 \cdot P[Y \geq(11+1,8+0,5)]]=\frac{4,5}{2000}[19,5 \cdot 0,372+5,14 \cdot 0,200]$ $=0,0186$ choques/ano (para a árvore)

Logo, o custo social é $(0,0986+0,0762) \times \mathrm{R} \$ 59.606,40+0,0186 \times \mathrm{R} \$ 141.004,81=\mathrm{R} \$$ 13.042/ano, e

$$
A C_{3}=13042 \cdot \sum_{n=1}^{10} \frac{1}{(1+0,06)^{n}}=\mathrm{R} \$ 95.990,00
$$

O custo de instalação e reparos da defensa é:

$$
D C_{3}=(352,03 \cdot 23)+(84,48+49,56) \times 10 \times 0,1748 \cdot \sum_{n=1}^{10} \frac{1}{(1+0,06)^{n}}=\mathrm{R} \$ 9.822,00
$$

Portanto,

$$
\mathrm{B} / \mathrm{C}_{3-1}=(54.899-95.990) /(9.822-0)=-4,18
$$


Com base no valor acima, não se tomaria a decisão da instalação da defensa metálica apenas para o sentido sul. Uma alternativa provavelmente viável seria a remoção da árvore.

\subsubsection{2. $\quad$ A presença do talude}

Será calculado o benefício/custo incremental das seguintes alternativas: 1) "não fazer nada” e 2) utilizar defensa metálica para ambos os sentidos e 3) utilizar defensa metálica somente para o sentido adjacente ao talude. Neste caso, serão usados os critérios da ABNT, sem os terminais.

\subsection{Alternativa 1: Não fazer nada}

$C_{f}^{S U L}=\frac{4,5}{2000}\left[(165+19,2) \cdot P[Y \geq 5]+5,14 \cdot \sum_{J=1}^{5} P\left[Y \geq\left(5+1,8+\frac{2 J-1}{2}\right)\right]\right]=$

$=\frac{4,5}{2000}[(184.2) \cdot(0,837)+5,14 \cdot(0,674+0,594+0,511+0,428+0,347)]=$

$=0,3765$ choques/ano

$C_{f}^{\text {NORTE }}=\frac{4,5}{2000}\left[(165+19,2) \cdot P[Y \geq 8,5]+5,14 \cdot \sum_{J=1}^{5} P\left[Y \geq\left(8,5+1,8+\frac{2 J-1}{2}\right)\right]\right]=$

$=\frac{4,5}{2000}[(184.2) \cdot(0,578)+5,14 \cdot(0,388+0,308+0,235+0,168+0,111)]=$

$=0,2535$ choques/ano

Portanto, em ambos os sentidos, $0,3765+0,2535=0,6300$ choques/ano ( 1 choque a cada 2 anos).

Com as características do talude, o valor de SI indicado no anexo A do RDG (2006) é 5. Logo, o custo social associado a presença do talude é $0,63 \times \mathrm{R} \$ 102.239,27=\mathrm{R} \$ 64.411,00 /$ ano. Então:

$A C_{1}=64.411 \cdot \sum_{n=1}^{10} \frac{1}{(1+0,06)^{n}}=\mathrm{R} \$ 474.071,00$

\subsection{Alternativa 2: Utilização de defensa metálica para ambos os sentidos}


De acordo com o critério da NBR 15486:2007, o comprimento necessário de defensa metálica para proteger os motoristas do talude de aterro, considerando ângulo de saída de pista de $11^{\circ} \mathrm{e}$ posicionamento da defensa a $3 \mathrm{~m}$ da borda da pista, é:

$X=2\left(\frac{10-3}{\operatorname{tg} 11^{\circ}}\right)+165=237 \mathrm{~m}$

A freqüência de choques esperada para a alternativa 2 é:

$C_{f}^{S U L}=\frac{4,5}{2000}[(237+19,2) \cdot P[Y \geq 3]+5,14 \cdot P[Y \geq(3+1,8+0,5)]]=\frac{4,5}{2000}[256,2 \cdot 0,939+5,14 \cdot 0,818]$

$=0,5507$ choques/ano

$C_{f}^{\text {NORTE }}=\frac{4,5}{2000}[(237+19,2) \cdot P[Y \geq 6,5]+5,14 \cdot P[Y \geq(6,5+1,8+0,5)]]=\frac{4,5}{2000}[256,2 \cdot 0,735+5,14 \cdot 0,553]$

$=0,4301$ choques/ano

Portanto, $\mathrm{C}_{\mathrm{f}}=0,5507+0,4301=0,9808$ choques/ano $(1$ choque a cada ano $)$.

O custo social esperado para a alternativa 2 é: $0,9808 \times \mathrm{R} \$ 59.606,40=\mathrm{R} \$ 58.462,00 /$ ano.

Então:

$A C_{2}=58.462 \cdot \sum_{n=1}^{10} \frac{1}{(1+0,06)^{n}}=\mathrm{R} \$ 430.285,00$

O custo total de instalação e reparos é:

$D C_{2}=(237 \times 352,03)+(84,48+49,56) \times 10 \times 0,9808 \cdot \sum_{n=1}^{10} \frac{1}{(1+0,06)^{n}}=\mathrm{R} \$ 93.110,00$

\subsection{Alternativa 3: Utilização de defensa metálica somente para o sentido adjacente ao talude}

O comprimento necessário na proteção do sentido norte é:

$X=\left(\frac{10-3}{\operatorname{tg} 11^{\circ}}\right)+165=201 m$ 
A freqüência de choques esperada para a alternativa 3 é:

$C_{f}^{S U L}=\frac{4,5}{2000}[(201+19,2) \cdot P[Y \geq 3]+5,14 \cdot P[Y \geq(3+1,8+0,5)]]=\frac{4,5}{2000}[220,2 \cdot 0,939+5,14 \cdot 0,818]$

$=0,4747$ choques/ano (para a defensa metálica)

$C_{f}^{\text {NORTE }}=\frac{4,5}{2000}[(201+19,2) \cdot P[Y \geq 6,5]+5,14 \cdot P[Y \geq(6,5+1,8+0,5)]]=\frac{4,5}{2000}[220,2 \cdot 0,735+5,14 \cdot 0,553]$

$=0,3706$ choques/ano (para a defensa metálica)

$C_{f}^{\text {NORTE }}=\frac{4,5}{2000}\left[(0+19,2) \cdot P[Y \geq 8,5]+5,14 \cdot \sum_{J=1}^{5} P\left[Y \geq\left(8,5+1,8+\frac{2 J-1}{2}\right)\right]\right]=$

$=\frac{4,5}{2000}[(19,2) \cdot(0,578)+5,14 \cdot(0,388+0,308+0,235+0,168+0,111)]=$

$=0,0390$ choques/ano (para o talude)

Logo, o custo social é $(0,4747+0,3706) \times \mathrm{R} \$ 59.606,40+0,0390$ x $\mathrm{R} \$ 102.239,27=\mathrm{R} \$$ 54.373,00/ano. Então:

$A C_{3}=54.373 \cdot \sum_{n=1}^{10} \frac{1}{(1+0,06)^{n}}=\mathrm{R} \$ 400.190,00$

O custo total de instalação e reparos da defensa é:

$D C_{3}=(201 \times 352,03)+(84,48+49,56) \times 10 \times 0,8453 \cdot \sum_{n=1}^{10} \frac{1}{(1+0,06)^{n}}=\mathrm{R} \$ 79.097,00$

\subsection{Análise benefício/custo incremental das alternativas}

O benefício/custo incremental da alternativa 2 em relação a alternativa 1 é:

$\mathrm{B} / \mathrm{C}_{2-1}=(474.071-430.285) /(93.110-0)=0,47$

O benefício/custo incremental da alternativa 3 em relação a alternativa 1 é:

$\mathrm{B} / \mathrm{C}_{3-1}=(474.071-400.190) /(79.097-0)=0,93$ 
Portanto, baseando-se nos valores B/C incremental acima, não se tomaria a decisão da instalação da defensa metálica, e deveria ser deixado exposto o talude de aterro, pois a razão é menor que 1 (isto é, os benefícios são menores que os custos).

É importante destacar que os modelos compreensivos são sensíveis aos valores do custo do acidente para vítimas fatais, não fatais e sem vítimas, devendo o analista de segurança viária escolher estes custos com bastante cautela.

Por exemplo, se fosse considerado os valores do FHWA para os custos sociais dos acidentes de trânsito conforme Tabela 3-6, com conversão em reais ao câmbio de U\$ $1,00=\mathrm{R} \$ 1,50$, os valores de AC e DC para o caso do talude de aterro seriam aqueles mostrados na Tabela 3-7.

\begin{tabular}{|c|c|c|c|c|c|c|}
\hline & \multicolumn{5}{|c|}{ Custo do acidente de acordo com FHWA (U\$) } & \\
\hline & $2.000,00$ & $19.000,00$ & $36.000,00$ & $180.000,00$ & $2.600 .000,00$ & \\
\hline SI & PDO & C & B & A & $\mathrm{K}$ & custo \\
\hline 0,5 & $100,0 \%$ & $0,0 \%$ & $0,0 \%$ & $0,0 \%$ & $0,0 \%$ & $\mathrm{R} \$ 3.000,00$ \\
\hline 1 & $90,4 \%$ & $7,3 \%$ & $2,3 \%$ & $0,0 \%$ & $0,0 \%$ & $\mathrm{R} \$ 6.034,50$ \\
\hline 2 & $71,0 \%$ & $22,0 \%$ & $7,0 \%$ & $0,0 \%$ & $0,0 \%$ & $\mathrm{R} \$ 12.180,00$ \\
\hline 3 & $43,0 \%$ & $34,0 \%$ & $21,0 \%$ & $1,0 \%$ & $1,0 \%$ & $\mathrm{R} \$ 64.020,00$ \\
\hline 4 & $30,0 \%$ & $30,0 \%$ & $32,0 \%$ & $5,0 \%$ & $3,0 \%$ & $\mathrm{R} \$ 157.230,00$ \\
\hline 5 & $15,0 \%$ & $22,0 \%$ & $45,0 \%$ & $10,0 \%$ & $8,0 \%$ & $\mathrm{R} \$ 370.020,00$ \\
\hline 6 & $7,0 \%$ & $16,0 \%$ & $39,0 \%$ & $20,0 \%$ & $18,0 \%$ & $\mathrm{R} \$ 781.830,00$ \\
\hline 7 & $2,0 \%$ & $10,0 \%$ & $28,0 \%$ & $30,0 \%$ & $30,0 \%$ & $\mathrm{R} \$ 1.269 .030,00$ \\
\hline 8 & $0,0 \%$ & $4,0 \%$ & $19,0 \%$ & $27,0 \%$ & $50,0 \%$ & $\mathrm{R} \$ 2.034 .300,00$ \\
\hline 9 & $0,0 \%$ & $0,0 \%$ & $7,0 \%$ & $18,0 \%$ & $75,0 \%$ & $\mathrm{R} \$ 2.977 .380,00$ \\
\hline 10 & $0,0 \%$ & $0,0 \%$ & $0,0 \%$ & $0,0 \%$ & $100,0 \%$ & $\mathrm{R} \$ 3.900 .000,00$ \\
\hline \multirow[t]{5}{*}{ Nota: } & \multirow{2}{*}{\multicolumn{6}{|c|}{$\begin{array}{l}\mathrm{K}=\text { danos fatais } \\
\mathrm{A}=\text { danos incapacitantes ou severos }\end{array}$}} \\
\hline & & & & & & \\
\hline & \multicolumn{6}{|c|}{$\begin{array}{l}A=\text { danos incapacitantes ou severos } \\
B=\text { danos moderados ou não incapacitantes }\end{array}$} \\
\hline & \multicolumn{6}{|c|}{$\mathrm{C}=$ danos mínimos } \\
\hline & $P D O=$ apenas dar & & & & & \\
\hline
\end{tabular}

Tabela 3-6 - Custos sociais correspondentes aos SIs, com valores compreensivos do FHWA

\begin{tabular}{l|r|r|} 
& \multicolumn{1}{c}{ AC (R\$) } & \multicolumn{1}{c}{ DC (R\$) } \\
\cline { 2 - 3 } Alternativa 1 & $1.715 .879,00$ & 0,00 \\
Alternativa 2 & $462.147,00$ & $93.110,00$ \\
\cline { 2 - 3 } Alternativa 3 $304.512,00$ & $79.097,00$ \\
\hline
\end{tabular}

Tabela 3-7 - Valores de benefícios e custos de acordo com os custos compreensivos do FHWA

E as taxas benefício/custo incremental seriam os mostrados na Tabela 3-8, abaixo:

\begin{tabular}{|c|c|c|c|}
\hline \multirow{4}{*}{$\begin{array}{l}\text { Alternativa } 1 \\
\text { Alternativa } 2 \\
\text { Alternativa } 3\end{array}$} & Alternativa 1 & Alternativa 2 & Alternativa 3 \\
\hline & - & 13,5 & 15,3 \\
\hline & - & - & 3,0 \\
\hline & - & - & - \\
\hline
\end{tabular}

Tabela 3-8 - B/C incremental para as três alternativas 
Desta forma, tanto a alternativa 2 quanto a alternativa 3 poderiam ser adotadas. Na comparação da alternativa 2 com a alternativa 3, vê-se que a alternativa 3 é melhor. Portanto, com base na análise da Tabela 3-8, poderia ser tomada a decisão de implantação da defensa metálica na proteção do fluxo de tráfego do sentido sul apenas.

Outro fator que possui grande influência na análise benefício/custo incremental é a medida de severidade do impacto com o obstáculo analisado, aqui representado pelo SI, que está intimamente relacionada com os custos sociais dos acidentes. Portanto, uma medida de severidade mais fidedigna que o SI deveria ser utilizado, já que este é baseado no julgamento subjetivo dos profissionais da área.

\subsection{VIABILIDADE DA APLICAÇÃO DE MODELOS COMPREENSIVOS}

Em princípio, pode-se ver que os modelos compreensivos acrescentam aspectos relevantes e que, além da dificuldade computacional (eventualmente contornada com simplificações convenientes), sua aplicação depende de obter diversas informações necessárias à aplicação do método de cálculo.

Os pontos mais importantes (e as fontes identificadas) seriam:

- as frequências de saídas de pista (baseado em taxas ou modelos que eventualmente podem ser calibrados ou ajustados para cada aplicação, em função dos acidentes atuais);

- as distribuições das características das saídas de pista ou, de forma simplificada, os valores típicos a serem adotados para velocidade de saída, ângulo de saída, etc.

- o levantamento das características do entorno da via (incluindo as alternativas de projeto para a proteção lateral);

- as condições de impacto decorrentes das características de saída de pista, da posição dos obstáculos (ou dispositivos), obtido das hipóteses dos modelos;

- a severidade decorrente do impacto, aspecto que parece depender fundamentalmente de um catálogo de informações empíricas (como as admitidas pelo ROADSIDE);

- a severidade decorrente do acidente, baseada na matriz de conversão e na eventual calibração ou ajuste em função dos dados sobre acidentes fatais ou com vítimas;

- os custos decorrentes dos acidentes e dos danos materiais. 


\section{ESTUDO DE CASO: RODOVIA PEDRO EROLES (SP-088)}

Como visto no capítulo anterior, os modelos compreensivos podem ser uma melhor opção para a tomada de decisão com relação às alternativas de segurança do entorno viário se comparados com os critérios tradicionalmente utilizados. Porém, este capítulo focará os critérios tradicionais.

Portanto, o objetivo deste capítulo é analisar, por meio de uma aplicação prática, a observância aos critérios recomendados no Brasil no que se refere à segurança do entorno da via e avaliar a relação entre os critérios recomendados e a segurança viária, medida através da ocorrência dos acidentes de trânsito.

A aplicação prática foi estruturada em quatro etapas.

A primeira etapa consistiu na coleta de dados necessários à aplicação dos critérios do uso de dispositivos de proteção lateral para a rodovia escolhida. Para isso, caracterizou-se o entorno da rodovia e o tráfego, com identificação dos possíveis obstáculos, altura e inclinação dos taludes, presença de dispositivos de proteção lateral, aclives e declives, presença de curvas horizontais, entre outros. 
$\mathrm{Na}$ segunda etapa foram coletados os dados sobre o histórico recente de acidentes, na forma de planilha, obtida junto ao DER/SP. Em função de dificuldades na obtenção de dados mais detalhados do DER/SP, fontes suplementares de dados foram buscadas junto à ARTESP (que gerencia concessionárias com trechos relevantes de rodovias de pista simples).

A terceira etapa consistiu na verificação da observância aos critérios revisados anteriormente nos capítulo 2 e 3 para a o uso dos dispositivos de proteção lateral.

E por fim, a última e quarta etapa consistiu na análise da relação entre os critérios recomendados e a ocorrência de acidentes.

\subsection{SELEÇÃO DA RODOVIA PARA O ESTUDO DE CAMPO}

A rodovia selecionada para o estudo foi a Rodovia Pedro Eroles (SP-088), localizada no Estado de São Paulo, à aproximadamente $50 \mathrm{~km}$ da capital, administrada pelo DER-SP, sob domínio da regional 10 (DR-10) do DER-SP. A Figura 4-1 mostra a localização da rodovia nos contextos do Estado de São Paulo e do DR-10.
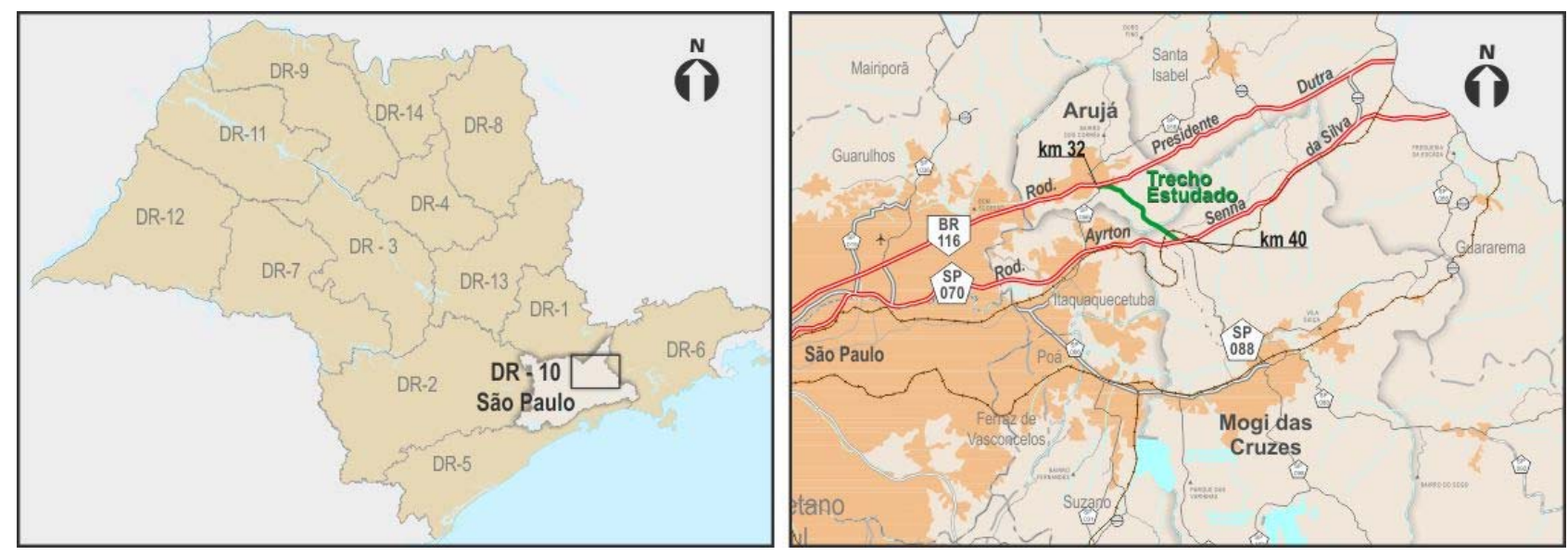

Figura 4-1 - Localização da rodovia SP-088

O trecho de rodovia estudada inicia-se no entroncamento com a Rodovia Presidente Dutra (BR116), no município de Arujá, e segue em direção ao sudeste, terminando no cruzamento com a Rodovia Ayrton Senna da Silva (SP-070). 
O referido trecho, compreendido entre os $\mathrm{km} 32$ e $\mathrm{km} \mathrm{39,} \mathrm{caracteriza-se} \mathrm{como} \mathrm{rodovia} \mathrm{de} \mathrm{pista}$ simples, com uma faixa de tráfego por sentido e acostamentos pavimentados. Nos trechos de rampas ascendentes, a faixa adicional para veículos pesados toma o lugar do acostamento. A topografia atravessada por este trecho da rodovia possui características onduladas, proporcionando um traçado pouco sinuoso com presença de tangentes longas. A faixa lindeira do trecho em questão é pouco urbanizada, com presença de alguns acessos às propriedades particulares, bem como acessos a instalações industriais e rodovias municipais.

Com relação aos obstáculos do entorno viário, os mais encontrados foram os taludes de aterro, taludes de corte, postes de energia elétrica e árvores de médio e grande porte. Em geral, neste trecho, os postes estão localizados próximos ao limite da faixa de domínio, mas em alguns lugares foram encontrados adjacentes ao acostamento. Os taludes de corte, em geral, estão localizados mais próximos à via que os taludes de aterro. Em menor número, os bueiros possuem suas extremidades razoavelmente afastadas da pista. Algumas características do trecho estudado estão mostradas a seguir (Figura 4-2, Figura 4-3, Figura 4-4 e Figura 4-5).

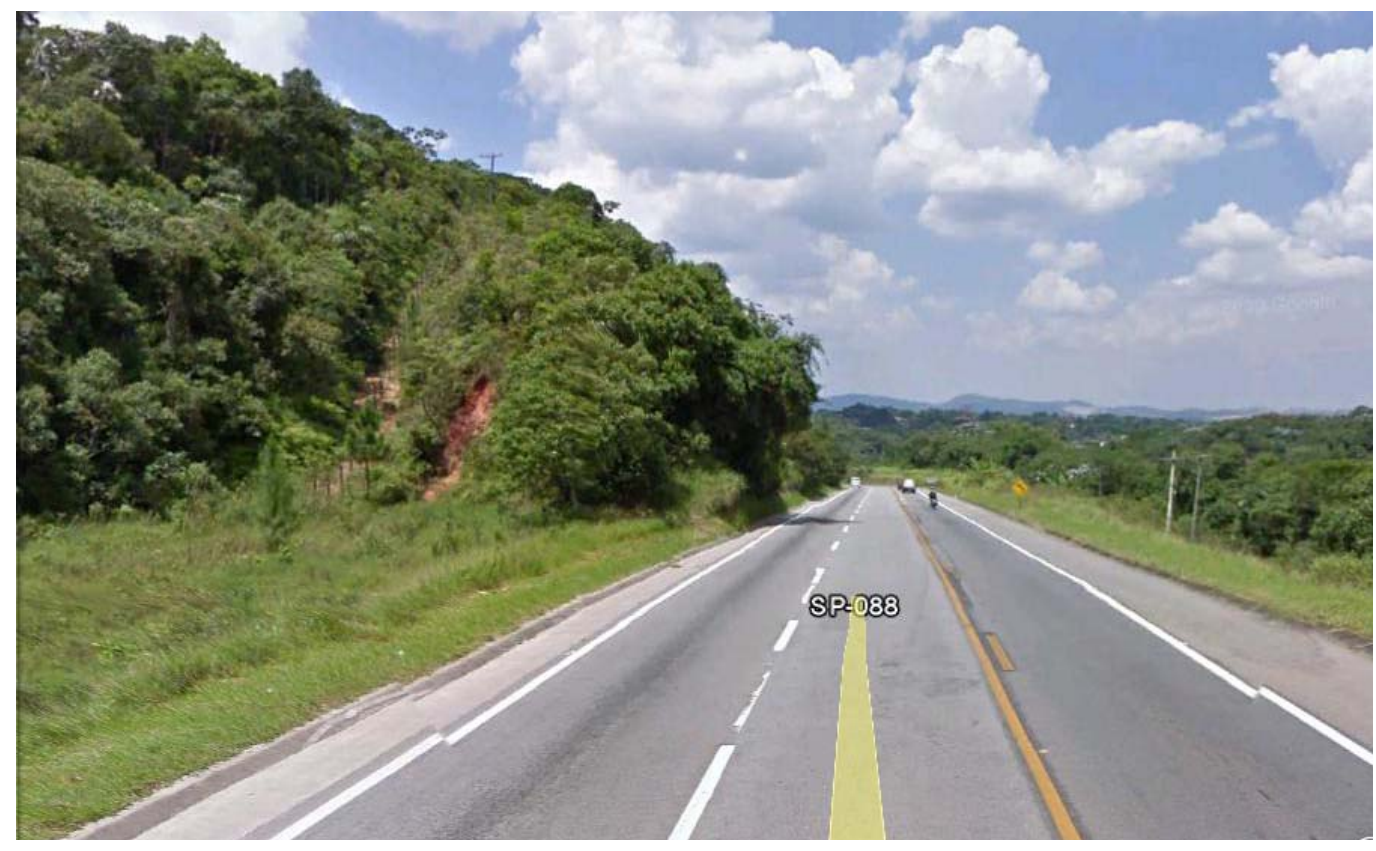

Figura 4-2 - Características do entorno, km 34, sentido Mogi das Cruzes. (Fonte: Google Earth, 2010) 


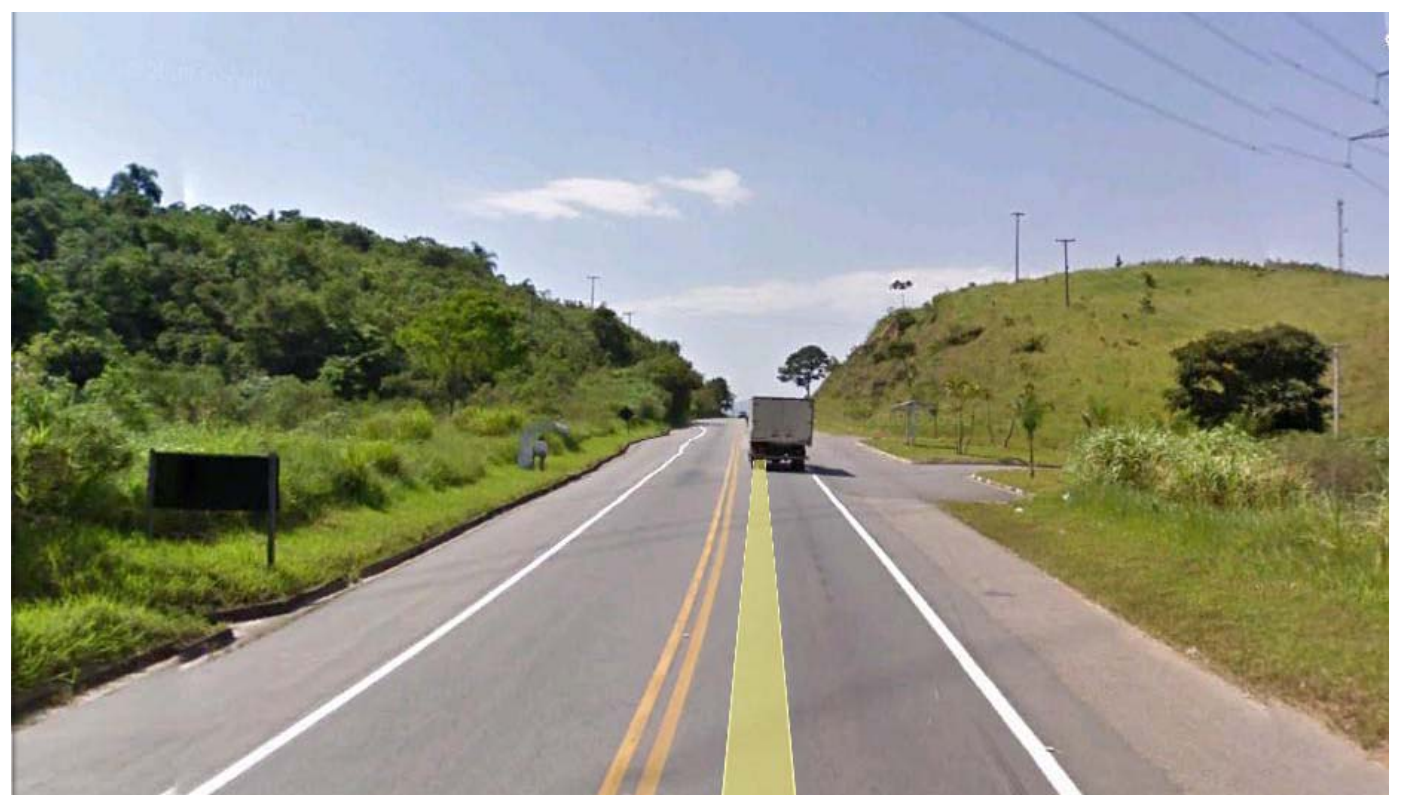

Figura 4-3 - Características do entorno, km 35+200, sentido Mogi das Cruzes. (Fonte: Google Earth, 2010)

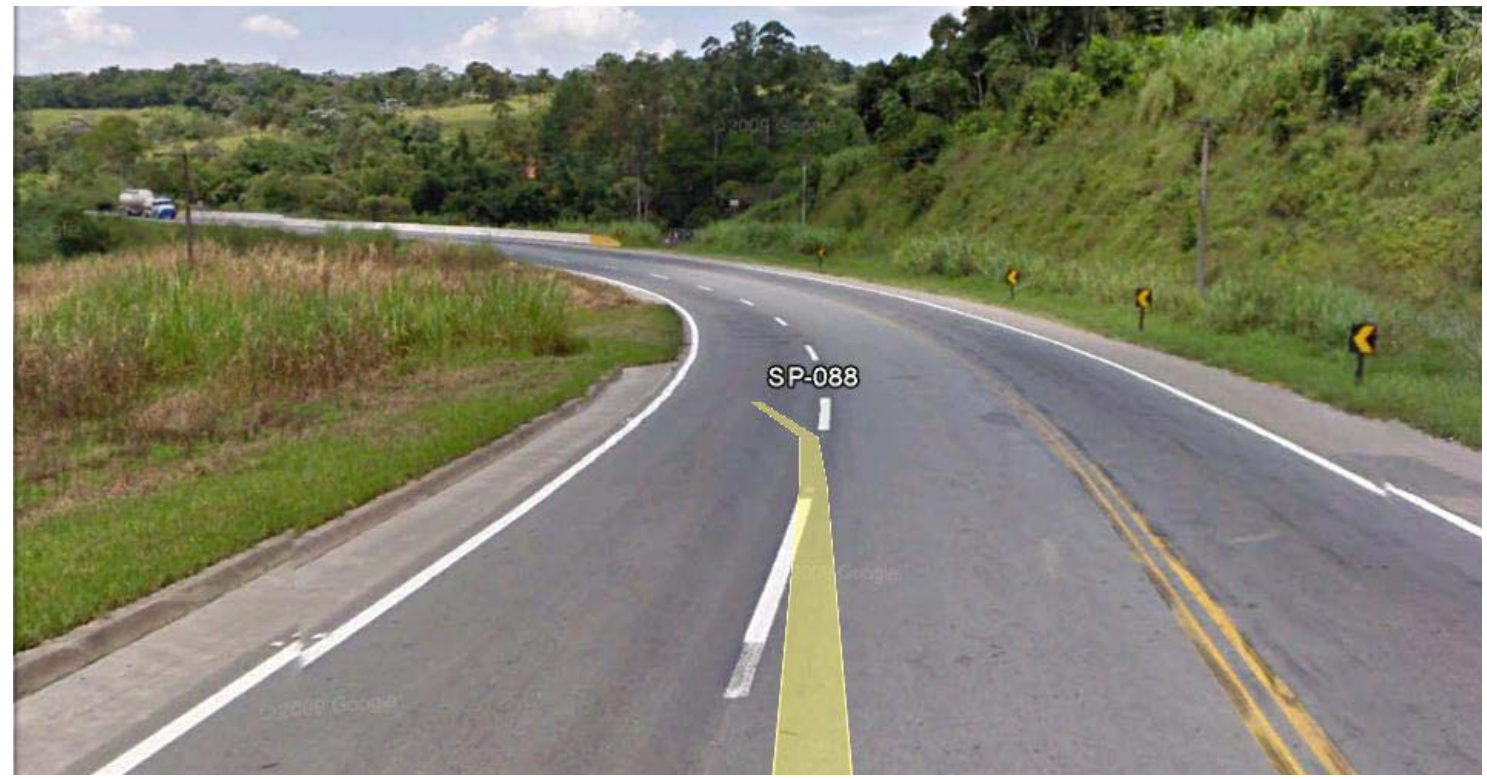

Figura 4-4 - Características do entorno, km 36+500, sentido Mogi das Cruzes. (Fonte: Google Earth, 2010) 


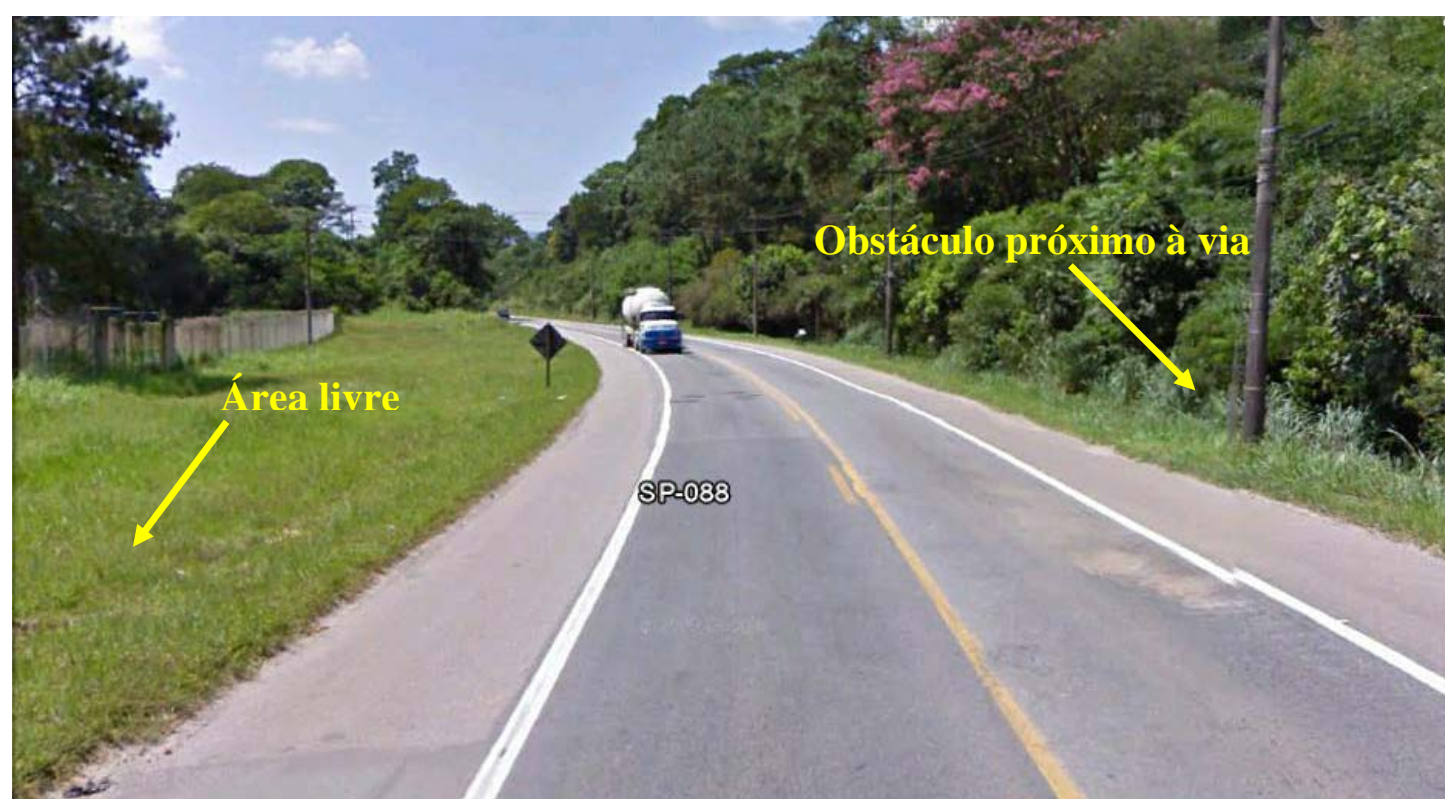

Figura 4-5 - Características do entorno, km 37+400, sentido Mogi das Cruzes. (Fonte: Google Earth, 2010)

As razões pelas quais a rodovia SP-088 foi escolhida são:

1. Facilidade de obtenção do levantamento topográfico cadastral: Por ser uma rodovia sob domínio do DER-SP, o levantamento topográfico cadastral pôde ser obtido com autorização do DER-SP.

2. Proximidade com a cidade de São Paulo: o levantamento fotográfico e as filmagens puderam ser feitos ao longo do trecho em tempo relativamente curto, uma vez que o tempo de viagem de São Paulo a rodovia SP-088 é de aproximadamente 40 minutos. Além disso, esta curta distância permitiu uma fácil vistoria do trecho de acordo com as necessidades que surgiram ao longo da pesquisa. Outra vantagem relacionada à proximidade com a cidade de São Paulo é o recurso Street View do programa de computador Google Earth ${ }^{\circledR}$, que permite a visualização da rodovia no nível do solo, bem como a melhor resolução disponível para as imagens aéreas nesta região.

3. Características geométricas e do entorno da via: A rodovia possui características geométricas que abrangem curvas horizontais para os dois sentidos, curvas verticais, rampas ascendentes e descendentes, e presença de obstáculos laterais como taludes de corte e aterro, postes de energia elétrica, árvores, dispositivos de proteção lateral e central, dispositivos de drenagem, etc. 
4. Características operacionais: Com um VDM de aproximadamente 16.000 e velocidade sinalizada de $80 \mathrm{~km} / \mathrm{h}$ torna-se interessante a aplicação dos critérios convencionais. Ao longo da rodovia, estas características são homogêneas, a menos de um trecho específico $(\mathrm{km} \mathrm{34+500} \mathrm{à} \mathrm{km} \mathrm{35+500)}$ onde são usados dispositivos redutores de velocidade (lombadas físicas) e a sinalização de regulamentação reduz o limite de velocidade para 30 $\mathrm{km} / \mathrm{h}$, pontualmente.

\subsection{COLETA DE DADOS DA RODOVIA SP-088}

\subsubsection{Levantamento dos obstáculos}

O cadastramento dos obstáculos compreende a identificação do tipo de obstáculo (poste, árvore, dispositivo de drenagem, dispositivo de proteção lateral, etc), a posição longitudinal com relação ao início do trecho, o afastamento lateral com relação à borda da pista, a extensão, a largura do obstáculo, e o lado da via onde se encontra o obstáculo. A identificação destes parâmetros é suficiente para aplicação das recomendações existentes apresentados nos capítulos 2 e 3 .

Para a identificação dos obstáculos foi tomado como referência o sentido crescente de quilometragem. Por exemplo, obstáculos localizados à direita ou à esquerda da via tem como base a observação para o sentido crescente de quilometragem, ou seja, o sentido Arujá - Mogi das Cruzes. Da mesma forma, a localização do início e fim dos obstáculos não pontuais baseia-se na quilometragem da rodovia. $\mathrm{O}$ afastamento lateral do obstáculo foi tomado com relação à borda da pista mais próxima ao obstáculo, isto é, para os obstáculos localizados à direita, foram tomadas as distâncias entre o obstáculo e a borda direita da pista, incluindo-se no afastamento a largura do acostamento (caso exista), e para o caso dos obstáculos localizados à esquerda, foram medidas as distâncias do obstáculo à borda esquerda da pista de rolamento, equivalente à borda direita da pista para o motorista que dirige em sentido contrário. A Figura 4-6 ilustra os parâmetros tomados no cadastramento dos obstáculos. 


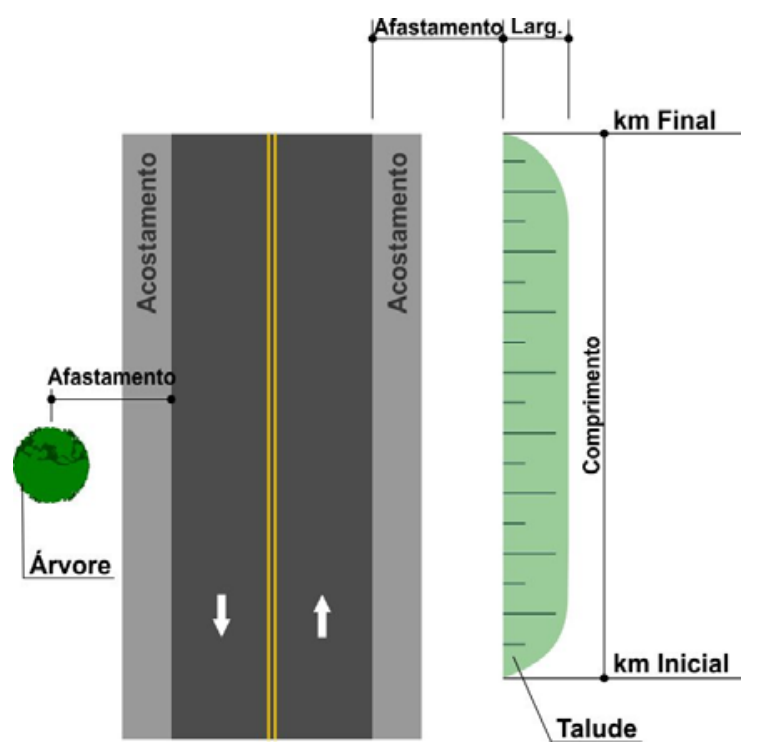

Figura 4-6 - Parâmetros tomados para o cadastramento dos obstáculos

Para a identificação dos obstáculos foram utilizados três recursos simultâneos: análise do levantamento topográfico em arquivo digital em formato $d w g$ com utilização do programa de computador AutoCAD ${ }^{\circledR}$, investigação de imagens aéreas do Google Earth ${ }^{\circledR}$ e investigação com o auxilio do recurso Street View do Google Earth ${ }^{\circledR}$. Como a data do levantamento topográfico é anterior a 2005 e as imagens do Google Earth ${ }^{\circledR}$ e do Street View são dos anos de 2008 e 2009, respectivamente, foram realizadas vistorias ao local com o objetivo de confirmação dos dados obtidos com os recursos mencionados. Durante a vistoria, foram feitas filmagens de todo o trecho, nos dois sentidos, bem como o registro fotográfico de alguns locais.

Foram adotados os seguintes critérios de seleção dos obstáculos para o estudo:

1. Não foram cadastrados obstáculos localizados além de taludes de corte altos, considerando que este tipo de característica é intransponível, com possibilidade nula do veículo desgovernado atingir tais obstáculos.

2. Não foram selecionados arbustos, árvores ou placas de sinalização de pequeno porte por não apresentarem consequências relevantes à saída de pista. Da mesma forma, cercas vivas nos limites das propriedades também não foram tomadas.

3. Não foram tomados os obstáculos localizados fora da área de levantamento topográfico, cuja faixa varia entre $30 \mathrm{~m}$ e $100 \mathrm{~m}$.

As Figura 4-7 e Figura 4-8, ilustram os casos 1 e 2, respectivamente. 


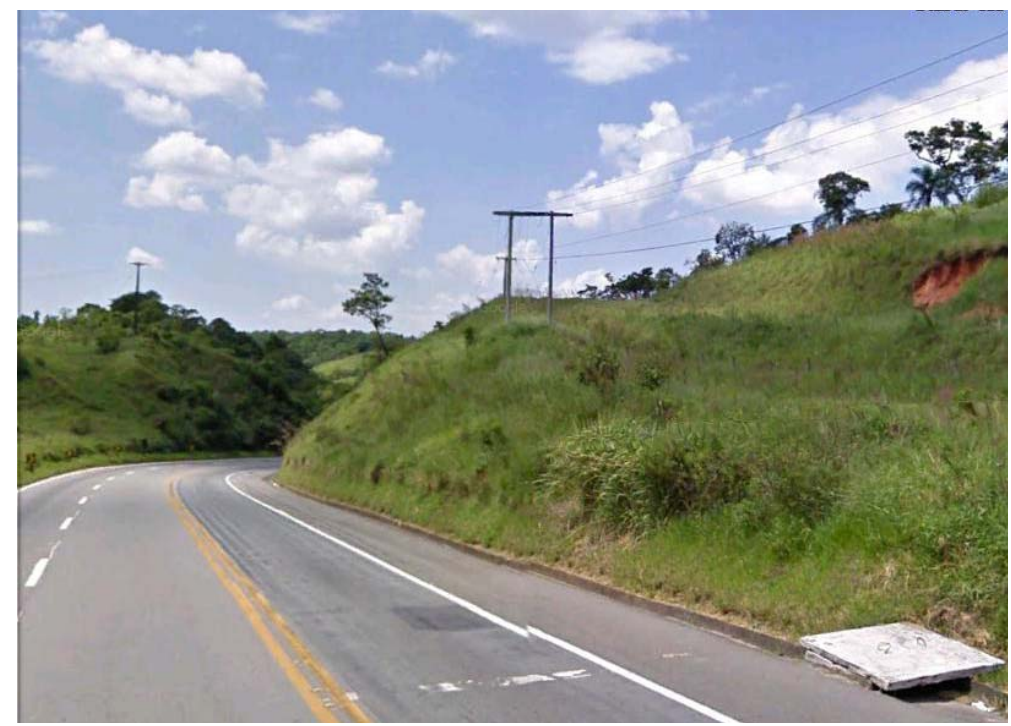

Figura 4-7 - Postes sobre cortes altos não foram considerados como obstáculos potenciais (foto: Google Earth, abril de 2011)
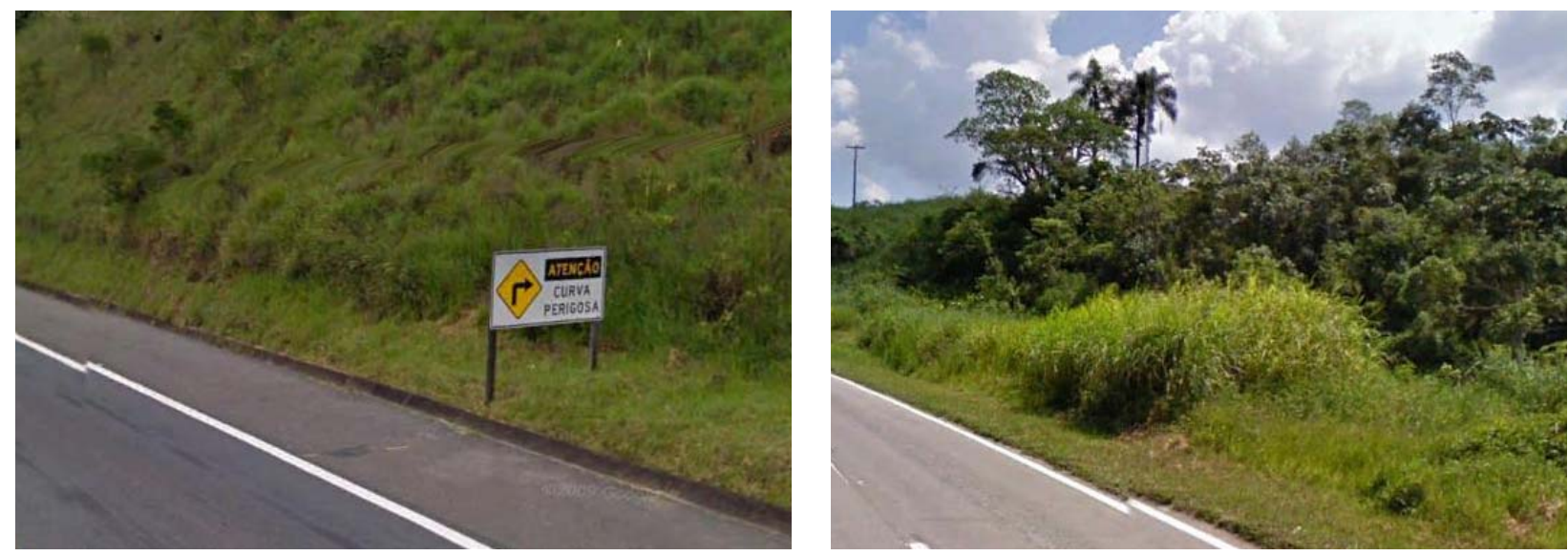

Figura 4-8 - À esquerda, placa de sinalização, e à direita, arbustos. Ambos não representam ameaças potenciais para veículos desgovernados (fotos: Google Earth, abril de 2011)

A identificação dos obstáculos baseou-se primeiramente na observação da topografia. Uma vez identificado o obstáculo, a verificação foi feita pelas imagens aéreas do Google Earth ${ }^{\circledR}$ e pelas fotos do recurso Street View do Google Earth ${ }^{\circledR}$. Verificado a coerência entre as fontes, as características do obstáculo como afastamento lateral, largura, extensão e quilometragem foram tomadas com o auxilio do programa de computador $A u t o C A D \circledR$.

Além do procedimento acima descrito para cadastramento dos obstáculos, foram feitas verificações, com o auxílio do recurso Street View, para identificar obstáculos que não estavam contidos no levantamento topográfico ou que foram alterados após o levantamento. Por exemplo, alguns postes e árvores faltavam no levantamento topográfico e puderam ter suas posições 
estimadas no Google Earth ${ }^{\circledR}$. Outro exemplo é a barreira de concreto situada aproximadamente

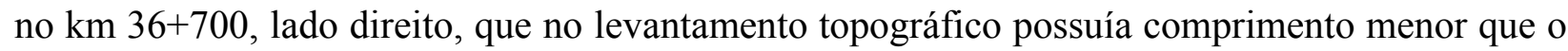
identificado no Street View.

A verificação final da existência/inexistência dos obstáculos foi feita através de vistoria de campo com auxilio de filmagens e fotografias realizadas durante o percurso do trecho, nos dois sentidos. Detectou-se, durante a vistoria de campo, que além dos obstáculos identificados nos recursos computacionais, havia duas placas de sinalização de grande porte, uma no km 32+825 e

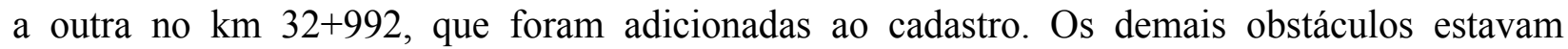
coerentes, segundo a vistoria.

Após a verificação da existência dos obstáculos, estes foram cadastrados em uma planilha contendo nas colunas as informações "código", "km inicio", "km fim”, "extensão do obstáculo", "tipo de obstáculo", "lado da via", "afastamento lateral”, "largura da pista direita", "largura da pista esquerda" e "largura do obstáculo". No caso dos dispositivos de proteção, foram também cadastrados os obstáculos por eles protegidos (seguindo os mesmos critérios).

Para cada obstáculo foram atribuídos códigos para facilitar o relacionamento do obstáculo no desenho em planta e suas características contidas na planilha de obstáculos:

- "TA" atribuídos aos obstáculos do tipo talude de aterro;

- "TC" aos obstáculos do tipo talude de corte;

- "TT" aos taludes transversais;

- "PE" aos postes de energia;

- “AR” às árvores;

- "DD" aos dispositivos de drenagem;

- "DP" aos dispositivos de proteção lateral;

- "ED” às edificações;

- "BR" aos brejos;

- "SI" aos dispositivos de sinalização de grande porte;

- "DE” para os desníveis gerados por passagens inferiores. 
A planilha completa contendo os 379 obstáculos considerados para o trecho entre os $\mathrm{km} 32+600$ e km 39+000 encontra-se no Anexo A, e a planta topográfica com a indicação dos obstáculos encontra-se no Anexo B.

Algumas dificuldades encontradas na fase do cadastramento dos obstáculos foram:

1. Ponto exato do marco quilométrico: no arquivo digital de topografia adquirido, as indicações dos marcos quilométricas foram feitas através de textos, sem conter linhas, círculos ou outra simbologia qualquer, que poderia indicar precisamente o quilômetro da rodovia. Outra questão é a defasagem quilométrica da rodovia entre os dois sentidos de circulação, isto é, a indicação do quilômetro para cada sentido da rodovia através da sinalização vertical nem sempre estava contida na mesma seção transversal. Portanto, como artifício para o referenciamento dos obstáculos, usou-se um novo estaqueamento buscando coincidir ao máximo as informações contidas na topografia e nas fotos do Google Earth ${ }^{\circledR}$.

2. Cadastros incompatíveis: devido à defasagem entre as datas do levantamento topográfico, das fotos aéreas do Google Earth ${ }^{\circledR}$ e do recurso Street View, alguns obstáculos precisaram ter suas posições e localizações estimadas, com base no posicionamento de entidades físicas presentes em mais de uma fonte. Além disso, por exemplo, as dimensões de algumas árvores, postes ou pontos de ônibus, por não estarem representados de forma fidedigna no desenho de topografia, tiveram de ser estimados com base na observação de elementos físicos de dimensões conhecidas presentes nas proximidades de tais obstáculos.

3. Inclinação dos taludes de corte e aterro. Embora bem representado no desenho de topografia, as curvas de nível que deveriam aparecer nos taludes de corte e aterro foram interrompidas, dificultando a medição da inclinação destes taludes.

Os obstáculos mais encontrados no entorno do trecho estudado, em termos de quantidade, foram os postes de iluminação $(38,1 \%)$, seguidos das árvores $(18,1 \%)$, taludes de corte $(15,2 \%)$ e taludes de aterro $(13,1 \%)$. Durante o cadastramento dos obstáculos, percebeu-se que nos acessos aos condomínios residenciais a quantidade de árvores decorrentes de razões paisagísticas era grande. A Figura 4-9 mostra a quantidade de obstáculo por tipo. 
Naturalmente, apesar dos postes estarem presentes em maior quantidade, a extensão efetiva resultante da somatória dos diâmetros de cada unidade representa pouco em relação ao comprimento total do trecho, por serem obstáculos pontuais. Por exemplo, admitindo que um poste tenha diâmetro de $25,5 \mathrm{~cm}$, a somatória dos diâmetros de todos os postes equivaleria a $37 \mathrm{~m}$, enquanto que a extensão total de taludes de aterro é de $4.502 \mathrm{~m}$. Mesmo ponderando uma área de influência que inclui duas vezes a largura dos veículos (menos de 5,1m no total) a somatória dos trechos com influência dos postes não passaria de 740m. Obviamente, deve-se ter em mente que nem todos os postes de energia estão em seções diferentes, podendo estar lado a lado, em uma mesma seção transversal. A Figura 4-10 mostra a extensão total por tipo de obstáculo.

Embora em maior número, como se vê na Figura 4-11, os postes de energia estão afastados lateralmente em relação à borda da pista, em média, de 18,7m. Já as defensas metálicas e as barreiras de concreto estão, em média, a 3,2 $\mathrm{m}$ e 2,0 $\mathrm{m}$ da borda da faixa de tráfego. Tomando a largura média da faixa de domínio obtida do levantamento topográfico de $25 \mathrm{~m}$, percebe-se que a maioria dos obstáculos cadastrados encontra-se dentro da faixa de domínio da rodovia.

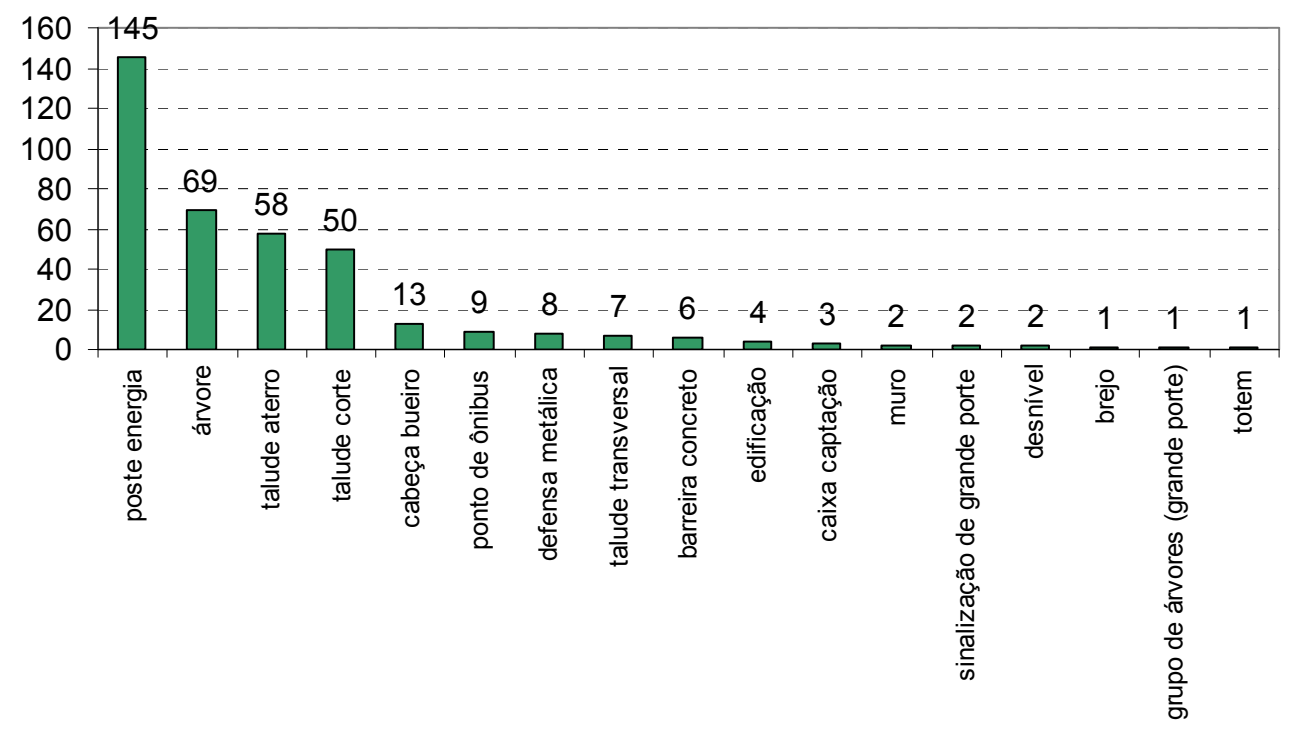

Figura 4-9 - Quantidade de obstáculos por tipo 


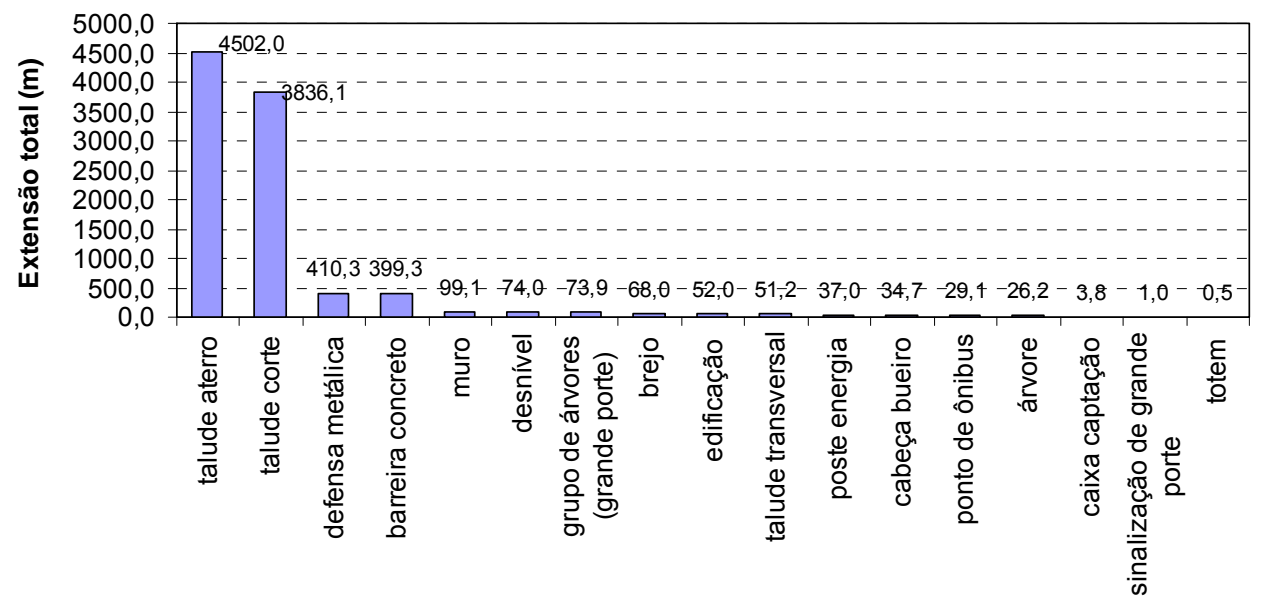

Figura 4-10 - Extensão total por tipo de obstáculo

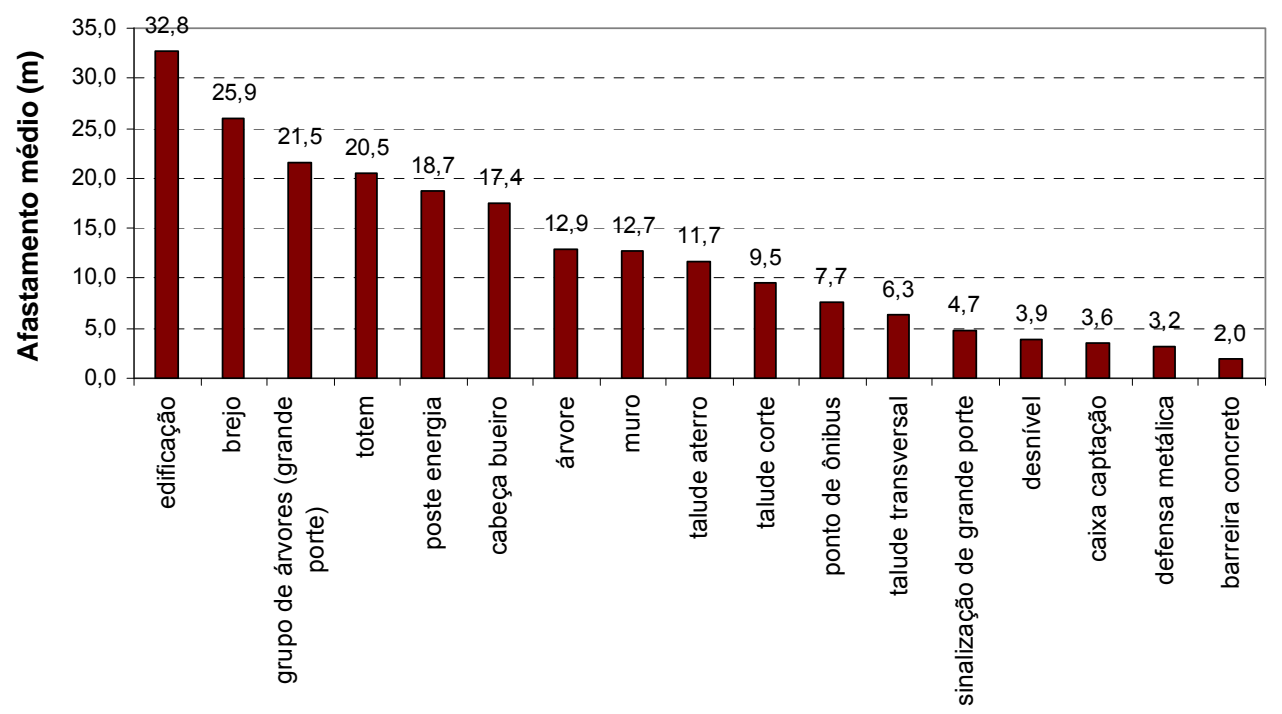

Figura 4-11 - Afastamento lateral médio do obstáculo à borda da pista

\subsubsection{Obtenção e tratamento dos dados de acidentes}

Para analisar a relação entre a segurança e as características do entorno da via no estudo de caso rodoviário, foram obtidas, junto ao DER/SP, as planilhas de acidentes de trânsito da SP-088, abrangendo o trecho do estudo, para os anos de 2009 e 2010. Estas planilhas contêm as informações de cada acidente ocorrido, tais como, o $\mathrm{km}$ em que ocorreu, o tipo de acidente, a data, a hora e o sentido da pista em que o acidente ocorreu. A informação sobre gravidade dos acidentes foi obtida apenas para 2009. Estas planilhas estão reproduzidas no Anexo C.

A separação dos acidentes por local ocorrido foi feita alocando-os em segmentos de $100 \mathrm{~m}$, dado o limite na precisão das informações constantes nas planilhas obtidas do DER/SP e dos 


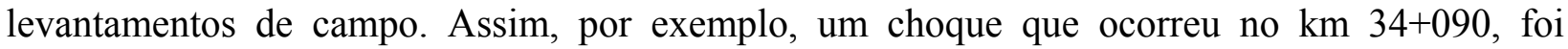

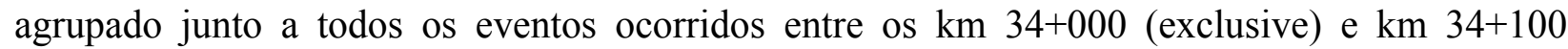
(inclusive). As Tabela 4-1 e Tabela 4-2 mostram o resultado da alocação dos acidentes por segmentos de $100 \mathrm{~m}$, para o sentido crescente e para o sentido decrescente.

Tabela 4-1 - Distribuição dos acidentes da planilha do DER/SP em segmentos de 100m (sentido crescente)

\begin{tabular}{|c|c|c|c|c|c|c|c|c|c|c|c|c|c|c|c|c|c|c|c|c|}
\hline \multirow{3}{*}{ Intervalo } & \multicolumn{20}{|c|}{ Sentido Crescente } \\
\hline & 2010 & 2009 & 2010 & 2009 & 2010 & 2009 & 2010 & 2009 & \begin{tabular}{|l|l|}
2010 & 2009 \\
\end{tabular} & \begin{tabular}{|l|l|}
2010 & 2009 \\
\end{tabular} & 2010 & 2009 & 2010 & 2009 & 2010 & 2009 & 2010 & 2009 & 2010 & 2009 \\
\hline & \multicolumn{2}{|c|}{$\mathrm{CHO}$} & \multicolumn{2}{|c|}{ CAP } & \multicolumn{2}{|c|}{ TOM } & & ATR & ATR AN. & ENG & C. $F$ & FRO & & LAT & C.TF & RAN & C.TR & RAS & OL & UT \\
\hline $\mathrm{km} 32600$ ao 32700 & & & & & & & & & & & & & & & & & & & & \\
\hline $\mathrm{km} 32700$ ao 32800 & & & & & & & & & & & & & & & & & & & & \\
\hline $\mathrm{km} 32800$ ao 32900 & & & & & & & & & & & & & & & & & & & & \\
\hline $\mathrm{km} 32900$ ao 33000 & & & & & & & 1 & & & & & & & & & & & & & \\
\hline $\mathrm{km} 33000$ ao 33100 & & & & & & & & 1 & & & & & & & & 1 & & & & \\
\hline $\mathrm{km} 33100$ ao 33200 & & & & & & & & & & & 1 & & & & & & & & & \\
\hline $\mathrm{km} 33200$ ao 33300 & & & & & & & & & & & & & & & & & & & & \\
\hline $\mathrm{km} 33300$ ao 33400 & & & & & & & & & & & & & & & & & & & & \\
\hline $\mathrm{km} 33400$ ao 33500 & & & & & & & & & & & & & & & & & & & & \\
\hline $\mathrm{km} 33500$ ao 33600 & & & & & & & & & & & & & & & & & & & & \\
\hline km 33600 ao 33700 & & & & & & & & & & & & & & & & & & & & \\
\hline $\mathrm{km} 33700$ ao 33800 & & & & & & & & & & & & & & & & & & & & \\
\hline $\mathrm{km} 33800$ ao 33900 & & & & & & & & & & & & & & & & & & & & \\
\hline $\mathrm{km} 33900$ ao 34000 & & & & 1 & & & & & & & & & & & & & & & & \\
\hline $\mathrm{km} 34000$ ao 34100 & & & & & & & & & & & & & & & & & & & & \\
\hline km 34100 ao 34200 & & & & & & & & & & & & & & & & & & & & \\
\hline $\mathrm{km} 34200$ ao 34300 & & & & & & & & & & & & & & & & & & & & \\
\hline $\mathrm{km} 34300$ ao 34400 & & & & & & & & & & & & & & & & & & & & \\
\hline $\mathrm{km} 34400$ ao 34500 & & 1 & & & & & & & & & & & & & & & & & & \\
\hline $\mathrm{km} 34500$ ao 34600 & & & & & 1 & & & & & & & & & & & & & & & \\
\hline $\mathrm{km} 34600$ ao 34700 & & & & & & & & & & & & & & & & & 2 & & 1 & \\
\hline $\mathrm{km} 34700$ ao 34800 & & & & & & & & & & & & & & & & & 4 & 1 & & \\
\hline $\mathrm{km} 34800$ ao 34900 & & & & & & & & & & & & & & & & & & & & \\
\hline $\mathrm{km} 34900$ ao 35000 & & & & & & & & & & & & & & & 1 & & 1 & & & \\
\hline km 35000 ao 35100 & & & & & & & & & & & & & & & & & 2 & & & \\
\hline $\mathrm{km} 35100$ ao 35200 & & & & & & & & & & & & & & & & & 2 & & & \\
\hline $\mathrm{km} 35200$ ao 35300 & & & & & & & & & & & & & & & & & 1 & & & \\
\hline $\mathrm{km} 35300$ ao 35400 & & & & & & & & & & & & & & & & & & & & \\
\hline $\mathrm{km} 35400$ ao 35500 & & & & & & & & & & & & & & & & & & & & \\
\hline $\mathrm{km} 35500$ ao 35600 & & & & & & & & & & & & & & & & & & & & \\
\hline $\mathrm{km} 35600$ ao 35700 & & & & & & & & & & & & & & & & & & & & \\
\hline $\mathrm{km} 35700$ ao 35800 & & & & & & & & & & & & & & & & & & & & \\
\hline $\mathrm{km} 35800$ ao 35900 & & & & & & & & & & & & & & & & & & & & \\
\hline $\mathrm{km} 35900$ ao 36000 & & 1 & & & & & & & & & & & & 1 & & 1 & & & & \\
\hline $\mathrm{km} 36000$ ao 36100 & 1 & 1 & & & & & & & & & & 1 & & & & & & & 1 & \\
\hline $\mathrm{km} 36100$ ao 36200 & & & & & & & & & & & & & & & & & & & & \\
\hline $\mathrm{km} 36200$ ao 36300 & & & & & & & & & & & & & & & & & & & & \\
\hline $\mathrm{km} 36300$ ao 36400 & & & & & & & & & & & & & & & & & & & & \\
\hline $\mathrm{km} 36400$ ao 36500 & & & & & & & & & & & & & & & & & & & & \\
\hline $\mathrm{km} 36500$ ao 36600 & & & & & 1 & & & & & & & & & & & & & & & \\
\hline $\mathrm{km} 36600$ ao 36700 & & & & & & 1 & & & & & & & & & & & & & & \\
\hline $\mathrm{km} 36700$ ao 36800 & & & & & & & & & & & & & & & & & & & & \\
\hline $\mathrm{km} 36800$ ao 36900 & & & & & & & & & & & & & & & & & & & & \\
\hline $\mathrm{km} 36900$ ao 37000 & & & 1 & & & & & & & & & & & & & & & & & \\
\hline $\mathrm{km} 37000$ ao 37100 & & & & & & & & & & & & & & & & & & & & \\
\hline $\mathrm{km} 37100$ ao 37200 & & & & & & & & & & & & & & & & & & & & \\
\hline km 37200 ao 37300 & & & & & & & & & & & & & & & & & & & & \\
\hline $\mathrm{km} 37300$ aо 37400 & & & & & & & & & & & & & & & & & & & & \\
\hline $\mathrm{km} 37400$ ao 37500 & & & & & & & & & & & & & & & & & & & & \\
\hline km 37500 ao 37600 & & & & & & & & & & & & & & & & & & & & \\
\hline km 37600 ao 37700 & & & & & & & & & & & & & & & & 1 & & & & \\
\hline km 37700 ao 37800 & & & & & & & & & & & & & & & & & & & & \\
\hline km 37800 aо 37900 & 1 & & & & & & & & & & & & 1 & & & & & 1 & & \\
\hline $\mathrm{km} 37900$ ao 38000 & & & & & & & & & & & & & & & & & 1 & & & \\
\hline $\mathrm{km} 38000$ ao 38100 & & & & & & & & & & & & & & & & 1 & & & & \\
\hline $\mathrm{km} 38100$ ao 38200 & & & & & & & & & & & & & & & & & & & & \\
\hline $\mathrm{km} 38200$ aо 38300 & & & & & & & & & & & & & & & & 1 & & & & \\
\hline $\mathrm{km} 38300$ ao 38400 & & & & & & & & & & & & & & & & & & & & \\
\hline $\mathrm{km} 38400$ ao 38500 & & 1 & & & & & & & & & & & & & & & & & & \\
\hline $\mathrm{km} 38500$ aо 38600 & & & & & & & & & & & & & & & & & & & & \\
\hline $\mathrm{km} 38600$ aо 38700 & & & & & & & & & & & & & & & & & & & & \\
\hline $\mathrm{km} 38700$ ao 38800 & & & & & & & & & & & & & & & & & 1 & & & \\
\hline $\mathrm{km} 38800$ ao 38900 & & & & & & & & & & & & & & & 1 & & 1 & & & \\
\hline $\mathrm{km} 38900$ aо 39000 & & & & & & & & & & & & & & & 1 & & 1 & 2 & & \\
\hline
\end{tabular}


Tabela 4-2 - Distribuição dos acidentes da planilha do DER/SP em segmentos de 100m (sentido decrescente)

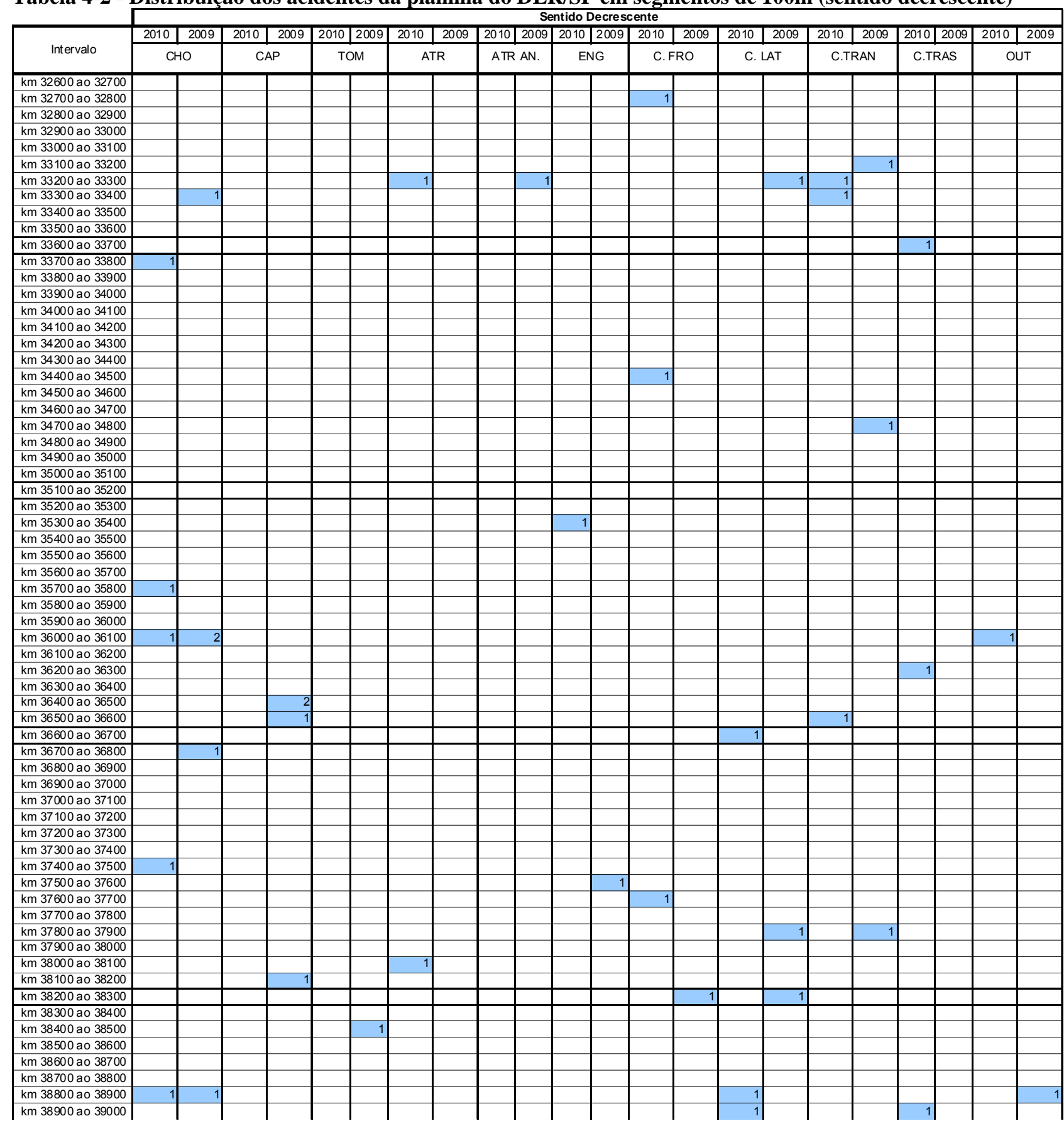

Como o foco do estudo é o entorno da via, o ideal seria obter a descrição de cada acidente que ocorreu, buscando a identificação dos acidentes que tem como consequência uma saída de pista, o que não está explicitamente registrado nas planilhas obtidas do DER/SP.

Os tipos de acidentes mais comumente associados às saídas de pista são os choques, os tombamentos e os capotamentos. No entanto, as colisões com ciclistas e os atropelamentos de pedestres podem ocorrer na lateral da via. Além disso, outros tipos de acidentes como as colisões 
frontais, laterais, traseiras e transversais, também podem ter saída de pista associadas e, por esta razão, não podem ser desprezadas. Por outro lado, um choque, por exemplo, pode ocorrer tanto com obstáculo fora da via, quanto com obstáculo dentro da via (que pode ser um veículo parado na via, ou algum objeto que caíra de algum outro veículo). Por isso, a análise dos acidentes de trânsito baseadas em boletins de ocorrência policiais ou informação similar para o trecho estudado seriam de melhor qualidade, mas infelizmente a obtenção destes dados não foi possível.

Para contornar a deficiência da falta da descrição dos acidentes nas planilhas obtidas junto ao $\mathrm{DER} / \mathrm{SP}$, teve-se de recorrer a uma pesquisa baseada nos relatórios de acidentes relevantes, fornecidas pela ARTESP, para trechos de rodovias de pista simples de cinco concessionárias de rodovias. Esta pesquisa consistiu na separação dos relatórios relacionados a acidentes ocorridos em trechos de pista simples e na análise do croqui e da descrição dos acidentes, buscando identificar aqueles em que houve saída de pista como conseqüência do primeiro evento.

Desta forma, cada acidente dos relatórios da ARTESP foi separado segundo seu tipo e a ocorrência ou não de uma saída de pista. As saídas de pista foram ainda separadas quanto ao lado de ocorrência, isto é, dado o sentido em que ocorreu o acidente, se ocorreram para o lado adjacente ou para o lado oposto do sentido considerado. Nos casos em que ocorreram saídas de pista para os dois lados como, por exemplo, em uma colisão frontal em que os dois veículos saíram para lados opostos, foram considerados 0,5 para cada lado (ou seja, metade do acidente para cada lado).

Com base na separação dos acidentes que tiveram ou não saídas de pista, as proporções dos acidentes com saídas de pista para cada tipo de acidente puderam ser obtidos segundo a expressão abaixo:

$$
f_{i, j}=\frac{n_{i, j}}{n_{i, \text { total }}}
$$

Onde

$\mathrm{f}_{\mathrm{i}, \mathrm{j}}=$ fator de correção do tipo $i$ para o lado $j$.

$\mathrm{n}_{\mathrm{i}, \mathrm{j}}=$ número de ocorrências do acidente do tipo $i$ para o lado $j$. 
$\mathrm{n}_{\mathrm{i}, \text { total }}=$ número de acidentes do tipo i com saída de pista para ambos os lados mais o número de acidentes sem saída de pista.

$\mathrm{i}=$ tipo de acidentes (choque, tombamento, capotamento, colisão frontal, etc.)

$\mathrm{j}=$ lado adjacente ou lado oposto

Portanto, a porcentagem dos acidentes de cada tipo que envolve saídas de pista pode ser utilizado como um fator de correção para obter acidentes com saídas de pista. A Tabela 4-3 abaixo mostra os valores calculados a partir dos dados de acidentes das cinco concessionárias analisadas.

Um problema encontrado nos relatórios de acidentes relevantes da ARTESP é que nem todas as descrições ou croquis dos acidentes com ocorrência de saídas de pista eram claros quanto ao lado da saída. Portanto, estes casos foram separados como "saída sem informação" e posteriormente foram alocadas entre as saídas adjacentes e saídas opostas em proporção às observadas. Outro problema foi o referente a selecionar rodovias com padrão físico e de tráfego similar ao do trecho estudado. Avaliou-se a variação dos fatores e da amostra de acidentes nos trechos de pista por concessionária e decidiu-se por utilizar fatores médios globais, dado que a amostra reduzida de acidentes em muitos trechos terminava por produzir padrões aleatórios na variação dos fatores médios específicos que não era possível explicar.

Nota-se, pela Tabela 4-3, que do total de colisões laterais e transversais, respectivamente $60 \%$ e $71,4 \%$ geraram saídas de pistas. Tendo em vista que estes tipos de acidentes em geral ocorrem em locais onde existem interseções, pode-se questionar, por exemplo, se o critério de majoração da área livre deveria restringir-se ao caso das curvas, ou também deveria ser aplicado em locais com interseções onde normalmente há obstáculos presentes. Estes aspectos não foram destacados na literatura analisada. 
Tabela 4-3 - Proporção de acidente com saída de pista calculados a partir dos dados dos relatórios de acidentes relevantes de cinco concessionárias de rodovias de pista simples da ARTESP.

\begin{tabular}{|c|c|c|c|c|c|c|c|c|}
\hline & \multicolumn{5}{|c|}{ Número de ocorrências } & \multirow[b]{2}{*}{$\begin{array}{l}\text { Fator para } \\
\text { saidas totais }\end{array}$} & \multirow[b]{2}{*}{$\begin{array}{c}\text { Fator para } \\
\text { saidas } \\
\text { adjacentes }\end{array}$} & \multirow[b]{2}{*}{$\begin{array}{c}\text { Fator para } \\
\text { saidas opostas }\end{array}$} \\
\hline Tipologia do acidente & $\begin{array}{c}\text { Sem saida } \\
\text { de pista }\end{array}$ & $\begin{array}{c}\text { Com saida } \\
\text { adjacente }\left({ }^{* *}\right)\end{array}$ & $\begin{array}{l}\text { Com saída } \\
\text { oposta }\left({ }^{* *}\right)\end{array}$ & $\begin{array}{c}\text { Saída sem } \\
\text { informação } \\
\text { de lado }\end{array}$ & Total & & & \\
\hline colisão frontal * & 15 & 9,5 & 3,5 & 1 & 29 & $48,3 \%$ & $35,3 \%$ & $13,0 \%$ \\
\hline colisão traseira & 8 & 1 & 2 & 0 & 11 & $27,3 \%$ & $9,1 \%$ & $18,2 \%$ \\
\hline colisão lateral & 2 & 2 & 0 & 1 & 5 & $60,0 \%$ & $60,0 \%$ & $0,0 \%$ \\
\hline colisão transversal & 2 & 2,5 & 2,5 & 0 & 7 & $71,4 \%$ & $35,7 \%$ & $35,7 \%$ \\
\hline choque & 0 & 5 & 1 & 1 & 7 & $100,0 \%$ & $83,3 \%$ & $16,7 \%$ \\
\hline capotamento & 0 & 3 & 1 & 2 & 6 & $100,0 \%$ & $75,0 \%$ & $25,0 \%$ \\
\hline atropelamento pedestre & 8 & 1 & 0 & 1 & 10 & $20,0 \%$ & $20,0 \%$ & $0,0 \%$ \\
\hline atropelamento animal & 0 & 0 & 0 & 0 & 0 & $0,0 \%$ & $0,0 \%$ & $0,0 \%$ \\
\hline engavetamento & 0 & 0 & 0 & 0 & 0 & $0,0 \%$ & $0,0 \%$ & $0,0 \%$ \\
\hline tombamento & 0 & 0 & 0 & 0 & 0 & $0,0 \%$ & $0,0 \%$ & $0,0 \%$ \\
\hline outros & 1 & 3 & 0 & 0 & 4 & $75,0 \%$ & $75,0 \%$ & $0,0 \%$ \\
\hline
\end{tabular}

Notas:

1. para as colisões frontais, a referencia para oposto e adjacente é o sentido em que ocorreu o evento.

2. nos casos em que cada um dos veículos saiu para um lado distinto, foi computado 0,5 para oposto e 0,5 para adjacente.

3. Os acidentes sem informação de lado de saída de pista foram alocados proporcionalmente entre as saídas adjacentes e saídas opostas.

É importante deixar claro que os relatórios de acidentes relevantes da ARTESP dizem respeito aos acidentes com fatalidades ou acidentes com conseqüências relevantes para o meio ambiente ou para a rodovia. Porém, duas das cinco concessionárias analisadas também forneceram dados acerca dos acidentes sem fatalidades ou sem conseqüências relevantes. Entretanto, devido à pequena amostra destes relatórios de acidentes não fatais, estes dados não puderam ser validados para serem agregados aos demais dados dos relatórios dos acidentes relevantes. Tampouco a informação sobre a composição dos acidentes por severidade foi considerada representativa.

Como critério de determinação para uma saída de pista, foi considerado aqueles casos de acidentes em que pelo menos um dos veículos envolvidos ultrapassou o limite da faixa de tráfego. Portanto, se o veículo após o evento primário parou no acostamento, o acidente foi considerado como com saída de pista. Obviamente, os dispositivos de proteção lateral estão ou deveriam estar além do acostamento, porém, o fato de ter ocorrido uma saída de pista dentro do acostamento é uma evidência de que o local é potencialmente um candidato a ter uso de dispositivo de proteção lateral. Naturalmente, buscou-se excluir os casos em que as saídas de pista para o acostamento foram controladas (e não decorreram do acidente).

\subsubsection{Localização dos acidentes com saída de pista}

Para a determinação dos acidentes com saídas de pista baseado nos acidentes relacionados nas Tabela 4-1 e Tabela 4-2, foram consideradas duas hipóteses: 
- A hipótese 1 considera que todos os tipos de acidentes ocorridos na SP-088 geram saídas de pista segundo a proporção indicada na Tabela 4-3. Para um determinado acidente ocorrido em um determinado sentido, pode haver saída de pista para a esquerda ou para a direita. Portanto, o cálculo do número de acidentes com saídas de pista para um segmento à direita, por exemplo, deve ser feito somando-se as saídas de pista adjacentes ocorridas no sentido crescente com as saídas de pista opostas ocorridas no sentido decrescente (com a utilização dos fatores de correção adjacentes e opostos encontrados na Tabela 4-3). O cálculo das saídas de pista para os segmentos à esquerda devem ser feitos de forma análoga. Baseado neste raciocínio, a determinação do número acidentes com saídas de pista para cada segmento foi feita somando-se o produto do número de acidentes de cada tipo pelo correspondente fator de correção obtido da Tabela 4-3, para os dois sentidos. Os gráficos das Figura 4-12 e Figura 4-13 mostram, respectivamente, a distribuição das médias (de 2009 e 2010) das saídas de pista por km, para o lado direito e esquerdo, segundo a hipótese 1 .

Saídas de pista, hipótese 1, lado direito

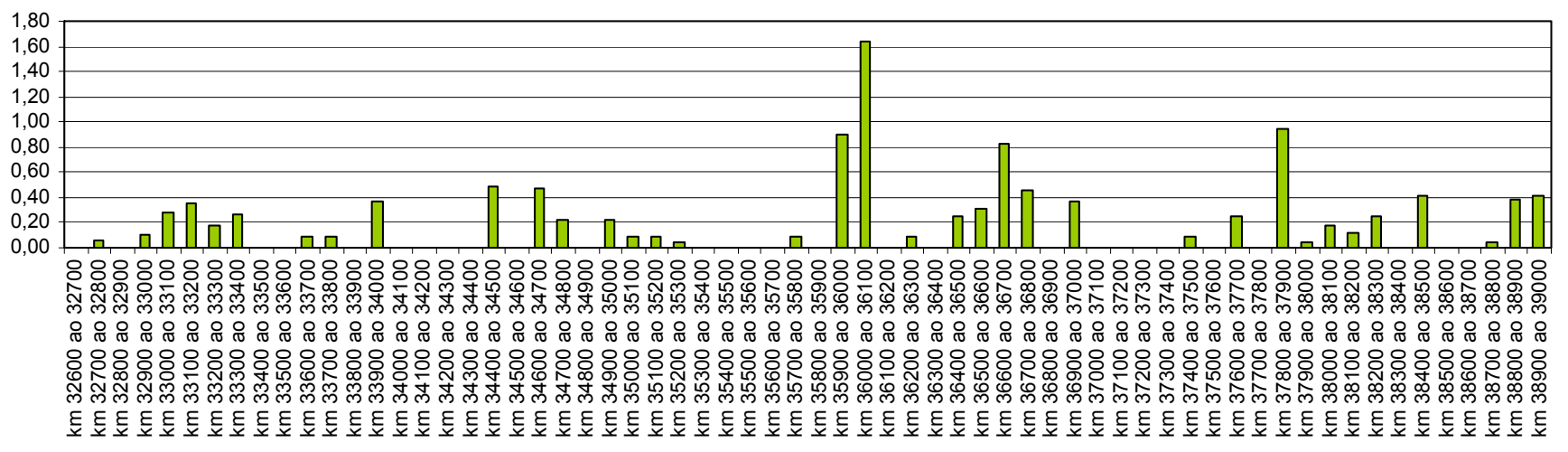

Figura 4-12 - Número de acidentes com saídas de pista x segmento (lado direito, hipótese 1)

Saídas de pista, hipótese 1, lado esquerdo

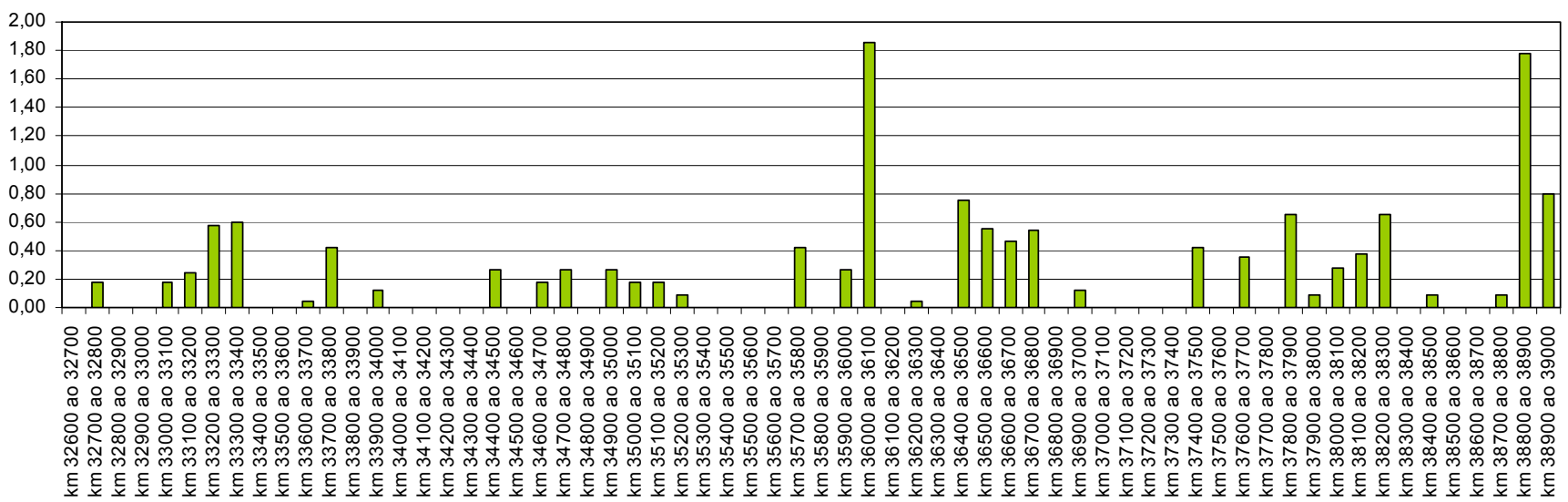

Figura 4-13 - Número de acidentes com saídas de pista x segmento (lado esquerdo, hipótese 1) 
- A hipótese 2 considera que 100\% dos choques, tombamentos e capotamentos decorreram de saídas de pista e ocorreram devido à presença de obstáculos nas laterais da rodovia. Foi considerado que os choques, tombamentos e capotamentos que ocorrem para o sentido crescente geram saídas de pista para o lado direito e os que ocorrem para o sentido decrescente geram saídas de pista para o lado esquerdo. Os gráficos das Figura 4-14 e Figura 4-15 mostram a distribuição das médias (de 2009 e 2010) das saídas de pista por km, para os lados direito e esquerdo, segundo a hipótese 2.

Saídas de pista, hipótese 2, lado direito

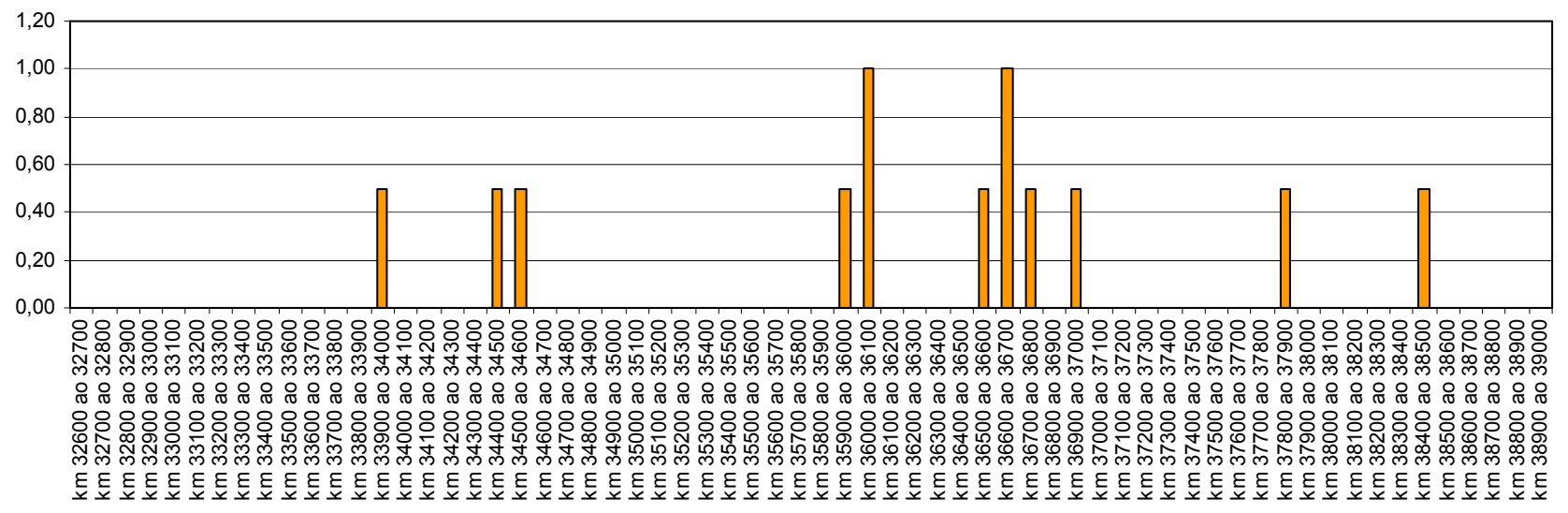

Figura 4-14 - Número de acidentes com saídas de pista x segmento (lado direito, hipótese 2)

Saídas de pista, hipótese 2, lado esquerdo

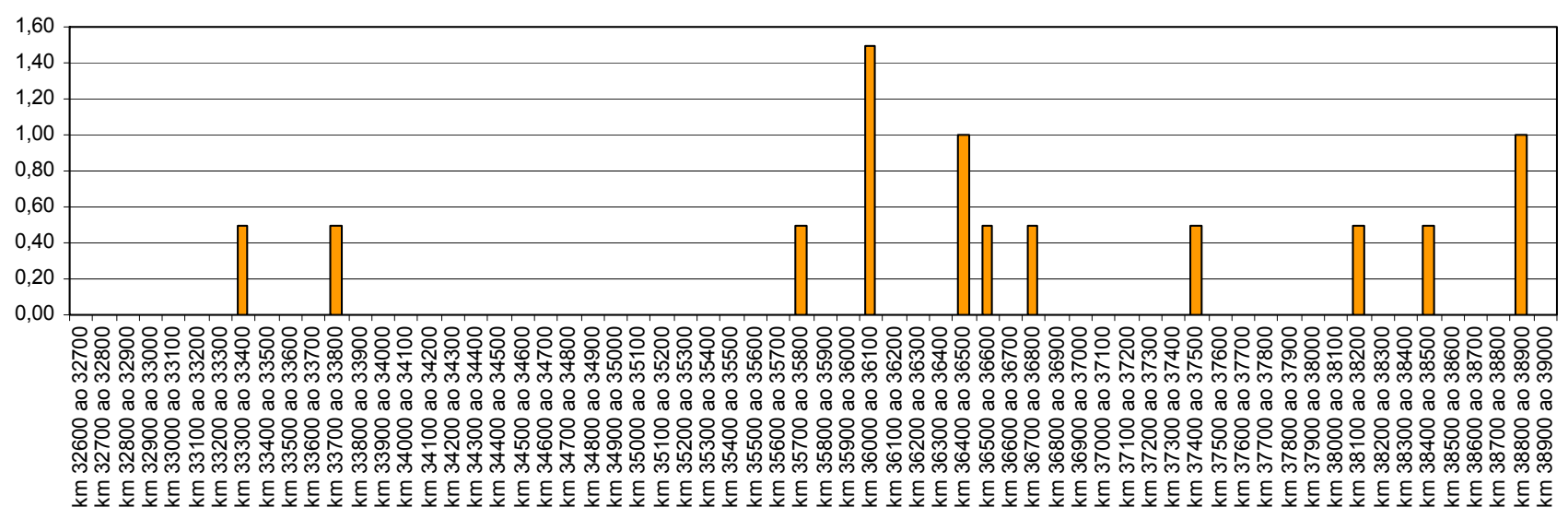

Figura 4-15 - Número de acidentes com saídas de pista x segmento (lado esquerdo, hipótese 2)

Para as análises seguintes, adotou-se como preferida a hipótese 1. A hipótese 2 foi adotada para verificar a robustez das conclusões. Ressalta-se que ambas as hipóteses tem as deficiências de contarem com um número reduzido de anos de observação $(2009,2010)$ e de não terem a 
descrição de cada acidente ocorrido para melhor identificação do que aconteceu (se realmente houve ou não saída de pista) e da gravidade do acidente.

As Tabela 4-4 e Tabela 4-5 ilustram o número médio de acidentes com saídas de pista, para as hipóteses 1 e 2 (e que deram origem aos gráficos das Figura 4-12, Figura 4-13, Figura 4-14 e Figura 4-15). Nestas mesmas tabelas são reproduzidas as respostas da aplicação do critério de proteção do RDG (2006) e do critério ampliado, que serão vistos com mais detalhes nos próximos itens. 
Tabela 4-4 - Situação dos segmentos quanto aos critérios e presença de acidentes com saídas de pista (lado direito)

\begin{tabular}{|c|c|c|c|c|c|c|}
\hline \multicolumn{7}{|c|}{ LADO DIREITO } \\
\hline \multirow{2}{*}{ Intervalo } & \multirow{2}{*}{$\begin{array}{c}\text { Requer } \\
\text { proteção? (RDG, } \\
2006)\end{array}$} & \multirow{2}{*}{$\begin{array}{l}\text { Requer proteção } \\
\text { ? (critério amplo) }\end{array}$} & \multirow{2}{*}{ Hipótese 1} & \multirow{2}{*}{ Hipótese 2} & $\begin{array}{l}\text { Saídas de pista } \\
\text { total (hipótese 1) }\end{array}$ & $\begin{array}{c}\text { Saídas de pista } \\
\text { total (hipótese 2) }\end{array}$ \\
\hline & & & & & média $(2009,2010)$ & média $(2009,2010)$ \\
\hline $\mathrm{km} 32600$ ao 32700 & sim & $\operatorname{sim}$ & não tem & não tem & 0,00 & 0,00 \\
\hline km 32700 ao 32800 & não & não & tem & não tem & 0,06 & 0,00 \\
\hline km 32800 ao 32900 & $\operatorname{sim}$ & $\operatorname{sim}$ & não tem & não tem & 0,00 & 0,00 \\
\hline km 32900 ao 33000 & $\operatorname{sim}$ & $\operatorname{sim}$ & tem & não tem & 0,10 & 0,00 \\
\hline km 33000 ao 33100 & $\operatorname{sim}$ & $\operatorname{sim}$ & tem & não tem & 0,28 & 0,00 \\
\hline km 33100 ao 33200 & não & não & tem & não tem & 0,35 & 0,00 \\
\hline km 33200 ao 33300 & $\operatorname{sim}$ & $\operatorname{sim}$ & tem & não tem & 0,18 & 0,00 \\
\hline km 33300 ao 33400 & não & $\operatorname{sim}$ & tem & não tem & 0,26 & 0,00 \\
\hline km 33400 ao 33500 & não & $\operatorname{sim}$ & não tem & não tem & 0,00 & 0,00 \\
\hline km 33500 ao 33600 & não & $\operatorname{sim}$ & não tem & não tem & 0,00 & 0,00 \\
\hline km 33600 ao 33700 & não & $\operatorname{sim}$ & tem & não tem & 0,09 & 0,00 \\
\hline km 33700 ao 33800 & $\operatorname{sim}$ & $\operatorname{sim}$ & tem & não tem & 0,08 & 0,00 \\
\hline km 33800 ao 33900 & não & $\operatorname{sim}$ & não tem & não tem & 0,00 & 0,00 \\
\hline km 33900 ao 34000 & $\operatorname{sim}$ & $\operatorname{sim}$ & tem & tem & 0,38 & 0,50 \\
\hline km 34000 ao 34100 & $\operatorname{sim}$ & $\operatorname{sim}$ & não tem & não tem & 0,00 & 0,00 \\
\hline $\mathrm{km} 34100$ ao 34200 & $\operatorname{sim}$ & $\operatorname{sim}$ & não tem & não tem & 0,00 & 0,00 \\
\hline km 34200 ao 34300 & não & não & não tem & não tem & 0,00 & 0,00 \\
\hline km 34300 ao 34400 & não & $\operatorname{sim}$ & não tem & não tem & 0,00 & 0,00 \\
\hline km 34400 ao 34500 & não & $\operatorname{sim}$ & tem & tem & 0,48 & 0,50 \\
\hline $\mathrm{km} 34500$ ao 34600 & não & não & não tem & tem & 0,00 & 0,50 \\
\hline km 34600 ao 34700 & não & não & tem & não tem & 0,47 & 0,00 \\
\hline km 34700 ao 34800 & não & não & tem & não tem & 0,22 & 0,00 \\
\hline km 34800 ao 34900 & $\operatorname{sim}$ & $\operatorname{sim}$ & não tem & não tem & 0,00 & 0,00 \\
\hline km 34900 ao 35000 & não & não & tem & não tem & 0,22 & 0,00 \\
\hline km 35000 ao 35100 & $\operatorname{sim}$ & $\operatorname{sim}$ & tem & não tem & 0,09 & 0,00 \\
\hline km 35100 ao 35200 & não & $\operatorname{sim}$ & tem & não tem & 0,09 & 0,00 \\
\hline km 35200 ao 35300 & não & não & tem & não tem & 0,05 & 0,00 \\
\hline km 35300 ao 35400 & não & não & não tem & não tem & 0,00 & 0,00 \\
\hline km 35400 ao 35500 & não & $\operatorname{sim}$ & não tem & não tem & 0,00 & 0,00 \\
\hline km 35500 ao 35600 & não & $\operatorname{sim}$ & não tem & não tem & 0,00 & 0,00 \\
\hline km 35600 ao 35700 & $\operatorname{sim}$ & $\operatorname{sim}$ & não tem & não tem & 0,00 & 0,00 \\
\hline km 35700 ao 35800 & $\operatorname{sim}$ & $\operatorname{sim}$ & tem & não tem & 0,08 & 0,00 \\
\hline km 35800 ao 35900 & não & $\operatorname{sim}$ & não tem & não tem & 0,00 & 0,00 \\
\hline km 35900 ao 36000 & não & $\operatorname{sim}$ & tem & tem & 0,90 & 0,50 \\
\hline km 36000 ao 36100 & não & $\operatorname{sim}$ & tem & tem & 1,63 & 1,00 \\
\hline km 36100 ao 36200 & não & não & não tem & não tem & 0,00 & 0,00 \\
\hline km 36200 ao 36300 & não & não & tem & não tem & 0,09 & 0,00 \\
\hline km 36300 ao 36400 & $\operatorname{sim}$ & $\operatorname{sim}$ & não tem & não tem & 0,00 & 0,00 \\
\hline km 36400 ao 36500 & $\operatorname{sim}$ & $\operatorname{sim}$ & tem & não tem & 0,25 & 0,00 \\
\hline km 36500 ao 36600 & não & não & tem & tem & 0,30 & 0,50 \\
\hline km 36600 ao 36700 & $\operatorname{sim}$ & $\operatorname{sim}$ & tem & tem & 0,83 & 1,00 \\
\hline km 36700 ao 36800 & $\operatorname{sim}$ & $\operatorname{sim}$ & tem & tem & 0,46 & 0,50 \\
\hline km 36800 ao 36900 & $\operatorname{sim}$ & $\operatorname{sim}$ & não tem & não tem & 0,00 & 0,00 \\
\hline km 36900 ao 37000 & $\operatorname{sim}$ & $\operatorname{sim}$ & tem & tem & 0,38 & 0,50 \\
\hline km 37000 ao 37100 & $\operatorname{sim}$ & $\operatorname{sim}$ & não tem & não tem & 0,00 & 0,00 \\
\hline km 37100 ao 37200 & $\operatorname{sim}$ & $\operatorname{sim}$ & não tem & não tem & 0,00 & 0,00 \\
\hline km 37200 ao 37300 & não & $\operatorname{sim}$ & não tem & não tem & 0,00 & 0,00 \\
\hline km 37300 ao 37400 & $\operatorname{sim}$ & $\operatorname{sim}$ & não tem & não tem & 0,00 & 0,00 \\
\hline km 37400 ao 37500 & $\operatorname{sim}$ & $\operatorname{sim}$ & tem & não tem & 0,08 & 0,00 \\
\hline km 37500 ao 37600 & $\operatorname{sim}$ & $\operatorname{sim}$ & não tem & não tem & 0,00 & 0,00 \\
\hline km 37600 ao 37700 & $\operatorname{sim}$ & $\operatorname{sim}$ & tem & não tem & 0,24 & 0,00 \\
\hline km 37700 ao 37800 & $\operatorname{sim}$ & $\operatorname{sim}$ & não tem & não tem & 0,00 & 0,00 \\
\hline km 37800 ao 37900 & $\operatorname{sim}$ & $\operatorname{sim}$ & tem & tem & 0,94 & 0,50 \\
\hline km 37900 ao 38000 & não & não & tem & não tem & 0,05 & 0,00 \\
\hline km 38000 ao 38100 & não & não & tem & não tem & 0,18 & 0,00 \\
\hline km 38100 ao 38200 & $\operatorname{sim}$ & $\operatorname{sim}$ & tem & não tem & 0,13 & 0,00 \\
\hline km 38200 ao 38300 & $\operatorname{sim}$ & $\operatorname{sim}$ & tem & não tem & 0,24 & 0,00 \\
\hline km 38300 ao 38400 & não & não & não tem & não tem & 0,00 & 0,00 \\
\hline km 38400 ao 38500 & $\operatorname{sim}$ & $\operatorname{sim}$ & tem & tem & 0,42 & 0,50 \\
\hline km 38500 ao 38600 & $\operatorname{sim}$ & $\operatorname{sim}$ & não tem & não tem & 0,00 & 0,00 \\
\hline km 38600 ao 38700 & $\operatorname{sim}$ & $\operatorname{sim}$ & não tem & não tem & 0,00 & 0,00 \\
\hline km 38700 ao 38800 & $\operatorname{sim}$ & $\operatorname{sim}$ & tem & não tem & 0,05 & 0,00 \\
\hline km 38800 ao 38900 & $\operatorname{sim}$ & $\operatorname{sim}$ & tem & não tem & 0,39 & 0,00 \\
\hline km 38900 ao 39000 & $\operatorname{sim}$ & $\operatorname{sim}$ & tem & não tem & 0,41 & 0,00 \\
\hline
\end{tabular}


Tabela 4-5 - Situação dos segmentos quanto aos critérios e presença de acidentes com saídas de pista (lado esquerdo)

\begin{tabular}{|c|c|c|c|c|c|c|}
\hline \multicolumn{7}{|c|}{ LADO ESQUERDO } \\
\hline \multirow{2}{*}{ Intervalo } & \multirow{2}{*}{$\begin{array}{c}\text { Requer } \\
\text { proteção? (RDG, } \\
2006)\end{array}$} & \multirow{2}{*}{$\begin{array}{l}\text { Requer proteção } \\
\text { ? (critério a mplo) }\end{array}$} & \multirow{2}{*}{ Hipótese 1} & \multirow{2}{*}{ Hipótese 2} & $\begin{array}{c}\text { Saídas de pista total } \\
\text { (hipótese 1) }\end{array}$ & $\begin{array}{l}\text { Saídas de pista } \\
\text { total (hipótese 2) }\end{array}$ \\
\hline & & & & & média $(2009,2010)$ & $\begin{array}{c}\text { média }(2009, \\
2010)\end{array}$ \\
\hline $\mathrm{km} 32600$ ao 32700 & não & não & não tem & não tem & 0,00 & 0,00 \\
\hline km 32700 ao 32800 & não & não & tem & não tem & 0,18 & 0,00 \\
\hline km 32800 ao 32900 & $\operatorname{sim}$ & $\operatorname{sim}$ & não tem & não tem & 0,00 & 0,00 \\
\hline km 32900 ao 33000 & $\operatorname{sim}$ & sim & não tem & não tem & 0,00 & 0,00 \\
\hline km 33000 ao 33100 & sim & sim & tem & não tem & 0,18 & 0,00 \\
\hline km 33100 ao 33200 & $\operatorname{sim}$ & $\operatorname{sim}$ & tem & não tem & 0,24 & 0,00 \\
\hline km 33200 ao 33300 & $\operatorname{sim}$ & $\operatorname{sim}$ & tem & não tem & 0,58 & 0,00 \\
\hline km 33300 ao 33400 & $\operatorname{sim}$ & $\operatorname{sim}$ & tem & tem & 0,60 & 0,50 \\
\hline km 33400 ao 33500 & $\operatorname{sim}$ & sim & não tem & não tem & 0,00 & 0,00 \\
\hline km 33500 ao 33600 & $\operatorname{sim}$ & sim & não tem & não tem & 0,00 & 0,00 \\
\hline km 33600 ao 33700 & não & $\operatorname{sim}$ & tem & não tem & 0,05 & 0,00 \\
\hline km 33700 ao 33800 & não & $\operatorname{sim}$ & tem & tem & 0,42 & 0,50 \\
\hline km 33800 ao 33900 & não & $\operatorname{sim}$ & não tem & não tem & 0,00 & 0,00 \\
\hline km 33900 ao 34000 & não & $\operatorname{sim}$ & tem & não tem & 0,13 & 0,00 \\
\hline km 34000 ao 34100 & $\operatorname{sim}$ & sim & não tem & não tem & 0,00 & 0,00 \\
\hline km 34100 ao 34200 & não & sim & não tem & não tem & 0,00 & 0,00 \\
\hline km 34200 ao 34300 & não & sim & não tem & não tem & 0,00 & 0,00 \\
\hline km 34300 ao 34400 & não & sim & não tem & não tem & 0,00 & 0,00 \\
\hline km 34400 ao 34500 & não & sim & tem & não tem & 0,26 & 0,00 \\
\hline km 34500 ao 34600 & $\operatorname{sim}$ & $\operatorname{sim}$ & não tem & não tem & 0,00 & 0,00 \\
\hline km 34600 ao 34700 & $\operatorname{sim}$ & $\operatorname{sim}$ & tem & não tem & 0,18 & 0,00 \\
\hline km 34700 ao 34800 & $\operatorname{sim}$ & $\operatorname{sim}$ & tem & não tem & 0,27 & 0,00 \\
\hline km 34800 ao 34900 & $\operatorname{sim}$ & sim & não tem & não tem & 0,00 & 0,00 \\
\hline km 34900 ao 35000 & $\operatorname{sim}$ & sim & tem & não tem & 0,27 & 0,00 \\
\hline km 35000 ao 35100 & $\operatorname{sim}$ & $\operatorname{sim}$ & tem & não tem & 0,18 & 0,00 \\
\hline km 35100 ao 35200 & não & $\operatorname{sim}$ & tem & não tem & 0,18 & 0,00 \\
\hline km 35200 ao 35300 & $\operatorname{sim}$ & $\operatorname{sim}$ & tem & não tem & 0,09 & 0,00 \\
\hline km 35300 ao 35400 & não & sim & não tem & não tem & 0,00 & 0,00 \\
\hline km 35400 ao 35500 & $\operatorname{sim}$ & $\operatorname{sim}$ & não tem & não tem & 0,00 & 0,00 \\
\hline km 35500 ao 35600 & $\operatorname{sim}$ & $\operatorname{sim}$ & não tem & não tem & 0,00 & 0,00 \\
\hline km 35600 ao 35700 & $\operatorname{sim}$ & $\operatorname{sim}$ & não tem & não tem & 0,00 & 0,00 \\
\hline km 35700 ao 35800 & $\operatorname{sim}$ & $\operatorname{sim}$ & tem & tem & 0,42 & 0,50 \\
\hline km 35800 ao 35900 & não & $\operatorname{sim}$ & não tem & não tem & 0,00 & 0,00 \\
\hline km 35900 ao 36000 & não & não & tem & não tem & 0,26 & 0,00 \\
\hline km 36000 ao 36100 & não & $\operatorname{sim}$ & tem & tem & 1,86 & 1,50 \\
\hline km 36100 ao 36200 & $\operatorname{sim}$ & $\operatorname{sim}$ & não tem & não tem & 0,00 & 0,00 \\
\hline km 36200 ao 36300 & $\operatorname{sim}$ & $\operatorname{sim}$ & tem & não tem & 0,05 & 0,00 \\
\hline km 36300 ao 36400 & $\operatorname{sim}$ & $\operatorname{sim}$ & não tem & não tem & 0,00 & 0,00 \\
\hline km 36400 ao 36500 & $\operatorname{sim}$ & $\operatorname{sim}$ & tem & tem & 0,75 & 1,00 \\
\hline km 36500 ao 36600 & $\operatorname{sim}$ & sim & tem & tem & 0,55 & 0,50 \\
\hline km 36600 ao 36700 & $\operatorname{sim}$ & $\operatorname{sim}$ & tem & não tem & 0,47 & 0,00 \\
\hline km 36700 ao 36800 & $\operatorname{sim}$ & $\operatorname{sim}$ & tem & tem & 0,54 & 0,50 \\
\hline km 36800 ao 36900 & não & sim & não tem & não tem & 0,00 & 0,00 \\
\hline km 36900 ao 37000 & $\operatorname{sim}$ & $\operatorname{sim}$ & tem & não tem & 0,13 & 0,00 \\
\hline km 37000 ao 37100 & $\operatorname{sim}$ & sim & não tem & não tem & 0,00 & 0,00 \\
\hline km 37100 ao 37200 & $\operatorname{sim}$ & $\operatorname{sim}$ & não tem & não tem & 0,00 & 0,00 \\
\hline km 37200 ao 37300 & $\operatorname{sim}$ & $\operatorname{sim}$ & não tem & não tem & 0,00 & 0,00 \\
\hline km 37300 ao 37400 & não & não & não tem & não tem & 0,00 & 0,00 \\
\hline km 37400 ao 37500 & não & $\operatorname{sim}$ & tem & tem & 0,42 & 0,50 \\
\hline km 37500 ao 37600 & $\operatorname{sim}$ & $\operatorname{sim}$ & não tem & não tem & 0,00 & 0,00 \\
\hline km 37600 ao 37700 & $\operatorname{sim}$ & $\operatorname{sim}$ & tem & não tem & 0,35 & 0,00 \\
\hline km 37700 ao 37800 & $\operatorname{sim}$ & $\operatorname{sim}$ & não tem & não tem & 0,00 & 0,00 \\
\hline km 37800 ao 37900 & $\operatorname{sim}$ & $\operatorname{sim}$ & tem & não tem & 0,65 & 0,00 \\
\hline km 37900 ao 38000 & $\operatorname{sim}$ & $\operatorname{sim}$ & tem & não tem & 0,09 & 0,00 \\
\hline km 38000 ao 38100 & $\operatorname{sim}$ & $\operatorname{sim}$ & tem & não tem & 0,28 & 0,00 \\
\hline km 38100 ao 38200 & $\operatorname{sim}$ & sim & tem & tem & 0,38 & 0,50 \\
\hline km 38200 ao 38300 & $\operatorname{sim}$ & $\operatorname{sim}$ & tem & não tem & 0,65 & 0,00 \\
\hline km 38300 ao 38400 & não & não & não tem & não tem & 0,00 & 0,00 \\
\hline km 38400 ao 38500 & $\operatorname{sim}$ & $\operatorname{sim}$ & tem & tem & 0,08 & 0,50 \\
\hline km 38500 ao 38600 & não & não & não tem & não tem & 0,00 & 0,00 \\
\hline km 38600 ao 38700 & $\operatorname{sim}$ & $\operatorname{sim}$ & não tem & não tem & 0,00 & 0,00 \\
\hline km 38700 ao 38800 & $\operatorname{sim}$ & $\operatorname{sim}$ & tem & não tem & 0,09 & 0,00 \\
\hline km 38800 ao 38900 & não & não & tem & tem & 1,78 & 1,00 \\
\hline km 38900 ao 39000 & $\operatorname{sim}$ & $\operatorname{sim}$ & tem & não tem & 0,80 & 0,00 \\
\hline
\end{tabular}




\subsection{ANÁLISE DA OBSERVÂNCIA ÀS RECOMENDAÇÕES PARA O USO DE DISPOSITIVOS DE PROTEÇÃO LATERAL}

A análise da observância às recomendações existentes para o uso de dispositivo de proteção lateral foi baseada, a priori, em cada obstáculo individualmente. Esta análise considerou basicamente o atendimento aos critérios de área livre contidas no RDG (2006) e a presença do obstáculo que necessita ser protegido.

Para determinada característica geométrica e operacional do local no qual o obstáculo está inserido, foi determinada a área livre requerida através da Tabela 2-2, e corrigida, de acordo com a presença de curvas horizontais, pelos fatores da Tabela 2-3. Os valores de área livre requerida corrigidos foram então comparados com os afastamentos laterais dos obstáculos para determinar a necessidade do uso de proteção lateral.

Obviamente, como recomendam os manuais e normas apresentados no capítulo 2 acerca da área livre e do entorno tolerante, antes da utilização da proteção lateral é necessário avaliar outras medidas, tais como, a remoção ou relocação do obstáculo, a utilização de materiais colapsíveis ou a possibilidade de tornar o obstáculo atravessável. No entanto, no caso de obstáculos que claramente poderiam ser removidos ou relocados, a necessidade de proteção foi inicialmente mantida, examinando-se posteriormente a existência da opção de remover ou relocar.

Alguns obstáculos não pontuais precisaram ser segmentados de acordo com as características geométricas do alinhamento horizontal, pois no caso de um obstáculo longo, parte dele poderia estar em tangente, e parte na curva. Além disso, como a análise da relação entre os critérios para o uso de dispositivo de proteção lateral e a ocorrência de acidentes, apresentada no próximo item, foi feita através de segmentos de $100 \mathrm{~m}$ de extensão, então os obstáculos que excederam esta dimensão também foram segmentados, porém mantidos com a mesma codificação.

As tabelas do Anexo A contêm, além dos obstáculos cadastrados, a análise da observância aos critérios de área livre e ao uso de dispositivos de proteção lateral. A antepenúltima coluna das tabelas do Anexo A mostra o valor de área livre requerido para a velocidade considerada no segmento e para as características geométricas do local. A penúltima coluna mostra se o obstáculo requer ou não proteção, baseado na comparação entre a área livre requerida e o afastamento lateral do obstáculo. Se o obstáculo requer proteção e não está protegido, então o 
valor da coluna é "sim", isso é, "sim, requer proteção". Se o obstáculo não requer proteção e não está protegido, então o valor da coluna é "não". Se o obstáculo requer proteção e já estiver protegido, então o valor da coluna é "protegido". Não foram encontrados casos em que o obstáculo não requer proteção, mas que existe a proteção na situação existente. Para as defensas metálicas e barreiras de concreto, o valor da coluna é "proteção".

Um aspecto peculiar foi analisado de forma distinta. De acordo com a Tabela 2-1 obtida do RDG (2006), os taludes de corte sem protuberâncias geralmente não requerem proteção. Entretanto, a intuição leva a crer que o impacto com um talude de corte com inclinação da ordem de 1:1 pode causar conseqüências graves. Portanto, decidiu-se avaliar este tipo de característica como sendo um obstáculo potencial, separadamente na última coluna, nomeado de "critério ampliado", baseado na comparação entre a ocorrência de acidentes com saídas de pista apresentado no próximo item. A última coluna diferencia-se da penúltima com relação à consideração dos taludes de corte como obstáculos potenciais. Portanto, nesta última coluna, as linhas correspondentes aos taludes de corte possuem valor "sim".

A Figura 4-16(a) abaixo mostra o percentual de obstáculos ou segmentos de obstáculos segundo sua situação na via. Entre os casos que não requerem proteção, há total coerência com o critério do RDG (2006). Para os casos que requerem proteção a situação é distinta: dos $27 \%$ que requerem proteção, $3 \%$ dos locais estão protegidos e $24 \%$ não estão ( $88 \%$ dos que requerem proteção), uma divergência notável. Portanto $76 \%$ dos obstáculos ou segmentos de obstáculos observam os critérios existentes, representado pela soma daqueles que não necessitam proteção e não estão protegidos $(73 \%)$ com aqueles que necessitam proteção e que estão protegidos (3\%), com preponderância dos casos sem proteção. Por outro lado, $24 \%$ dos obstáculos estão incoerentes com os critérios existentes para o uso de proteção lateral pela sua falta de utilização e em nenhum caso pelo uso injustificado. Para o critério amplo, como se vê na Figura 4-16(b), $37 \%$ dos obstáculos ou segmentos de obstáculos deveriam estar protegidos e não estão.

(a)

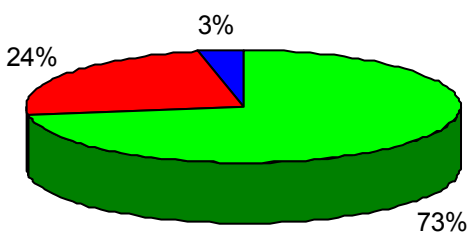

(b)

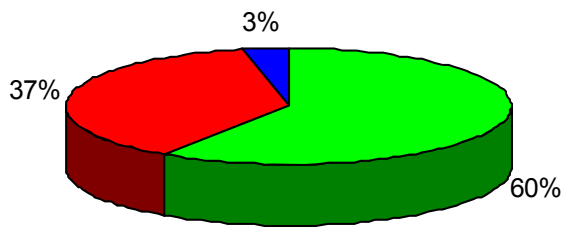

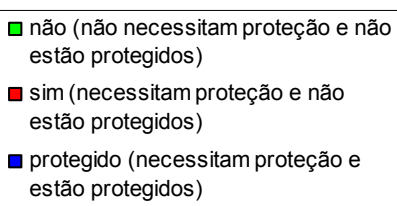

não (não necessitam proteção e não

protegido (necessitam proteção e estão protegidos)

Figura 4-16 - Porcentagem dos obstáculos ou segmentos de obstáculos que observam ou não: (a) os critérios do RDG (2006) para o uso de proteção lateral, (b) critério ampliado 
Tabela 4-6 - Quantidade de obstáculos ou segmentos de obstáculos que observam ou não os critérios do RDG (2006) para o uso de proteção lateral e critério ampliado

\begin{tabular}{|c|c|c|c|c|c|c|}
\hline \multirow{2}{*}{ Situação do obtáculo } & \multicolumn{3}{c|}{ Critério RDG (2006) } & \multicolumn{3}{c|}{ Critério Ampliado } \\
\cline { 2 - 7 } & direito+esquerdo & esquerdo & direito & direito+esquerdo & esquerdo & direito \\
\hline $\begin{array}{c}\text { não (não nec essitam proteção e } \\
\text { não estão protegidos) }\end{array}$ & 330,00 & 148,00 & 182,00 & 269,00 & 120,00 & 149,00 \\
$\operatorname{sim} \begin{array}{c}\text { (necessitam proteção e não } \\
\text { estão protegidos) }\end{array}$ & 108,00 & 60,00 & 48,00 & 169,00 & 88,00 & 81,00 \\
$\begin{array}{c}\text { protegido (necessitam proteção e } \\
\text { estão protegidos) }\end{array}$ & 15,00 & 6,00 & 9,00 & 15,00 & 6,00 & 9,00 \\
\hline
\end{tabular}

Excluindo-se os obstáculos ou segmentos de obstáculos que não necessitam ser protegidos e analisando somente aqueles que necessitam ser protegidos, a inobservância aos critérios do RDG (2006) passa de 88\%, conforme Figura 4-17(a), para 92\% com relação ao critério amplo, conforme Figura 4-17(b).

(a)

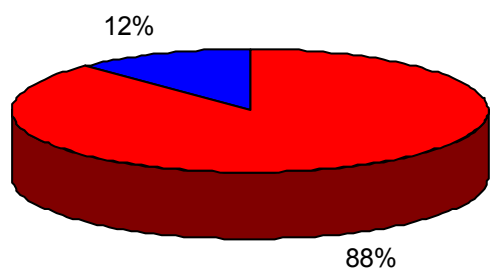

(b)

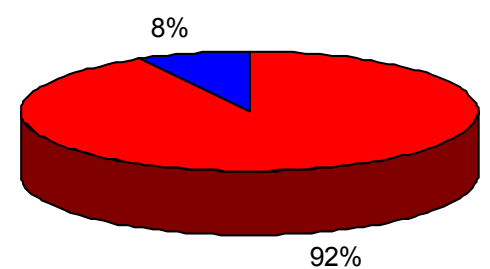

$\operatorname{sim}$ (necessitam proteção e não estão protegidos)

- protegido (necessitam proteção e estão protegidos)

Figura 4-17 - Porcentagem dos obstáculos ou segmentos de obstáculos que requerem proteção e que são ou não protegidos: (a) pelo critério do RDG(2006), (b) pelo critério ampliado.

Dentre os obstáculos ou segmentos de obstáculos que deveriam ser protegidos, os taludes de aterro correspondem à maior parte (58\%), seguidos das árvores $(17 \%)$ e dos postes de energia elétrica (11\%), considerando o critério do RDG (2006) (ver Figura 4-18a). Em se tratando do critério amplo, os taludes de corte representam grande parte dos obstáculos que deveriam ser protegidos e não estão (ver Figura 4-18b). Pontos de ônibus, taludes transversais e caixas de captação de águas pluviais, representam as menores parcelas.

(a)

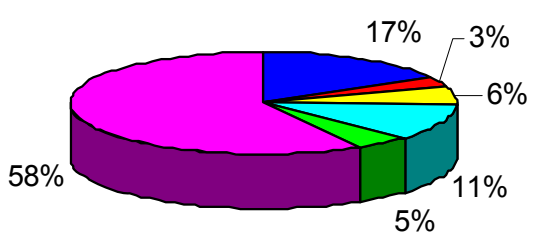

(b)

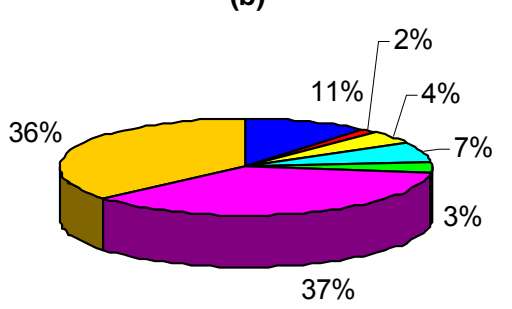

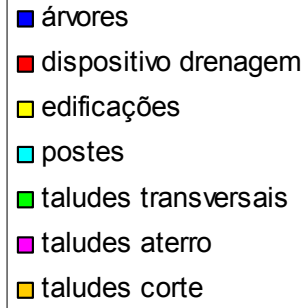

Figura 4-18 - Obstáculos que não observam as recomendações: (a) do RDG (2006) e (b) do critério ampliado 
Tabela 4-7 - Número de obstáculos que requerem proteção e não estão protegidos

\begin{tabular}{l|rrr}
\hline \multirow{2}{*}{ Obstáculo } & direito & esquerdo & direito+esquerdo \\
\cline { 2 - 4 } & \multicolumn{2}{c|}{ Critério RDG (2006) } \\
\hline árvores & 8,00 & 10,00 & 18,00 \\
dispositivo drenagem & 2,00 & 1,00 & 3,00 \\
edificações & 2,00 & 5,00 & 7,00 \\
postes & 10,00 & 2,00 & 12,00 \\
taludes transversais & 2,00 & 3,00 & 5,00 \\
taludes aterro & 24,00 & 39,00 & 63,00 \\
TOTAL & 48,00 & 60,00 & 108,00 \\
& & & \\
& Critér io ampliado & 18,00 \\
árvores & 8,00 & 10,00 & 3,00 \\
dispositivo drenagem & 2,00 & 1,00 & 7,00 \\
edificações & 2,00 & 5,00 & 12,00 \\
postes & 10,00 & 2,00 & 5,00 \\
taludes transversais & 2,00 & 3,00 & 63,00 \\
taludes aterro & 24,00 & 39,00 & 61,00 \\
taludes corte & 33,00 & 28,00 & 108,00 \\
TOTAL & 81,00 & 88,00 & \\
\hline
\end{tabular}

Ainda analisando os obstáculos que não observam os critérios recomendados pelo RDG (2006), concluiu-se que $68 \%$ deles não possuíam alternativas ao uso de proteção lateral, ou pelo menos estas alternativas seriam mais custosas ou de maior dificuldade de execução, e pelo critério amplo esta proporção chega a $80 \%$. Nestas situações se enquadrariam os taludes de aterro, taludes de corte, os pontos de ônibus e os taludes transversais. Os demais obstáculos possuíam alternativas para a observância aos critérios recomendados como a remoção, a relocação ou torná-los transpassável, em geral aplicados às árvores, aos postes de energia e aos dispositivos de drenagem, respectivamente. A Figura 4-19 ilustra esta proporção.

Portanto, a inobservância para os casos que requerem proteção é ainda relevante.

(a)

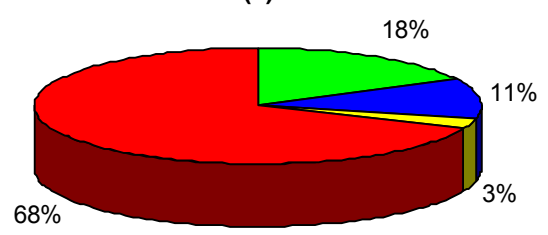

(b)

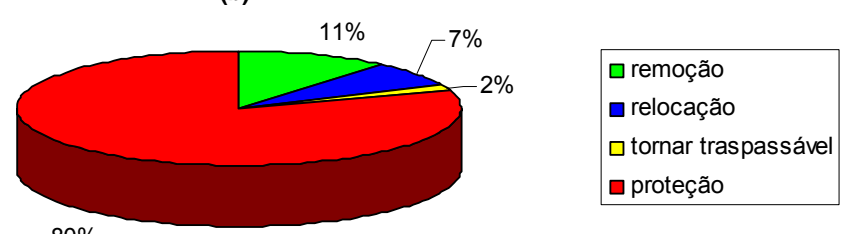

$80 \%$

Figura 4-19 - Alternativas ao uso de proteção lateral para os obstáculos que não foram protegidos: (a) sem considerar taludes de corte, (b) considerando talude de corte 
Tabela 4-8 - Número de obstáculos com tratamento alternativo à proteção lateral

\begin{tabular}{l|ccc}
\multicolumn{1}{c}{ Tratamento alternativo } & direito & esquerdo & direi to+esquerdo \\
\cline { 2 - 4 } & \multicolumn{3}{c}{ Critério RDG (2006) } \\
\hline remoção & 8,00 & 11,00 & 19,00 \\
relocação & 11,00 & 1,00 & 12,00 \\
tornar traspassável & 2,00 & 1,00 & 3,00 \\
proteção & 27,00 & 47,00 & 74,00 \\
TOTAL & 48,00 & \multicolumn{3}{c}{ Critério ampliado } \\
\cline { 2 - 4 } & 8,00 & 11,00 & 108,00 \\
remoção & 11,00 & 1,00 & 19,00 \\
relocação & 2,00 & 1,00 & 3,00 \\
tornar traspassável & 60,00 & 75,00 & 135,00 \\
proteção & 81,00 & 88,00 & 169,00 \\
TOTAL & \multicolumn{3}{c}{} \\
\hline
\end{tabular}

\subsection{ANÁLISE DA RELAÇÃO ENTRE OS CRITÉRIOS RECOMENDADOS E A OCORRÊNCIA DE ACIDENTES COM SAÍDAS DE PISTA}

O objetivo deste tópico é analisar a relevância para a segurança de tráfego da aplicação dos critérios do RDG (2006) à rodovia SP-088, por meio da verificação da ocorrência de acidentes com saídas de pista, em segmento de 100m. Quatro situações podem ocorrer:

1. O segmento requer proteção e tem acidente com saída de pista;

2. O segmento requer proteção e não tem acidentes com saída de pista;

3. O segmento não requer proteção e tem acidentes com saída de pista;

4. O segmento não requer proteção e não tem acidentes com saída de pista.

É importante frisar que a necessidade de proteção lateral está relacionada com a presença de obstáculo e não com as saídas de pista. Locais com elevada frequência de saídas de pista, porém com área livre de obstáculos, em tese, não necessitam de proteção lateral. O que se quer verificar neste tópico é a relação entre o que é recomendado e a ocorrências de saídas de pista com a possibilidade de haver choque com obstáculo na lateral da via. Portanto, a situação 1 indicaria o sucesso da recomendação, e neste caso a inobservância seria importante. $\mathrm{Na}$ situação 2, a recomendação teria fracassado e a inobservância não seria claramente condenada (com os dados utilizados). Uma redução do requisito de área livre seria uma potencial correção do critério.

$\mathrm{Na}$ situação 3, a ocorrência de acidentes indicaria que a presença de obstáculo deveria recomendar a proteção, o que pode não ter ocorrido por falha no critério de área livre. Por fim, a situação 4 é ambígua: a falta de acidentes com saídas de pista pode decorrer da ausência de obstáculos (se eles existissem haveria uma recomendação correta) ou da ausência de saídas de 
pista (caso em que mesmo a presença de obstáculo dispensaria proteção). A extensão da área livre também seria uma questão relevante, em ambos os casos.

Conforme dito anteriormente, a análise está baseada em segmentos de $100 \mathrm{~m}$, e como pode haver mais de um obstáculo nesta extensão, o segmento foi classificado como "requer proteção" se pelo menos um obstáculo requer proteção. Por outro lado, se nenhum obstáculo requer proteção, então o segmento é classificado como "não requer proteção". Além disso, os segmentos foram divididos em "lado direito" e "lado esquerdo", pois os obstáculos são diferentes para cada lado, bem como a ocorrência de acidentes com saídas de pista. Assim, o trecho estudado da SP-088 foi dividido em 64 segmentos para o lado direito e 64 segmentos para o lado esquerdo. Embora estas simplificações afetem os resultados, sua influência não atingiu um número de casos relevante.

Primeiramente será apresentada a análise dos critérios para uso de proteção lateral com relação às quatro situações que podem ocorrer (mencionados no início deste capítulo) de acordo com a proporção de segmentos que se enquadram em cada uma destas situações. Posteriormente, será verificada a associação entre a ocorrência de acidentes e três características da via, a saber, taludes de corte, curvas horizontais e acessos a propriedades. Por fim, será apresentada a comparação entre o critério do RDG e o critério ampliado, baseado na ocorrência de acidentes e na análise da especificidade e sensibilidade que serão definidas adiante.

\subsubsection{Relação entre o critério recomendado e a ocorrência de acidentes com saídas de pista}

De acordo com o gráfico da Figura 4-20 vê-se que 35\% dos segmentos que requerem proteção pelo critério do RDG (2006) tem acidentes com saídas de pista baseado na hipótese 1 e $26 \%$ dos que requerem proteção não tem acidentes com saídas de pista (pelo mesmo critério e hipótese). Analisando a ocorrência de acidentes com saídas de pista de acordo com a hipótese 2, a Figura 4-21 referente ao critério do RDG (2006) mostra que a parcela dos segmentos que requerem proteção e que não tem acidentes com saídas de pista aumentam sobremaneira, passando a 51\%. 


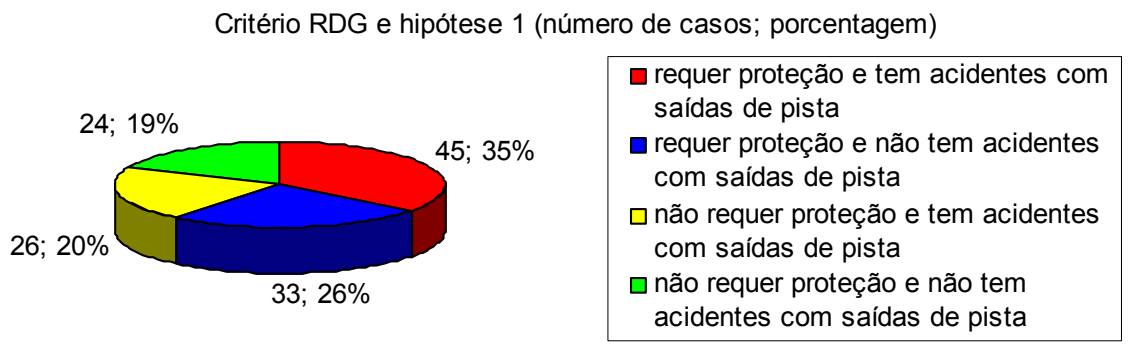

Figura 4-20 - Distribuição das situações dos segmentos com relação à necessidade de proteção e a ocorrência de acidentes (critério do RDG e hipótese 1)

Critério RDG e hipótese 2 (número de casos; porcentagem)

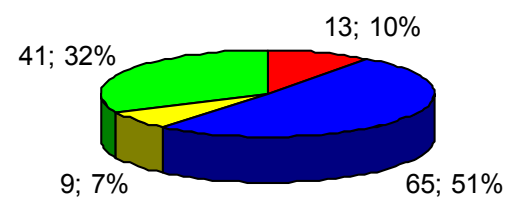

\begin{tabular}{|l|}
\hline requer proteção e tem acidentes com \\
saídas de pista \\
requer proteção e não tem acidentes com \\
saídas de pista \\
$\square$ não requer proteção e tem acidentes com \\
saídas de pista \\
não requer proteção e não tem acidentes \\
com saídas de pista
\end{tabular}

Figura 4-21 - Distribuição das situações dos segmentos com relação a necessidade de proteção e a ocorrência de acidentes (critério do RDG e hipótese 2)

Como a hipótese 1 considera mais acidentes com saída de pista do que a hipótese 2, é natural que a primeira hipótese exagere os erros potenciais de não requerer proteção e ter acidentes $(20 \%$ contra 7\%) e a segunda hipótese exagere os erros potenciais de requerer proteção e não ter acidentes (26\% contra 51\%), ressalvando-se neste segundo caso a limitação decorrente de terem sido considerados dados de acidentes referentes a somente dois anos (2009 e 2010), mas a soma dos erros potenciais ( $46 \%$ com a hipótese 1 e $58 \%$ com a hipótese 2 ) é relevante com ambas as hipóteses (maior em requerer proteção onde não há acidentes, o menos grave).

De forma similar, os potenciais acertos de requerer proteção onde há acidentes (35\% contra 10\%) e não requerer proteção onde não há acidentes (19\% contra 32\%), feita a mesma ressalva anterior, estariam abaixo do esperado em ambos os casos (54\% contra $42 \%)$.

É relevante analisar, sob o aspecto da ocorrência de acidentes com saída de pista, os obstáculos que não observam os critérios recomendados e que estão contidos em segmentos onde não há ocorrência de saídas de pista, ou seja, a ausência de saídas de pista poderia explicar a inobservância aos critérios. Todavia, vê-se pela Figura 4-22, que 58\% dos obstáculos que não observam o critério do RDG estão contidos em segmentos que possuem acidentes com saídas de pista, pela hipótese 1. Apesar da necessidade de proteção lateral estar relacionada aos obstáculos, os dados enfatizam a importância da observância às recomendações para estes obstáculos, uma 
vez que eles estão presentes em locais com saídas de pista com possibilidade de serem atingidos. Analisando a hipótese 2, percebe-se o inverso. A maior parte dos obstáculos que não observam o critério do RDG está contida em segmentos que não tem acidentes (84\%).

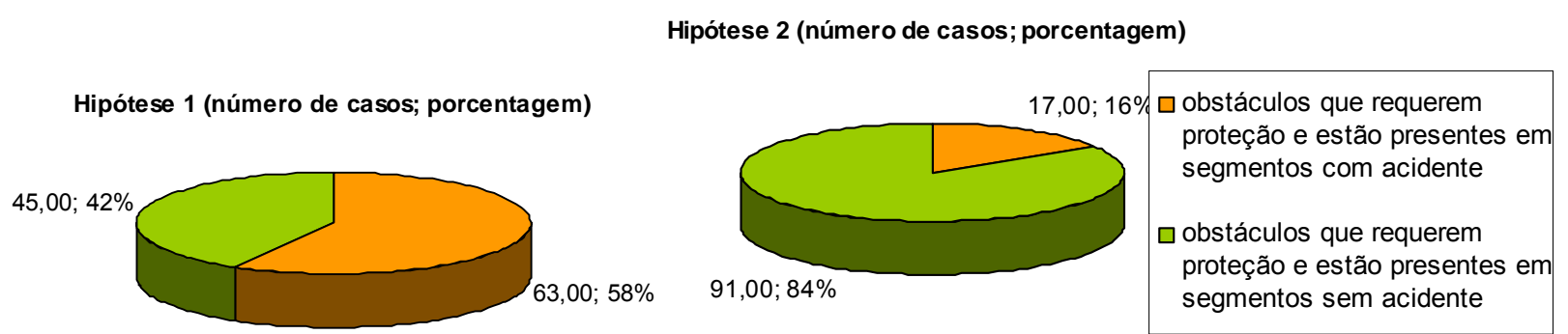

Figura 4-22 - Obstáculos com inobservância os critérios, presentes em segmentos com e sem acidentes com saída de pista: (critério do RDG, hipótese 1 e hipótese 2)

Considerando o critério ampliado, que insere os taludes de corte como obstáculos a serem protegidos, a porção dos segmentos que requer proteção aumenta para $83 \%$, com $45 \%$ tendo ocorrência de saídas de pista e 38\% não tem, de acordo com a hipótese 1 (ver Figura 4-5). Para a hipótese 2, a porção dos segmentos que requer proteção permanece em $83 \%$, porém com $15 \%$ tendo ocorrência de saídas de pista e $68 \%$ não tem.

Novamente é natural que a hipótese 1 exagere os erros potenciais de não requerer proteção e ter acidentes ( $10 \%$ contra $2 \%$ ) e a hipótese 2 exagere os erros potenciais de requerer proteção e não ter acidentes (38\% contra 68\%), de novo ressalvando-se neste segundo caso a limitação decorrente de terem sido considerados dados de acidentes referentes a somente dois anos (2009 e 2010). A soma dos erros potenciais (48\% com a hipótese 1 e $70 \%$ com a hipótese 2) é maior e mais relevante com ambas as hipóteses, mas o erro mais grave foi bastante reduzido em ambas (não requerer proteção onde há acidentes). Este resultado apóiaria a idéia de adotar o critério ampliado.

De forma similar, os potenciais acertos de requerer proteção onde há acidentes ( $45 \%$ contra 15\%) e não requerer proteção onde não há acidentes ( $7 \%$ contra $15 \%)$, feita a mesma ressalva anterior, estariam abaixo do esperado em ambos os casos (52\% contra $30 \%)$. 


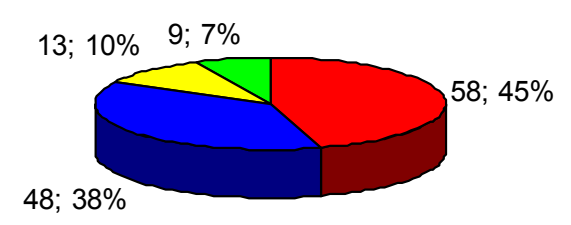

$\square$ requer proteção e tem acidentes com saídas de pista

requer proteção e não tem acidentes

com saídas de pista

$\square$ não requer proteção e tem acidentes

com saídas de pista

$\square$ não requer proteção e não tem acidentes

com saídas de pista

Figura 4-23 - Distribuição das situações dos segmentos com relação a necessidade de proteção e a ocorrência de acidentes (critério amplo e hipótese 1)

Critério amplo e hipótese 2 (número de casos; porcentagem)

$19 ; 15 \%$

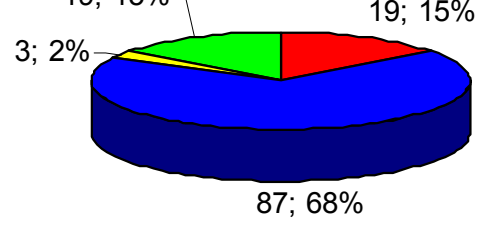

$\square$ requer proteção e tem acidentes com

saídas de pista

$\square$ requer proteção e não tem acidentes com saídas de pista

$\square$ não requer proteção e tem acidentes com saídas de pista

$\square$ não requer proteção e não tem acidentes com saídas de pista

Figura 4-24 - Distribuição das situações dos segmentos com relação a necessidade de proteção e a ocorrência de acidentes (critério amplo e hipótese 2)

Analisando a relação da inobservância ao critério ampliado e a ocorrência de acidentes pela hipótese 1, percebe-se, pela Figura 4-25, que mais da metade dos obstáculos (54\%) estão contidos em segmentos que ocorrem acidentes com saídas de pista. Por outro lado, quando se analisa através da hipótese 2, vê-se novamente, como ocorreu para o critério do RDG, que a grande maioria dos obstáculos estão contidas nos segmentos que não tem ocorrência de saídas de pista.

Hipótese 1 (número de casos; porcentagem)

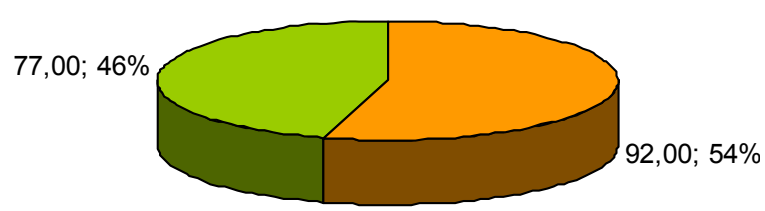

Hipótese 2 (número de casos; porcentagem)

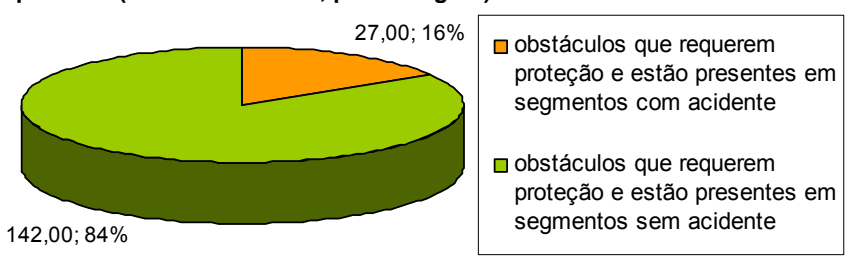

Figura 4-25- Obstáculos com inobservância os critérios presentes em segmentos com e sem acidentes com saída de pista: (critério ampliado, hipótese 1 e hipótese 2)

Partindo a premissa de que a hipótese 2 considera que $100 \%$ dos choques, tombamentos e capotamentos decorrem da presença de obstáculos, nota-se que grande parte dos obstáculos que requerem proteção, tanto pelo critério do RDG como pelo ampliado, não foram atingidos e podem estar posicionados em local com pouco ou nenhuma probabilidade de serem atingidos. 
Dever-se-ia, portanto, considerando a hipótese 2, rever a aplicação dos critérios para boa parte destes obstáculos, baseado nesta hipótese menos plausível.

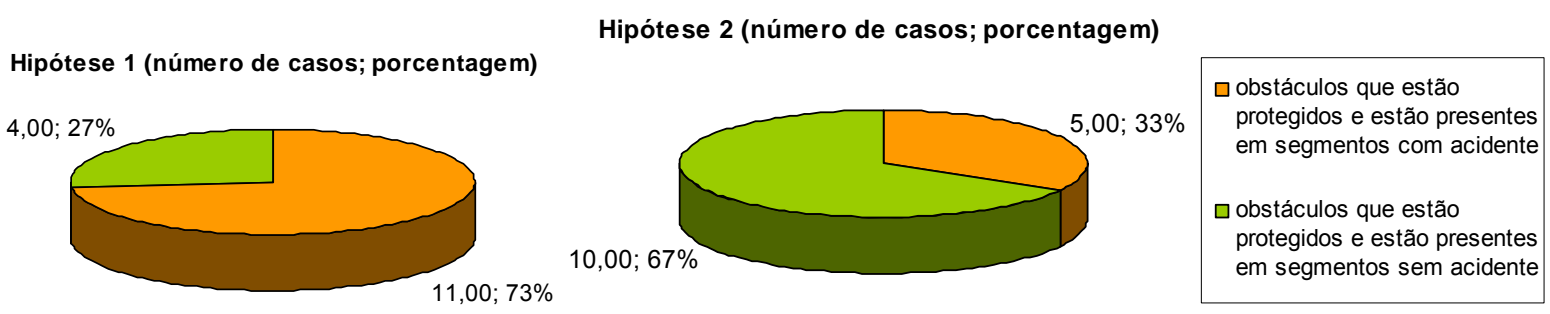

Figura 4-26 - Obstáculos que requerem proteção, estão protegidos e a ocorrência de acidentes com saída de pista (hipóteses 1 e 2)

Para os obstáculos que requerem proteção e estão protegidos, pelos critérios do RDG e ampliado (neste caso é igual), vê-se pela Figura 4-26, que novamente, para a hipótese 1, a maior parte dos obstáculos estão presentes em segmentos com acidentes envolvendo saídas de pista (73\%). Já pela hipótese 2, 67\% dos obstáculos estão presentes em segmentos que não tem acidentes com saídas de pista.

\subsubsection{Associação entre a ocorrência de acidentes e as características da via}

Neste item será avaliado se há associação entre as seguintes variáveis, para as hipóteses 1 e 2:

- Acidentes x taludes de corte

- Acidentes x curvas horizontais

- Acidentes x acessos

A estatística utilizada na análise será o qui-quadrado, definida abaixo:

$$
\chi^{2}=\sum_{i=0}^{1} \sum_{j=0}^{1} \frac{\left(O_{i j}-E_{i j}\right)^{2}}{E_{i j}}
$$

Onde

$\mathrm{O}_{\mathrm{ij}}$ : número observado de segmentos com valor i para a variável acidentes e j para variável talude/curvas/acesso;

$\mathrm{E}_{\mathrm{ij}}$ : número esperado de segmentos com valor i para a variável acidentes e j para variável talude/curvas/acesso; 
$\mathrm{i}, \mathrm{j}: 1$ = tem a característica; 0 = não tem a característica;

com significância de $95 \%$ e valor crítico igual a 3,84.

As Tabela 4-9, Tabela 4-10 e Tabela 4-11 mostram, respectivamente, os testes para os pares acidentes $\mathrm{x}$ talude de corte, acidentes $\mathrm{x}$ curvas horizontais e acidentes $\mathrm{x}$ acessos.

Tabela 4-9 - Teste qui-quadrado para acidentes $x$ talude de corte

\begin{tabular}{|c|c|c|c|c|c|c|c|}
\hline \multirow{2}{*}{\multicolumn{4}{|c|}{$\begin{array}{c}\text { PRESENÇA DE TALUDE DE CORTE (Hipótese 1) } \\
\text { OBSERVADO }\end{array}$}} & \multirow{2}{*}{\multicolumn{4}{|c|}{$\begin{array}{c}\text { PRESENÇA DE TALUDE DE CORTE (Hipótese 2) } \\
\text { OBSERVADO }\end{array}$}} \\
\hline & & & & & & & \\
\hline & $\begin{array}{l}\text { tem talude de } \\
\text { corte }\end{array}$ & $\begin{array}{l}\text { não tem talude de } \\
\text { corte }\end{array}$ & TOTAL & & $\begin{array}{l}\text { tem talude de } \\
\text { corte }\end{array}$ & $\begin{array}{l}\text { não tem } \\
\text { talude de } \\
\text { corte }\end{array}$ & TOTAL \\
\hline com acidente & 13 & 58 & 71 & com acidente & 6 & 16 & 22 \\
\hline sem acidente & 15 & 42 & 57 & sem acidente & 22 & 84 & 106 \\
\hline TOTAL & 28 & 100 & 128 & TOTAL & 28 & 100 & 128 \\
\hline \multicolumn{4}{|c|}{ ESPERADO } & \multicolumn{4}{|c|}{ ESPERADO } \\
\hline & $\begin{array}{l}\text { tem talude de } \\
\text { corte }\end{array}$ & $\begin{array}{l}\text { não tem talude de } \\
\text { corte }\end{array}$ & TOTAL & & $\begin{array}{l}\text { tem talude de } \\
\text { corte }\end{array}$ & $\begin{array}{c}\text { não tem } \\
\text { talude de } \\
\text { corte }\end{array}$ & TOTAL \\
\hline com acidente & 15,531 & 55,469 & 71 & com acidente & 4,813 & 17,188 & 22 \\
\hline sem acidente & 12,469 & 44,531 & 57 & sem acidente & 23,188 & 82,813 & 106 \\
\hline TOTAL & 28,000 & 100,000 & 128 & TOTAL & 28,000 & 100,000 & \\
\hline \multicolumn{4}{|c|}{$\left((\mathrm{O}-\mathrm{E})^{2}\right) / \mathrm{E}$} & \multicolumn{4}{|c|}{$((\mathrm{O}-\mathrm{E}))^{2} / \mathrm{E}$} \\
\hline & $\begin{array}{l}\text { tem talude de } \\
\text { corte }\end{array}$ & $\begin{array}{l}\text { não tem talude de } \\
\text { corte }\end{array}$ & & & $\begin{array}{l}\text { tem talude de } \\
\text { corte }\end{array}$ & $\begin{array}{c}\text { não tem } \\
\text { talude de } \\
\text { corte }\end{array}$ & \\
\hline com acidente & 0,413 & 0,116 & & com acidente & 0,293 & 0,082 & \\
\hline sem acidente & 0,514 & 0,144 & & sem acidente & 0,061 & 0,017 & \\
\hline qui $^{2}=$ & 1,186 & significância & $72,38 \%$ & qui $^{2}=$ & 0,453 & significância & $49,90 \%$ \\
\hline quil $^{2}$ _crítico $=$ & 3,84 & significância & $95,00 \%$ & qui ${ }^{2} \_$crítico $=$ & 3,84 & significância & $95,00 \%$ \\
\hline
\end{tabular}

Tabela 4-10 - Teste qui-quadrado para acidentes $x$ curvas horizontais

\begin{tabular}{|c|c|c|c|}
\hline \multicolumn{4}{|c|}{ PRESENÇA DE CURVA (Hipótese 1) } \\
\hline \multicolumn{4}{|c|}{ OBSERVADO } \\
\hline & tem curva & não tem curva & TOTAL \\
\hline com acidente & 22 & 49 & 71 \\
\hline sem acidente & 14 & 43 & 57 \\
\hline TOTAL & 36 & 92 & 128 \\
\hline \multicolumn{4}{|c|}{ ESPERADO } \\
\hline & tem curva & não tem curva & TOTAL \\
\hline com acidente & 19,969 & 51,031 & 71 \\
\hline sem acidente & 16,031 & 40,969 & 57 \\
\hline TOTAL & 36,000 & 92,000 & \\
\hline \multicolumn{4}{|c|}{$\left((\mathrm{O}-\mathrm{E})^{2}\right) / \mathrm{E}$} \\
\hline & tem curva & não tem curva & \\
\hline com acidente & 0,207 & 0,081 & \\
\hline sem acidente & 0,257 & 0,101 & \\
\hline $\begin{array}{c}\text { qui }{ }^{2}= \\
\text { qui }^{2} \text { crítico }=\end{array}$ & $\begin{array}{l}0,646 \\
3,84\end{array}$ & $\begin{array}{l}\text { significância } \\
\text { sianificância }\end{array}$ & $\begin{array}{l}57,83 \% \\
95,00 \%\end{array}$ \\
\hline
\end{tabular}

\begin{tabular}{|c|c|c|c|}
\hline \multicolumn{4}{|c|}{ PRESENÇA DE CURVA (Hipótese 2) } \\
\hline \multicolumn{4}{|c|}{ OBSERVADO } \\
\hline & tem curva & $\begin{array}{c}\text { não tem } \\
\text { curva }\end{array}$ & TOTAL \\
\hline com acidente & 10 & 12 & 22 \\
\hline sem acidente & 26 & 80 & 106 \\
\hline TOTAL & 36 & 92 & 128 \\
\hline \multicolumn{4}{|c|}{ ESPERADO } \\
\hline & tem curva & $\begin{array}{c}\text { não tem } \\
\text { curva }\end{array}$ & TOTAL \\
\hline com acidente & 6,188 & 15,813 & 22 \\
\hline sem acidente & 29,813 & 76,188 & 106 \\
\hline TOTAL & 36,000 & 92,000 & \\
\hline \multicolumn{4}{|c|}{$\left((\mathrm{O}-\mathrm{E})^{2}\right) / \mathrm{E}$} \\
\hline & tem curva & $\begin{array}{c}\text { não tem } \\
\text { curva }\end{array}$ & \\
\hline com acidente & 2,349 & 0,919 & \\
\hline sem acidente & 0,488 & 0,191 & \\
\hline 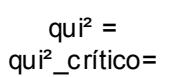 & $\begin{array}{c}3,947 \\
3,84\end{array}$ & $\begin{array}{l}\text { significância } \\
\text { significância }\end{array}$ & $\begin{array}{l}95,30 \% \\
95,00 \%\end{array}$ \\
\hline
\end{tabular}


Tabela 4-11 - Teste qui-quadrado para acidentes $x$ acessos

\begin{tabular}{|c|c|c|c|c|c|c|c|}
\hline \multirow{2}{*}{\multicolumn{4}{|c|}{$\frac{\text { PRESENÇA DE ACESSO (Hipótese 1) }}{\text { OBSERVADO }}$}} & \multicolumn{4}{|c|}{ PRESENÇA DE ACESSO (Hipótese 2) } \\
\hline & & & & \multicolumn{4}{|c|}{ OBSERVADO } \\
\hline & tem acesso & não tem acesso & TOTAL & & tem acesso & $\begin{array}{c}\text { não tem } \\
\text { acesso }\end{array}$ & TOTAL \\
\hline com acidente & 43 & 28 & 71 & com acidente & 13 & 9 & 22 \\
\hline sem acidente & 27 & 30 & 57 & sem acidente & 57 & 49 & 106 \\
\hline TOTAL & 70 & 58 & 128 & TOTAL & 70 & 58 & 128 \\
\hline \multicolumn{4}{|c|}{ ESPERADO } & \multicolumn{4}{|c|}{ ESPERADO } \\
\hline & tem acesso & não tem acesso & TOTAL & & tem acesso & $\begin{array}{c}\text { não tem } \\
\text { acesso }\end{array}$ & TOTAL \\
\hline com acidente & 38,828 & 32,172 & 71 & com acidente & 12,031 & 9,969 & 22 \\
\hline sem acidente & 31,172 & 25,828 & 57 & sem acidente & 57,969 & 48,031 & 106 \\
\hline TOTAL & 70,000 & 58,000 & & TOTAL & 70,000 & 58,000 & \\
\hline \multicolumn{4}{|c|}{$\left((\mathrm{O}-\mathrm{E})^{2}\right) / \mathrm{E}$} & \multicolumn{4}{|c|}{$\left((\mathrm{O}-\mathrm{E})^{2}\right) / \mathrm{E}$} \\
\hline & tem acesso & não tem acesso & & & tem acesso & $\begin{array}{c}\text { não tem } \\
\text { acesso }\end{array}$ & \\
\hline com acidente & 0,448 & 0,541 & & com acidente & 0,078 & 0,094 & \\
\hline sem acidente & 0,558 & 0,674 & & sem acidente & 0,016 & 0,020 & \\
\hline $\begin{array}{c}\text { qui }{ }^{2}= \\
\text { qui }^{2} \text { crítico }=\end{array}$ & $\begin{array}{l}2,221 \\
3,84\end{array}$ & $\begin{array}{l}\text { significância } \\
\text { significância }\end{array}$ & $\begin{array}{l}86,39 \% \\
95,00 \%\end{array}$ & $\begin{array}{c}\text { qui }{ }^{2}= \\
\text { qui }^{2} \text { crítico }\end{array}$ & $\begin{array}{c}0,208 \\
3,84\end{array}$ & $\begin{array}{l}\text { significância } \\
\text { significância }\end{array}$ & $\begin{array}{l}35,16 \% \\
95,00 \%\end{array}$ \\
\hline
\end{tabular}

Com relação ao talude de corte, o teste chi-quadrado indica que não há uma associação forte com a ocorrência de acidentes ao nível de significância de 95\% (com qui-quadrado crítico de 3,84) pela hipótese 1 . Com a hipótese 2 a associação é ainda menor, confirmando a conclusão obtida através da hipótese 1 , e portanto, há robustez.

A análise sobre as outras duas variáveis (curvas e acessos) mostra que a presença de curva tem fraca associação com a ocorrência de acidentes com saída de pista, considerando a hipótese 1, mas o resultado não é robusto, pois, considerando a hipótese 2 , a associação entre as variáveis é forte (com mais de 95\% de significância).

A presença de acessos teria um grau de associação relevante, mas com significância menor que 95\% admitindo a hipótese 1 e um grau de associação irrelevante admitindo a hipótese 2. Portanto, a conclusão sobre a associação ocorre na hipótese preferida 1, mas não é uma conclusão robusta.

Considerando a hipótese 1 , a conclusão não é consistente com a consideração da presença de curva como fator relevante nos critérios utilizados pelo RDG, que majora a extensão da área livre recomendada e afirma a necessidade de proteção se obstáculos estiverem presentes nessa extensão. 
Uma análise mais minuciosa não parece ser possível a partir dos dados disponíveis, ponderando suas deficiências, particularmente considerando que deveria ser avaliado o impacto na redução da gravidade dos acidentes, além do impacto na ocorrência (ou frequência dos acidentes).

\subsubsection{Análise do critério do RDG (2006) e do critério ampliado}

O método utilizado na análise do critério do RDG (2006) e do critério ampliado basear-se-á na determinação das medidas do valor preditivo dos critérios testados, quais sejam, a sensibilidade, a especificidade, o valor preditivo positivo, o valor preditivo negativo, a prevalência e a acurácia. Estes são os conceitos usualmente utilizados na análise de testes de diagnósticos em outras áreas, como discutido em MAZUCHELI et alii (2008), por exemplo.

Posteriormente estas medidas serão comparadas considerando os dois critérios analisados e será avaliada a robustez da conclusão, comparando a análise feita com a hipótese 1 e 2 definidas anteriormente. Porém, antes de prosseguir com a análise é importante fazer algumas definições.

As primeiras definições estão relacionadas com as quatro situações que podem ser enquadrados os segmentos de $100 \mathrm{~m}$ analisados, com base nos critérios analisados para a recomendação de dispositivos de proteção lateral:

1. O segmento requer proteção e tem acidente com saída de pista;

2. O segmento requer proteção e não tem acidentes com saída de pista;

3. O segmento não requer proteção e tem acidentes com saída de pista;

4. O segmento não requer proteção e não tem acidentes com saída de pista.

Define-se como Verdadeiro Positivo (VP) a situação em que o critério analisado recomenda a proteção lateral acertadamente, em local onde existem acidentes com saídas de pista (situação 1 acima). Define-se como Falso Positivo (FP) a situação em que o critério recomenda equivocadamente a proteção lateral em segmento que não há acidente (situação 2). Define-se como Falso Negativo (FN) a situação no qual o critério analisado não recomenda o uso de proteção lateral em locais com ocorrência de acidentes com saídas de pista (situação 3). Por fim, define-se como Verdadeiro Negativo (VN) a situação em que o critério analisado não recomenda, 
corretamente, a proteção lateral em segmentos que não tem ocorrência de acidentes com saídas de pista (situação 4).

Nesta concepção tradicional, os medidores VP e VN correspondem ao sucesso do critério, enquanto que os medidores FN e FP indicam o fracasso do critério. A Tabela 4-12 abaixo mostra as possíveis situações para cada segmento e os respectivos medidores definidos acima.

Tabela 4-12- Situações possíveis para a classificação dos segmentos

\begin{tabular}{cccc}
\multirow{2}{*}{ Resposta do critério } & \multicolumn{3}{c}{ Ocorrência de acidentes } \\
\cline { 2 - 4 } & tem acidente (D+) & não tem acidente (D-) & total \\
\hline requer proteção (T+) & VP & FP & NR \\
não querer proteção (T-) & FN & VN & NS \\
\hline total & NC & NN
\end{tabular}

Dentre todos os segmentos que possuem acidentes, a proporção deles que foi recomendada a proteção lateral por um critério (seja o critério do RDG, seja o critério ampliado) é denominado de sensibilidade, e pode ser calculado pela expressão abaixo:

$$
\mathrm{S}=\frac{\mathrm{VP}}{\mathrm{NC}}=\frac{\mathrm{VP}}{\mathrm{VP}+\mathrm{FN}}
$$

A sensibilidade, portanto, é a proporção de acertos do critério dentre os segmentos que possuem acidentes, ou seja, é a probabilidade do critério recomendar a proteção dado que o segmento tem acidente.

Já a proporção de acertos do critério dentre os segmentos que não tem acidentes é denominada especificidade, que também pode ser entendido como a probabilidade do critério não recomendar a proteção dado que o segmento não tem acidentes. A especificidade é calculada de acordo com a expressão abaixo:

$$
\mathrm{E}=\frac{\mathrm{VN}}{\mathrm{NN}}=\frac{\mathrm{VN}}{\mathrm{VN}+\mathrm{FP}}
$$

O valor preditivo positivo é a probabilidade de o segmento ter acidente dado que o critério apontou a necessidade de proteção, isto é, é a proporção de diagnósticos acertados da 
recomendação de proteção (e, portanto, em locais que tem acidentes) dentre todos os segmentos nos quais o critério indicou a necessidade de proteção:

$$
\mathrm{VPP}=\frac{\mathrm{VP}}{\mathrm{NR}}=\frac{\mathrm{VP}}{\mathrm{VP}+\mathrm{FP}}
$$

O valor preditivo negativo é a probabilidade do segmento não ter acidente dado que o critério não recomendou a proteção lateral, isto é, é a proporção de diagnósticos acertados da recomendação de não proteção (e, portanto, onde não há acidentes) dentre todos os segmentos nos quais o critério indicou a não necessidade de proteção.

$$
\mathrm{VPN}=\frac{\mathrm{VN}}{\mathrm{NS}}=\frac{\mathrm{VN}}{\mathrm{VN}+\mathrm{FN}}
$$

A prevalecência (de acidentes, no caso) é a probabilidade do segmento ter acidente, independentemente do critério apontar necessidade ou não de proteção lateral:

$$
p=\frac{V P+F N}{V P+F N+V N+F P}=\frac{N C}{N C+N N}=\frac{N C}{N T}
$$

A acurácia é a proporção de acertos do critério considerando todos os segmentos. Os acertos seriam a indicação da necessidade de proteção onde tem acidentes (verdadeiro positivo) e a indicação da não necessidade de proteção onde não tem acidentes (verdadeiro negativo). A acurácia pode ser calculada pela expressão abaixo:

$$
\mathrm{Ac}=\frac{\mathrm{VP}+\mathrm{VN}}{\mathrm{VP}+\mathrm{FN}+\mathrm{VN}+\mathrm{FP}}=\frac{\mathrm{VP}+\mathrm{VN}}{\mathrm{NT}}=\frac{\mathrm{NA}}{\mathrm{NT}}
$$

A obtenção destas últimas informações exige uma amostra representativa quanto à prevalência dos acidentes. A obtenção da sensibilidade e da especificidade exige amostras representativas da eficácia do critério de diagnóstico nos locais com acidentes e nos locais sem acidentes, em qualquer proporção (mesmo diferente da prevalência real).

Com as definições acima, prossegue-se com as análises. 
As tabelas abaixo mostram a quantidade de segmentos de $100 \mathrm{~m}$ enquadrados em cada uma das quatro situações possíveis, considerando as recomendações do critério do RDG ou critério ampliado, e as hipóteses 1 ou 2 para a ocorrência de acidentes.

Tabela 4-13 - Número de segmentos enquadrados em cada uma das quatro situações possíveis (critério RDG, hipótese 1)

\begin{tabular}{ccc}
\cline { 2 - 3 } & $\begin{array}{c}\text { com acidente } \\
\text { D+ }\end{array}$ & $\begin{array}{c}\text { sem acidente } \\
\text { D- }\end{array}$ \\
\hline $\begin{array}{c}\text { recomenda } \\
\text { proteção }(\mathrm{T}+)\end{array}$ & 45 & 33 \\
$\begin{array}{c}\text { não recomenda } \\
\text { proteção (T-) }\end{array}$ & 26 & 24 \\
\hline Total & 71 & 57
\end{tabular}

Tabela 4-14 - Número de segmentos enquadrados em cada uma das quatro situações possíveis (critério ampliado, hipótese 1)

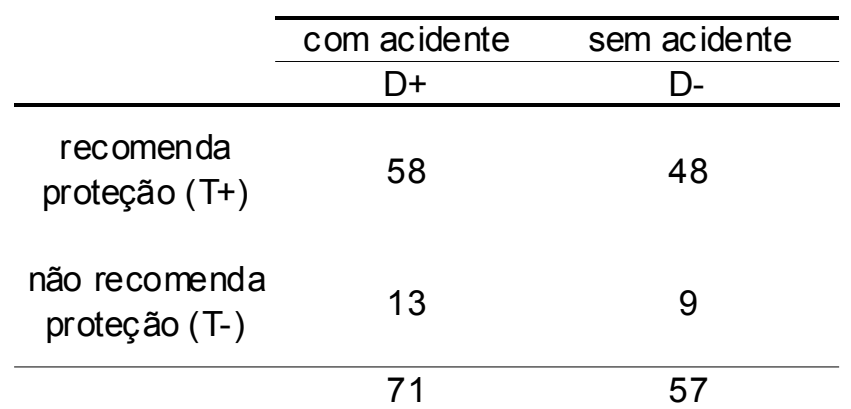

Analisando-se os resultados correspondente à hipótese 1, vê-se que o critério do RDG tem sensibilidade de $S=45 / 71=0,6338$ e especificidade de $E=24 / 57=0,4211$ enquanto o critério ampliado tem sensibilidade de 0,8169 (melhor) a custa de uma especificidade de 0,1579 (pior).

Tabela 4-15 - Número de segmentos enquadrados em cada uma das quatro situações possíveis (critério RDG, hipótese 2)

\begin{tabular}{cccc} 
& & $\begin{array}{c}\text { com acidente } \\
\mathrm{D}+\end{array}$ & $\begin{array}{c}\text { sem acidente } \\
\mathrm{D}-\end{array}$ \\
\cline { 2 - 4 } requer prot. & $\begin{array}{c}\text { recomenda } \\
\text { proteção } \\
(\mathrm{T}+)\end{array}$ & 13 & 65 \\
não & $\begin{array}{c}\text { não } \\
\text { recomenda } \\
\text { proteção (T-) }\end{array}$ & 9 & 41 \\
\cline { 2 - 4 } & 22 & 106
\end{tabular}




\section{Tabela 4-16 - Número de segmentos enquadrados em cada uma das quatro situações possíveis (critério}

ampliado, hipótese 2)

\begin{tabular}{ccc} 
& $\begin{array}{c}\text { com acidente } \\
\mathrm{D}+\end{array}$ & $\begin{array}{c}\text { sem acidente } \\
\mathrm{D}-\end{array}$ \\
\hline $\begin{array}{c}\text { recomenda } \\
\text { proteção } \\
(\mathrm{T}+)\end{array}$ & 19 & 87 \\
não & & \\
$\begin{array}{c}\text { recomenda } \\
\text { proteção (T-) }\end{array}$ & 3 & 19 \\
\hline & 22 & 106
\end{tabular}

Analisando-se os resultados correspondente à hipótese 2, vê-se o critério do RDG tem sensibilidade de 0,5909 e especificidade de 0,3868 enquanto o critério ampliado tem sensibilidade de 0,8636 (melhor) a custa de uma especificidade de 0,1792 (pior).

Portanto, a alteração no padrão de recomendação é robusto e decorre, naturalmente, da ampliação do critério (mais sensível mas menos específico).

A forma tradicional de avaliar a qualidade do critério de diagnóstico é normalmente traduzida na comparação das recomendações de tratamento entre os grupos com e sem deficiência. A expectativa é que um bom critério de diagnóstico recomende mais tratamentos no grupo com deficiência (o que corresponde à probabilidade $S$ ) do que no grupo sem deficiência (o que corresponde à probabilidade 1-E). Como estas probabilidades são proporções, esta expectativa pode também ser analisada estatisticamente. MARTINEZ e LOUZADA-NETO (2000) recomendam o teste proposto por LINNET e BRANDT (1986).

Esta forma tradicional pressupõe o conhecimento do estado de deficiência a partir de um teste confiável (chamado padrão-ouro). No caso estudado, esta informação corresponde às hipóteses 1 e 2, aproximadas, utilizadas para verificar a robustez da conclusão.

A análise estatística consiste em testar a hipótese H0: $\mathrm{S}>(1-\mathrm{E})$. Para testar H0: $\mathrm{S}>(1-\mathrm{E})$ calcula-se as variâncias de $\mathrm{S}$ e (1-E) e faz-se um teste t de Student (seguindo, por exemplo, BUSSAB e MORETTIN, 2002, pg 362-365).

O procedimento é exemplificado detalhadamente para a análise do critério do RDG (2006) avaliado com a hipótese 1 . De acordo com a Tabela 4-13, S é 0,634 com o critério estrito do 
RDG (isto é, o critério RDG recomenda proteger $63,4 \%$ dos locais com acidente pela hipótese 1) e (1-E) é 0,579 com o mesmo critério (isto é, o critério RDG recomenda proteger também 57,9\% dos locais sem acidente pela hipótese 1). Na análise estatística tem-se:

- a variância de S é (onde "n" é o tamanho da amostra com acidentes, 71 com H1, para Tabela 4-13):

$$
v(S)=\frac{S(1-S)}{n-1} n=0,235
$$

- a variância de (1-E) é (onde "m" é o tamanho da amostra sem acidentes, 57 com H1, para Tabela 4-13)

$$
v(1-E)=\frac{(1-E) E}{m-1} m=0,248
$$

- e a variância da diferença entre a média de $\mathrm{S}$ e a média de (1-E) é

$$
v(S-(1-E))=\frac{v(S)}{n}+\frac{v(1-E)}{m}=0,00767
$$

portanto, t de Student é:

$$
t=\frac{S-(1-E)}{\sqrt{v(S-(1-E))}}=0,626
$$

com graus de liberdade igual a:

$$
v=\left(\frac{\left(\frac{v(S)}{n}+\frac{v(1-E)}{m}\right)^{2}}{\frac{\left(\frac{v(S)}{n}\right)^{2}}{n-1}+\frac{\left(\frac{v(1-E)}{m}\right)^{2}}{m-1}}\right)^{2}=118,7
$$


Conclui-se que a diferença não tem significância maior que 95\%, que corresponderia a $\mathrm{t}_{\text {crítico }}=1,658$ adotando $v=120$ na tabela de BUSSAB e MORETTIN (2002, pg 499) para teste unicaudal. Para $\mathrm{t}=0,626$ o nível de significância para a H0: $\mathrm{S}>(1-\mathrm{E})$ é da ordem de $75 \%$.

A observação fundamental de LINNET e BRANDT (1986) refere-se ao passo correspondente à formula 4-13, justificando a hipótese implícita de independência pelo fato de $\mathrm{S}$ e E serem estimados em amostras distintas (dos locais com ou sem acidentes, respectivamente).

Para os demais pares "critério x hipótese", a tabela abaixo resume os resultados encontrados para cada parâmetro da análise estatística.

Tabela 4-17 - Teste t de Student para o par "critério x hipótese"

\begin{tabular}{ccccc}
\hline \multirow{2}{*}{ Parâmetros } & \multicolumn{4}{c}{ Critérios e hipóteses testadas } \\
\cline { 2 - 5 } & RDG c/ H1 & RDG cl H2 & AMPLO cl H1 & AMPLO c/ H2 \\
\hline Sensibilidade (S) & 0,6338 & 0,5909 & 0,8169 & 0,8636 \\
Especificidade (E) & 0,4211 & 0,3868 & 0,1579 & 0,1792 \\
(1-E) & 0,5789 & 0,6132 & 0,8421 & 0,8208 \\
Valor pred.pos. (VPP) & 0,5769 & 0,1667 & 0,5472 & 0,1792 \\
Valor pred.neg. (VPN) & 0,4800 & 0,8200 & 0,4091 & 0,8636 \\
Acurácia (Ac) & 0,5391 & 0,4219 & 0,5234 & 0,2969 \\
Prevalência (p) & 0,5547 & 0,1719 & 0,5547 & 0,1719 \\
variância de S & 0,2354 & 0,2532 & 0,1517 & 0,1234 \\
variância de (1-E) & 0,2481 & 0,2394 & 0,1353 & 0,1485 \\
variância de (S-(1-E)) & 0,0077 & 0,0138 & 0,0045 & 0,0070 \\
t de Student & 0,6264 & $-0,1900$ & $-0,3753$ & 0,5122 \\
graus de liberdade & 118 & 29 & 122 & 32 \\
significância para t & $73,4 \%$ & $42,5 \%$ & $35,4 \%$ & $69,4 \%$ \\
t para 95\% de significância & 1,658 & 1,699 & 1,658 & 1,699 \\
\hline
\end{tabular}

A análise detalhada do impacto do critério ampliado em relação ao critério do RDG com a hipótese 1 indica que há uma melhora interessante da sensibilidade mas uma redução aparentemente mais preocupante da especificidade. O teste estatístico sugere que o critério RDG é válido (t positivo), mas a conclusão tem significância bastante menor que $95 \%$ enquanto o critério ampliado parece inválido (t negativo), e a conclusão de validade tem significância de 35,4\%. Portanto, em ambos os casos a conclusões não tem significância ao nível de 95\%. 
Usando a hipótese 2, as conclusões sobre a validade dos critérios invertem-se, mas a consideração sobre a significância menor que $95 \%$ ocorre novamente em ambos os casos. Desta forma, não é possível obter uma conclusão válida, embora na hipótese preferida $(\mathrm{H} 1)$ o critério ampliado seja pior. Dever-se-ia manter, então, o critério estrito até a obtenção de dados melhores que permitissem recomendar/justificar a ampliação do critério.

De forma mais geral, observou-se que a conclusão não é robusta e que a limitação na qualidade dos dados sobre os acidentes prejudica investigações mais detalhadas. 


\section{CONCLUSÃO}

Este trabalho procurou estudar os critérios recomendados para aplicação de dispositivos de proteção lateral em rodovias, do ponto de vista teórico e prático. As conclusões obtidas são a seguir organizadas em dois tópicos específicos, sobre cada um destes aspectos.

\subsection{Da Revisão Teórica}

Os capítulos 2 e 3 trataram da revisão teórica. Durante a revisão bibliográfica das recomendações para o uso de dispositivos de proteção lateral, notou-se que alguns conceitos acerca da segurança do entorno viário são consagrados na literatura nacional e internacional, como os conceitos de entorno tolerante e de área livre.

O conceito de área livre está praticamente em todos os manuais revisados e, em muitos deles, percebe-se a influência americana. Entre estes, além do RDG (2006) americano, estão os manuais canadenses (TAC, 1999) e a normal brasileira atual (ABNT, 2004 ou 2007).

Apesar do TAC (1999) ser claramente baseado no manual americano, percebe-se que o manual canadense é mais consciente em chamar atenção para alguns pontos fracos do manual americano, destacando a necessidade de se adotar critérios mais compreensivos. Observou-se que os critérios tradicionais não incorporam aspectos relevantes, como a declividade longitudinal da 
rodovia na determinação da largura da área livre (que é considerado nos modelos compreensivos apresentados no capítulo 3).

Notou-se que os critérios recomendados muitas vezes carregam valores e definições sem, no entanto, fazer referências aos estudos que deram origem a estes critérios. Muitos deles baseiamse em situações peculiares, antigas e simplificadas, e que podem não ser adequadamente utilizados em outras situações. Um exemplo é o ábaco tradicional para determinação da necessidade do uso de proteção lateral em aterros, mostrado na figura 2-7, e que evoluiu para a versão mostrada na figura 2-8, esta última em concordância com o conceito de taludes críticos. O ábaco original, apresentado pelo RDG (1989) e adotado pelo DNER (1999), foi baseado no estudo de GLENNON E TAMBURRI (1967), que determinaram a curva de igual severidade através da comparação da severidade do impacto com defensas metálicas e o atravessamentos de diversas condições de talude de aterro. Nenhum dos manuais revisados faz referência ao estudo original, tampouco mencionam que o gráfico foi obtido para defensas metálicas e não para barreiras de concreto. Outro ponto importante é que as ponderações de severidade adotadas pelo estudo foram baseadas em custos diretos da época, e o modelo adotado, segundo os autores, é sensível a estes custos. Além disso, o critério baseado nos referidos ábacos não levam em conta a frequência de saídas de pista (relacionada ao volume de tráfego) e a extensão lateral da saída.

Com relação ao afastamento lateral dos dispositivos de proteção, notou-se que alguns critérios eram conflitantes. Enquanto o RDG (2006) recomenda que os dispositivos de proteção lateral sejam posicionados o mais afastado possível da via, o TAC (1999) diz que este posicionamento não deve superar os $4 \mathrm{~m}$, alegando que quanto maior o afastamento lateral, maior a probabilidade de o veículo atingir a proteção com ângulo maior. A ABNT, através da NBR 14885:2004, também menciona que este afastamento deve ser de no máximo 3,6, sem explicar a razão.

No que tange ao tratamento de segurança dos dispositivos de drenagem, viu-se que a literatura técnica nacional pouco discute o tema. Os manuais de projeto geométrico e de drenagem do DNER/DNIT não mencionam os tratamentos de segurança para dispositivos de drenagem. A ABNT apenas repete os critérios adotados pelo RDG (2006), e este, por sua vez, não faz referências à origem dos ábacos de seções transversais preferíveis para canais abertos. Entretanto, segundo GLENNON (2004), estes ábacos têm origem nos estudos de WEAVER, MARQUIS, OLSON (1975). 
Uma das conclusões do estudo de WEAVER, MARQUIS, OLSON (1975) é que manobras de retorno à pista podem ser executadas em taludes com inclinações iguais ou mais suaves que $3 \mathrm{H}: 1 \mathrm{~V}$, à velocidade de $120 \mathrm{~km} / \mathrm{h}$ e ângulo de saídas de pista de $15^{\circ}$ sem que haja tombamento/capotamento. Nota-se, portanto, que muito provavelmente a origem teórica do limite para taludes críticos de $1 \mathrm{~V}: 3 \mathrm{H}$ baseia-se neste estudo. Outro ponto importante obtido deste estudo é a relevância do coeficiente de atrito da superfície do talude na recuperação dos veículos. Este aspecto foi negligenciado nos manuais revisados durante a apresentação dos conceitos de taludes recuperáveis, não recuperáveis e críticos.

No capítulo 3 foram apresentados os modelos compreensivos que podem ser uma ferramenta de análise melhor do que os critérios tradicionalmente recomendados, pois incorporam não só a probabilidade de saídas de pista, mas também a presença do obstáculo, a extensão lateral da saída de pista e a gravidade decorrente de tal evento.

Foi visto que os modelos compreensivos baseiam-se em modelos de saídas de pista e no risco de acidente decorrente de uma série de probabilidades condicionais: probabilidade de saída de pista, probabilidade de choque dado que ocorreu uma saída de pista, probabilidade de severidade dado que ocorreu um choque, e custo associado a esta severidade. Como também se viu, o custo social do acidente de trânsito é um ponto delicado para os modelos compreensivos, que são muito sensíveis a esta informação.

Dois programas de computador (o RSAP e o ROADSIDE) que incorporam modelos compreensivos foram apresentados no capítulo 3, destacando que se assemelham pela formulação estrutural e diferem-se pela estratégia de cálculo (o ROADSIDE obtém a solução de forma determinística e o RSAP de forma estocástica).

Foi visto que a frequência básica de saídas de pista adotada nos programas acima mencionados são baseados em estudo antigos, relativos à saídas de pista em canteiros centrais e não a saídas de pista laterais. Tanto no estudo de COOPER (1980) quanto no de HUTCHINSON e KENNEDY (1967), as saídas de pista foram baseadas em observações de trilhas de rodas e não distinguiam as saídas de pista intencionais das não intencionais. Ambos os estudos mostraram que a frequência de saídas de pista cresce em função do VDM até valores próximos a 4000 e 5000 , onde a partir daí, a freqüência de saídas de pista decresce, até o VDM aproximado de 6000 a 
8000. Após este intervalo, a frequência de saídas de pista volta novamente a crescer, com o crescimento do VDM.

HUTCHINSON e KENNEDY (1967), em seu estudo, determinaram o ângulo médio de saída de pista de $11^{\circ}$, extensão de saída de pista de $87 \mathrm{~m}$ e extensão lateral da saída de pista de $6,9 \mathrm{~m}$. Uma curiosidade destacada no estudo foi a relação entre as mudanças na inclinação da curva de distribuição da extensão lateral de saída de pista e as quebras da seção transversal das rodovias estudadas. Outra questão interessante é o valor teórico de $9 \mathrm{~m}$ encontrado pelos autores do estudo em que todos os motoristas supostamente conseguiriam recuperar o controle de seus veículos. Este valor pode ter sido a origem do valor fixo de área livre proposto inicialmente pelo Yellow Book.

Notou-se que o modelo de previsão de choques adotado pelo TAC (1999) é similar ao proposto por GLENNON (1974) (porém com unidades métricas), inclusive na adoção do ângulo de saída de pista de $11^{\circ}$. Uma diferença notada no modelo do TAC (1999) é a supressão da zona referente ao canto do obstáculo (relativo ao modelo de envoltória de risco).

Uma evolução importante do modelo de previsão de impactos adotado pelo RSAP na comparação com o ROADSIDE é a consideração de impactos múltiplos, isto é, o RSAP considera a possibilidade do veículo romper um obstáculo e atingir um outro atrás do primeiro. Já o ROADSIDE considera os obstáculos separadamente e, portanto, despreza o efeito escudo de um obstáculo sobre o outro.

Com relação à severidade do acidente, a revisão mostrou que o SI é o indicador mais utilizado nos modelos, e que está associado ao tipo de objeto e as condições de impacto. Foram mostradas diversas formas de se obter o SI: baseado em julgamento subjetivo de especialistas, baseado na ponderação de acidentes fatais, não fatais e sem vítimas (nos casos em que há dados de acidentes) e baseado em análise dinâmica (obtida com aceleração do veículo em cada eixo e com os respectivos limites toleráveis).

Destacou-se outras formas alternativas ao SI para obter a severidade de um acidente através de modelos oriundos da área de reconstrução de acidentes, como o exemplo mostrado de LIMPERT (1994), obtendo a variação de velocidade antes e depois do impacto com uma parede rígida. Porém, como comentado, a relação entre o $\Delta \mathrm{V}$ e a severidade do impacto é inadequada, uma vez 
que é desconsiderado o tempo de deformação do sistema, função da rigidez dos seus componentes, e sem o tempo de deformação não se pode determinar a desaceleração no impacto. Assim, barreiras rígidas e defensas metálicas possuiriam o mesmo índice de severidade.

No exemplo numérico de aplicação dos modelos compreensivos do capítulo 3, foi visto que estes modelos são extremamente sensíveis aos custos sociais dos acidentes de trânsito. Portanto, como se chamou a atenção, a adoção dos custos deve ser feita com cautela. Além disso, os custos reais dos acidentes de trânsito são de difícil determinação. Viu-se também a diferença entre os custos dos acidentes determinados pelo estudo do IPEA (2006) e os americanos (do RDG ou do FHWA), e que a adoção de um e de outro influencia a resposta da análise benefício/custo.

Recomenda-se, para aplicação prática, um melhor entendimento dos modelos compreensivos, bem como a calibração de seus parâmetros, na busca de obtenção de resultados coerentes. Recomenda-se também o esforço conjunto das autoridades rodoviárias para a obtenção de dados relevantes à calibração dos modelos compreensivos para a realidade local, com o detalhamento preciso das informações acerca dos acidentes de trânsito, especialmente aqueles relacionados aos eventos de saídas de pista.

\subsection{Da Aplicação Prática}

No capítulo 4 foi feita uma aplicação prática, utilizando dados da rodovia SP-088, com o objetivo de verificar a observância aos critérios recomendados para o uso de dispositivo de proteção lateral e a verificação da relação entre os critérios recomendados e a ocorrência de acidentes. Dificuldades na obtenção dos dados trouxeram dificuldades à aplicação prática e pouco se pode concluir das análises.

$\mathrm{Na}$ análise da observância aos critérios, viu-se que a maior parte dos obstáculos não requer proteção e, de fato, não tem. Por outro lado, quando analisados os casos que requerem proteção, a grande maioria não tem proteção (88\% para o critério do RDG e 92\% para o critério amplo, que considera os taludes de corte como obstáculos potenciais). E dentre os obstáculos que requerem proteção lateral, a maior parte não tem alternativas à proteção lateral $(68 \%$ para o critério do RDG e $80 \%$ para o critério amplo), mostrando ainda mais a relevância da inobservância. 
Para a análise da relação entre os critérios recomendados e a ocorrência dos acidentes com saídas de pista, viu-se que a proporção de falhas (isto é, requerem proteção onde não tem acidente e não requerer proteção onde tem acidente) tanto para o critério estrito do RGD, quando para o critério ampliado, em ambas as hipóteses 1 e 2, é maior que o esperado. Porém, notou-se uma diminuição do erro mais grave de não requerer proteção onde tem acidente para o critério ampliado, para ambas as hipóteses, o que levaria a apoiar a adoção do critério ampliado.

Analisou-se também o grau de associação entre os pares de variáveis acidentes/presença de curvas, acidentes/presença de acessos e acidentes/presença de taludes de corte, através da estatística qui-quadrado. Para estes últimos dois pares, concluiu-se que não há associação das variáveis para um nível de significância de 95\%, e esta conclusão é robusta (com coerência para ambas as hipóteses). Por outro lado, para a análise da associação entre presença de curvas e acidentes com saídas de pista não se obteve conclusão robusta, com associação irrelevante para a hipótese 1 (preferida) e forte associação para a hipótese 2.

Através dos conceitos de especificidade e sensibilidade, foram testados e os critérios estrito do RDG e o critério ampliado, baseado na ocorrência de acidente com as hipóteses 1 e 2. Apesar de haver uma melhora da sensibilidade para o critério ampliado se comparado com o critério estrito do RDG para a hipótese 1, a especificidade do critério ampliado foi bastante menor que o mesmo indicador para o critério do RDG, resultando em estatística t de Student negativo para o critério ampliado. Embora o teste $\mathrm{t}$ de Student seja válido $(\mathrm{t}>0)$ para o critério estrito do RDG, a conclusão tem significância bastante menor que 95\%. Portanto, não se pode afirmar, com significância de 95\% e com a utilização dos dados precários de acidentes obtidos, que ambos os critérios recomendam acertadamente o uso de proteção lateral. Com a utilização da hipótese 2, a consideração sobre a significância menor que 95\% ocorre novamente em ambos os critérios. Dever-se-ia manter, então, o critério estrito do RDG até a obtenção de dados melhores que permitissem justificar a ampliação do critério, pois a limitação na qualidade dos dados sobre acidentes prejudicou investigações mais detalhadas.

\subsection{Recomendações}

Apesar do capítulo 4 ter focado nos critérios convencionais adotados no Brasil, mostrou-se que os modelos compreensivos são ferramentas melhores de decisão para o projeto de segurança do entorno viário, pois utilizam avaliação econômica entre alternativas de projetos de segurança. 
Além disso, os modelos compreensivos são capazes de incorporar questões como a influência da presença da proteção lateral (que em geral estão mais próximos à via), no aumento da frequência de acidentes.

Recomenda-se, portanto, estudos mais aprofundados dos modelos compreensivos no contexto brasileiro, com calibração para a realidade local, pois, como se viu, os modelos compreensivos são muito sensíveis aos custos sociais dos acidentes de trânsito e aos valores de severidade adotados para cada condição de impacto e obstáculo atingido. Assim, deve-se estudar a aplicação dos modelos compreensivos com dados de acidentes de melhor qualidade, que dependeria da sinergia entre os detentores dos dados de acidentes e os detentores dos conhecimentos teóricos e práticos, ambos buscando a melhoria contínua da segurança viária no país.

Uma forma alternativa de avaliar os critérios recomendados para o uso de dispositivos de proteção lateral é baseada no enfoque dos modelos compreensivos, adotando o ponto de vista econômico, com análise custo-benefício. Nesta avaliação, o conhecimento da gravidade dos acidentes é de suma importância, uma vez que a intervenção requerida pelo critério, de uma forma geral, reduz a gravidade dos acidentes, com aumento da freqüência deles. Através do custo social do acidente com vítima fatal e do acidente com vítima não fatal, é possível avaliar se o benefício da redução dos acidentes com fatalidades supera o acréscimo do custo dos acidentes com vítimas não fatais somados ao custo da intervenção (inclusive em locais tratados de forma desnecessária). Uma metodologia para a definição de um critério baseado em avaliação econômica foi proposto por PIETRANTONIO e TOURINHO (2004). 


\section{REFERÊNCIAS}

AASHO. Highway Design and Operational Practices Related to Highway Safety, American Association of State Highway Officials, Washington, D.C., 1967.

AASHTO. Guide for Selecting, Locating and Designing Traffic Barriers, American Association of State Highway and Transportation Officials, Washington, D.C., 1977.

A Policy on Geometric Design of Highways and Streets, American Association of State Highway and Transportation Officials, Washington, D.C., 2001.

. Roadside Design Guide, American Association of State Highway and Transportation Officials, Washington, D.C., 1996.

. Roadside Design Guide, American Association of State Highway and Transportation Officials, Washington, D.C., 2002.

. Roadside Design Guide, American Association of State Highway and Transportation Officials, Washington, D.C., 2006.

ARTESP. Relatório Consolidado de Segurança Viária, Agência Reguladora de Serviços Públicos Delegados de Transportes do Estado de São Paulo, São Paulo, 2010. (RC.06.OPR.03.01.2010).

ASSOCIAÇÃO BRASILEIRA DE NORMAS TÉCNICAS. NBR 10697 - Pesquisa de acidentes de trânsito, 1989.

. NBR 6971 - Defensas metálicas - Projeto e implantação, 1999.

. NBR 14885 - Segurança no tráfego - Barreiras de concreto, 2004.

. NBR 15486 - Segurança no tráfego - Dispositivos de contenção viária - Diretrizes, 2007. 
AUSTROADS. Rural Road Design: Guide to the Geometric Design of Rural Roads, Sydney, 2003.

BRASIL. Ministério da Saúde: Saúde Brasil 2007 - Uma Análise da Situação de Saúde Perfil de Mortalidade do Brasileiro, Secretaria de Vigilância em Saúde, Brasilia, 2008. Disponível em: <http://portal.saude.gov.br/portal/arquivos/pdf/coletiva_saude 061008.pdf>. Acessado em: Jan. 2010.

. Confederação Nacional de Municípios: Estudos Técnicos - Mapeamento das Mortes por Acidentes de Trânsito no Brasil, 2009. Disponível em $<$ http://portal.cnm.org.br/sites/9000/9070/Estudos/Transito/EstudoTransito-versaoconcurso.pdf $>$. Acessado em: Jan. 2010.

COOPER, P.: Analysis of Roadside Encroachment - Single-Vehicle Run-off-Road Accident Data Analysis for Five Provinces, B. C. Research, Vancouver, British Columbia, Canada, Mar. 1980.

DNER. Manual de Projeto Geométrico de Rodovias Rurais, Departamento Nacional de Estradas de Rodagem, Diretoria de Desenvolvimento Tecnológico, Divisão de Capacitação Tecnológica, Rio de Janeiro, 1999.

DER. Projeto de Dispositivos de Segurança. Departamento de Estradas de Rodagem do Estado de São Paulo. Diretoria de Engenharia. São Paulo. 2005

EUROPEAN COMMITTEE FOR STANDARDIZATION. EN 1317-1 - Road restrint systems - Part 1: Terminology and General Criteria for Test Methods, 1998.

EN 1317-2 - Road restrint systems - Part 2: Performance Classes, Impact Test Acceptance Criteria and Test Methods for Safety Barriers, 1998.

. EN 1317-3 - Road restrint systems - Part 3: Performance Classes, Impact Test Acceptance Criteria and Test Methods for Crash Cushions, 2000. 
EN 1317-4 - Road restrint systems - Part 4: Performance Classes, Impact Test Acceptance Criteria and Test Methods for Terminals and Transitions of Safety Barriers, 2001.

. EN 1317-5 - Road restrint systems - Part 5: Durability and Evaluation of Conformity, 1998.

TAC. Geometric Design Guide for Canadian Roads, Transportation Association of Canada, 1999, Chapter 3.1.

GRAHAM, J. L.; HARDWOOD, D. W.: National Cooperative Highway Research Program Report 247: Effectiveness of Clear Recovery Zones, Transportation Research Board, Washington, D.C., 1982.

GLENNON, J. C.; HILL, P. F.: Roadway Safety and Tort Liability, Lawyers and Judges Publishing; 2 edition, 2004, Chapter 2, 3.

GLENNON, J. C.; TAMBURRI, T. N.: Objective Criteria for Guardrail Installation, Highway Research Record 174, p. 184-206, 1967.

GLENNON, J. C.: National Cooperative Highway Research Program Report 148: Roadside Safety Improvement Programs on Freeways - A Cost-effectiveness Priority Approach, Transportation Research Board, Washington, D.C., 1974.

GOLD, P. A.: Segurança de Trânsito - Aplicações de Engenharia para Reduzir Acidentes, Banco Interamericano de Desenvolvimento, 1998.

HRB. Highway Guardrail, Special Report 81, Highway Research Board, Washington, D.C., 1974.

HOLDRIDGE, J. M.; SHANKAR, V. N.; ULFARSSON, G. F.: The crash severity impacts of fixed roadside objects, Journal of Safety Research 36, p. 139-147, 2005. 
HUTCHINSON, J. W.; KENNEDY, T. W.: Safety Consideration in Median Design, Highway Research Record 162, Transportation Research Bord, Washington, D. C., 1966.

HYDE, A. S.; Biodynamics and Crashworthiness of Vehicle Structures, Wyle Laboratories Research Staff Report WR 68-3, Vol III of IV, Mar. 1968.

IPEA. Impactos sociais e econômicos dos acidentes de trânsito nas rodovias brasileiras Relatório Executivo, Instituto de Pesquisas Econômicas Aplicadas, Brasília, 2006.

LEE J.; MANNERING, F.: Impact of Roadside Features on the Frequency and Severity of Run-Off-Roadway accidents: an Empirical Analysis, Accident Analysis and Prevention 34,pg 149-161, 2002.

LIMPERT, R.: Motor Vehicle Accident Reconstruction and Cause Analysis, Fourth Edition, The Michie Company, 1994.

LINNET, K.; BRANDT, E.: Assessing Diagnostic Tests Once an Optimal Cutoff Point Has Been Selected, Clinical Chemistry, Vol. 32, n. 7, 1986.

LYNAN, D. A.; KENNEDY, J. V.: Published Project Report PPR298 - The Travel of Errant Vehicles After Leaving the Carriageway, TRL, The Highways Agency, 2005.

MAK, K. K.; SICKING, D. L.: National Cooperative Highway Research Program Project 22-9: Roadside Safety Analysis Program (RSAP) - User's Manual. Transportation Research Board, Washington, D.C., 2002.

MAK, K. K.; SICKING, D. L.: National Cooperative Highway Research Program Report 492: Roadside Safety Analysis Program (RSAP) - Engineer's Manual. Transportation Research Board, Washington, D.C., 2003.

MAK, K. K.; SICKING, D. L.; ROSS, H. E.: Real-World Impact Conditions for Run-Off-theRoad Accidents, Transportation Research Record 1065, Transportation Research Board, Washington, DC, 1986. 
MARTINEZ, E. Z.; LOUZADA-NETO, F.: Metodologia estatística para testes diagnósticos e laboratoriais com respostas dicotomizadas, Rev. Mat. Estat., São Paulo, v.18 , p.83-101, 2000.

MAZUCHELI, J.; LOUZADA-NETO, F.; GUIRADO, L.; MARTINEZ, E. Z.: Algumas Medidas do Valor Preditivo de um Modelo de Classificação, Rev. Bras. Biom., São Paulo, v.26, n.2, p. 83-91, 2008.

MCLEAN, J.: Review of the Development of US Roadside Design Standards, Road \& Transport Research, Vol. 11, No. 2, 2002

MONTELLA, A.; PERNETTI, M.: Heavy-Goods Vehicle Collisions with Steel Road Safety Barriers - Combined Influences of Position of Center of Mass and Tire-Pavement Friction, Transportation Research Record 1690, Transportation Research Board, Washington, DC, 1999.

OLSON, R. M.; WEAVER, G. D.; MARQUIS, E. L.: National Cooperative Highway Research Program Report 158: Selection of Safe Roadside Cross Sections, Transportation Research Board, Washington, D.C., 1975.

Pietrantonio, H.; TOURINHO, L. F. B.: A Decision Based Criterion for Selecting Parameters in Evaluation of Pedestrian Safety Problems with the Traffic Conflict Analysis Technique, Submitted for publication in the journal Transportation Planning and Technology, November 2004.

ROSS, H. E.; POST, E. R.; NIXON, J. F.; HUSTACE, D.; KRISTAPONIS, E. V.: Warrants for Guardrail on Embankments, Highway Research Board, Record 460, p. 85-96, 1973.

ROSS, H. E.; SICKING, D. L.; ZIMMER R. A.; MICHIE, J. D.: National Cooperative Highway Research Program Report 350: Recommended Procedures for the Safety Performance Evaluation of Highway Features. Transportation Research Board, Washington, D.C., 1993.

SAX, C. R.; MAZE, T. H.; SOULEYRETTE, R. R.; HAWKINS, N.; CARRIQUIRY, A. L.: Optimum Urban Clear Zone Distance, Transportation Research Record 2195, p. 27-35, 2010. 
SZULADZINSKI, G.: Formulas for Mechanical and Structural Shock and Impact, CRC Press, 2010.

TURNER, D. S.; HALL, J. W.: National Cooperative Highway Research Program Synthesis 202: Severity Indices for Roadside Features. Transportation Research Board, Washington, D.C., 1994.

U.K.DfT. Design Manual for Roads and Bridges, United Kingdom Department for Transport, Highways Agency, Vol 2, Sec 2, Part 8, TD 19/06, 2006.

VINER J. G.: Rollovers on Sideslopes and Ditches, Accident Analysis and Prevention, Vol. 27, No 4, pp 483-491, Elsevier Science Ltd, 1995.

WRIGHT, P. H.; ROBERTSON, L. S.: Priorities for Roadside Hazard Modification, Southern Section ITE Best Technical Award, 1975. 


\section{ANEXO A}

\section{Planilha de cadastro dos obstáculos}

\section{Lado direito}

\begin{tabular}{|c|c|c|}
\hline \multicolumn{2}{|c|}{ 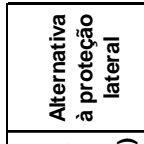 } & \multirow{2}{*}{ 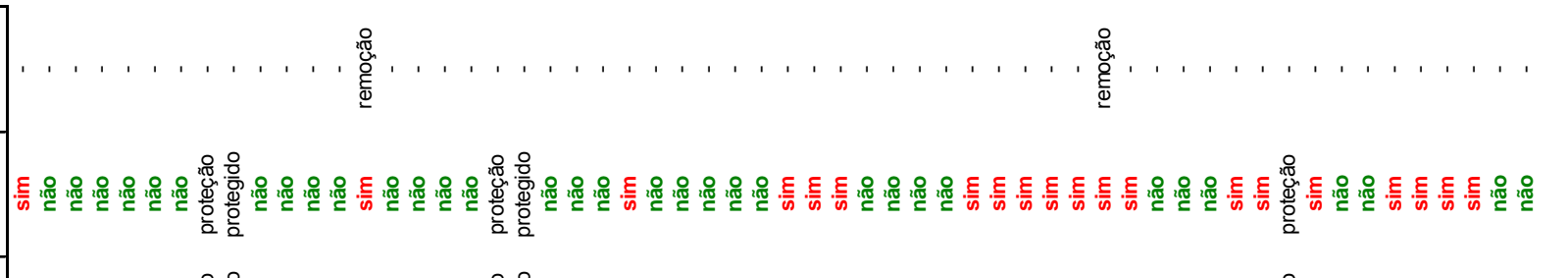 } \\
\hline & & \\
\hline & 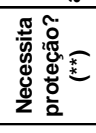 & 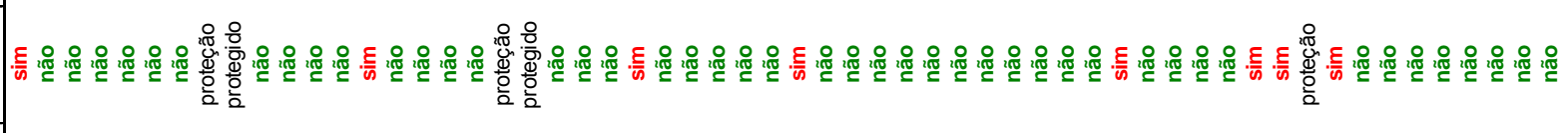 \\
\hline & 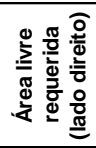 & 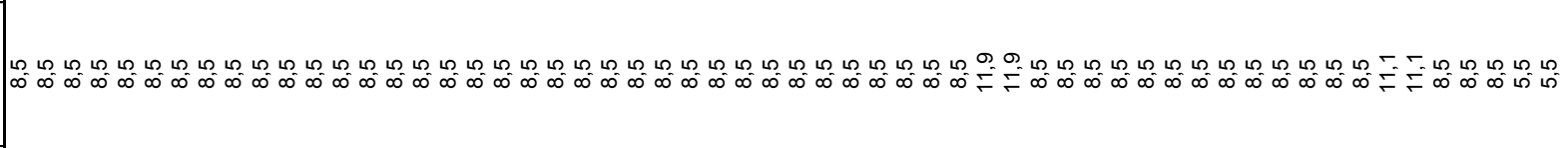 \\
\hline & 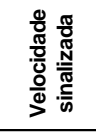 & வ வ \& \\
\hline & 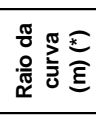 & 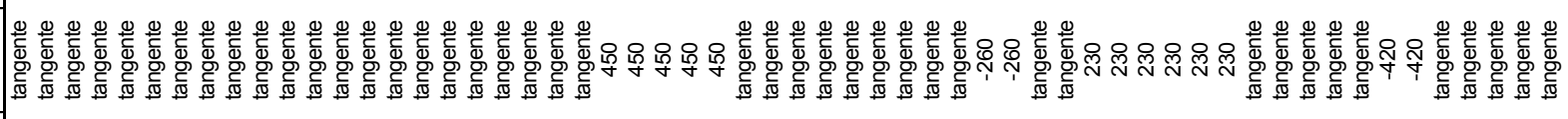 \\
\hline & & 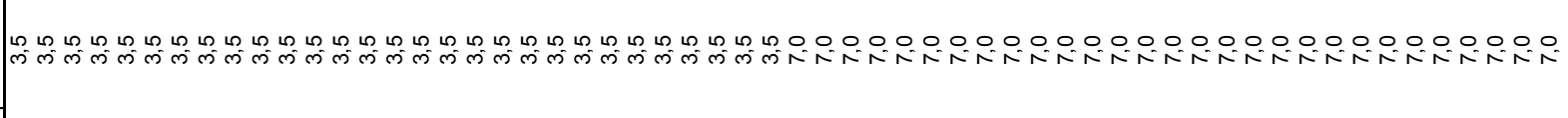 \\
\hline & & 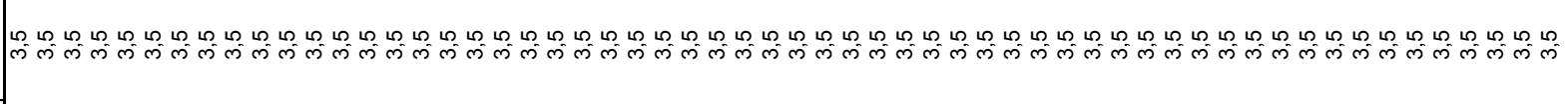 \\
\hline & 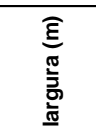 & 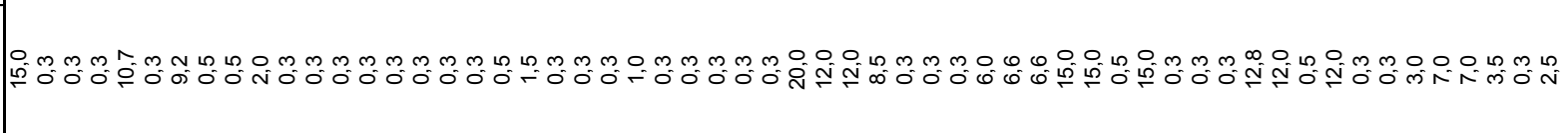 \\
\hline & 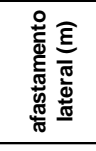 & 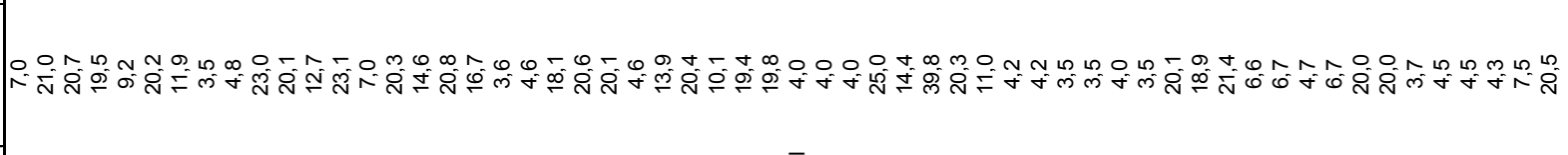 \\
\hline & 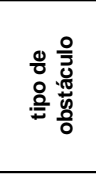 & 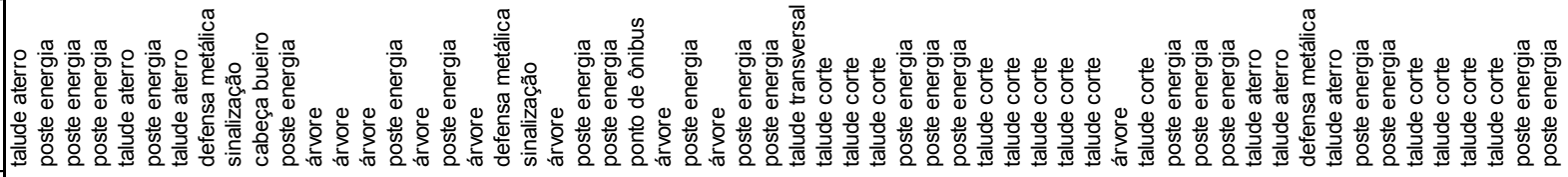 \\
\hline & 产 & 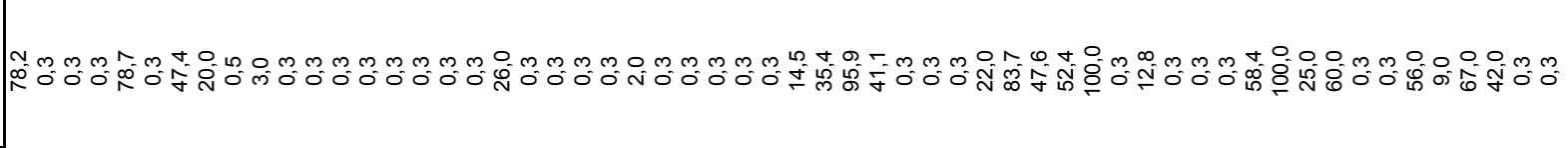 \\
\hline & $\begin{array}{l}\underline{E} \\
\underline{\underline{E}} \\
\end{array}$ & 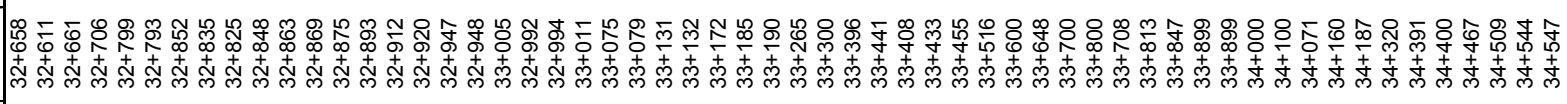 \\
\hline & 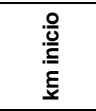 & 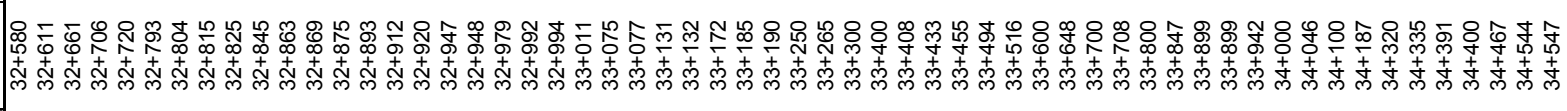 \\
\hline & 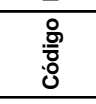 & \\
\hline & 通 & 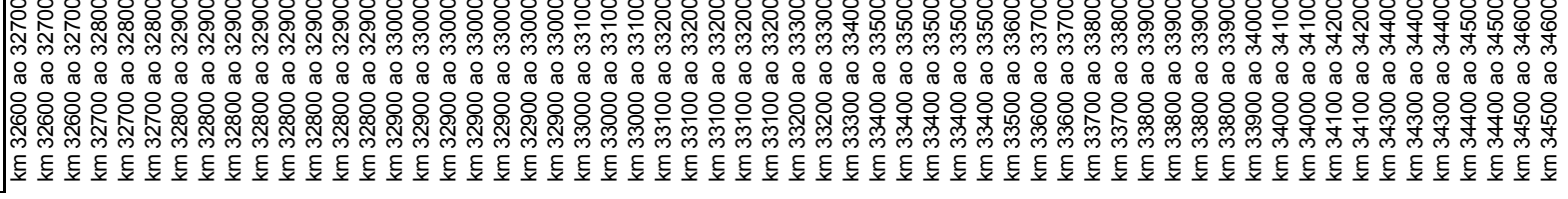 \\
\hline
\end{tabular}




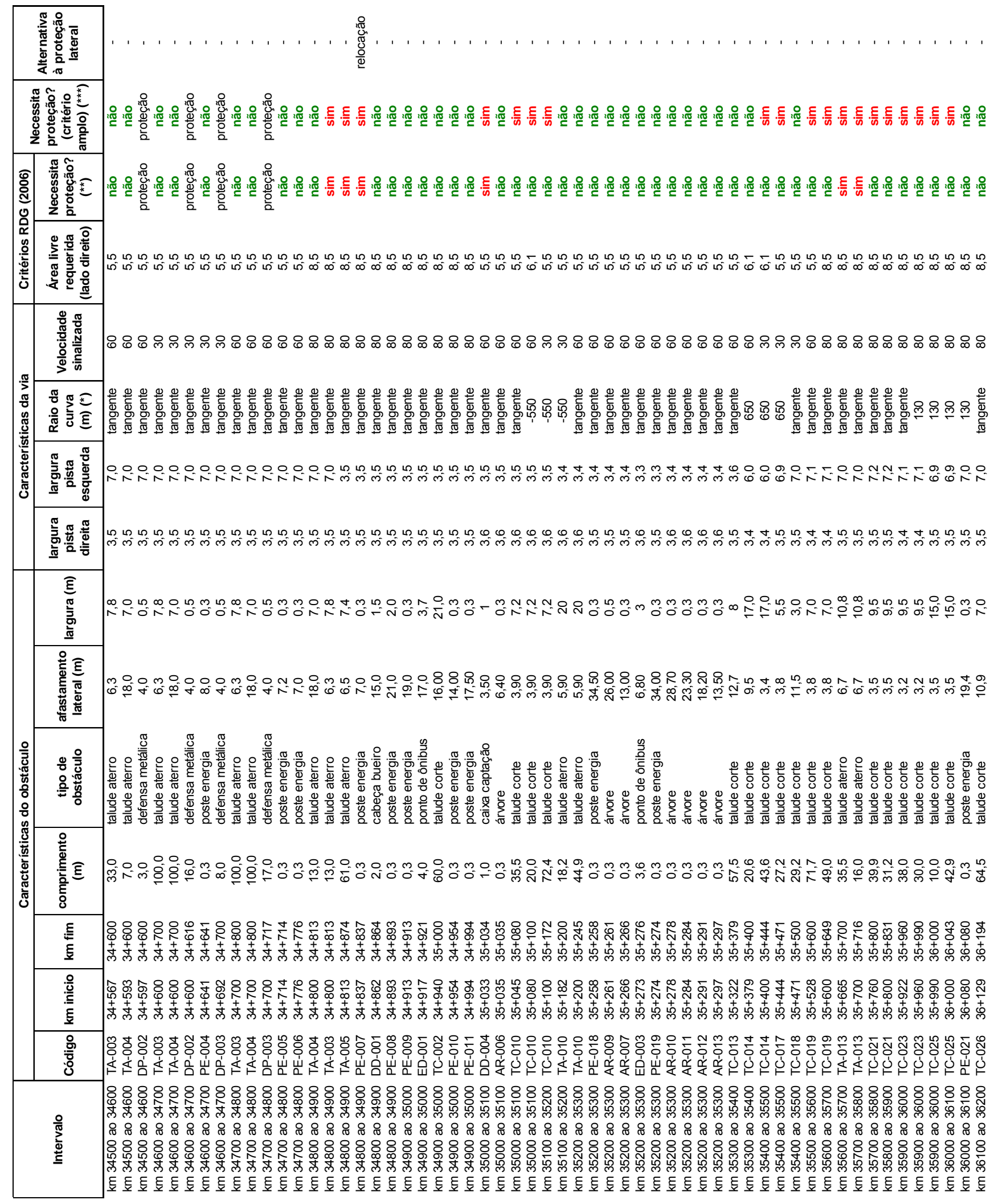




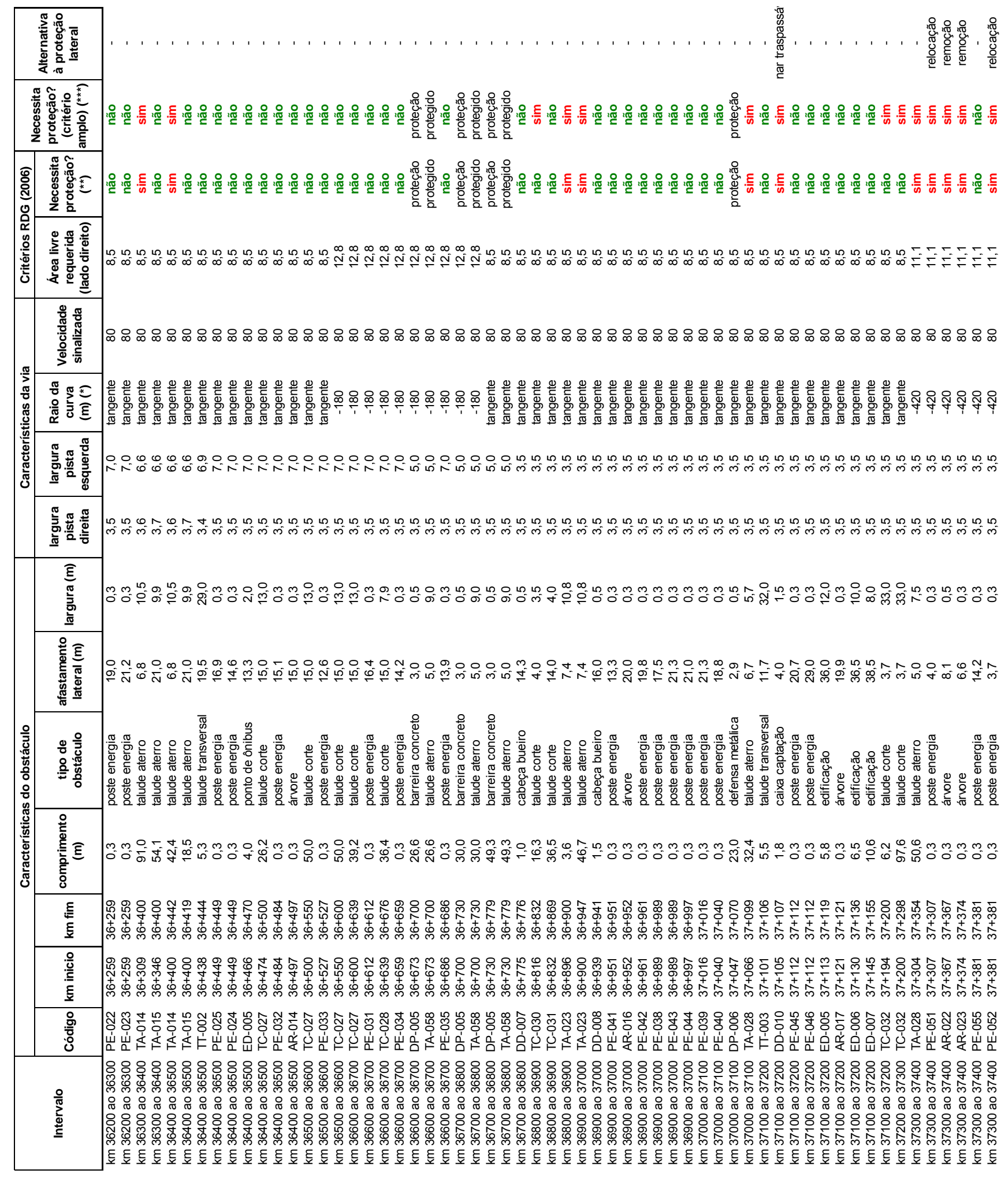




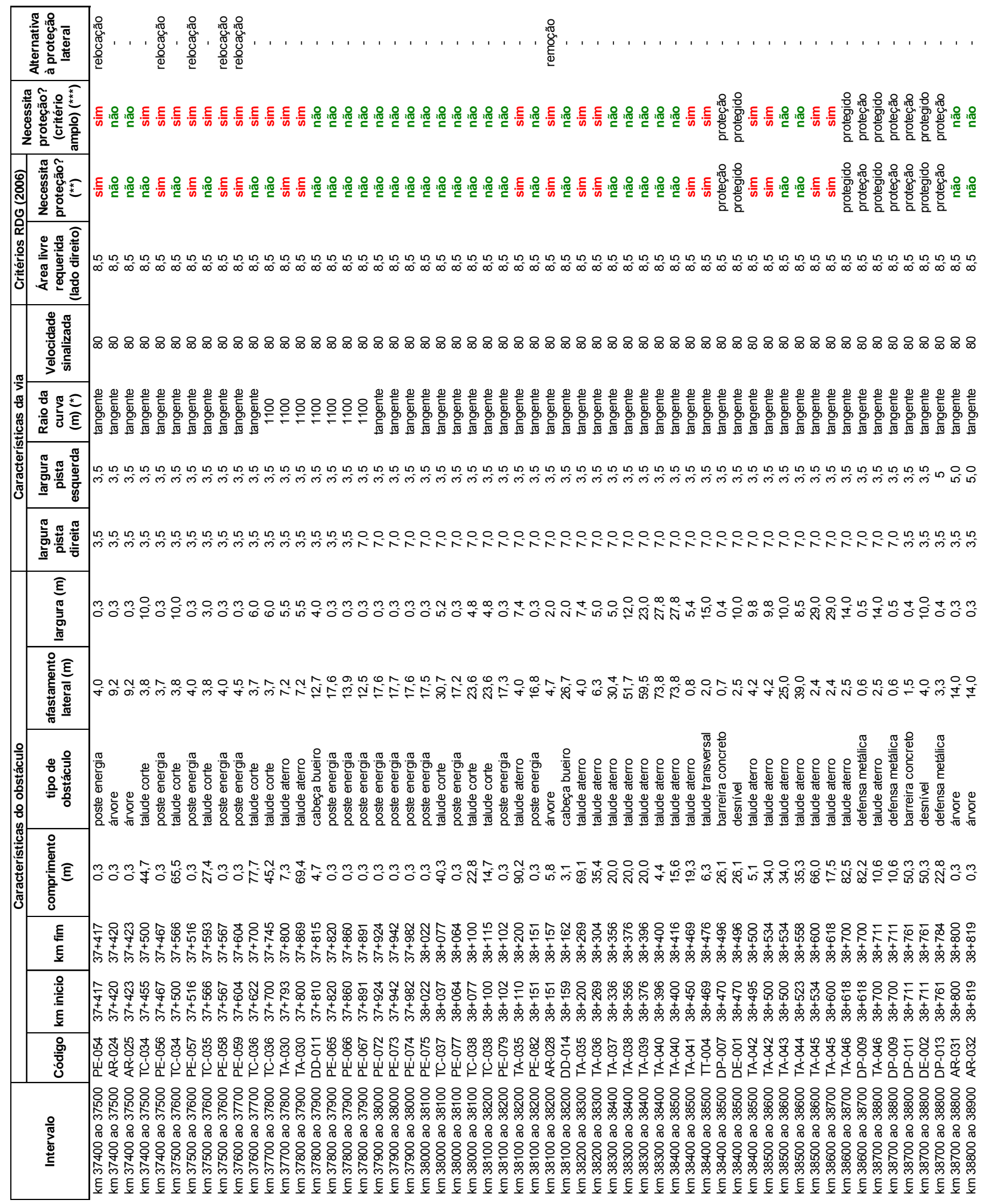




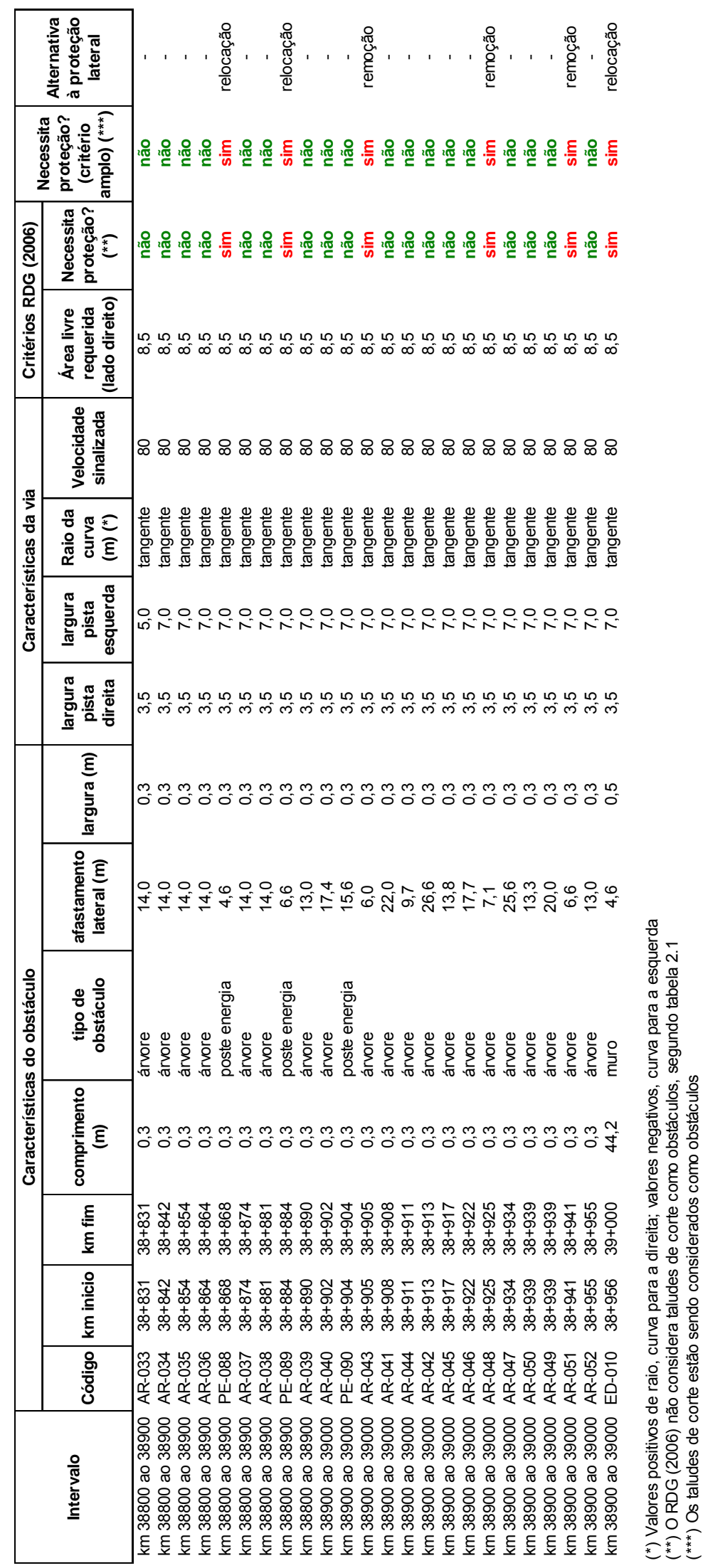




\section{Lado esquerdo}

\begin{tabular}{|c|c|c|}
\hline \multicolumn{2}{|c|}{ 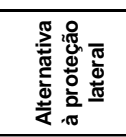 } & \multirow[b]{2}{*}{ 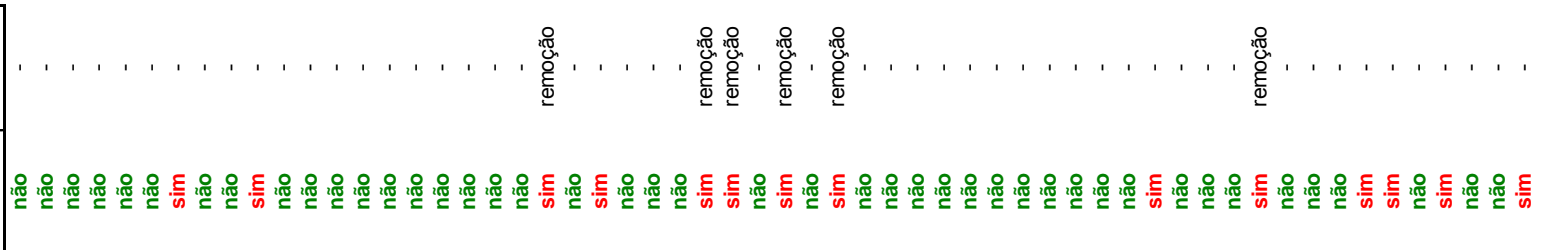 } \\
\hline & 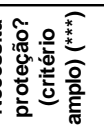 & \\
\hline & 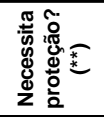 & 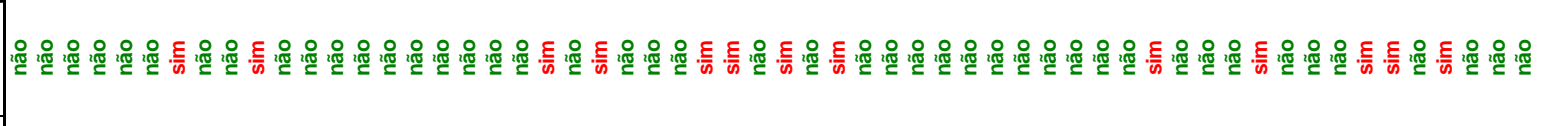 \\
\hline & 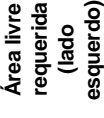 & 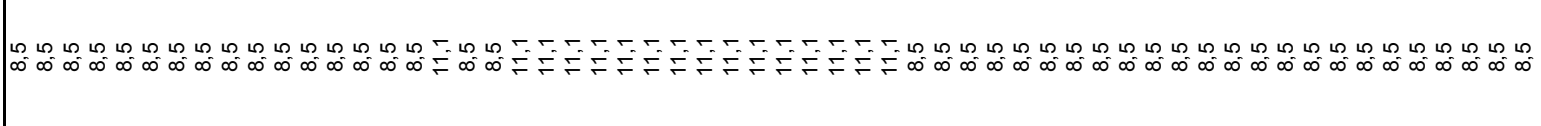 \\
\hline & 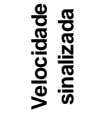 & 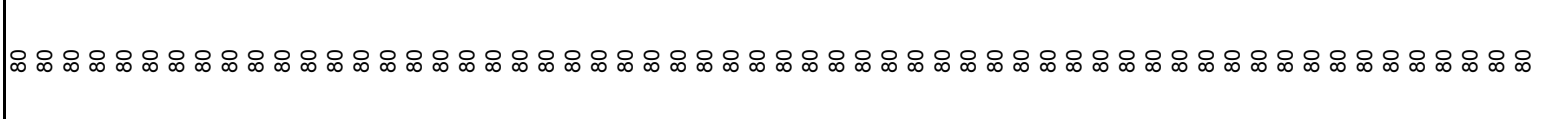 \\
\hline & 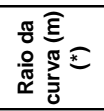 & 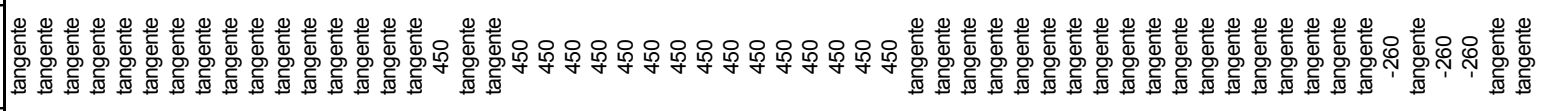 \\
\hline & 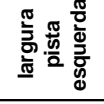 & 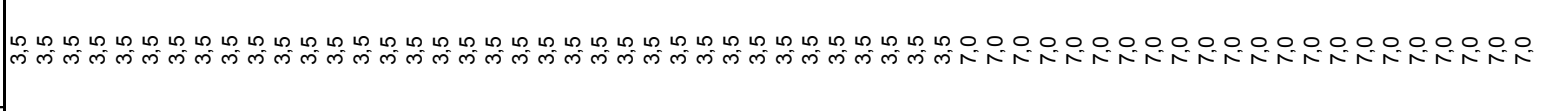 \\
\hline & 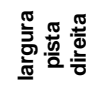 & 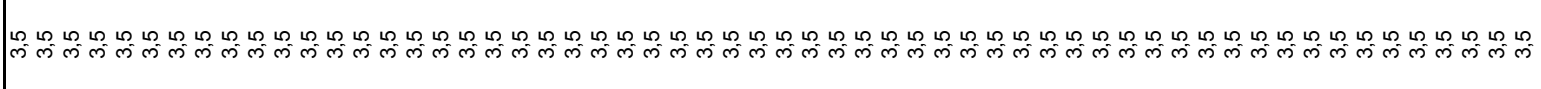 \\
\hline & 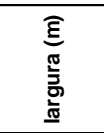 & 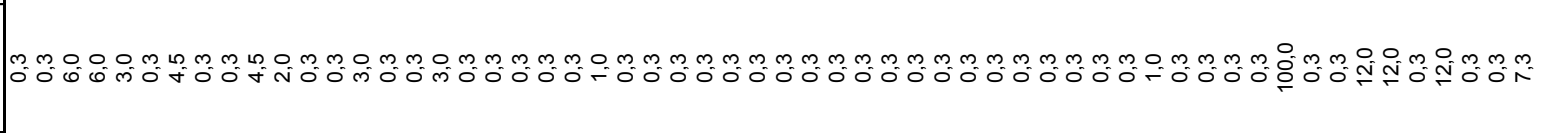 \\
\hline & 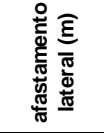 & 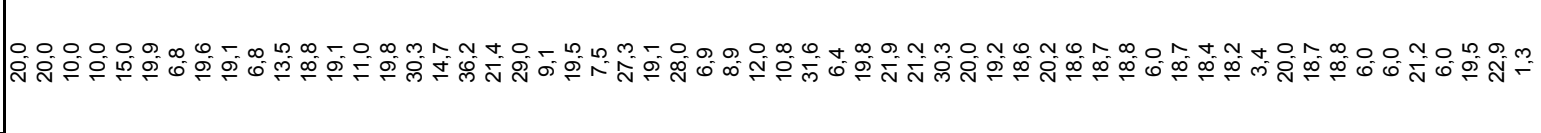 \\
\hline 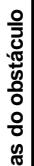 & 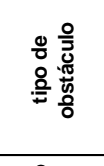 & 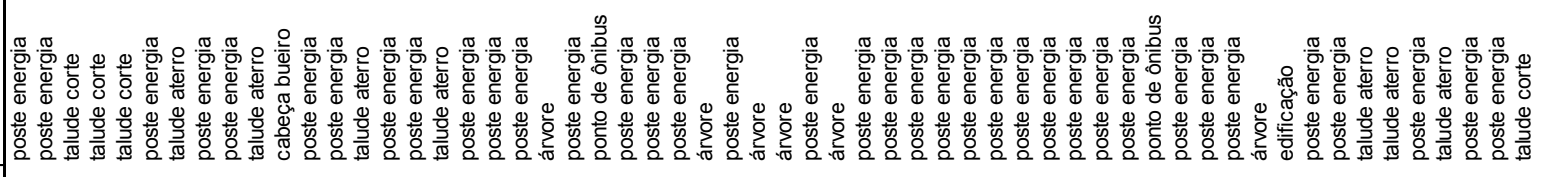 \\
\hline & 窟 & 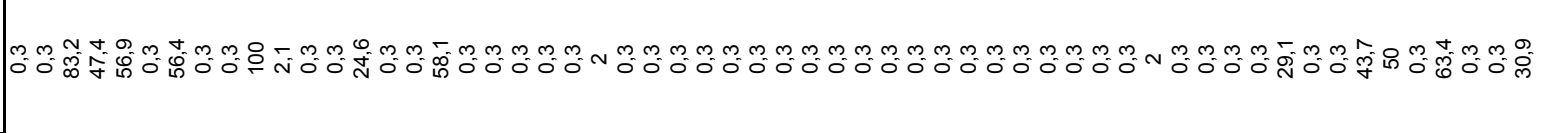 \\
\hline & $\begin{array}{ll}\underline{\underline{\underline{E}}} \\
\underline{\underline{E}}\end{array}$ & 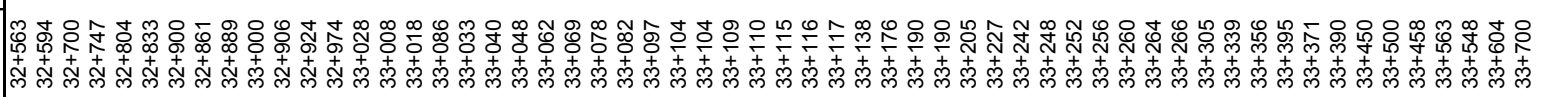 \\
\hline & 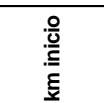 & 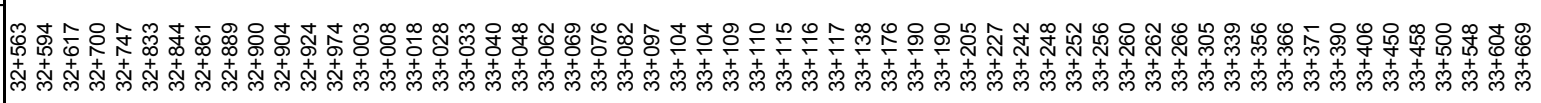 \\
\hline & 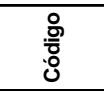 & 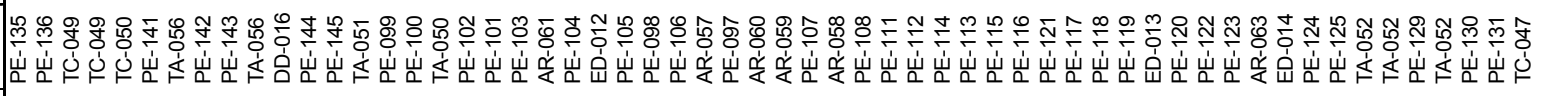 \\
\hline & 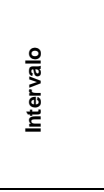 & 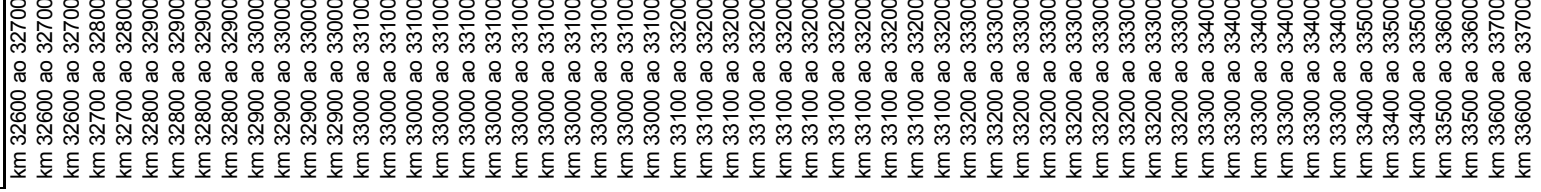 \\
\hline
\end{tabular}




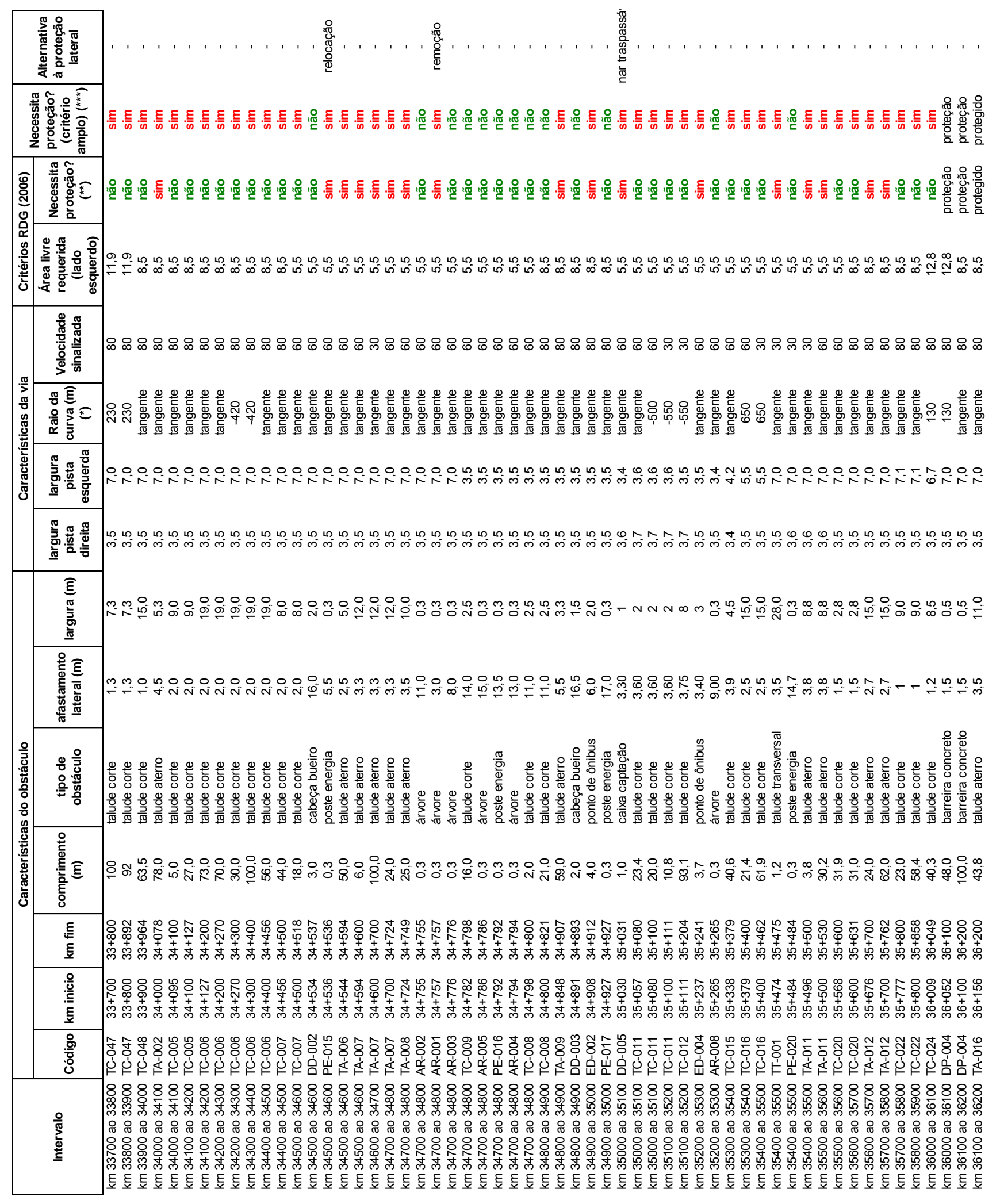




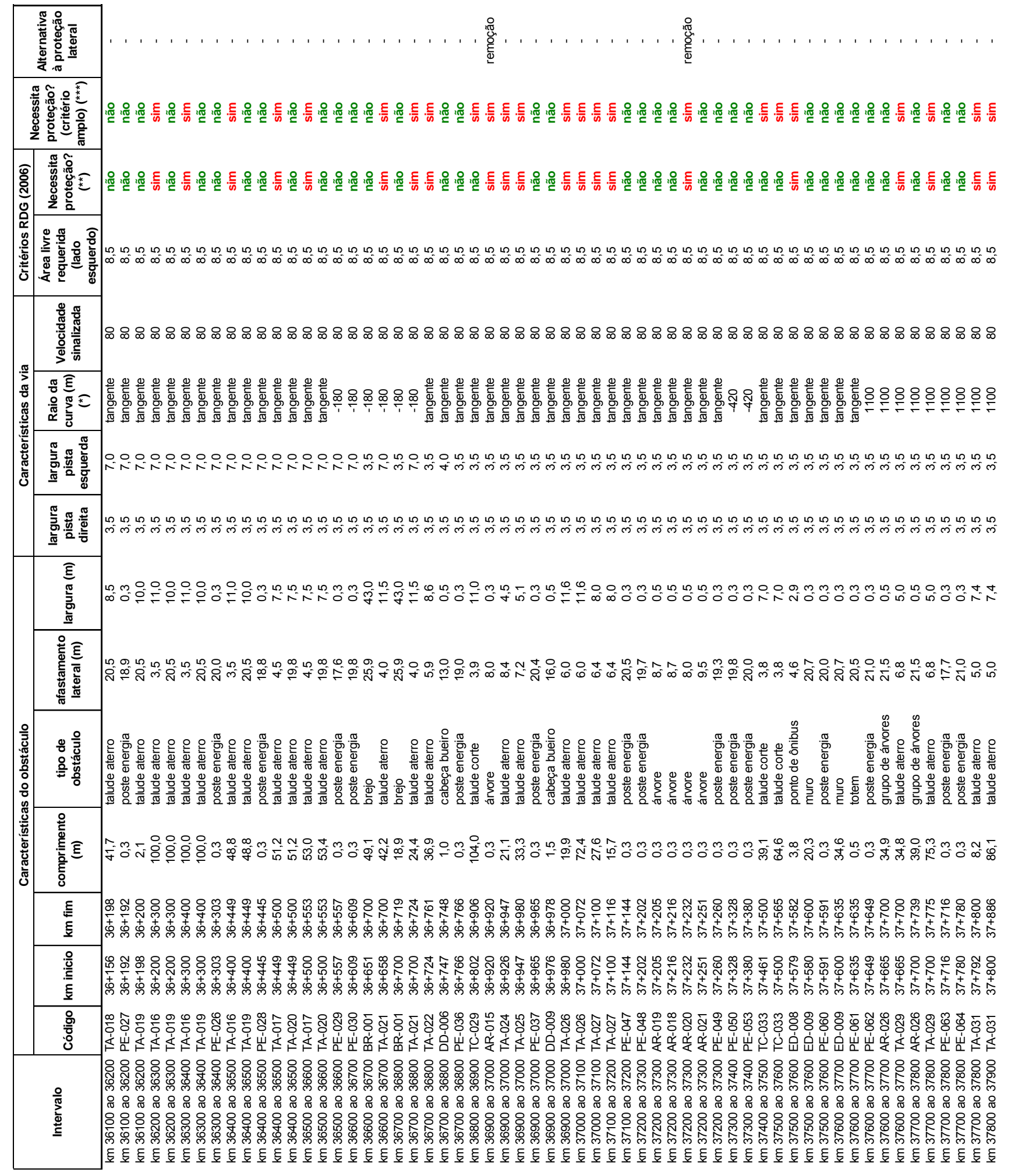




\begin{tabular}{|c|c|c|c|}
\hline & 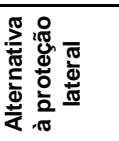 & 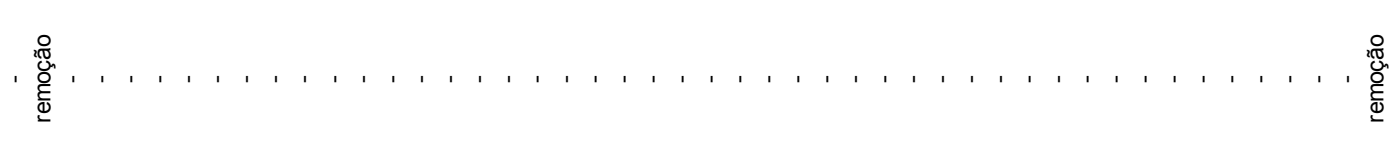 & \\
\hline & 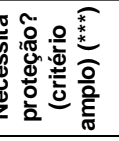 & 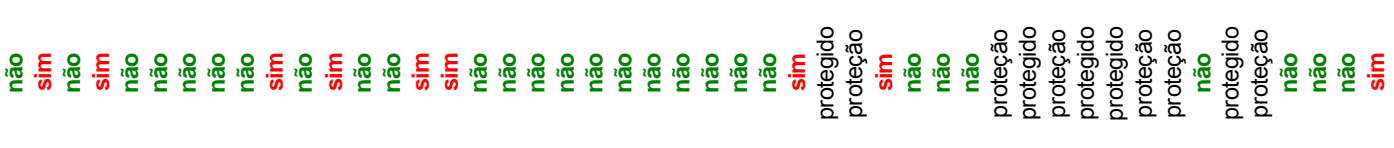 & \\
\hline 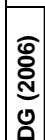 & 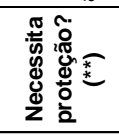 & 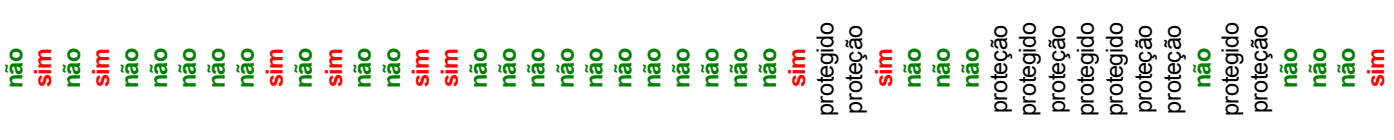 & \\
\hline & 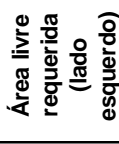 & 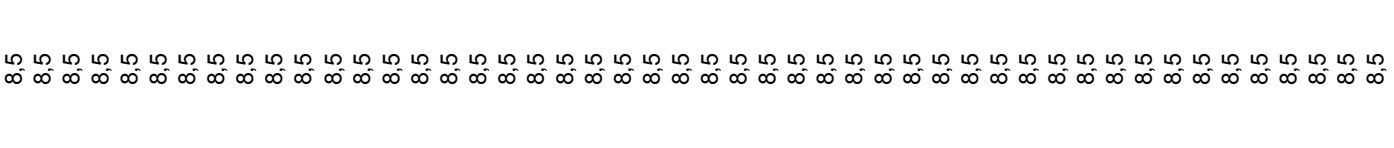 & \\
\hline & 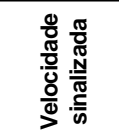 & 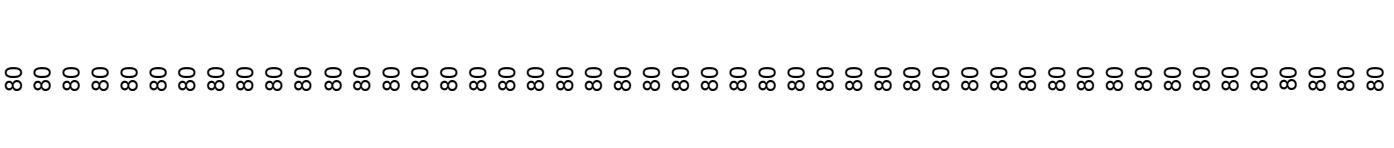 & \\
\hline & 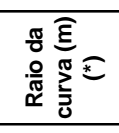 & 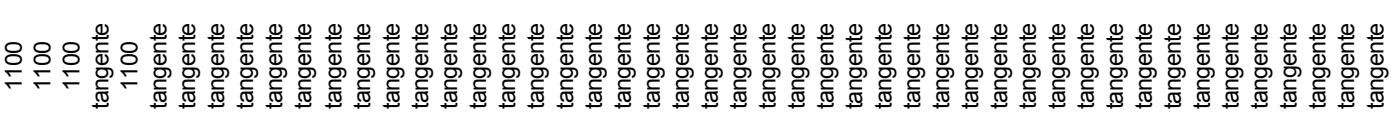 & \\
\hline & 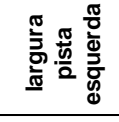 & 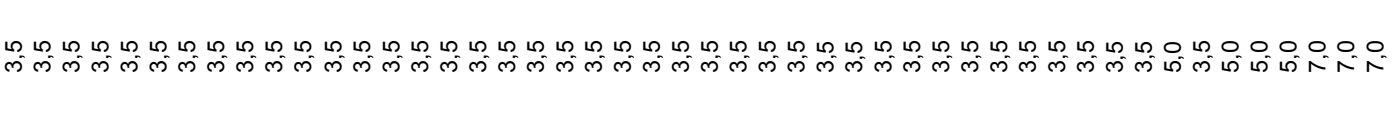 & \\
\hline & 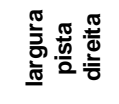 & 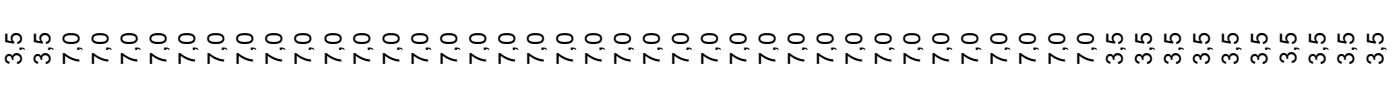 & \\
\hline & 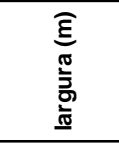 & 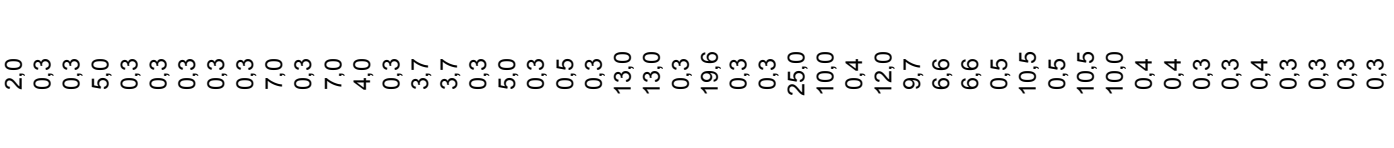 & \\
\hline & 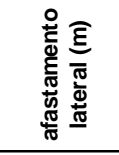 & 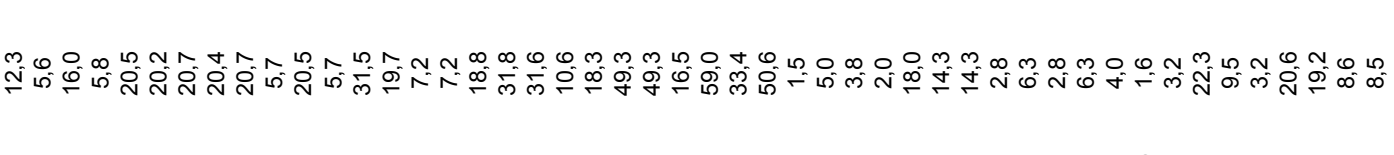 & \\
\hline 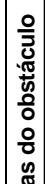 & 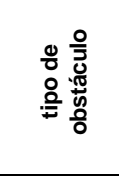 & 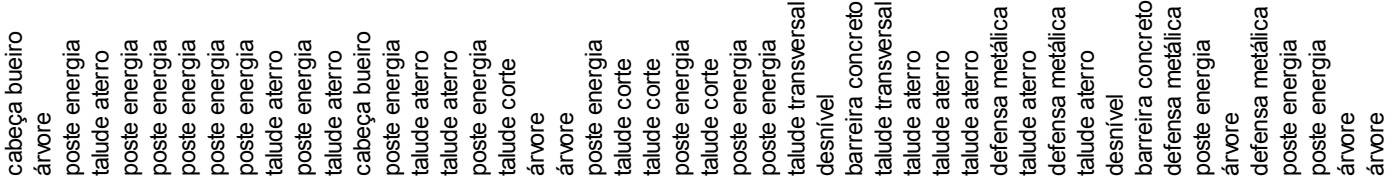 & 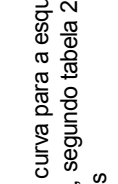 \\
\hline 总 & 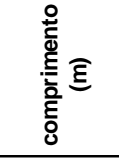 & 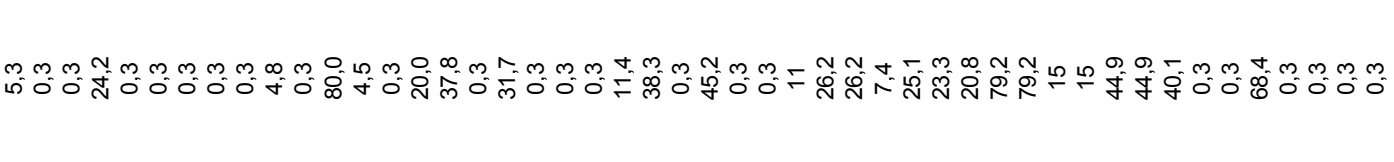 & 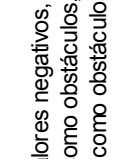 \\
\hline & $\begin{array}{l}\underline{\underline{\underline{E}}} \\
\underline{\underline{\xi}}\end{array}$ & 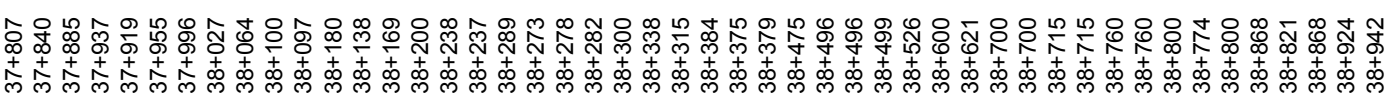 & \\
\hline & 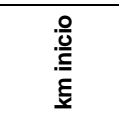 & 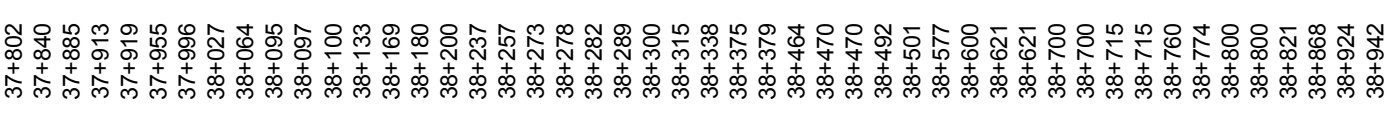 & \\
\hline & 递 & 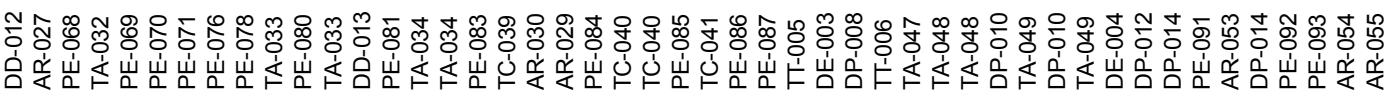 & \\
\hline & 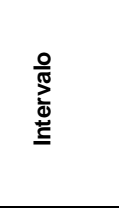 & 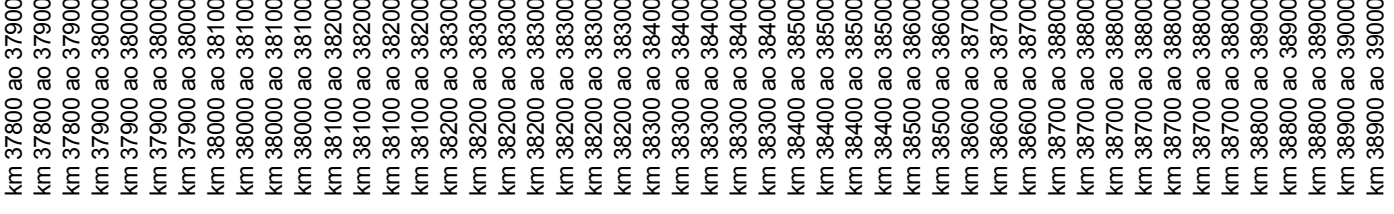 & 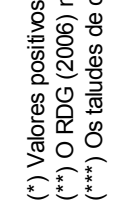 \\
\hline
\end{tabular}




\section{ANEXO B}

\section{Planta ilustrativa do trecho estudado}

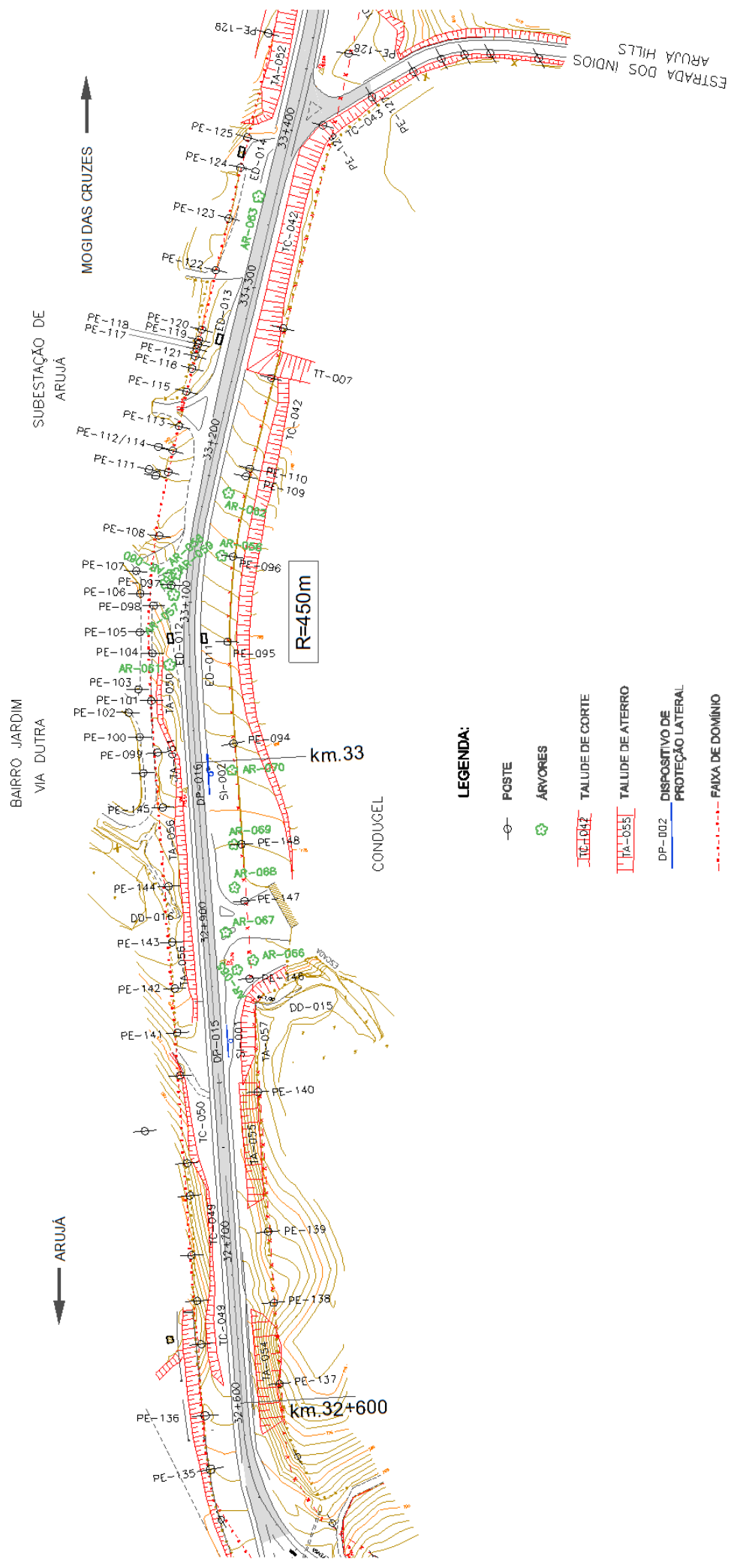




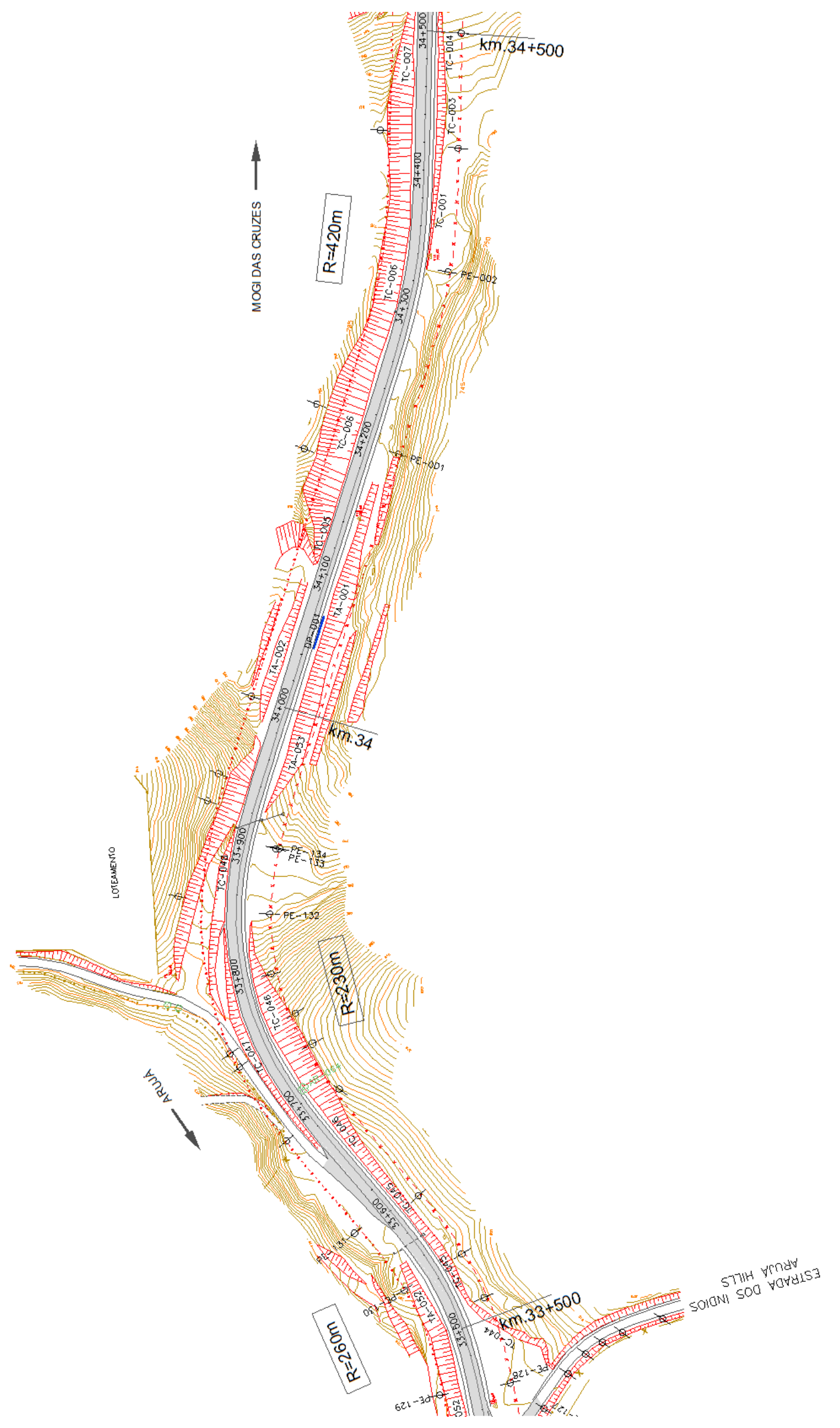




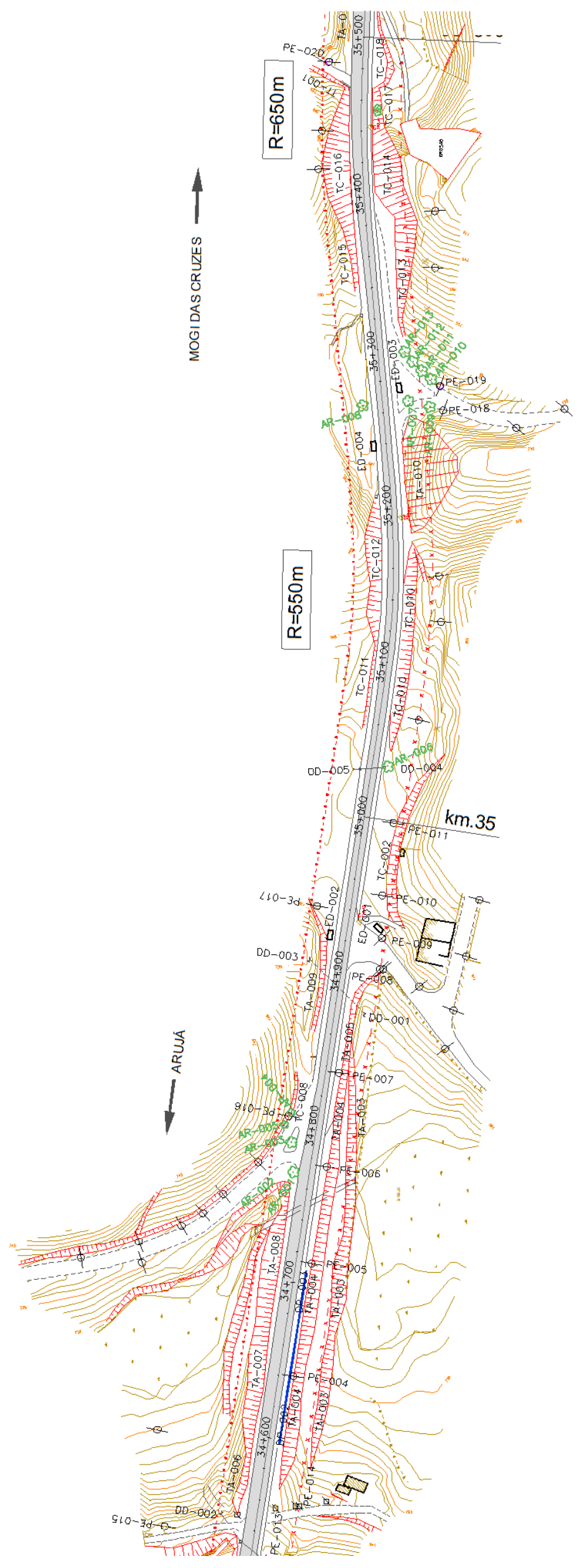




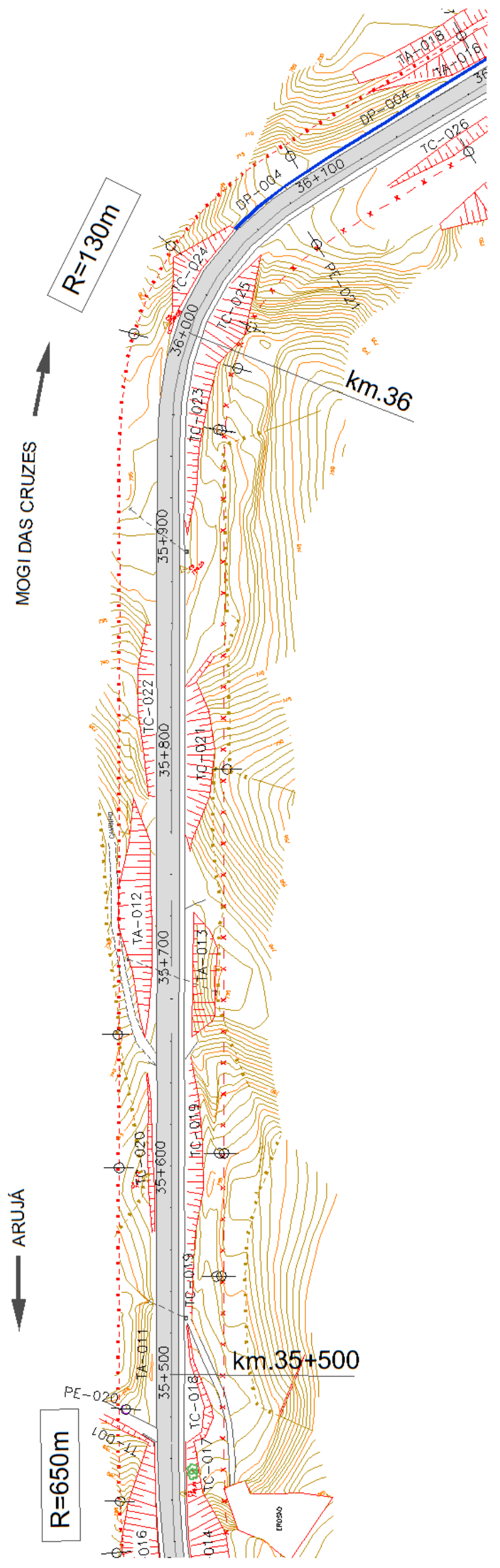




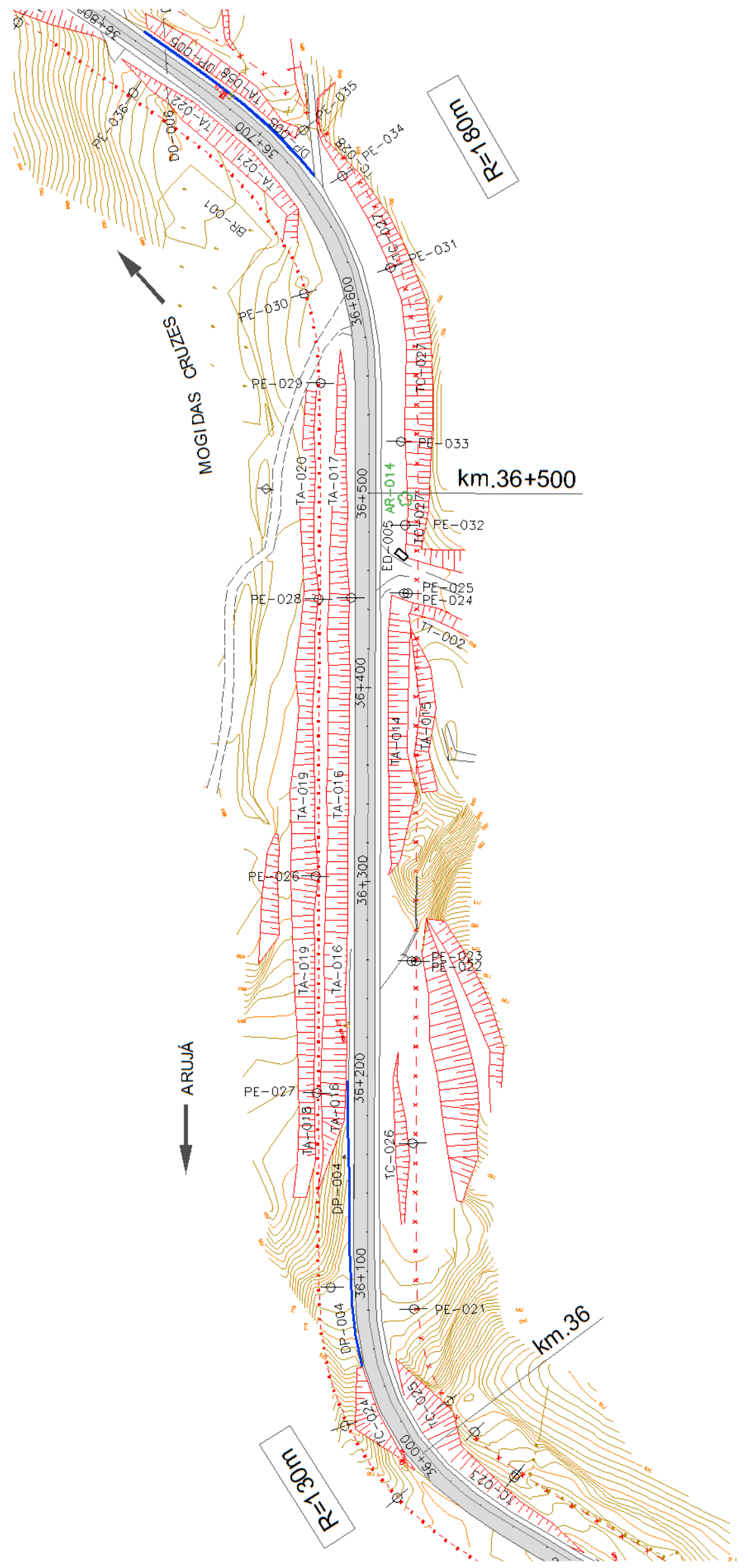




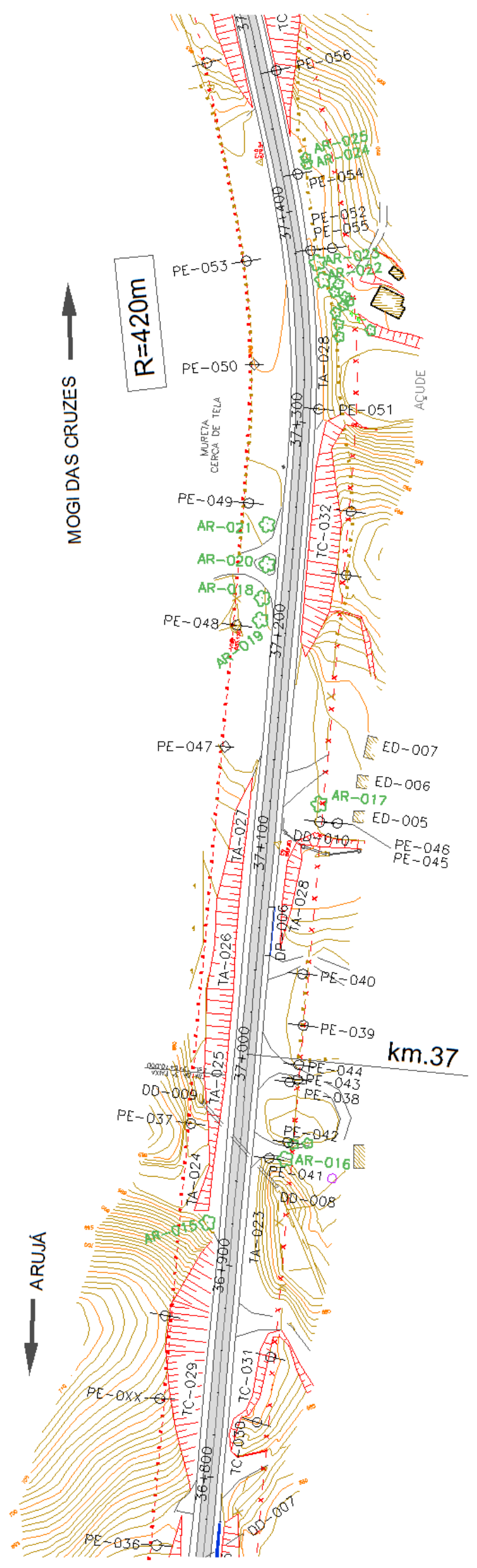




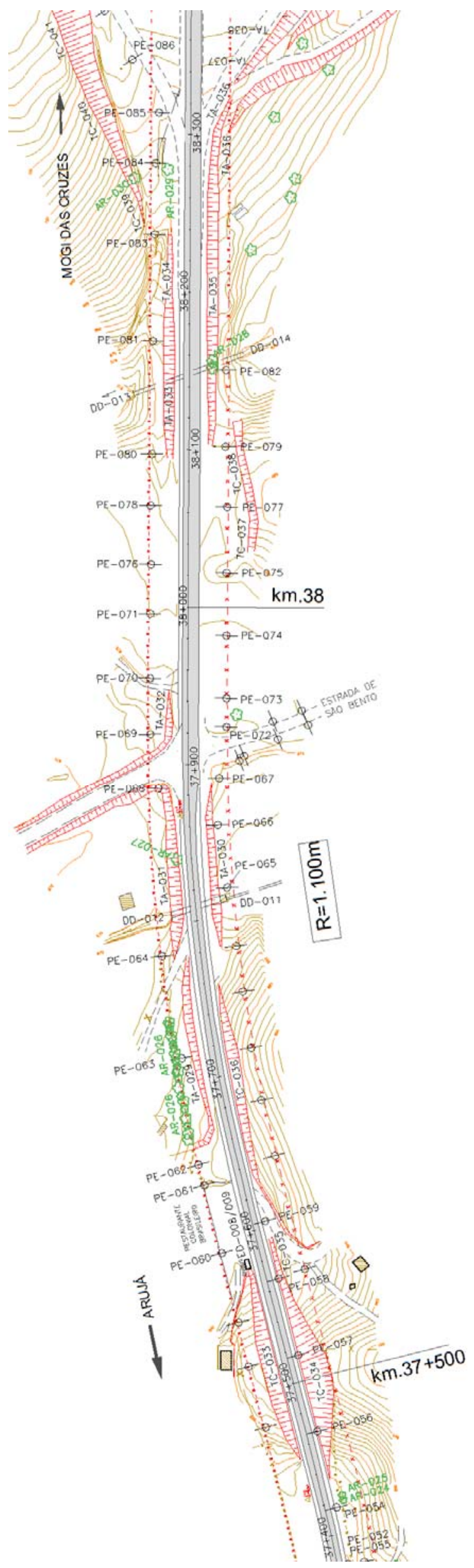




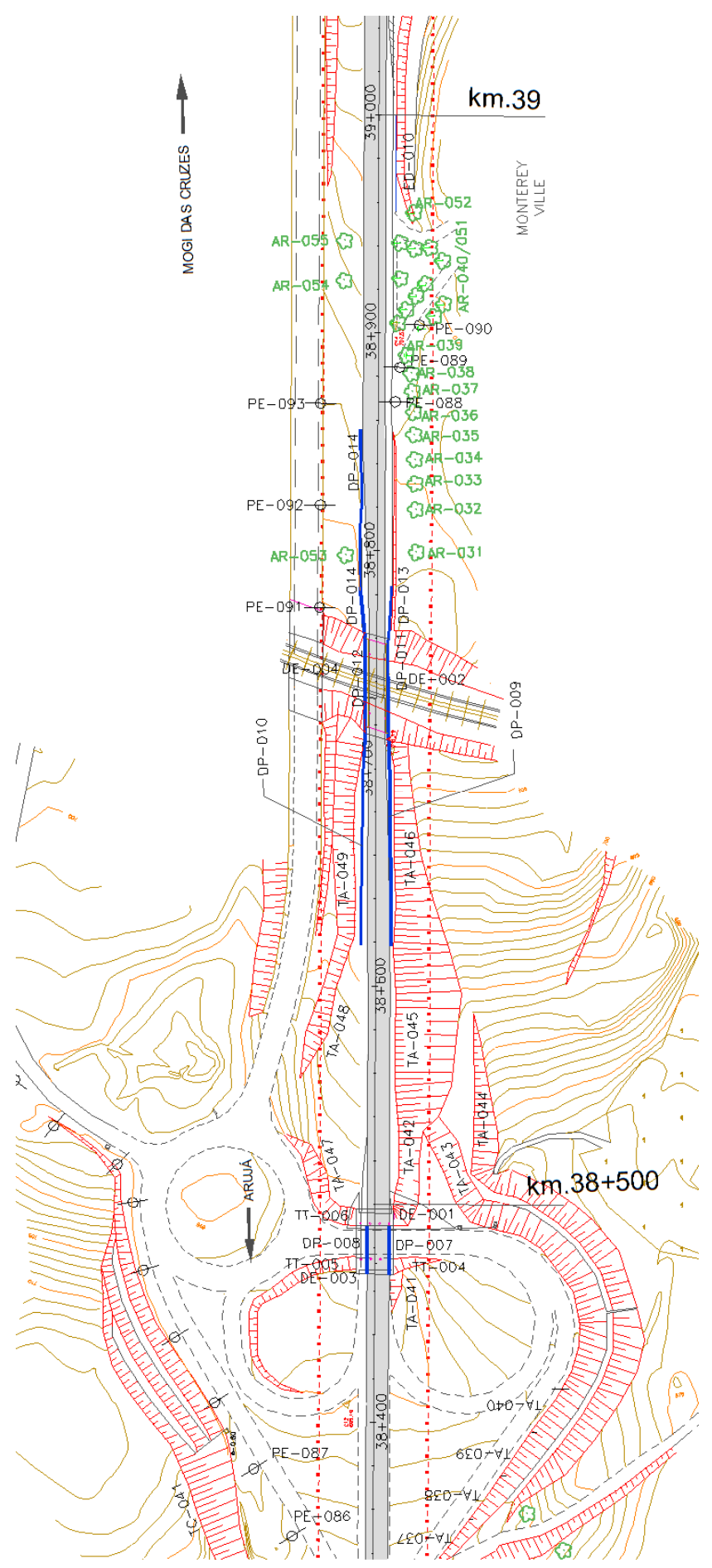




\section{ANEXO C}

\section{Planilha dos acidentes ocorridos na SP-088}

\section{Ano de 2009}

\begin{tabular}{|c|c|c|c|c|}
\hline km & Data & Hora & Tipologia & $\begin{array}{c}\text { Sentido em que o evento } \\
\text { ocorreu }\end{array}$ \\
\hline $33+100$ & $13 / 01 / 09$ & $17: 10$ & Atropelamento de Pedestre & Crescente \\
\hline $33+100$ & $15 / 07 / 09$ & $19: 40$ & Colisão Transversal & Crescente \\
\hline $33+200$ & $28 / 01 / 09$ & $20: 55$ & Colisão Transversal & Decrescente \\
\hline $33+300$ & $25 / 04 / 09$ & $04: 50$ & Atropelamento de Animal & Decrescente \\
\hline $33+300$ & $24 / 08 / 09$ & $20: 20$ & Colisão Lateral & Decrescente \\
\hline $33+350$ & $18 / 06 / 09$ & $16: 00$ & Choque & Decrescente \\
\hline $34+000$ & $13 / 12 / 09$ & $17: 20$ & Capotamento & Crescente \\
\hline $34+500$ & $28 / 06 / 09$ & $01: 20$ & Choque & Crescente \\
\hline $34+800$ & $16 / 05 / 09$ & 09:50 & Colisão Traseira & Crescente \\
\hline $34+800$ & $06 / 11 / 09$ & 23: 15 & Colisão Transversal & Decrescente \\
\hline $36+000$ & $24 / 05 / 09$ & $07: 00$ & Colisão Transversal & Crescente \\
\hline $36+000$ & $17 / 10 / 09$ & $12: 20$ & Colisão Lateral & Crescente \\
\hline $36+000$ & $06 / 11 / 09$ & 09:00 & Choque & Crescente \\
\hline $36+050$ & $22 / 09 / 09$ & $14: 40$ & Colisão Frontal & Crescente \\
\hline $36+100$ & $24 / 02 / 09$ & $04: 20$ & Choque & Decrescente \\
\hline $36+100$ & $18 / 05 / 09$ & 09:00 & Choque & Decrescente \\
\hline $36+100$ & $15 / 07 / 09$ & $20: 20$ & Choque & Crescente \\
\hline $36+500$ & $19 / 02 / 09$ & $11: 20$ & Capotamento & Decrescente \\
\hline $36+500$ & $19 / 09 / 09$ & 05:00 & Capotamento & Decrescente \\
\hline $36+550$ & $21 / 09 / 09$ & $16: 40$ & Capotamento & Decrescente \\
\hline $36+700$ & $24 / 09 / 09$ & $07: 00$ & Tombamento & Crescente \\
\hline $36+710$ & 05/02/09 & $08: 15$ & Choque & Decrescente \\
\hline $37+600$ & $06 / 03 / 09$ & $16: 30$ & Engavetamento & Decrescente \\
\hline $37+650$ & $17 / 04 / 09$ & $14: 00$ & Colisão Transversal & Crescente \\
\hline $37+900$ & $23 / 02 / 09$ & $11: 10$ & Colisão Traseira & Crescente \\
\hline $37+900$ & $27 / 04 / 09$ & $17: 00$ & Colisão Lateral & Decrescente \\
\hline $37+900$ & $25 / 11 / 09$ & $20: 00$ & Colisão Transversal & Decrescente \\
\hline $38+100$ & $22 / 01 / 09$ & $18: 00$ & Colisão Transversal & Crescente \\
\hline $38+200$ & $25 / 09 / 09$ & $05: 50$ & Capotamento & Decrescente \\
\hline $38+250$ & $30 / 05 / 09$ & $00: 02$ & Colisão Transversal & Crescente \\
\hline $38+300$ & $11 / 10 / 09$ & $12: 45$ & Colisão Lateral & Decrescente \\
\hline $38+300$ & $16 / 10 / 09$ & $01: 50$ & Colisão Frontal & Decrescente \\
\hline $38+420$ & $25 / 06 / 09$ & $08: 40$ & Tombamento & Decrescente \\
\hline $38+470$ & $10 / 12 / 09$ & $18: 45$ & Choque & Crescente \\
\hline $38+850$ & $01 / 06 / 09$ & $17: 40$ & Outros & Decrescente \\
\hline $38+900$ & $15 / 12 / 09$ & $21: 10$ & Choque & Decrescente \\
\hline $39+000$ & $14 / 02 / 09$ & $23: 50$ & Colisão Traseira & Crescente \\
\hline $39+000$ & $12 / 09 / 09$ & $15: 20$ & Colisão Traseira & Crescente \\
\hline
\end{tabular}


Ano de 2010

\begin{tabular}{|c|c|c|c|c|}
\hline km & Data & Hora & Tipologia & $\begin{array}{l}\text { Sentido em que o } \\
\text { evento ocorreu }\end{array}$ \\
\hline $32+700$ & $14 / 03 / 10$ & $18: 10$ & Colisão Frontal & Decrescente \\
\hline $33+000$ & 05/08/10 & $18: 10$ & Atropelamento de Pedestre & Cres cente \\
\hline $33+000$ & $03 / 12 / 10$ & 08:55 & Capotamento & Sem informação \\
\hline $33+200$ & $10 / 07 / 10$ & 23:20 & Colisão Frontal & Crescente \\
\hline $33+280$ & $16 / 07 / 10$ & 08:00 & Colisão Transversal & Decrescente \\
\hline $33+300$ & $16 / 04 / 10$ & $18: 30$ & Atropelamento de Pedestre & Decrescente \\
\hline $33+400$ & $06 / 08 / 10$ & $07: 50$ & Colisão Transversal & Decrescente \\
\hline $33+700$ & $14 / 08 / 10$ & $19: 15$ & Colisão Traseira & Decrescente \\
\hline $33+700$ & $29 / 10 / 10$ & $18: 30$ & Choque & Sem informação \\
\hline $33+800$ & $14 / 06 / 10$ & $21: 30$ & Choque & Decrescente \\
\hline $34+500$ & $16 / 12 / 10$ & $06: 50$ & Colisão Frontal & Decrescente \\
\hline $34+600$ & $19 / 04 / 10$ & $20: 00$ & Tombamento & Cres cente \\
\hline $34+650$ & $27 / 04 / 10$ & $20: 00$ & Outros & Cres cente \\
\hline $34+700$ & $14 / 08 / 10$ & $18: 25$ & Colisão Traseira & Cres cente \\
\hline $34+700$ & $26 / 09 / 10$ & $18: 10$ & Colisão Traseira & Cres cente \\
\hline $35+000$ & 09/10/10 & $13: 10$ & Colisão Transversal & Cres cente \\
\hline $35+000$ & $19 / 05 / 10$ & $18: 30$ & Colisão Traseira & Cres cente \\
\hline $35+100$ & $27 / 07 / 10$ & $11: 40$ & Colisão Traseira & Cres cente \\
\hline $35+100$ & $01 / 09 / 10$ & $06: 50$ & Colisão Traseira & Cres cente \\
\hline $35+150$ & $28 / 12 / 10$ & $14: 10$ & Colisão Traseira & Cres cente \\
\hline $35+200$ & 03/09/10 & $06: 00$ & Colisão Traseira & Cres cente \\
\hline $35+300$ & $26 / 04 / 10$ & $15: 10$ & Colisão Traseira & Cres cente \\
\hline $35+400$ & $03 / 07 / 10$ & $13: 00$ & Engavetamento & Decrescente \\
\hline $35+800$ & $22 / 08 / 10$ & $05: 45$ & Choque & Decrescente \\
\hline $36+000$ & $04 / 12 / 10$ & $15: 40$ & Tombamento & Sem informação \\
\hline $36+100$ & $17 / 02 / 10$ & $16: 45$ & Choque & Cres cente \\
\hline $36+100$ & $10 / 04 / 10$ & $00: 50$ & Outros & Cres cente \\
\hline $36+100$ & $10 / 04 / 10$ & $01: 15$ & Choque & Decrescente \\
\hline $36+100$ & $11 / 01 / 10$ & $14: 00$ & Outros & Decrescente \\
\hline $36+250$ & $13 / 04 / 10$ & $21: 00$ & Colisão Traseira & Decrescente \\
\hline $36+550$ & $16 / 12 / 10$ & $13: 00$ & Tombamento & Cres cente \\
\hline $36+550$ & $06 / 11 / 10$ & $04: 50$ & Colisão Transversal & Decrescente \\
\hline $36+650$ & $29 / 11 / 10$ & $14: 10$ & Choque & Cres cente \\
\hline $36+700$ & $14 / 04 / 10$ & $18: 10$ & Choque & Cres cente \\
\hline $36+700$ & $12 / 06 / 10$ & $10: 15$ & Colisão Lateral & Decrescente \\
\hline $36+800$ & $20 / 03 / 10$ & $04: 10$ & Capotamento & Cres cente \\
\hline $36+950$ & $18 / 05 / 10$ & $11: 40$ & Capotamento & Cres cente \\
\hline $\begin{array}{l}37+500 \\
37+650\end{array}$ & $\begin{array}{l}24 / 01 / 10 \\
27 / 05 / 10\end{array}$ & $\begin{array}{l}05: 10 \\
05: 20\end{array}$ & $\begin{array}{l}\text { Choque } \\
\text { Colisão Frontal }\end{array}$ & $\begin{array}{l}\text { Decrescente } \\
\text { Decrescente }\end{array}$ \\
\hline $37+900$ & $23 / 12 / 10$ & $18: 40$ & Choque & Cres cente \\
\hline $37+900$ & $10 / 02 / 10$ & $17: 10$ & Colisão Lateral & Cres cente \\
\hline $38+000$ & $14 / 06 / 10$ & $18: 20$ & Colisão Traseira & Cres cente \\
\hline $38+050$ & $10 / 07 / 10$ & $19: 50$ & Atropelamento de Pedestre & Decrescente \\
\hline $38+350$ & $03 / 11 / 10$ & $10: 25$ & Tombamento & Sem informação \\
\hline $38+750$ & $19 / 06 / 10$ & 09:00 & Colisão Traseira & Crescente \\
\hline $38+900$ & $01 / 08 / 10$ & $05: 50$ & Colisão Transversal & Cres cente \\
\hline $38+900$ & $01 / 02 / 10$ & $15: 00$ & Colisão Traseira & Cres cente \\
\hline $38+900$ & $27 / 03 / 10$ & $18: 00$ & Choque & Decrescente \\
\hline $38+900$ & 08/05/10 & 08:20 & Colisão Lateral & Decrescente \\
\hline $38+950$ & $31 / 08 / 10$ & $22: 10$ & Colisão Transversal & Cres cente \\
\hline $39+000$ & $20 / 11 / 10$ & $06: 10$ & Colisão Traseira & Cres cente \\
\hline $39+000$ & $18 / 11 / 10$ & $14: 00$ & Colisão Lateral & Decrescente \\
\hline $39+000$ & $08 / 04 / 10$ & $05: 30$ & Colisão Traseira & Decrescente \\
\hline
\end{tabular}

